\title{
Women album makers from the Canterbury region of New Zealand, 1890-1910, and their photographic practices
}
A thesis submitted to Victoria University of Wellington in fulfilment of the requirements for the degree of Master of Arts in Art History

Victoria Annabel Hearnshaw

Victoria University of Wellington 2017 



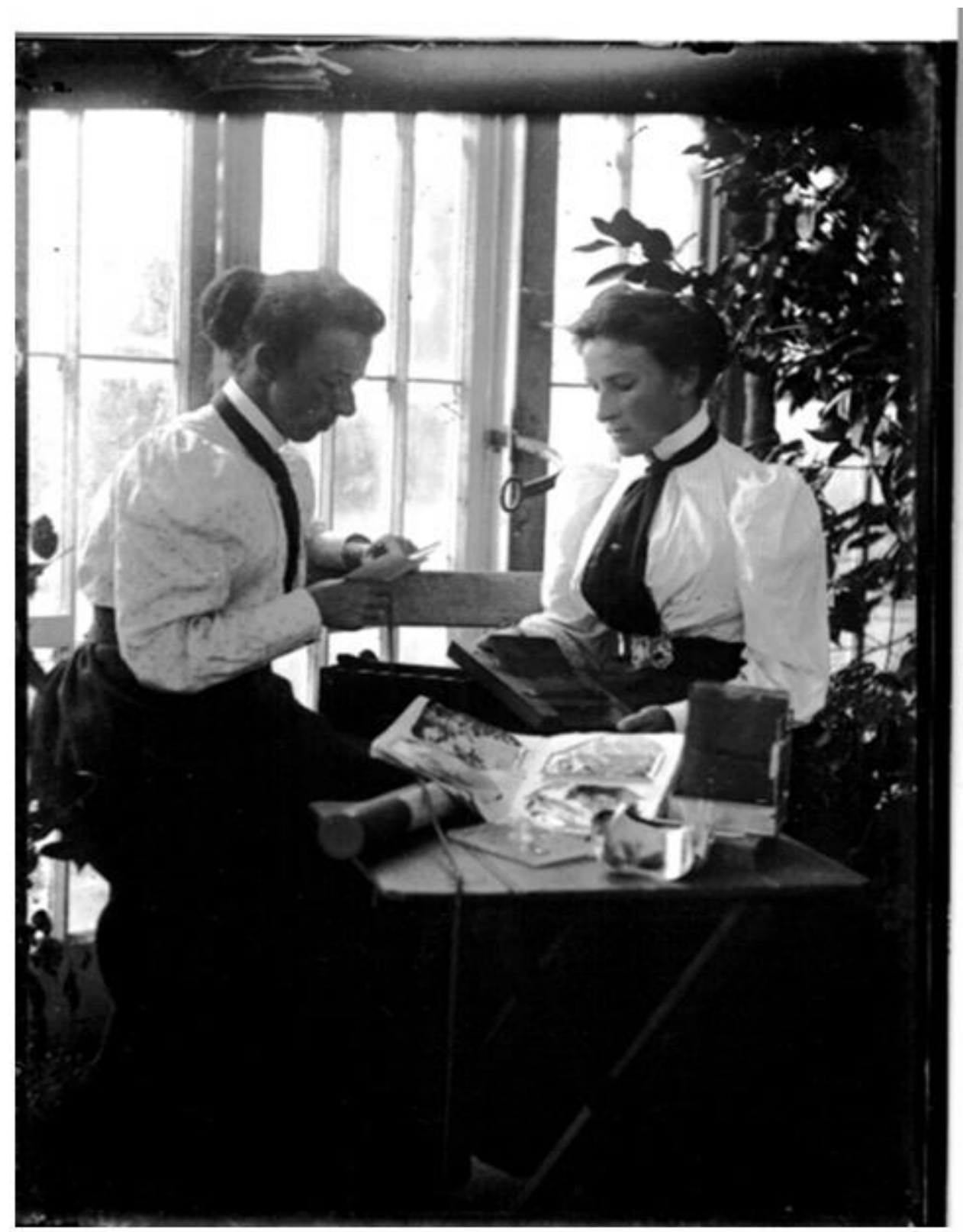

\section{Frontispiece}

[Harriet and Rosa Acland in the conservatory, Mt Peel Station], Lucy Acland photograph album, LA56, private collection, Christchurch. 


\begin{abstract}
This thesis examines the photograph albums created by fifteen women born during the reign of Queen Victoria living in the Canterbury region of New Zealand between the years 1890-1910. It will investigate how it was that these women, often working in close association with other members of their family, became involved in photography as an amateur recreational pastime. It will pursue this investigation within the conceptual and structural framework in which these women's photographs were produced, collected or processed, and organized into albums, arguing that the making of such albums was as much a cultural and social practice as a representational one.
\end{abstract}

Photograph albums are often considered to be generic objects. However this study will treat albums as distinctive and unique documents, comparable to other more-widely consulted primary sources such as letters and diaries. In particular, it will explore the capacity of the album to be a pictorial artefact that provides its own conditions for viewing images over time and space and contribute to a growing body of literature that insists that the photograph album is an important object of study within social history, and indeed within the history of photography in general.

In drawing attention to the album making as a gendered pastime I am acknowledging the significance of this activity for women from within the upper and middle classes as a significant aspect of feminine cultural production at this period in our colonial history. As cameras became easier to operate towards the end of the nineteenth century these improvements saw women begin to take their own photographs, and also to print and distribute them within their extended families and beyond. This reflects the extent to which the practices of photography and album-making had become integrated practices by this date. Thus, the role of the album compiler working in the domestic sphere was effectively transformed from a passive consumer (collecting photographs) into an active producer of photographs.

However, the extent to which the practice of photography was undertaken by women within colonial New Zealand is only now beginning to be realized. To date, the published evidence for this has been slight. This thesis endeavours to shed light on the contribution of these women working within the domestic sphere, but also those of their number who 
subsequently ventured to use this knowledge outside this limited sphere, and on their visual legacy at this formative period in New Zealand's history.

\section{List of Abbreviations}

Photograph Albums

\section{LA Lucy Acland}

MLB Margaret and Laura Bowen

CB Carrie Buckland

JB Jessie Buckland

SB Susan Buckland

SBc Susan Buckland, copy album

EC Elizabeth Colenso

KI Kate Ivens

MOS Margaret Stoddart

$\mathrm{MS}_{1} \quad$ Mary Stoddart, first album

$\mathrm{MS}_{2} \quad$ Mary Stoddart, second album

$\mathrm{KW}_{1}$ Kate Wood, first album

$\mathrm{KW}_{2}$ Kate Wood, second album

$\mathrm{KW}_{3}$ Kate Wood, third album

FW Florence Wright

Note: Numerals after abbreviations indicate page numbers in the photograph album. 


\section{Table of Contents}

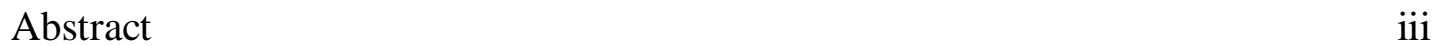

List of abbreviations

List of illustrations vii

Acknowledgements $\quad$ xiv

Chapter One: Scope and directions 1

$\begin{array}{ll}\text { Chapter Two: Family photography - Setting the scene } & 17\end{array}$

Chapter Three: Case study: John and Harriet Acland 37

Chapter Four: The Buckland family and their contribution to photography 51

Chapter Five: Seeking out the narrative structures in the photograph album 71

Chapter Six: The culture of image-sharing with others 90

$\begin{array}{ll}\text { Chapter Seven: The domestic sphere and beyond } & 111\end{array}$

$\begin{array}{lr}\text { Chapter Eight: Conclusion } & 130\end{array}$

$\begin{array}{ll}\text { Notes } & 137\end{array}$

$\begin{array}{ll}\text { Appendix I: Description of Photograph Albums } & 198\end{array}$

Appendix II: Gallery of Illustrations 202

Appendix III: Graphs I-VI 255

$\begin{array}{ll}\text { Bibliography } & 259\end{array}$ 


\section{List of Illustrations}

Fig. 1 [Harriet and Rosa Acland in the conservatory, Mt Peel Station], c. mid1890s, Lucy Acland photograph album, LA56, private collection, Christchurch.

Fig. 2 [Stoddart family, Diamond Harbour], c. 1897, Mary Stoddart photograph album 1, $\mathrm{MS}_{1} 4$, Canterbury Museum, Christchurch.

Fig. 3 A.C. Barker, The Stoddart family, Diamond Harbour, 1871, Dr A.C. Barker collection, Canterbury Museum, Christchurch.

Fig. 4 A.C. Barker, [Acland family, Mt Peel Station], 1872, Dr A.C. Barker collection, Canterbury Museum, Christchurch.

Fig. 5 [Acland family, Mt Peel Station], May 1895, Acland photographs collection, (MB44), Macmillan Brown Library, University of Canterbury, Christchurch.

Fig. 6 'Xmas I', Lucy Acland photograph album, LA40, private collection, Christchurch.

Fig. 7 'Xmas II', Lucy Acland photograph album, LA40, private collection, Christchurch.

Fig. 8 Ghémar Frères, Queen Victoria and Princess Beatrice, 1863.

Fig. 9 Leonida Caldesi, [The royal family at Osborne House], 1859.

Fig. 10 Harriet Acland, 'Father in Study, March, 1893', Acland photographs collection, (MB44), Macmillan Brown Library, University of Canterbury, Christchurch.

Fig. 11 John Acland, [Father in Study], 1893, Acland photographs collection, (MB44), Macmillan Brown Library, University of Canterbury, Christchurch.

Fig. 12 [Views of Peel Forest], 1893, Lucy Acland photograph album, LA37, private collection, Christchurch.

Fig. 13 Harriet Acland, [3 photographs of the drawing room at Mt Peel homestead], 1893, Dr Barker, [First habitations at Mt Peel Station], 1861, Lucy Acland photograph album, LA44, private collection, Christchurch.

Fig. 14 Harriet Acland, [Drawing room Mt Peel homestead], 1893, Lucy Acland photograph album, LA44, private Collection, Christchurch.

Fig. 15 Harriet Acland, [Sitting room of Lucy Acland], Lucy Acland photograph album, LA61, private collection, Christchurch. 
Fig. 16 [Kings and Queens of England], c. early 1890s, Susan Buckland photograph album, SB15, private collection, Louisville, Kentucky.

Fig. 17 'King Charles hiding in a tree...', c. early 1890s, Caroline Buckland photograph album, CB9, Hocken Library, University of Otago, Dunedin.

Fig. 18 Caroline Buckland, 'Baking Day', 1896, Susan Buckland photograph album, SB18, private collection, Louisville, Kentucky.

Fig. 19 Jessie Buckland, 'The Jackeroo', 1898, Jessie Buckland album, JB33, Hocken Library, University of Otago, Dunedin.

Fig. 20 Susan Buckland, 'After the Toil of the Day', 1898, Jessie Buckland album, JB33, Hocken Library, University of Otago, Dunedin.

Fig. 21 [The Water Carrier], Caroline Buckland photograph album, CB35, Hocken Library, University of Otago, Dunedin.

Fig. 22 [The Water Carrier], Jessie Buckland photograph album, JB16, Hocken Library, University of Otago, Dunedin.

Fig. 23 'The Sweet Burden', Caroline Buckland photograph album, CB35, Hocken Library, University of Otago, Dunedin.

Fig. 24 Susan Buckland, 'The Sweet Burden', Susan Buckland photograph album, SB60, private collection, Louisville, Kentucky.

Fig. 25 Jessie Buckland, 'Coming Thro' the Rye', 1897, Jessie Buckland photograph photograph album, JB8, Hocken Library, University of Otago, Dunedin.

Fig. 26 J.R. Hanna, 'Coming through the Rye', c. 1902, Cyclopedia of New Zealand, (Christchurch, 1902): 319.

Fig. 27 Jessie Buckland, 'Coming Thro' the Rye', 1897, Susan Buckland photograph album, SB72, private collection, Louisville, Kentucky.

Fig. 28 Elizabeth Hocken, 'Mother's Treasure Box', 1895, Susan Buckland photograph album, SB19, private collection, Louisville, Kentucky.

Fig. 29 Caroline Buckland, 'Baking Day', 1896, Jessie Buckland photograph album, JB5, Hocken Library, University of Otago, Dunedin.

Fig. 30 Jessie Buckland, 'Coming Thro' the Rye', Summer Scene, the Australasian, 29 May, 1897, p. 1079.

Fig. 31 'The Arcadia', Lucy Acland photograph album, LA1, private collection, viii 
Christchurch.

Fig. 32 'LCB MLB', [Laura and Margaret Bowen], The Bowen photograph album, MLB9, Canterbury Museum, Christchurch.

Fig. 33 Margaret and Laura Bowen, S.S. Discovery, 1901, The Bowen photograph album, MLB3, Canterbury Museum, Christchurch.

Fig. 34 [The Bowen family at Middleton], Detail of Fig. 33, MLB3.

Fig. 35 [Captain Scott at Middleton, Christchurch with his cousin, Robert Julian Scott and his wife, Gertrude Elizabeth Scott, née Bowen]. Detail of Fig. 33, MLB3.

Fig. 36 'Botanical Gardens, Melbourne', Australia, Margaret Stoddart photograph album, MOS26, Canterbury Museum, Christchurch.

Fig.37 'Mt Torlesse, August 1892', Margaret Stoddart photograph album, MOS10, Canterbury Museum, Christchurch.

Fig. 38 'Mt Torlesse, August 1893', Margaret Stoddart photograph album, MOS16, Canterbury Museum, Christchurch.

Fig. 39 [Matagouri], Mt Torlesse, August 1893, Margaret Stoddart photograph album, (MOS16), Canterbury Museum, Christchurch.

Fig. 40 [Homecoming], 'Peel Forest, 1892', Lucy Acland photograph album, LA42, private collection, Christchurch.

Fig. 41 Sample page from Jessie Buckland's album, JB44, Hocken Library, University of Otago, Dunedin.

Fig. 42 Sample page from Jessie Buckland's album, JB21, Hocken Library, University of Otago, Dunedin.

Fig. 43 Sample page from Jessie Buckland's album, JB64, Hocken Library, University of Otago, Dunedin.

Fig. 44 'Xmas 1896', [The Buckland/Hocken families], Jessie Buckland photograph album, JB30, Hocken Library, University of Otago, Dunedin.

Fig. 45 [Lionel Orbell], Susan Buckland photograph album, SB41, private collection, Louisville, Kentucky.

Fig. 46 [Mrs Barbara Stoddart and son, James, Diamond Harbour], c. 1897, Mary Stoddart photograph album, $\mathrm{MS}_{2} 29$, Diamond Harbour and Districts Historical Association Inc., Diamond Harbour. 
Fig. 47 'John Stoddart; James Stoddart', Mary Stoddart photograph album, $\mathrm{MS}_{1} 12$, Canterbury Museum, Christchurch.

Fig. 48 'James Stoddart', Mary Stoddart photograph album, $\mathrm{MS}_{2} 34$, Diamond Harbour and Districts Historical Association Inc., Diamond Harbour.

Fig. 49 'Mary Stoddart', Mary Stoddart photograph album, MS 2, Diamond Harbour, Diamond Harbour and Districts Historical Association Inc., Diamond Harbour.

Fig. 50 Verse from 'Whispering' included in Mary Stoddart's second photograph album, $\mathrm{MS}_{2} 2$, Diamond Harbour, Diamond Harbour and Districts Historical Association Inc., Diamond Harbour.

Fig. 51 'Lucy Acland and Tor', Lucy Acland photograph album, LA60, private collection, Christchurch.

Fig. 52 'Lucy Acland and Tor', Lucy Acland photograph album, (LA51), private collection, Christchurch.

Fig. 53 Kate Wood, [Deaconess Kate Spencer Ivens], Kate Wood photograph album 2, $\mathrm{KW}_{2} 2-10$, Private collection, Martinborough.

Fig. 54 [European Community on Norfolk Island], 1896, Elizabeth Colenso photograph album, EC15, Norfolk Island Museum.

Fig. 55 [Kate Wood], Kate Wood photograph album 2, $\mathrm{KW}_{2} 17$, private collection, Martinborough.

Fig. 56 Kate Wood and Kate Ivens, 'Creek Scenes', Little River, Canterbury, Kate Wood photograph album $1,\left(\mathrm{KW}_{1} 13 \& 14\right)$, private collection, Martinborough.

Fig. 57 Kate Ivens, 'Red Rocks', Melanesian Mission, Norfolk Island, 1896, Elizabeth Colenso photograph album, EC8, Norfolk Island Museum, Norfolk Island.

Fig. 58 Kate Ivens, 'Girls Cooking Saturday Dinner', Melanesian Mission, NI, 1896, Elizabeth Colenso photograph album, EC6, Norfolk Island Museum, Norfolk Island.

Fig. 59 Kate Ivens, 'Girls Washing Blankets', Melanesian Mission, Norfolk Island, 1896, Elizabeth Colenso photograph album, EC14, Norfolk Island Museum, Norfolk Island.

Fig. 60 'Kate Ivens' Writing Class', Melanesian Mission, Norfolk Island, 1896, Elizabeth Colenso photograph album, EC7, Norfolk Island Museum, Norfolk Island. 
Fig. 61 Kate Ivens, 'Oranges', Melanesian Mission, Norfolk Island, 1896, Elizabeth Colenso photograph album, EC9, Norfolk Island Museum, Norfolk Island.

Fig. 62 Inscription inside cover of Elizabeth Colenso's photograph album, EC1, Norfolk Island Museum, Norfolk Island.

Fig. 63 Florence Wright, [The Dell family, Windermere, mid-Canterbury], The Dell photograph album, FW1, private collection, Christchurch.

Fig. 64 Florence Wright, [The Dell family, Windermere, mid-Canterbury], The Dell photograph album, FW2, private collection, Christchurch.

Fig. 65 Florence Wright, [The Dell family, Windermere, mid-Canterbury], The Dell photograph album, FW29, Private collection, Christchurch.

Fig. 66 Florence Wright, [The Dell family, Windermere, mid-Canterbury], The Dell photograph album, FW27, private collection, Christchurch.

Fig. 67 [Wedding of Florence Wright to William Morgan], 1904, Windermere, Mid-Canterbury, The Dell photograph album, FW30, private collection, Christchurch.

Fig. 68 Florence Wright, 'Threshing at Windermere', from the Dell album, FW23, private collection, Christchurch, in Garth Cant, Rural Canterbury..., p. 99.

Fig. 69 [Jessie Buckland at the window of her photographic studio], c.1907, private collection, Christchurch.

Fig. 70 Announcement published in the Akaroa Mail, March-May 1907.

Fig. 71 Jessie Buckland, 'Sunrise', [View from the Glen towards Akaroa], Jessie Buckland photograph album, JB27, Hocken Library, University of Otago, Dunedin.

Fig. 72 Jessie Buckland, [Series of photographs of harvesting cocksfoot at Wainui], Jessie Buckland photograph album, JB69 and JB70, Hocken Library, University of Otago, Dunedin.

Fig. 73 Jessie Buckland, 'Cropping', [Harold Buckland cutting cocksfoot], Jessie Buckland photograph album, JB69, Hocken Library, University of Otago, Dunedin.

Fig. 74 Jessie Buckland, 'Bullock wagons wending...,' Jessie Buckland photograph album, JB70, Hocken Library, University of Otago, Dunedin.

Fig. 75 Jessie Buckland, 'Sunrise', [View from the Glen towards Akaroa], Jessie 
Buckland photograph album, JB55, Hocken Library, University of Otago, Dunedin.

Fig. 76 Jessie Buckland, 'Akaroa, 'Jessie Buckland photograph album, JB55,

Hocken Library, University of Otago, Dunedin.

Fig. 77 Jessie Buckland, 'Jolie St, Akaroa', Jessie Buckland photograph album, JB64, Hocken Library, University of Otago, Dunedin.

Fig. 78 Jessie Buckland, 'Bullock Wagons', Adolf Mortizson papers, (Arc-0023) MS-1143/01, Hocken Library, University of Otago, Dunedin.

Fig. 79 Jessie Buckland, 'Coming Thro' the Rye, Akaroa' Adolf Mortizson papers, (Arc-0023) MS-1143/01, Hocken Library, University of Otago, Dunedin.

Fig. 80 Jessie Buckland, 'Why the Mailbag was late?' Adolf Mortizson papers, (Arc-0023) MS-1143/01, Hocken Library, University of Otago, Dunedin.

Fig. 81 Jessie Buckland, 'Regatta Akaroa', 1907, (391A), Akaroa Museum, Akaroa.

Fig. 82 'Regatta Akaroa', (reverse of Fig. 81), (391B), Akaroa Museum, Akaroa. 
For all my family 


\section{Acknowledgements}

In late 1990, I began working on cataloguing the historic photograph collections originating from the Canterbury province and now donated to the Macmillan Brown Library of the University of Canterbury in Christchurch. As work progressed, it became evident that women from this region had made a small, but nevertheless significant contribution to these collections. This made me curious to find out more about these women and their lives. Thus I came to realize the importance of these women for the development of photography in New Zealand.

Here I would like to acknowledge those family members I approached who generously gave me access to family archival material in their possession, but more importantly, encouraged me to continue this research. They include John and Rosemary Acland of Mt Peel Station, Elizabeth Goodwin of Christchurch, Eve Wallace of Woodbury, the descendants of Harriet, Lucy and Rosa Acland; the late N.M. Buckland and her sister, the late Patricia Mackenzie, the nieces of the Buckland sisters; and also the present members of the Orbell family in Central Otago and Kentucky, USA. I would like to acknowledge those who came forward on learning of my research interests: in particular, Clive Morriss of Christchurch, a descendant of the Dell family; Sister Anne of the Community of the Sacred Name, Christchurch, and Dave Stewart of Martinborough, for introducing me to the photographic collections of Kate Ivens and Kate Wood respectively.

When I approached Geoffrey Batchen, soon after his arrival in this country to take up the professorship in Art History at Victoria, University at Wellington in 2010, he affirmed his interest in this topic. As principal supervisor, he has been supportive throughout. His fine scholarship and good humour, has helped to guide this thesis to fruition. In the event, much of the work was undertaken in unique circumstances, given the earthquakes which struck in the Canterbury region first in February 2011, and their impact on me as a resident of Christchurch. Also, I would like to acknowledge Charlotte Macdonald, Professor of History at Victoria University of Wellington, who has been my secondary supervisor. Her input was particularly helpful in the latter stages of the writing up of the thesis.

Special thanks also must go to William Main, formerly of the Centre of New Zealand Photography and founding editor of their journal, and also to Jim Toner and John Goddard xiv 
of the Canterbury Centre for Historic Photography and Film at the Ferrymead Trust in Christchurch, who shared their knowledge of New Zealand photography and its early practices.

In addition I would like to thank the staff from the following institutions for their assistance with the retrieval of archival material from their collections: the Alexander Turnbull Library, Wellington, the Hocken Library, Uare Taoka o Hākena, University of Otago, Dunedin, the Macmillan Brown Library, University of Canterbury, Christchurch, the Canterbury Museum, Christchurch, the Archives of the Anglican Diocese, Christchurch, the Community of the Sacred Name, Christchurch and the Auckland War Memorial Museum, Auckland. Special mention must go to Dr Kerry McCarthy, curator of pictorial collections at the Canterbury Museum, and Jane Teal, archivist for the Anglican Diocese in Christchurch, who facilitated the acquisition of archival material when these institutions were closed to the public during the earthquakes; also to Lisa Richards and Janelle Bulcher, curators of photographs, Norfolk Island Museum and Jan and Bill Studholme, Diamond Harbour and Districts Historical Association Inc., Diamond Harbour, who reproduced facsimile copies of the photograph albums of Elizabeth Colenso and Mary Stoddart.

Thanks are also due to Dr Deborah Laurs, of the Learning Services Programme and Dr Lizzie Towl, Post-Graduate Research Skills Coordinator, at Victoria, University of Wellington and my friend, Diana Moir, arts facilitator, for her help with editing and proofreading. Also, long-time colleague and friend, Dr Mark Stocker, Curator of Historic \& International Art at the Museum of New Zealand, Te Papa Tongarewa in Wellington, is thanked for his support. Finally, a really special thank you to my family, especially to John, who have been with me all of the way! 


\section{Chapter One}

\section{Scope and Directions}

\section{Introduction}

In this thesis I will show how amateur photography flourished within provincial New Zealand during the last years of the reign of Queen Victoria and was employed by the women from settler families as a means of expression, learning and communication about their own lives, and their families and their position within the world. ${ }^{1}$ Within settler families in New Zealand during the last years of the nineteenth century and the first years of the twentieth century, photography was a recreational pastime in which the whole family could become involved as a social practice. However, a comprehensive review of the photograph collections compiled by women from the Canterbury region during the specific period of 1890-1910, reveals that it was often the daughters in these households, who were engaged in the pastimes of photography and album making. And as I will demonstrate in the course of this study, by working together, they made a unique contribution to the photographic medium at a formative period in this country's history. My intention here is to raise awareness of the value of visual items produced by these women within the private world of the settler family. Thus the focus in this thesis will be confined to these families for whom the photography performed a crucial role as they adapted to the cultural and social changes in their lives.

The choice of the two decades this study covers is largely determined by the approximate dates of the photograph albums under discussion in this thesis. But at the same time what also must be taken into account in understanding the development of photography in New Zealand during these years is that these dates also reflect significant technological developments in the medium. Improvements in the dry photographic emulsions on glass plates from the early 1880 s had allowed photography to be pursued more widely within the home environment. Further, by the end of this decade, George Eastman of the Eastman Kodak Company in Rochester, New York, had launched his hand-held film camera onto the market. This opened up unprecedented opportunities for amateurs to take up photography. In New Zealand Kodak film cameras were in use from an early date. However, the service which Eastman Kodak also provided for processing films into prints 
for amateur photographers in other countries was not made available in New Zealand until mid-1909, when Kodak finally established an outlet in central Wellington. ${ }^{2}$ No doubt there were commercial considerations behind this decision, but the fact remains that this goes some way to explaining the reasons why the dry-plate mode of photography continued to be widely favoured by amateur photographers in this country up until this date, and it also explains the apparently slow transition to hand-held film cameras.

The circumstances which led to a close interest in this topic, specifically within provincial Canterbury, and thus to the development of a regional perspective for this thesis, were as follows. In 1992 I was commissioned by the Macmillan Brown Library of the University of Canterbury to transcribe the personal diaries of J.B.A. Acland (1823-1904) on behalf of the Mt Peel Homestead Trust. ${ }^{3}$ These diaries form an integral part of a much larger and more extensive collection of historic family documents which date from the time of Acland's from arrival in New Zealand on the Royal Stuart, in October 1854, and thus they constitute to a remarkable account of life of this settler family at a propitious time in the development of this country.

Also, among the items which form the photograph collection from this family archive is a photograph album which had been compiled by Lucy Acland (1869-1903), the fourth daughter of J.B.A. Acland and his wife, Emily, between the years 1892-1903. ${ }^{4}$ Although this album was in poor condition, it was still complete and in its original state. On viewing the images in Lucy's album, one photograph from this collection of family photographs immediately attracted me and continued to hold my attention. It was an image of two women, seated on either side of a small folding table, working on their photographic collections. ${ }^{5}$ (Fig. 1).

Women from period are more often associated with the pursuit of traditional female pastimes such as painting and drawing, letter writing and various handicrafts, including album making. To see a photograph of women pictured actively engaged as photographers within the domestic setting was significant, since it demonstrates how amateur photography was practised in this country at this time as a serious recreational practice. In this image, Lucy's sister, Rosa (1873-1950), (right) is shown engaged in printing a photograph glass plate in a printing-out frame, while her sister, Harriet (18661948), (left) is engaged in sorting through recently-processed photographs and placing 
them into files for safe keeping. As I examined this particular image of the two women seated at the folding table on which their photographic equipment had been laid out, so as to show the process of their actual engagement in these photographic practices more closely, I became convinced that this shot had been intentionally 'set up' as visual testimony to these women's involvement in the photographic medium. In addition, and perhaps more significantly, its reveals how these women understood themselves at this particular date and how they chose to be identified and to be represented. Thus, the photograph of these sisters working together on the family photograph collections from the photograph album of Lucy Acland was to prove of great importance in developing this study on women photographers and album making in the Canterbury region at the turn of the twentieth century as a cultural and social practice.

Within New Zealand the study of women and photography is only at a formative stage. The extent to which photography was undertaken as a significant aspect of cultural and social production by amateur photographers from within New Zealand colonial history continues to be not well understood. However, it was the comments of photo-historian Naomi Rosenblum, among others, who has devoted considerable time and effort in reclaiming the lives of early women photographers from North America and retrieving their photographic work, and it was she who provided the compelling reason for embarking on a study of the early women photographers who helped shape photography in this country. ${ }^{6}$ As she argues in the introductory notes to her book, A History of Women Photographers, 'history is an artefact... [it] does not exist until it is remembered and written down'. 7

But as Rosenblum also explains, undertaking a closely-observed analysis of women photographers demands considerable resourcefulness. It also requires, as I would find out, both perseverance and a modicum of serendipity. Nevertheless, eventually I was able to locate the names fifteen women from the Canterbury region of New Zealand who had practised photography as an amateur pursuit during the late colonial period and to locate their photograph collections. In addition to the three Acland sisters, Harriet, Lucy and Rosa Acland of Mt Peel Station in South Canterbury, I found twelve additional women from this region, for whom I had firm evidence that the photographic medium had been a serious recreational pastime at the turn of the twentieth century. These women include Margaret (1884-1978) and Laura Bowen (1886-1967) of Christchurch; Kate Ivens (1869- 
1942) and Kate Wood (1871-1961) also both of Christchurch; Caroline (1868-1930), Susan (1873-1946) and Jessie Buckland (1878-1939) of Taieri Lake Station, near Middlemarch in Central Otago and, after 1902, of The Glen, Akaroa on Banks Peninsula; Frances (1864-1941), Margaret (1865-1934), Mary (1868-1909) and Agnes Stoddart (1869-1956) of Diamond Harbour on Banks Peninsula and Florence Wright (1868-1929) of Windermere in mid-Canterbury.

Surveying all of these women and the locations where they resided established that photography was a pastime whose practice by women was widespread in Canterbury. Moreover, what also becomes apparent, although not surprising, was that they were almost equally divided between country and town dwellers. Therefore, these women form quite a diverse group. Nevertheless, when I looked into the family backgrounds of each of these women, although I could not establish any direct social contact between the women from these families, there were other significant factors linking them as a distinctive cultural and social group. For instance, all the women in this study were born in New Zealand of parents from upper and middle class backgrounds who had left the British Isles or northern Europe to come to New Zealand in the mid-nineteenth century to start a new life. From the evidence available, I ascertained that most of these women were aged in their early twenties, although some were only in their teens, at the time they embarked on photography, and all were single and were living within the family home. It was also clear that within these families, photography practiced as a recreational pastime was indeed likely to be undertaken in the company of a sibling, and usually it was with their sister(s).

The aim of this thesis is to investigate how the fifteen women selected for this study became involved in photography as an amateur pursuit from the early 1890 s and to show how photography developed into a significant recreational pastime for them. These investigations will include a close examination of these women and their pursuits through a critical analysis of the visible (the images and practices) and also the invisible (the effects and experiences induced by these images) and of the narratives that were constructed around them. In the course of this study I will also show how visual representations of the family enabled them to see themselves and their families within their home environment. Thus emphasizing the mediating role that the photographic images played for settler families and how these images fostered in these families a sense 
of connection to their new surroundings. New Zealand historians, Peter Gibbons and Philippa Wilson (who takes a uniquely women's perspective) are among those who have set out to define the distinguishing features of settler society from surviving accounts. ${ }^{8}$ They both believe, from their understanding of the experience of settlers in New Zealand, that through the act of migration these people, 'have left behind most of what had given their world meaning as human beings: kinship, community, accustomed landscape. 9 Therefore Gibbons argues that the settlers who made their way to this country were a product of two worlds - a European past and an antipodean present. As I will expand on in the following chapters of this thesis, these settlers adopted strategies, recognized by migrant populations the world over to restore continuity into their lives and make the unsettled world they now found themselves both manifest and manageable. They did this, by re-introducing social and cultural practices whereby they could reaffirm their identity.

This thesis will assess the extent to which the pastimes of amateur photography and album making had become a highly integrated form of cultural and social production for settlers families by the 1890s. Although, photograph albums are often considered to be generic objects, in this thesis I will treat the albums selected for this study as distinctive and unique documents and comparable to other more widely consulted primary sources for preserving of information, such as letters, diaries and journals. This approach to the analysis of albums also respects the intentions of the compiler, the original presentational context in which the images were placed in the album and their cultural significance as personally-constructed artefacts created through recognized forms of social practice. As Lucy Acland's album demonstrates, although individual images can tell a lot (notably the image of the two Acland sisters working on their photographs in her album), it is important also to understand how the images that make up a collection can provide information about wider cultural values and social attitudes. This also made me keenly aware of the need to view photograph albums in their entirety, particularly the interrelationships between these images. In this way my study will contribute to a growing body of literature that insists that the photograph album, as the English photohistorian Patrizia di Bello has argued, is an important object of visual culture in its own right. $^{10}$ 
The focus on the Canterbury region also enables a case to be made for the locality of cultural production. In taking this approach I am also acknowledging the recent in-depth studies of the photographic collections collected and organized by immigrant groups from specific regional locations as an important object for the study of social and cultural history. ${ }^{11}$ Therefore this study will also contribute to the increasing number of studies on the photographic collections produced by immigrant groups from specific geographical locations elsewhere in the world. In addition, it is hoped that this study will provide a rare female perspective on the unique pictorial these women from the Canterbury region have made to our social and cultural history, but also to the history of photography in general.

\section{The literature}

Albums have been largely neglected by scholars in New Zealand. There remains surprisingly little written about this genre, particularly with regard to women and their association with album making. In 1993, for example, the first comprehensivelyillustrated survey of New Zealand photography from the 1840s to the present was published by PhotoForum/Agfa-Gevaert. ${ }^{12}$ To all intents and purposes this pictorial history, co-edited by William Main and John B. Turner, followed the rather predictable single-page entry layout favoured for bio-narrative surveys. It is a format which allows little opportunity for the development of a critical analysis. Although Main and Turner received criticism at the time of its publication from Luit Bieringa, who complained of the need to give women greater visibility, it is to their credit that the editors attempted to introduce, for the first time, some women into their mainstream historical survey on photography. ${ }^{13}$ Included among the fifteen women selected for their book, there was a contribution on Jessie Buckland and her early life as a photographer. ${ }^{14}$ Nevertheless, this was at least an improvement on the token presence of the earlier surveys, such as those that Hardwicke Knight had undertaken in the 1970s and 1980s, and where much of the information was sourced from postal directories in which the names of male photographers predominated. ${ }^{15}$

David Eggleton, in his more recent historical survey, continued the trend initiated by

Main and Turner. ${ }^{16}$ As Paul Thompson conceded in his assessment of this book, it was, at least one more step on a journey underway. ${ }^{17}$ Nevertheless, Eggleton's commentary 
suffered from some of the same shortcomings that apply to Main and Turner's earlier survey, whose focus was on listing photographers. In this case, the list was longer including a passing mention of the Acland sisters. ${ }^{18}$ But Eggleton continued to overlook certain aspects of photographic practice in New Zealand. Most notably he omitted any reference to photograph albums.

The more recent contribution to the discourse in New Zealand comprises the twelve essays devoted to aspects of early photography edited by Angela Wanhalla and Erika Wolf. ${ }^{19}$ In the introduction, Wanhalla and Wolf claim that they are taking the discourse on photography away from the biographical studies of Main and Turner and of Eggleton in order to pursue new directions. Their publication includes three essays which feature photograph albums as a topic for study, an area which both editors describe as a valuable, although as yet under-utilized resource for the study of New Zealand visual history. As they point out, photographs have been routinely used to illustrate publications devoted to historical and cultural topics. But seldom have these photographs been subjected to critical scrutiny, unlike other primary sources. However, Wanhalla and Wolf do not include colonial women and their association with album making in their discussion of this period. Indeed, one of the obvious omissions from this book, and also one that the editors are aware of, is the role of women as active cultural producers. This oversight would appear to have been a missed opportunity to make a start to introduce women, especially in their role as album makers. The continuation of these attitudes towards women puts into question what has been learned in the years since the work undertaken by Hardwicke Knight in the 1970s.

The three essays devoted to albums in the collection include a study undertaken by Chris Brickell on the amateur photographer and album maker Robert Gant of Wellington, dating from the 1880-90s. ${ }^{20}$ Then, Brickell gave the same close attention to the photograph album of Nola Pratt, compiled in the years prior to World War I. ${ }^{21}$ Through his examination of these albums, Brickell was able to form a comprehensive picture of both Gant and Pratt and thus develop an understanding of these people and the society in which they lived. It was in this way that Brickell reached conclusions about aspects of their private lives, which would not have been possible without reference to the album as a cultural document. Brickell's work on the albums of Gant and Pratt highlights how reading a photograph can be enhanced by examining it within the context of its original 
setting within the album. It also confirms the role the album can perform in the recovery of primary information. If one was ever required, this is a compelling reason to recognize albums as a significant resource, especially when dealing with visual material from the colonial period.

While the close investigative study of photograph albums, such as Brickell has undertaken, has been overlooked in existing histories of photography in New Zealand, it is worth noting that some attention has been paid to them in other publications. For instance, the curator Julie King also successfully employed this approach in her critical survey of the New Zealand water-colourist Margaret Stoddart. ${ }^{22}$ King made an in-depth study of the albums compiled by Margaret and her sister Mary, dating from the late 1880s and 1890s. By this means she was able to find information about the painter and her whereabouts at this period, and about members of her family, that would have been unlikely to be located elsewhere. In addition, King's 1997 catalogue for Stoddart's retrospective exhibition incorporated copy prints as well as examples of complete pages from the photograph albums compiled by the Stoddart sisters, so as to provide visual support for her written commentary. ${ }^{23}$ Thus, King was able to bring an enhanced level of background detail to her study of Stoddart as a developing artist. She also included Margaret Stoddart's photograph album as an item within the exhibition, thus acknowledging its value as a personal artefact in its own right.

Through their separate studies, King and Brickell provide ample evidence of the advantages of making detailed studies of photographs in albums. They demonstrate how such an approach, allows for a more informed understanding than research limited to individual photographs. Their work demonstrates the importance of orientating studies around personal photograph albums, when seeking information into the lives of people operating in the domestic sphere. This is especially so when it comes to those for whom there may not be a large personal archive available for consultation, as is the case for many of the women in this study. It is therefore an approach which is to be regarded as exemplary. Although the photograph albums selected for this study will be supplemented, whenever possible, by contemporary documents mainly put together by contemporary family members, the photograph albums themselves will still remain the principal primary source. 
Albums may have been largely neglected by scholars in New Zealand, but there have been a number of significant studies undertaken elsewhere of this form of photographic practice. The most relevant have been the research undertaken by social scientists specializing in the field of visual culture. ${ }^{24}$ Notable for his early research in this area is the work of Pierre Bourdieu, who, in his survey of the photographic practices in the Béarn region of France during the 1960s, established family photography as a valid area for study within sociology. His book entitled Photography: A middle-brow art, published in French in 1965 Bourdieu produced an early exposition of his theory on how taste in the arts is determined by class, but further how it distinguishes one class from another. ${ }^{25}$ However, this study on family photography and its production has been less influential than might have been expected. To a certain extent this situation can be accounted for by the delay in the publication of his study in English until 1992. In the meantime, areas of family photography which Bourdieu had treated quite summarily in his study have become of increasing interest to a growing number of researchers who have since entered this field and also including extensive research on photograph albums, migrant communities and the role of women. It is for these reasons that, while I acknowledge Bourdieu's formative role, my intention is to also look beyond his early contributions, to the more recent studies, particularly those whose focus has been on undertaking empirical research on women and their role in family photography. ${ }^{26}$

Of particular significance for this study will be the research undertaken by Richard Chalfen on two Japanese-American immigrant families from California and New Mexico in the 1980s and Gillian Rose's survey of 28 women selected from south-east England, undertaken in the 2000s. ${ }^{27}$ These researchers, in their different ways, offer an exemplary approach to studies of photographic practices, and they provide a congenial framework in which to undertake my own exploration of photographic practices, including photograph albums; in both cases the areas of their research have immediate correspondences with this study.

What comes through in reviewing the findings of both these scholars is their concern for close observation as an important tool for analysis. This approach reflects Rose's contention that when considering visual images, 'there is no point in researching any aspect of the visual unless the visual and their effects are also acknowledged ${ }^{28}$ But as Chalfen has also argued, in order to focus attention directly onto the photograph albums 
themselves, and value the images they hold, album-making needs to be recognized for what it is, as a crucial site in its own right. ${ }^{29}$ It is here, after the photograph has been taken and printed, that additional decisions are made with regard to the selection of images to be included in the album and how they are to be arranged.

However, it is Chalfen's methodological approach that is particularly useful for this study. The commentary he provides as he progressively moves from considering aspects of the production of photographs to their organization in the albums and their subsequent circulation will provide a working model for the conceptual and structural framework of this thesis. He identifies characteristics relating to photographic production, such as patterns in image content, recurring themes in the photograph collections and also details of the photographers and their backgrounds. His observations are also illustrated with photographs drawn from albums to argue his point. Thus, he emphasizes the close relationship between the visual and verbal text within albums as forms of communication. Rose takes a rather different approach to understanding how people work with photographic images. In her analysis she considers the images, but also observes how people treat the images. Her analysis entails examining the range of things that is done with photographs after they are taken, and she argues that these activities follow certain patterns of behaviour. She also extends her study to consider the social context of their viewing and the possible, often unforeseen, effects that images may have on the viewer, but also the experiences that each individual brings to viewing.

As well as examining the ways in which women handle their collections of images, Rose considers the distribution of photographs to family and friends. Here again, she emphasizes the importance of time spent in the close observation of the practices surrounding the movement of photographs within the domestic sphere. Rose even looks at contemporary concerns, such as what happens to family photographs when they go public. Her overall understanding of visual culture practices is particularly helpful. She notes in her book Doing Family Photography that what became clear to her when she reviewed the findings of her research on family photography was that photograph collections are not simply images or a textual archive, nor even an ideology. ${ }^{30}$ It is above all, she explains, a social practice. 
A theoretical perspective will be incorporated into the discussion of these women and their work. For example, when investigating the field of photographic practice within settler families, the work of Theodore Schatzki and Andreas Reckwitz on social practice has been influential on Rose in developing her understanding of photography as a social practice. ${ }^{31}$ Reckwitz defines social practices as sets of activities which necessarily imply a certain collective, shared knowledge and therefore while culturally specific they only make sense in relation to the execution of those practices.

Likewise, the contribution of Erving Goffman to social theory has also been significant. ${ }^{32}$ Goffman has been influential on a generation of researchers from the early 1970s, including on Chalfen's early understanding of visual culture. In Goffman's view, certain practices demonstrate the individual's social obligation to the group. One area of photographic production where these social practices are clearly expressed, I will contend, is on the occasion when family members gather for a group photograph. In each case their input will provide a theoretical understanding of small group practice and the self-organizing systems whereby the individual finds a purpose within a group. In addition to widely consulting the studies of Chalfen and Rose, I will canvas a range of perspectives from specialists working in specific subject areas. For example I will incorporate the recent research on the impact of the movement of immigrants and the mechanisms new arrivals employ as they assimilate into another society. Of particular significance are the contributions of Hester Dibbits from the Netherlands, Divya ToliaKelly from Britain and Katie Walsh from Dubai. Deborah Chambers will bring an Australian perspective to the topic of recent immigration to that country. ${ }^{33}$

Also, in this study, I will refer to the growing number of studies produced since the 2000s on various aspects of nineteenth-century photograph albums for an overview of the culture and the practices which emerged following its introduction in 1839. Among these contributions within a diverse subject areas undertaken on albums, of particular interest are those of Elizabeth Siegel, Sarah McNair Vosmeier and Monique Berlier. ${ }^{34}$ Siegel's focus is on reviewing the developments in collecting practices which came about as a result of the succession of technological advances within the photographic medium. Vosmeier's and Berlier's focus is on analysing the narrative qualities of albums, and how stories are told within family albums. Both these women draw attention to the parallels between written and visual narratives and emphasize the importance of analysing 
photograph collections by these means. As Berlier points, adopting this approach, can be particularly invaluable when seeking to recover information on the social and cultural life of specific ethnic groups. Their investigations into visual narratives also complement the extensive research of Martha Langford on selected anonymous photograph collections from the Notman Collection in Montreal in Canada. ${ }^{35}$

Langford maintains that, in order to compensate for the apparent randomness of the arrangement of photographs found in many albums and to bring meaning to them, it is necessary to develop innovative strategies. In her early work on albums she drew extensively on the findings of Walter J. Ong (1912-2003) on the structure of early texts. ${ }^{36}$ She argues how introducing an oral framework as a method of analysis for visual cultural can be a profitable way to investigate albums and their organization, and thus to re-activate meaning to their contents of these albums. In her later study, Langford devised another method of approach. This time she employed an interview method as an interpretative analysis. This entailed preparing carefully structured interviews with five women she had recruited. By synthesizing their responses as a means of analysis, she argues she would be able to come to a consensus of what an album might signify. Langford's methods for addressing photograph albums clearly opens the way for developing more innovative approaches in this expanding field of research in relation to the analysis of the narratives structures of historic photographic collections.

In addition, I will refer extensively to studies undertaken on the history of women's involvement in photography in the British Isles during the second half of the nineteenth century. Of particular significance will be case studies which focus exclusively on women working as photographers and as album makers from this period. These will include the studies by Patrizia di Bello, Marta Weiss and Maggie Humm. ${ }^{37}$ Queen Victoria's early enthusiasm for photography, particularly her collecting practices and the albums which she assembled with the assistance of the ladies at her court, played a significant role in promoting this form of photographic practice as a suitable recreational pastime for women within contemporary society.

The Queen and those close to her at the royal court have received considerable attention, namely Frances, Viscountess Jocelyn 1867-1880), and Caroline, Lady Edgcumbe (18081881); also, women from upper-class outside the court, such as, Clementina, Lady 
Hawarden (1822-1865). ${ }^{38}$ In contrast, beyond the numerous studies profiling Julia Margaret Cameron (1815-1879), and her prodigious talent, less attention has been given to locating other women who were also active at this period of the middle class. ${ }^{39}$

However, recent studies, such as Patrizia di Bello's, do suggest that women from the middle classes were also involved in all aspects of photography from the mid-nineteenth century. Di Bello's major concern is the examination of women as creators of photographic albums and identifying the diverse practices associated with these activities. As she explains, albums became the most common format for storing, displaying and circulating photographs during the nineteenth century. Therefore she contends that these women's contribution to the visual culture of the period also deserves to be acknowledged in any discussion of the early history of the photographic medium. ${ }^{40}$

Maggie Humm's continuing research into the English sisters Vanessa and Virginia Stephen, from the 1890s, provides evidence of the close relationships which often formed between sisters working with photographic medium. Although Vanessa and Virginia Stephen are better known for their contributions to the fine arts and literature respectively, photography was also an important mode of creative expression for them, and central to their lives. Humm's account of their photographic practices highlights the similarities between these women and their New Zealand counterparts. For instance, Humm describes how the Stephen sisters developed an interest in the medium at an early age, and from the beginning they worked together on all facets of photographic practice including, at least initially, using the same camera. ${ }^{41}$ The albums Vanessa and Virginia compiled also reflect the collaborative nature of their collection practices. Humm also notes that the same family images appear in the albums of each woman, sometimes in duplicate, and indicates how important certain images were to both of them. Nevertheless, their albums also provided them with the opportunity to impose their own vision on these photographs through captioning, arranging or cutting and pasting them.

\section{Methodology}

In undertaking this thesis I will be extending the focus of a potentially, rather narrowly historically-based account, to encompass a more expansive understanding of women's visual culture within colonial New Zealand by adopting a cultural studies methodology. Cultural studies as a method of analysis emerged in the 1970s from the growing concern 
that, in undertaking any serious analysis of texts, it is essential to have a comprehensive understanding of the background of those who have contributed to these texts in whatever form, and the social context in which texts were produced. ${ }^{42}$ The underlying strength of a cultural studies approach is that it has the capacity to develop such an understanding of what Paula Saukko calls 'lived experience'. This concerns how people define themselves and how they represent themselves, and in turn, how they are perceived by society. ${ }^{43}$ Rose also believes that this type of analysis has the potential to realize a denser and richer understanding of individuals and the meanings that they give to their lives. ${ }^{44}$

In order to make the overall discussion of the photograph collections selected for this study more manageable, an interpretative framework will be introduced for examining the contents of the photograph albums to be discussed which draws extensively on recent qualitative as well as a quantitative methods of evaluation employed in the analysis of visual culture which I go into further in the review of outline of the chapters below. They will provide a means to examine in depth these collections in terms of the processes of their production, organization and circulation and the various contexts in which they may be encountered.

\section{Outline of the thesis}

In Chapters Two through Four I will explore the production of family photographs as a socially-constructed practice. The intention is to develop a deeper contextual understanding of the significance of these images for settler families living in New Zealand during the last years of the nineteenth century and those of the early twentieth century. These chapters will emphasize how instrumental photography was to the successful integration of these families. In Chapter Two, critical attention will be given to the overview of the production of family photographs and the historical precedence for them. What becomes apparent from these photographs is that some families invested more emotional capital in the visual representation of the family than others. For some families in this study the actual taking of family photographs became part of ritualized practices associated with the high points of family life. In addition to addressing these issues in relation to the production of family photographs as a social practice, Chapter Two will also approach them in terms of their capacity to evoke within their audience certain conditioned responses. 
Chapters Three and Four will aim to provide an understanding of the way in which family members worked together on photography as a shared recreational pastime - particularly the daughters of the household, who found continued support for this activity from within the family circle, and for whom it became an intensely absorbing and highly productive pastime. In these two case studies I will examine the collaborations of siblings from two families and the circumstances which inform them. The first case study makes a detailed study of the working relationship between John Acland (1863-1944) and Harriet Acland of Mt Peel Station in South Canterbury. The focus here is on a series of portrait studies undertaken by them of their father, in March 1893, on the occasion of his forthcoming seventieth birthday. The second case study involves the three Buckland sisters, Carrie, Susan and Jessie, originally of Taieri Lake Station in Central Otago, but after 1902 of Akaroa, on Banks Peninsula. In this chapter I will explore in detail the collaborative nature of photography as it was practised at this period in order to shed some light on the close working relationship that developed between these women. Particular attention will be given to the photographic images that they are known to have produced together, and duplicated prints which often found their way into their personal albums. But, despite the apparent similarity, careful examination of their albums also indicates how, in the organization of the page layout and the narratives they constructed around them, each sister expressed herself in distinctly different ways. This raises the possibility of a profitable comparative reading of their albums.

Chapter Five is concerned with coming to a more informed understanding of the narrative structures employed by the women in this study to tell their stories in their photograph albums. Bearing in mind the considerable contribution that has already been made to this area of research by Martha Langford, attempting to develop another interpretative framework for negotiating photograph albums may appear unnecessary. Nevertheless, in this undertaking I will be applying a method of analysis devised by Susan Stewart initially in Nonsense: Aspects of Intertextuality in Folklore and Literature, which will be most formative. ${ }^{45}$ Although, the method Stewart proposes is not specifically designed with photography in mind, but has the distinct advantage of being comprehensive, yet quite precise. It therefore has particular potential when it comes to identifying the various approaches employed by the women in this study in organizing material in their albums and for making distinctions between them. 
Chapters Six and Seven investigate the circulation of photographs, within both the private and public spheres. In Chapter Six I will recount the background to the presentation of an album of photographs taken by Florence Wright of John Dell and his family in the early 1900s. As Gosden and Marshall rightfully argue, objects of exchange form a special category of things. ${ }^{46}$ Such items are treasured within families independently of any market value. In Chapter Six I will explore the special significance of this gift to the Dell family and their descendants, and for whom, without any other forms of documentary evidence, this album provided a pictorial heritage. In addition, I consider how Wright's apparently simple gesture created an enduring bond between the parties which cannot be under estimated.

In Chapter Seven I will pay sustained attention to what happens to photographs from family collections when they circulate beyond their domestic boundaries and become available to a wider public audience. In this chapter I will trace the transition of Jessie Buckland, from an amateur photographer to a professional operating from her own studio, which she opened in Akaroa in early 1907. During this five-year period, she ventured into producing her own postcards, which eventually became a lucrative part of her photographic business. Initially her postcards were almost exclusively scenes of Akaroa and Banks Peninsula. Later, Buckland incorporated photographs taken while living in Central Otago in the 1890 s, which she reformatted into postcards.

In the concluding chapter, Chapter Eight, I will review the findings that have emerged in relation to this examination of women and photography from the Canterbury region between the years 1890 and 1910. I will argue that amateur photography flourished within provincial New Zealand during the last years of the reign of Queen Victoria and was employed by settler families as a means of expression, learning and communication about their own lives and their families and their position within the world. This study will be offered as a model for future studies on women and their contribution to family photography elsewhere in this country. In broader terms it is hoped that this research will add to the growing volume of literature on women photographers engaged in photography and album making from other parts of the world. 


\section{Chapter Two}

\section{Family Photography}

\section{Setting the scene}

In Chapter Two a comprehensive understanding is developed of the role that photography performed in the lives of settler families in New Zealand during the last years of the nineteenth century and the first years of the twentieth. In this discussion it is shown how the visual representations of family, mediated through the agency of the domestic spaces in which they were constituted, enabled these families to see themselves within these surroundings. This circumstance fostered in them a sense of connection to their new environment, which was so crucial for groups undergoing cultural adaptation and social changes in their lives.

In the first instance, the analysis of the family photographs selected from photograph albums will focus on several key images from the collections of the Acland and Stoddart families. Close attention will be given to the context of the production of these images during the colonial period. This will include an analysis of the practices associated with the taking of these photographs, in order to reach an understanding of family photography and its origins. In addition, this chapter will address the wider concerns of family photography, by exploring the motivations for the photographs' production and the functional objectives they served in the perpetuation of cultural identities and the construction of social values. I will begin this discussion with the Stoddart family.

The Stoddarts were a well-respected settler family within colonial society. Mark Pringle Stoddart (1819-1885) had arrived in New Zealand from Scotland, via Australia, in the early 1850 s. $^{1}$ Soon afterwards, he took up a small parcel of freehold land on the southern shores of Lyttelton Harbour at what was initially known as Mr Stoddart's Bay, but subsequently was renamed by Stoddart as Diamond Harbour, inspired as he was by the sparkle on the water in the bay on a fine day. ${ }^{2}$ In the following years Stoddart laboured hard to develop his land into a productive farm and he prospered by selling the fresh produce he had grown on his property to the residents of Lyttelton and Christchurch. 
In 1862 Mark Stoddart married Anna Barbara Schjött (1835-1911), a governess of Norwegian extraction, who had come to New Zealand under an assisted emigration scheme some two years earlier. ${ }^{3}$ Together they had seven children. By the late 1870 s, with his health severely compromised, Stoddart reluctantly relinquished control over his farm at Diamond Harbour and relocated his family to Christchurch. However, some ten years after his death, when the mortgage over the property was not fully discharged and in accordance with the trust deed, the title of this land reverted into the ownership of the Stoddart family once more.

The first photograph I want to consider is an image of the Stoddart family of Diamond Harbour (fig. 2). ${ }^{4}$ This photograph, which forms the frontispiece of the first photograph album compiled by Mary Stoddart from the mid-1890s, was taken after the family's return to live permanently on their property at Diamond Harbour in $1897 .{ }^{5}$ In this photograph Mrs Anna Stoddart, now a widow, is seated beside a low table on which the tea things have been set out on the front verandah of her home. She is looking towards the camera, waiting expectantly for the photographer to take the photograph. Stoddart is in the company of four of her six surviving adult children: from left to right, they are daughters Agnes, Margaret and Mary, and son James, (back in this country from Southern Africa on an extended visit), and the family sheep dog, Roy. It can be described as a show of familial solidarity, as this family reinstates its authority over their property.

Settler families like the Stoddarts, who were cut off from their past through geographical migration, sought strategies to maintain a sense of their own identity in spite of unprecedented change in their lives. ${ }^{6}$ In her study of thirteen middle-class European women living in New Zealand during the first half of the nineteenth century, Philippa Wilson has shown how the early resumption of social and cultural practices was a priority for these women. ${ }^{7}$ She has described how they expended a considerable amount of effort to create a suitable environment in which they could resume routine practices within their everyday lives and which affirmed their social standing and cultural background. An excerpt from a letter written by Kate Williams while staying in Nelson, to her mother Marianne Williams, in the Bay of Islands, dated 29 April 1851, amply illustrated the way in which the recognized forms of social of interaction continued to be observed by women within colonial society. ${ }^{8}$ In her letter to mother, Kate related how she had been spending her time while she was in Nelson. She told her, how, since her arrival, several 
women from the town, whom she also named, had called to extend invitations for her to come and take tea with them. ${ }^{9}$ According to Wilson, from the early days of settlement, tea was a popular drink among the women within colonial society and formed an integral ritual among their select company on all manner of occasions. ${ }^{10}$ Ritual practices, such as taking tea, had a normalizing influence over the 'unsettled' world in which these women found themselves, and thus brought a sense of community to their lives. ${ }^{11}$

Clearly Wilson is conversant with the extensive literature devoted to the investigation of the connections between cultural and social practices as drivers for change within groups undergoing considerable upheaval. She refers in some detail, in particular, to the formative contributions to this area of research of anthropologists, John and Jean Comaroff, among others. ${ }^{12}$ It is evident, from the line of enquiry that Wilson pursues in support of her overall argument, that her primary focus is on investigating those aspects of these social and cultural practices that emphasize continuity in the changing world experienced by the settler women selected for her study. Wilson is notably less concerned, and even reluctant, to extend the scope of her investigations beyond the continuation of certain specific rituals. Nor does she consider how vital, or in what ways, the resumption of these practices might also be mechanisms for facilitating change within a settler society. In taking this position, Wilson says she is mindful of Claudia Knapman's advice. In her study of European women living in Fiji during the colonial period, Knapman cautions that, when it comes to assessing a period other than our own, it is important not to impose our own subjective values. To do so may say more about the pervasive attitudes of the present time, than reflect those of Victorian society. ${ }^{13}$ Richard Chalfen has agreed with this assessment. He concedes that questions of continuity and change, and how they are negotiated by any group, can be extremely complex and certainly not easy to isolate from an historical perspective. ${ }^{14} \mathrm{He}$ has explained, based on his extensive studies of Japanese groups living in America, how, without a comprehensive understanding of the context in which particular activities are performed, one activity may be mistaken for another. Acts which reflect continuity and discontinuity can often take place at the same time, as transformations and the reformulation of cultural values are enacted in the course of our everyday lives. In his opinion, this is most often observable in the continued use of material objects of specific cultural significance from the past, which are carried forward into the present. This has raised the interesting question of the role of photography in this process. An important 
aspect of Chalfen's study is his tracing of how continuity and change are expressed visually within photographic images. This point will be returned to and enlarged upon with regard to the photograph of the Stoddart family taking tea on the front verandah of their home at Diamond Harbour.

There is a growing number of studies being undertaken on migratory patterns, in particular on the late twentieth-century phenomenon of the transnational who voluntarily relocates to host countries for short periods and lucrative work opportunities. These studies provide ample evidence of how different cultural groups negotiate continuity in the face of change. ${ }^{15}$ What emerges is their commitment to recreating within their new, but nevertheless alien surroundings is a suitable space in which to accommodate personal possessions that they had brought with them. Hester Dibbits, in her survey of guest workers in The Netherlands, found that it was not just a simple matter of introducing personal items into the places where they lived. Such items were a way of marking and maintaining cultural differences for purely decorative effect, in order to make them feel more 'at home'. ${ }^{16}$ Dibbits found that the items that these people brought with them were usually those related to their heritage, enabling them to resume their cultural and social traditions and therefore maintain a sense of continuity within their everyday lives. The objects most often cited by participants were those associated with re-establishing their customary practices in relation to the consumption of food and drink. In her survey of transnationals living in Dubai, Katie Walsh also observed how, in many cases, these items served as a means through which these people could express their identity and the social grouping to which they belonged. ${ }^{17}$ She came to the conclusion that, through the reiteration of these performative activities, they were re-affirming their ethnic origins.

Within colonial society in New Zealand, similar cultural and social adaptations also took place with regard to customary practices in relation to the consumption of food and drink: for example, the custom of drinking tea. As already mentioned vis-à-vis the discussion of Wilson and her work on women living in New Zealand during the nineteenth century, tea was a popular drink from the early days of settlement and was widely consumed on all manner of occasions within colonial society. ${ }^{18}$ In this instance, the tea things, as everyday items, became a tangible means by which these women could express their identity through the re-enactment of a ritual performance. 


\section{Performing continuity and change}

Erving Goffman is another who has offered insights into the significance of these social and cultural practices based on his extensive studies of the theory of ritual performance. ${ }^{19}$ In many instances these practices may be described in terms of a social drama since, like any performance, each action is sequenced temporally, as well as being choreographed spatially. This also assumes that these activities have a recognized structure and therefore that each action refers to a preceding action and those following as a social process. Although these performances have much in common with a theatrical act, as Elizabeth Edwards has observed, they should not be regarded in the same way. These social and cultural practices can be understood as integrally linked to a staged spatial form, in which the actors take control of these spaces in which the activities take place. Such performative acts should be considered in terms of 'a presentation, a heightening, a containment or as a projection'. ${ }^{20}$ Ideally, undertaking these activities gives people time to reflect upon the particular situation in life in which they find themselves, and also to consider how they may define themselves by way of it. In the process of maintaining these performances, people are encouraged to consolidate their collective identity within the group and transcend their individual aspirations.

Returning to the image of the Stoddart family taken out on the front verandah, the tea things are shown laid out on the table. Therefore, this photograph provides visible evidence of how the settler families in New Zealand introduced their traditional social and cultural practices into their homes. Also, how they adapted them to living spaces that were formerly outside their previous experience, such as to the verandah, which was attached to the main structure of many colonial dwellings.

By the mid-nineteenth century the verandah had become a recognizable feature of the vernacular building style within Australasia, for the very good reason that it was a versatile space and well-suited to the local environment. It was a transitional space: that is, it was similar to a public space, open and welcoming, with the capacity to extend the spatial footprint beyond the dwelling by the way of steps into the immediate surroundings. Yet, at the same time, it was also an enclosed space, and in this sense acted as a private area in which the family members could gather to transact their daily lives. Introducing customary practices within such spaces demonstrated how settlers adapted their traditional rituals to their present surroundings. It also showed the extent to which 
their immediate surroundings influenced how these actions were conducted within these social spaces. In addition, it often defined how these cultural and social routines were performed. More importantly for this study, the customary practices provide proof of how, in the course of these processes being carried out, such as taking tea on the verandah, an observable change in the practice takes place. Further to this, the possibility of 'new' traditions emerges.

The photographing of the ritual performance of the Stoddart family taking tea on the verandah is a reminder of how the camera functions as a witness to such processes. This highlights how photographs as visual statements can also provide material evidence of changes in certain observable behaviours.

\section{Photographic images from a nineteenth-century perspective}

Photographic images are not simply looked at; they are read, deciphered and subjected to a range of interpretations. Joan Schwartz and James Ryan have reminded us, how the Victorian viewer perceived their world. They explain how the content of photographs was regarded as empirically objective, and therefore photographs were treated as transparent reflections of fact and as carriers of true evidence, to be taken on trust. ${ }^{21}$ For colonial families, whose immediate families had been fragmented by geographical migration, sending photographs to family living elsewhere in the world was a way of keeping in contact. It also served as a motivation for taking more photographs, since the settlers themselves often considered the letters they wrote were inadequate to the task of describing aspects of their lives to an audience who knew little of colonial New Zealand. For instance, early colonist Jane Maria Atkinson described the dilemma she faced in a letter to her relatives in England. She wrote in 1867, 'It is a most difficult thing for me to form any notion of how much you do know of my life and surroundings..., letters are so immensely unsatisfactory'. ${ }^{22}$ Similarly, Mary Taylor commented in 1852 how she 'had often tried to give... a picture' of her situation, 'but I have not the skill'. She explained to her friend, English author Charlotte Brontë, 'I get a heap of details, most paltry in themselves and not enough to give you an idea of the whole'. ${ }^{23}$

In certain instances, such visual records may have also been intended to fulfil a role beyond the representation of family. They functioned as visual evidence of their wellbeing. Photographs provided an authentic witness, especially in circumstances where 
family elsewhere was unable to verify the true situation owing to distance. They could be employed to act as a surrogate for first-hand observation. In her study of Margaret Stoddart, Julie King draws attention to the not-unusual occurrence in the colonial period when kin had invested in the financial welfare of extended family members. ${ }^{24} \mathrm{King}$ informs us that Mark Stoddart's brother, James, in Scotland, held a substantial financial interest in the home the Stoddarts had acquired in Christchurch, following their departure from Diamond Harbour in the late 1870s. In these circumstances, photographic images take on a different level of meaning altogether - acting, in this context, in terms of a financial report.

However, when considering the audience for these photographs, it is not primarily a case of the 'Home' audience. ${ }^{25}$ It concerns, first and foremost, the actors themselves as their own audience. This emphasizes the vital role that photography performed within the settler families in the acculturation process during the late nineteenth century. As Deborah Chambers points out, the photographic image, as a visual presence, works to provide new ways of seeing ourselves in the company of those closest to us through ritual displays of togetherness. ${ }^{26}$ In this way, it encourages a sense of belonging within a particular family group. Therefore, photographs often provide essential visual feedback, which reinforces a sense of ourselves to ourselves as members of a social grouping and within a specific cultural setting.

One of the outcomes to be derived from Chambers' recent survey of women who had moved to Australia in the 1950s was the recognition by her subjects of the value of family photographs and their role in the process of negotiating the changes they had gone through since their arrival. ${ }^{27}$ Invariably the women emphasized the enduring value of the photographs they had collected and compiled in their albums as active cultural agents in relationship to their naturalization. The photographs provided visual evidence of their presence within these spaces and thus invited new ways of seeing themselves, particularly in relation to their immediate surroundings. They added that this experience could not be underestimated.

These findings have shown how, for these immigrant women, their photographs provide them with a permanent record of a particular moment in time, and give meaning to the performance of being 'family'. At the same time, they also provide memories of a lived 
experience, which Chambers found could also be a trigger for future storytelling. So often in these situations, as both Barbara Harrison and Susan Sontag have concluded, photographs can provide people with an imaginary possession of space. Initially, these people may not have admitted to feeling entirely secure in their new environment; thus the photographs acted to strengthen their claims to the ownership of the particular space in which they found themselves and effectively worked to legitimize certain situations and actions. ${ }^{28}$ Therefore such visual images made an active contribution to the acculturation process and played a significant factor in the successful integration of people into a given society. In the photograph of the Stoddart family gathered together on the front verandah of their home, the domestic setting acts as a framework that demonstrates the family in command of the space which they inhabit.

At the time that the photograph of the family on the verandah at Diamond Harbour was taken, Anna Stoddart may have well reflected on previous occasions when the family had been pictured together. They included those occasions dating from when the children were young, when the photographs were taken by Dr A.C. Barker (1819-1873), a physician and amateur photographer in Christchurch. According to entries in Mark Stoddart's diary for these years, Barker came over to Diamond Harbour from Christchurch to take photographs of the family on two occasions, in 1868 and 1871 respectively. ${ }^{29}$ On 10 March 1871 Stoddart noted in his diary: 'Barker came with his daughter, Mary, to take photographs, ${ }^{30}$ Only one photograph is known to have survived from this session. It was taken of the family in the garden at Diamond Harbour and shows Mark and Anna Stoddart seated on a rustic bench with their elder children, Fanny, Margaret and James (fig. 3). ${ }^{31}$

Dr Barker, who was a Canterbury pilgrim himself, recognized the specific needs of the early colonists and was attentive to them. To fulfil their perceived needs, he went to extraordinary lengths to trundle his cumbersome photographic equipment, for developing the wet collodion glass negatives, throughout the province in the 1860s and into the early 1870s. This was so he could locate his subjects within an environment, which they had so recently created by their own labours, and where they felt 'at home'. Less than one year after his trip to the Stoddart family at Diamond Harbour, Barker made what was, in those days, the arduous journey down to the Acland family of Mt Peel Station in South Canterbury. J.B.A. Acland recorded Dr Barker's three-day visit to Mt Peel in his diary. 
On 25 January 1872 he announced that Barker had arrived. ${ }^{32}$ In his entry for the following day he described how Barker had been 'busy taking views of house and church and so forth...' Besides the images of the house and the church, Barker also took several photographs of members of the family out in the garden and gathered on the steps leading up to the verandah at the front of the homestead (fig. 4). ${ }^{33}$

\section{Family photography as a set of social practices}

When we examine family photographs and how they are taken, it becomes evident that the specific set of integrated practices involved in these practices, follow certain widelyrecognized social and cultural conventions which are carried out in the course of their production. ${ }^{34}$ Furthermore, the participants' actions and their shared knowledge of the order of things and how they are to be undertaken are subject to discernible controlling mechanisms which make little allowance for individual intentions. Thus the genre of family photography is clearly instrumental in the production of a certain type of image. Here it seems appropriate to re-introduce Goffman and to apply his formative research on sociology of social occasions to the practice of photography. ${ }^{35}$ He defined social interactions, as occasions when those who come together feel obliged to follow the established social codes of the group. They are also frequently bound up in a series of well understood ritual moments within family life. Bourdieu observed the desire to capture cultural rituals, noting that they are most likely to be associated with cultural holidays when family members gather, such as at Christmas, and what he identified, as the high points of family life. ${ }^{36}$

Some families invest more of their emotional capital in the visual representation of family values than others. Ann Victoria Bliss has enlarged on this point. ${ }^{37}$ She observes how individual families frequently develop their own photographic rituals. For some families the actual taking of family photographs could be described as a ritualized practice. Likewise, Gillian Rose is also keen to pick up on photography as a regular practice within certain families. ${ }^{38}$ Rose explains what she means by this, referring to Reckwitz, who understood visual practice as consisting of recognizable actions which are interconnected. ${ }^{39}$ Such actions include both mental and bodily activities, specific objects (eg: a camera) and their uses, as well as the set of circumstances in which the photograph was to be taken. Goffman also noted how clearly identifiable behaviours become a significant aspect within the context of small group situations. ${ }^{40}$ 
The Acland family of Mt Peel Station in South Canterbury came together to celebrate important dates on their family calendar. As time went by, they marked such occasions by taking photographs. Taking photographs thus also became an integral part of these family gatherings. One such date that the family recognized each year was the anniversary of the arrival of the family onto the land, which they took up in May 1856. Years later J.B.A. Acland recounted that arrival to his brother in England. Acland explained that 'as it so happens [the month of] May is what we call Mt Peel Anniversary, that is to say that next 11th May is exactly 31 years since the day we pitched our tent within a very few yards from where I sit'. ${ }^{41} \mathrm{He}$ added, 'little did we foresee all that was before us and what a change 30 years would make in our chosen country'. Given the number of photographs taken to mark the anniversary on 11 May that one finds when leafing through the photograph album compiled by his daughter Lucy during the 1890 s, this was certainly the case. For example, Lucy devoted one page of her albums to photographs taken in 1895 to mark the anniversary of the arrival of Acland and his business partner, Charles Tripp, on their land in South Canterbury. ${ }^{42}$ All four were group photographs and they included images of family members at home at that time, shown grouped together. They included one of J.B.A. Acland and his wife Emily, along with their daughters Harriet, Bessie, Lucy and Rosa, taken in the garden (fig. 5). ${ }^{43}$

Christmas was also an occasion when it was customary for the Acland family to take photographs. In fact the ritualized Christmas photograph became an integral part of this family's way of celebrating this important festival on the Christian calendar (figs 6 \& 7). ${ }^{44}$ This was particularly the case during the 1890s when a number of the children in the family took an active role in photography. However, before turning to examine specific examples in more detail, it is worth noting how Chalfen is in agreement with Bourdieu's comment that taking family photographs cannot be considered as a random act. ${ }^{45}$ As Chalfen has explained, taking photographs is an activity which follows a prescribed pattern. Moreover, although he believed that more work needs to be done in this area, Chalfen says that he has confirmed this from his own observations, contrary to Bourdieu's assessment of photographic production as being under the control of the photographer alone, taking of a family photograph was in fact a collective decision. ${ }^{46}$ Clark McPhail, who has also observed the interaction of actors at temporary gatherings, says that the way in which members of a group co-operate with one another should be 
seen as highly complex forms of collective action. ${ }^{47}$ He says that this demonstrates how, in such circumstances, actors are amenable to direction from others within the group. In other words they are more likely to have been active participants in an exchange of pictorial ideas. McPhail has described how the operator and the subjects decide what to do and who and what to include, in consultation with others in the group. During the course of this process it becomes apparent that choices are being made, either explicitly or implicitly, by all those involved. It is operator and the subjects decide together as to 'what to do', and 'who to include'. And therefore, Chalfen concludes everyone also takes on the responsibility for 'doing things in the right way', since everyone involved has a vested interest in a good outcome. ${ }^{48}$ This also leaves the individual feeling the activity they have been involved in has a rightness to it.

Other scholars suggest that social interactions, such as those relating to family photography, can only take place among the membership of a given group. ${ }^{49}$ Those who feel strongly about their membership are impelled to enter into close relationships with others, relationships which become 'fully meaningful in the sense that the beliefs, values, norms and symbolism carried in the primary group's culture [and] ... a major part of what they might regard as their identity as a group'. These conditions seem to coincide with what is apparent within the performative actions associated with taking a photograph. In this way, the participants fulfil their obligations in accordance with their collective responsibilities as members of the group and through their participation demonstrate solidarity with the group. Erving Goffman describes these encounters as a selection of moments that idealize family life. In his opinion, like other social and cultural practices, they take on the characteristics of a choreographed performance. ${ }^{50}$ Furthermore, in many cases, in collective representations it is the social actors, through symbolic and material means, who will implicitly orient themselves towards others, in much the same way as actors on a stage. They do this in order to make manifest their intentions, and in a calculated way extract responses from their audience. Chalfen concludes that, when it comes to having family photographs taken, everyone does their best to bring about a good result. It is the moment in time, which is caught when the shutter closes, that the photographer, the subjects and the viewer all collectively experience this event and in the same way. ${ }^{51}$ Of course this is what makes this 'moment' so special and why it is remembered by those present. 
When we examine the two photographs I have entitled Xmas Group I and Xmas Group II, taken over the summer holiday period of 1896 and found in the photograph album of Lucy Acland, the unity of purpose of the actors is clearly demonstrated (figs $6 \& 7$ ). In both of these images, three generations of the Acland family gather before a flight of the steps leading up to the homestead, which thus confirms the location of photograph. Their presence is not clearly positioned in the frame, as it is, for example, in the group photograph taken of the family by A.C. Barker more than twenty years before in 1872 (fig. 4). In this one the Acland family appears informally grouped together on the steps and the verandah. Nevertheless, as Elizabeth Edwards has pointed out, the very act of taking a photograph also takes into account spaces outside the frame, which, at the same time, resonate within it. ${ }^{52}$ In these group photographs, the Acland family presented a dynamic whole. In fact, they could be described as symbolizing a veritable embodiment of a closely-knit family, reflected directly through the body language of the actors. The patriarch, J.B.A. Acland and his wife Emily are central to the group around which the other members of the family are clustered. In Xmas Group I, many of the family hold up to the camera images of absent family members, as if to communicate that, although they are not with us in person, they are one of us. The implication is that there will be a certain incompleteness to the family group if they are also not acknowledged, even if it is only with the aid of a photographic image. As Geoffrey Batchen has noted the inclusion of these material objects acts as a virtual presence within the photographic space. ${ }^{53}$ For instance, in Xmas Group I, Emily Acland holds up a double portrait of her sons, Henry and Hugh. They were the only two of her nine children not present at the time the photograph was taken, as they were studying in England. In her gesture of holding this image of her sons she illustrates how people approach images of loved ones. They are directly channelled through a combination of sight and touch and it is this physical engagement with these items what gives them their resonance for a beholder.

Xmas Group II is, to all intents and purposes, almost identical to Xmas Group I. However, although the overall composition of the group does exhibit similarities, if this image is examined more closely it is apparent that the family has, in fact, regrouped between the two photo shoots. For instance, Rosa Acland, who is positioned on the left hand side of the group in the first photograph, is located in the second photograph at the centre front. In the interval between the taking of the two photographs she has apparently been responsible for collecting the cartes-de-visite from the various family members, which 
many of them had been holding up to the camera for the first photograph. As we see in the second photograph, in her haste to be seated for the next photograph, they fall from her hands in a blurry mass as the shutter closes. Perhaps we can also infer from the actions of Rosa that the womenfolk within this family were directly involved in taking care of aspects of the image-making within the family on this occasion. Probably it was they who, during these years, took on the responsibility of overseeing the photo-shoot of the family group; certainly, they were actively involved in the processes of printing and distribution afterwards. This adds credence to Geoffrey Poister's observation, from his studies of family photography, that it was the women in the family, who, if they are not responsible for the actual taking of family photographs themselves, are usually the ones who instigate the events. ${ }^{54}$

Including photographs within photographs as a symbolic presence became a common practice during the Victorian period. It featured in image-making of the royal family, a practice which they sought to closely control, especially following the untimely death of Prince Albert in December 1861. A good example of what I mean is the well-known study of Queen Victoria with Princess Beatrice on her knee, taken by Ghémar Frères of Brussels in 1862 (fig. 8). ${ }^{55}$ It was made in the aftermath of the Prince Consort's death, when the royal family was thrown into deep mourning. Through the interaction between the Queen and Beatrice, her youngest child, it is apparent how ideas of emotional attachment and the senses become engaged, both in the pose of the daughter seated on her mother's knee, and in the unified focus of their gaze towards the photograph of Albert, which Beatrice clasps in her hands. However, unlike the situation in the photograph of Xmas I taken of the Acland family, in this case her hands conceal rather than reveal the image that she is holding (fig. 6).

\section{Queen Victoria and family photography}

What is often overlooked in many of the discussions on family photography is how spatial intimacy has a long history within Western society. It goes back almost to the advent of photography, as in the first images taken of Victoria and Albert and their children dating from the early 1840s. Deborah Chambers and more recently, Anne Lyden, are two scholars who acknowledge this history. ${ }^{56}$ They both claim that Victoria was central to the ideological and signifying systems that became synonymous with her age, and that her attitude towards the photographic medium had a considerable impact. ${ }^{57}$ This 
phenomenon was made manifest within public consciousness through the wide circulation of photographic images of the royal family.

Queen Victoria's extraordinary fascination with every aspect of photography has only come in for serious scrutiny in recent years. Much has been made of the Queen as an assiduous collector of photographs and of the large collection of photograph albums that she amassed during her lifetime. ${ }^{58}$ In addition, attention has also been given to the support that both Victoria and Albert gave to the medium of photography, particularly to their role as patrons. ${ }^{59}$ Conversely, comparatively less attention has been given to other facets of Victoria's active engagement with photography, including the complex issue of how she came to use the process and practice as a means of establishing her own image and defining her identity. As John Plunkett has pointed out in his book, Queen Victoria: First Media Monarch, her relationship with the print media, particularly with regard to their role in the circulation of the Queen's image and that of members of her family, also deserves closer investigation. ${ }^{60}$

There is an ongoing debate as to whether it was Victoria herself who was responsible for the image she projected in her photographs as a devoted wife and mother, and later, a grieving widow, or whether it was orchestrated for her by outside forces. ${ }^{61}$ What is not in dispute, however, is that the persona she projected in the many photographs taken of her, throughout her long life, was one she steadfastly maintained. Significantly, the photographic image of her taken largely for domestic consumption could be strangely at odds with the official representations produced of the Queen. This makes Victoria a particularly interesting subject for the study of the production of royal identity. A good example is the portrayal of the Queen 'in majesty', showing the Queen and Prince Albert and their children, painted by Franz Xavier Winterhalter in 1846. The royal family is represented according to the conventions of a well-established artistic tradition in court painting: Victoria, as titular head of state, with Albert by her side, are both shown seated on large throne-like chairs before an idealized setting. Their eldest son, Albert Edward, stands on the right-hand side of Victoria, indicating the line of descent, while his younger siblings are grouped together in the foreground of the composition. Victoria is reputed to have liked this painting, which hung for many years at Osborne House, her home on the Isle of Wight. ${ }^{62}$ Yet, paradoxically, this was precisely the type of representation that she went out of her way to distance herself from in her photographs. Within her photographs, 
her preference was for a more understated image, devoid of the outward displays of her rank; one that presented her as within the well-understood parameters of containment within the domestic sphere. This was an age where every aspect of how a person presented themselves was representative of some status category. Choosing how to visualize herself in her photographs was Victoria's way, within the limitations of her constitutional powers, of expressing the social and cultural values which she personally held to be important. Bourdieu has since described this as bodily inscription. ${ }^{63}$ It was a strategy which made Victoria appear, on the one hand, more approachable to her subjects, while on the other, more relevant to their lives. Elizabeth Longford concluded, in her authoritative biography Queen Victoria: Born to succeed, that it was in the very simple act of 'seeming to be like her subjects' that her real power lay. ${ }^{64}$ What is significant here, is that she chose not to differentiate herself from her subjects in her photographic images. Victoria thus became a model for emerging middle class values. How this sector within British society would in turn choose to represent itself was to have implications for the future development of the genre of family photography. ${ }^{65}$

According to Bill Jay, Victoria saw her first photographic image in late $1839 .^{66}$ However, because of the ongoing problems with the chemical instability of photographic images at this early period, it was not until March 1842, when Prince Albert sat for William Constable in his studio at Brighton, that the first successful photograph of any member of the royal family was made. ${ }^{67}$ This study was soon followed by a second, taken by Richard Beard of London, in the same month. By the mid-1840s Victoria and Albert had begun to make a point of regularly engaging commercial photographers to photograph them and their growing family. Although these photographs were initially intended only for the royal family's private consumption, from the late 1850 s selected photographs from the royal collections began to appear in the public domain. It demonstrates Victoria's early interest in photography and her continuing commitment to the medium, both of which were instrumental in how photography was accepted by the population at large. $^{68}$

One of the first photographs of the royal family to be put on public display came from a series of photographs that had been taken by Leonida Caldesi in the weeks following the birth of Princess Beatrice on 14 April 1857, when the royal family was in residence at Osborne House (fig. 9). ${ }^{69}$ This particular image was chosen for inclusion in the fifth 
annual exhibition of the London Photographic Society at the South Kensington Museum in May 1857. The reviewer from The Liverpool and Manchester Photographic Journal reported that this photograph, as well as being well-executed, was also highly interesting from the point of view of the domestic tenor of the photograph. This, he said, was typified by the casual manner in which the children were grouped before the camera (as opposed to being formally lined up). They were standing between the figures of their mother, the Queen, seated with Beatrice on her knee on the right side of the photograph, and their father, Prince Albert, by the balustrade on the left. ${ }^{70}$ The apparent informality in which the royal family was framed within this photograph captured the attention of the reviewer. This has since come to be a recognized feature of family photographs and as a hallmark of the genre. Significantly, in June 1859, Dominic Colnagni issued engraved prints of this photograph for public circulation. ${ }^{71}$ Within days of their release reproductions of this image were reproduced by command of the Queen in leading publications on both sides of the Altantic including the London Illustrated News in Britain and the Harper's Weekly in the United States. ${ }^{72}$ This then was the start of what was to become an ever-increasing release of photographic images for public consumption from the royal household. These photographs would, in turn, create within the public at large an extraordinary interest in representations of the royal family, as demonstrated by the demand for the Royal Album produced by John Jabez Edwin Mayall (1813-1901). Within days of going on sale in August 1860 an extraordinary number of orders had been placed for it. ${ }^{73}$ And as the public demand for this portfolio of fifteen cartes-de-visite studies of members of the royal family continued, it became available through commercial outlets around the world, as far afield as New Zealand and Australia. For instance, within this country, Wellington photographers, Swan and Wigglesworth, acted as local distributors. ${ }^{74}$

However, it was not her fascination with photography alone which helped to keep the image of Victoria and members of her family before the public. In their survey of print media during the first half of the nineteenth century, Andrew King and John Plunkett point out how a succession of key technological developments in the first half of the nineteenth century had an impact on production methods, making news media more affordable and leading to a significant increase in circulation. ${ }^{75}$ These developments were to have important implications for how all illustrations, including photographs, could be reproduced before the emergence of half-tone engraving in the 1880s. According to King and Plunkett, the revival of wood engraving, a considerably less expensive process than 
the more recently introduced copper or steel-plate engraving, was of particular significance. Furthermore, as they point out, woodblocks also had the advantage that, as a form of relief printing, they could be printed simultaneously with typeface, thus saving time and reducing the costs of production. ${ }^{76}$

The Queen's appropriation of these modes of publication greatly benefitted her as a public figure, especially during her years of widowhood. However, with Victoria's retreat from public life after Albert's death, disseminating her image became a critical issue. From that point in time onwards, the photographic medium, in conjunction with print media, provided a vehicle through which the Queen, at her discretion, could continue to be visibly accessible to her subjects at home and abroad. ${ }^{77}$

During the 1860s images of Victoria were increasingly reproduced within the daily newspapers, as well as in a growing number of periodicals, including those directed towards women's exclusive consumption. Before Victoria, these media had generally not covered the activities of royalty to any extent. The latter publications, in particular, had considerable influence on how Victoria and her family were perceived, as they provided countless opportunities for royal images to be a constant presence before women at home. Take for instance, the intimate photographic study of the Queen with Princess Beatrice on her knee taken by Ghémar Frères, already referred to in relation to the more effective aspects of family photography. This particular image was also reproduced by Marion and Co. of London in a carte-de-visite format and released for sale by them to the public. It was also reworked as a wood engraving at this period. Further, in the same week as the wedding of the Prince and Princess of Wales in March 1863, this rendition of the image of the Queen with Beatrice appeared on the front cover of The Lady's Newspaper and Pictorial Times, a publication which was soon to be incorporated into The Queen. ${ }^{78}$ This is just one example of what was to be an ever-growing trend by a public who were progressively making the monarch and her family into media celebrities.

\section{Family photography as displays of intimacy and family togetherness}

The image that the royal family projected as the embodiment of familial unity and togetherness, enacted in the many visual representations produced from the midnineteenth century, has become the model for how the ideal family should look. In her 
series of interviews with women in Southern England in the early 2000s, Rose noted that what they described as demonstrations of 'togetherness' were most frequently cited by these women in relation to what family photographs show. Of course there is nothing particularly new in these findings. ${ }^{79}$ As Rose has said herself, a review of the extensive literature concerning family photography already has defined family unity as a widely recognized attribute of the medium. This is well-reflected in the first images taken of the royal family, where the close interaction between members family becomes a recognizable feature of these photographs. Certainly they were responsible for popularizing this photographic genre. ${ }^{80}$ Rose describes how signs of togetherness are expressed principally through bodily proximity and articulated at the time of the production of the photographic image. However, as she also pointed out, affect is a complex issue. In an effort to better define what she means by this, she once again turns to the work of Reckwitz. ${ }^{81}$ It is he who outlines the importance of emotion and feelings in relation to understanding family photography as a social practice. ${ }^{82}$ However, for these to be invoked, the performative actions displayed within the photograph at the time of production have to be seen as credible. Therefore to be effective to an audience, they must appear to have been enacted properly.

When we look at Xmas Group I and Xmas Group II, it is this aspect of photograph taking which is one of their defining features. On this particular occasion, at least two photographs were taken (or at least, only two images are known to have survived). In both these photographs the unity of the family group was established through the close interaction of everyone present and the almost theatrical containment of the group. ${ }^{83}$ If this image is compared with the Stoddart family photograph, the differences in how relationships are expressed within these family photographs become apparent. Although the expression of close proximity is a feature of all family photographs, we also have to take into account that the primary group's requirement for intimacy was also governed by the controls and constraints of secondary association. In his study of small group relationships and their characteristics, sociologist, Howard Nixon points out that, in many cases, although governed by the obligations of the primary group of which they are a member, what also comes into the mix are the controls and constraints evidenced by the secondary associations, in which personal interactions are less intimately involved. ${ }^{84}$ Furthermore, there may be contributing factors which also display aspects of togetherness. If not expressed outwardly, they are expressed in other ways. In the case of 
the Stoddart family, shown together on the verandah taking tea, perhaps this activity may also equate to an outward expression of intimacy, in the sense that the viewer is witness to the day-to-day routines of private family life. As well as rituals of togetherness, at the same time there is also the expression of continuity.

There may be other extenuating circumstances which contribute to a presentation of family unity within a particular photograph. Without further information it is impossible to ascertain the circumstances in which this photograph was taken or, for that matter, for whom the photograph was intended. However, we can intelligently speculate, based on our knowledge of dress codes of the period that the photograph was taken to capture the family together, perhaps, one last time, before James' imminent departure for Southern Africa. This departure is indicated by the travelling habit he is wearing and the rawhide bag shown on the left hand side of the photograph by his sister Agnes. If indeed this is so, then this image of the Stoddart family is one that is also tinged with sadness at his departure.

Rose has been keen to stress, when it comes to family photography, that togetherness is not only enacted by what a photographic image shows, as Bourdieu has claimed. She explains that togetherness is also enacted through a range of social and cultural practices surrounding what is also done with these photographs, including the space and time and manner in which they are encountered. ${ }^{85}$ This aspect of family images has been given rather less critical attention than it deserves within the developing discourse on family photography, in comparison to the extensive commentary on what an image shows. ${ }^{86}$ Rose and also Chalfen, in their separate studies, recognize these shortcomings in relation to the integral set of practices that make up photography, and therefore their findings are of significance for this study. ${ }^{87}$ Rose's work, with regard to the organization and distribution of photographs, is particularly significant, since she uniquely focuses on women and their role in the care of photographic images as a strongly gendered practice. These practices include decisions concerning the display of family photographs.

In this context, it is worth noting how Lucy Acland placed the two images taken of her family, Xmas I and Xmas II, side by side on the same page in her photograph album (figs $6 \& 7)$. Thus, a sense of closeness continued to be maintained in the presentation of these family photographs within her album. Another well-recognized aspect of the practices 
developed around family photography was, of course, the sending of photographs to relatives and friends, thus keeping up familial relationships, through staying in touch. Family photographs show family members together; they were looked at together; they are displayed together and they are sent to family members, as a means of maintaining togetherness. ${ }^{88}$ It is all these aspects, and not just the photographs themselves, that make up the integral set of practices which make family photographs significant.

\section{Summary}

Family photography dates back to the mid-nineteenth century in the years following the introduction of the photographic medium. By the end of that century, when the photographs in this study were taken, family photography was a recognized genre of photography, with its own distinctive and well-defined codes of practice.

What we learn from this examination of family photographs taken at the turn of the century is that, for the colonial families of Canterbury, photography became an active agent in relation to their successful integration into colonial society. Visual representations, such as those of the Stoddart and Acland families gathered together, enabled these families, experiencing considerable cultural and social change in their lives, to see themselves in the company of those closest to them within these recently settled surroundings. Furthermore, through their participation in these outward displays of family solidarity, they were also shown to be reaffirming their affiliation to a particular cultural and social grouping. Again, this emphasizes the capacity of family photographs to evoke within their audiences certain conditioned responses and reminds us why the images of family groups performed such a crucial role within these colonial families.

By the 1890s, photography was becoming a significant recreational pastime for some settler families. In order to develop a better understanding of the working relationships that formed within these families, Chapters Three and Four will investigate, through case studies, the special set of circumstances which characterized these photographic practices, in particular the close collaborations between the daughters of these families. 


\section{Chapter Three}

\section{Case Study: John and Harriet Acland}

\section{Introduction}

This first section of Chapter Three is concerned with developing an understanding of the special working relationship between brother and sister, John (1863-1944) and Harriet Acland, with respect to their photographic production during the early 1890s. The focus, in the first instance, will be on their photographic portraits of their father, J.B.A. Acland. These were taken in his study in the homestead at Mt Peel Station during the first half of 1893 (figs $10 \& 11) .{ }^{1}$ These images will form a case study of John and Harriet's photographic practice. To introduce this study, I will reconstruct the background to this collaboration. This will entail outlining the circumstances surrounding the actual photoshoot from the supporting documentation available from the extensive family archives relating directly to these photo sessions. Then I will move on to establish the wider context in which these photographs were constituted. This will involve consulting contemporary diaries and letters as well as photograph albums from the family archives. ${ }^{2}$ As I have already suggested in Chapter One, diaries, letters and photograph albums provide the ways and means for individuals to make a permanent record of their everyday experiences and provide useful resources when it comes to verifying contemporary events and the social practices invested in them. ${ }^{3}$

\section{Piecing together the textual fragments}

First, what do the photographs yield? In searching through the photograph collection from the Acland papers in the Macmillan Brown Library, two loose photographs are found which picture J.B.A. Acland seated at his writing desk in his study. One of these photographs is captioned and entitled Father-in-Study (fig. 10). Significantly, this photograph is dated March 1893. What is more, it is also inscribed with the initials 'HDA'. From these initials it can be inferred that this image is the work of Acland's daughter, Harriet, and thereby assign with some certainty her authorship to it. The second image also shows J.B.A. Acland seated at his desk (fig. 11). It bears no inscription, but presumably it was taken at the same time as the photograph taken by Harriet. However, it is also possible that another camera was used for the second print as the format is 
different. This suggests that more than one operator may have been involved in the actual photo-shoot.

In relation to these portrait studies, other textual resources in the family archives include the diaries and letters of J.B.A. Acland himself. Acland was a conscientious diarist. Although his entries are generally short and cryptic in style, they are informative of his and his family's whereabouts, from the time of his departure from Plymouth for New Zealand in 1855 up until the late 1890s. For instance, on referring to his diary from the early 1890s from the Acland papers, it is found that Acland entered into his diary for 20 March, 1893 that he was 'photographed in [his] study'. Although, this brief note may not seem very illuminating, what it does do is confirm that a photo-shoot in his study actually did take place in the early part of 1893 and thereby verifies the authenticity of the caption on the photograph taken of him in his study by his daughter, Harriet.

Similarly, Acland's letters from this period are also a useful source. One letter is of particular significance since it provides further details about the nature of the photosessions undertaken in the study. In this letter, dated 3 April, 1893, some two weeks after his diary entry on 20 March, Acland informed his son, Henry, about how the sessions were progressing. ${ }^{5} \mathrm{He}$ wrote, 'They are taking to photographing me in study while [I am] supposed to be writing etc.' He goes on to explain to Henry, 'It is hard to be immobile for 3 solid minutes.' However, 'today John took a [successful] photograph of me in under 30 seconds'. Acland's letter confirms the fact that the photo-shoot in his study was undertaken by at least two of his children. Harriet's involvement can be deduced from the inscription below the photograph taken by her. Acland's letter to Henry provides confirmation that her brother, John, was working with her. Hence it can be concluded that these photo-sessions were very much a combined effort and therefore that the second photograph of J.B.A. Acland taken in his study found in the family archives was likely to have been the work of John. Furthermore, it is probable, from Acland's letter, that the photographing session that he refers to in his diary on 20 March was the first of a number of intensive photo sessions spaced out over a timeframe of several weeks. By way of these snippets of information from family archives a clearer picture emerges of the undertaking. Although this information is only fragmentary, I think that it is possible to infer that this photo session was anything but ordinary; rather, given that John and Harriet were only amateur photographers, it could be considered as really rather extraordinary 
and demonstrates that they had technical skills that most amateurs would not have acquired at that time.

Acland's brief references to the sessions in which John and Harriet were involved imply that, if he did not actively encourage his children in this undertaking, he at least agreed to their request. This is ascertained from the way in which Acland explains in his letter to his son, Henry, that 'it is very difficult to keep a pose for that length of time'. If he had been an unwilling subject, he would not have committed himself to what appears to have been quite a lengthy process, requiring a lot of patience. From this it can be assumed that Acland probably also played an active role in the outcome.

Jane Fletcher makes the point that, when considering the subject of portraiture, all too often the input of the sitter is not given enough emphasis in comparison with the operator of the camera. ${ }^{6}$ In many cases the relationship between the photographer and the sitter is a formative one and should be seen as a dynamic interaction between the parties involved in this undertaking. Part of any dialogue that took place between the parties involved would occur in all likelihood prior to the commencement of the actual shoot.

Photographer Brad Jackson claims that it is impossible to work on a serious undertaking with a camera unless you first know what you intend to do, as so many decisions have to be made. ${ }^{7}$ For instance, questions such as where these photographs are to be taken have to be considered. Employing plate cameras to take photographs within interior settings poses considerable technical problems, particularly at this period. It is likely that John and Harriet had the skills to carry out such an undertaking, and that their father was confident of a good result and therefore he gave the venture the go-ahead. Yet, having said this, his remarks on the exposures times do suggest that this exercise was not without its technical difficulties. ${ }^{8}$ In this context, Sarah Anne Carter's observations are useful. In her opinion, only professional or serious amateurs would have had the ability to take photographs within interior spaces, where the lighting was as low. ${ }^{9}$ As it happens, J.B.A. Acland's study was south-facing and therefore relatively dimly lit. Carter points to the difficulties of being able to manage the striking contrasts between light and dark encountered in this type of photographic work. Her comments are based on remarks from a guide book published in the 1890s for photographers on the topic of how to photograph interiors. This book outlines in detail some of the challenges, particularly coping with strong contrasts of light and dark within a single frame, most notably from the natural light 
coming through the windows in relation to the dark spaces encountered elsewhere in the room. Even now, with all the sophisticated equipment available to photographers, working within dimly-lit interiors still poses problems. Jane Ussher commented on this problem while recounting her experiences on her recent visit to Antarctica to photograph the interiors of Scott's and Shackleton's huts. ${ }^{10}$ She described how she overcame these technical difficulties by screening the glare from the windows, while at the same time making sure that enough light was thrown into the dark areas of the rooms to capture the detail within these spaces during the long exposure times that were necessary.

John and Harriet, confronted with similar difficulties, may have also decided to introduce another light source into this interior setting by experimenting with some type of early flash. Although this cannot be confirmed from Acland's written description, what we do know is that the exposure times over the course of these photo-sessions had become shorter. ${ }^{11}$ This could be partially accounted for by the use of two different cameras. But a more probable reason for the improved times, I will argue, came as a direct result of the production of additional lighting from an artificial source such as from a flash apparatus. John Goddard, a specialist in early photographic techniques says that, by this date, the flash compounds employed by photographers had become more stable, and therefore the whole process was more reliable. ${ }^{12} \mathrm{He}$ also points to the strength of the reflections on items with polished surfaces in these photographic prints as an indicator that this, in fact, was likely to have been the case.

\section{A portrait of a gentleman}

In both the extant photographs of Acland, taken over the two-week period from lateMarch until early-April, he is shown with his back to the fireplace, sitting at his writing desk, pen poised in his right hand. His face is bathed in the natural light from the windows on his left, which highlights the features of his face. In her photograph of her father, Harriet has decided to stand closer to her subject and point the camera at a higher angle than did her brother. John, meanwhile, has decided to stand back somewhat and therefore positioned the camera further away from his father. This has enabled him to achieve a wider-angled view of his subject and in doing so he has been able to include within the frame more of the room and its contents. 
As Elizabeth Edwards remarks, the very act of photography conveys its own set of spatial relations. The subject is placed physically before the apparatus, thus bringing a further social space into play. ${ }^{13}$ This aspect becomes apparent when John's image of his father is considered. In contrast to Harriet's, it shows Acland surrounded by items of personal value gathered over a lifetime. The care with which these objects have been included in the frame reminds us that the arrangement of such objects has an essential role in how we naturalize the home environment as a lived-in space. Moreover, on a wider level it enables us to understand everyday experiences through our connections with the materiality of certain chosen items. Theodore Schatzki and Andreas Reckwitz describe this area of social practice as an activity made up of several elements that are usually intimately interconnected. ${ }^{14}$ Both of them outline how interactions with things and the ways they are used can become a part of our daily lives, and thereby how habitual behaviours are performed within certain spaces. It is through these ritualized actions that our identities are made manifest. This has been explained in Chapter Two with regard to the Stoddart family, pictured outside on the verandah of their home at Diamond Harbour while taking afternoon tea.

If the photographs by John and Harriet Acland are considered from the perspective of what is represented in these photographs, it is possible to understand their father as a person, not only through his presence pretending to work at his papers in his study, but also by way of the objects that background these actions in the course of his daily life. The French philosopher, Maurice Merleau-Ponty was one of the first to specify how the links we make to the familiar spaces we inhabit should be considered as extensions of ourselves. ${ }^{15}$ His observation is significant in this instance since it draws attention to how important surroundings are to the development of an individual's identity and sense of self. Mihaly Csikszentmihalyi and Eugene Rochberg-Halton build on Merleau-Ponty’s premise by outlining the various ways people make social contracts with things about them within these familiar spaces. ${ }^{16}$ Further to this point, interactions that take place within this particular realm, such as in the domestic sphere, may occur on a daily basis, and are therefore very much involved in the ongoing patterns, however discrete, of everyday life. Chosen objects of this sort are also intimately connected to us through the senses and the feelings they evoke in us. Transactions between people and things are an important part of our responses to who we are, providing, as they inevitably do, evocation of past memories, present experiences, and future aspirations. All these intangible 
elements of social life are inextricably linked to the objects that are present in our environment. In fact, Csikszentmihalyi concludes that we are defined by things. ${ }^{17}$

In the photographs produced by the adult children of J.B.A. Acland, we clearly discern his emotional need to be surrounded by objects that proclaim the self. For instance, on the left, in John's photograph, above the walking sticks on their rack and over the mantelpiece amongst candles for reading by and the jumble of other paraphernalia, pictures are grouped. Some can be clearly identified as family portraits; others as landscapes. The landscapes are probably scenes of places familiar to Acland from his youth. A letter written by Acland in April 1887 to his brother, Tom Acland (1809-1898), in relation to a scene of the Devonshire countryside which Tom had sent out to him from England as a gift, he explains that mementos of his early life 'are still important to him' ${ }^{18}$ He writes that 'after I have had it framed it will become a part of my special collection'. On his desk, and closer at hand, books lie stacked at his left elbow. These include his current leather-bound diary, in which he made daily entries, including the entry on 20 March 1893 concerning the actual photo-shoot.

Erving Goffman says that individual expression may include not only the discursive elements of language, but also non-discursive elements like manners. ${ }^{19}$ At the same time, he suggests, material items associated with an individual should not be overlooked, as they are important in shaping identity. The significant thing here is that both parent and children recognize the study to be a space filled with objects of personal association with the subject of the photographs. This fact is made implicit by Acland's placement at the centre of the composition of each photograph. Therefore, whatever or whoever we are, we are also what we do. As we naturally are involved in many different things, it can be said that we also have many selves. J.B.A. Acland was undoubtedly a man of many parts. Outside his family, (he was very much a family man, as we can see from the photographs taken at this period of the Acland family), his consuming interest was in developing his land. He took a hands-on interest in this, particularly with respect to the designs for the present homestead and the church on the property, which were both completed in the 1860s. He also oversaw the development of the extensive garden that he laid out and watched flourish over the years. In addition, he was a committed churchman and had a long career in local and national politics, notably as the representative for South Canterbury in the Upper House of the New Zealand parliament. ${ }^{20}$ 
Of course, everybody is at liberty to control their own behaviour and shape their lives. By becoming active agents, as individuals, we have the ability to choose how we represent ourselves and how we respond to the situations within our own social world. As Stuart Hall remarks, cultural identities have to come from somewhere and are frequently couched within quite elaborate histories. ${ }^{21}$ Identity is a process of 'becoming' as well as of 'being'. In other words, while it undoubtedly belongs to the past, one's identity is also subject to the ongoing play of history, culture and power. Whether we acknowledge it or not, we are always in a continual state of flux. Harriet and John Acland are mindful of their father's identity as a migrant in choosing to photograph him surrounded by memorial objects in his study. Their clear intention has been to show him with material objects accumulated over a lifetime, all of which contribute to the story of his origins in Devonshire, England. At the same time they show him caught in the here and now in his own private domain in New Zealand, frozen at a particular moment in time and space by the removal and then the replacement of the lens cap of a camera or by the closing of the shutter.

Elizabeth Edwards also observes that, in certain circumstances, space and place become more than just settings for action: they are better conceived as being constructed from cultural and social entities. ${ }^{22}$ Celia Lury also sees photographs as significant in this process of becoming, since they are one of the few ways in which self-understanding of the possessive self can be expressed, as well as successfully secured. ${ }^{23}$ This of course is largely due to the inherent properties of the photographic medium of frame, freeze and fix. Through the mechanics of the camera, J.B.A. Acland and his children together have constructed a visible statement of who he is and what his interests are, and in this way they have produced an outward expression of his identity.

But of course, this is only one of the possible 'masks' that Acland could have adopted before the camera. Therefore, it must be assumed that, in having his photograph taken within his own private domain, with his memorabilia about him, this was Acland's preferred view of himself. In this way, it be could argued, he is also playing a part. In so doing, as any actor knows, he implicitly requests his audience to take the character that is represented seriously and actually possesses the attributes he appears to possess. What is 
crucial in all of this, when posing such a question, is whether the actor himself actually believes in his own impression of reality.

Much of the documentary evidence concerning the two photographs, as I already suggested, is at best fragmentary. Hence our understanding of the whole undertaking is less than complete. However, what this study does reveal is how individual members of one family worked together in producing images as forms of social practice. It becomes clear that the actual shooting process was undertaken in much the same way as has already been discussed with regard to taking of photographs of family groups, whereby all concerned worked together towards a successful outcome.

A further series of questions arises, particularly with regard to the future use of these photographs following the actual photo-sessions. Harriet's photograph is not only clearly identified as to the authorship of the image and the date when it was taken; it is also inscribed as being no. 30. This suggests that the portrait studies taken of J.B.A. Acland were likely to have been a part of a larger portfolio of photographs taken at about the same time. Whether they in fact remained loose or were assembled into an album format cannot be ascertained. What we can say is that John and Harriet were responsible for taking a series of photographs numbering up to at least thirty images. The portrait studies of Acland taken by his children were part of a more comprehensive undertaking. This comes from the fact that a number of these photographs, identified as being taken by either John or Harriet and dating from 1893, appear in the album compiled by their sister, Lucy Acland.

Lucy Acland's photograph album, which she began in this same year, also provides the means to understand what other photographs may have made up such a portfolio.

Although the portrait photographs of her father in his study do not actually appear in Lucy's album, there is a group of up to twenty-four photographs which include images of the house, the church and views of surrounding land inscribed by Lucy as being taken by either John or Harriet during 1893 (fig. 12). ${ }^{24}$ Taking this information into consideration, I think that it is highly likely that there may have been more photographs in the portfolio than the extant images found in either Lucy Acland's album or the Acland papers in the Macmillan Brown Library. ${ }^{25}$ Hence it can be concluded that the portrait studies taken of J.B.A. Acland were also included in this undertaking. Euan Duff notes that, although 
photographs may appear self-evident, more often than not they remain open to interpretation, contextually incomplete and frequently ambiguous. ${ }^{26}$ However, to make proper sense of them, they need to be seen in conjunction with other visual or textual material. That is: photographic images should be seen as significant in themselves for what they show, but also regarded as part of a larger whole.

J.B.A. Acland was in his seventieth year at the time the portrait studies were taken by John and Harriet. One possible motivation for such a portfolio of photographs being produced during the course of this year was a desire to produce a tribute to their father in anticipation of this significant anniversary, on 25 November of the same year. In this context, it should be remembered that Acland had previously engaged a number of itinerant photographers over the years to come to the property to take photographs of the dwellings, the garden and the church as well as the progress of his growing family. For instance, if we go through his diaries, besides the visits of Dr A.C. Barker, who came to take photographs in 1861 and 1872, Acland also noted down the names of the following photographers: D.L. Mundy in 1866 and 1868, C.P. Sealy in 1866, and a Mr Phillips in 1878. ${ }^{27}$ All these photographers took photographs of Mt Peel Station, which he compiled into an album. There is, however, no documentation in his diaries of any photographs being taken for another fifteen years. Nevertheless, their father's early interest in photography had a formative influence on his offspring. It is highly probable that Acland would have been aware that it was now many years since such a series of photograph had been carried out, and when the suggestion was made to him by his children to take a series of photographs, he was therefore keen to take it up.

\section{Back story}

John Acland took up photography seriously in the mid-1880s following the visit to Mt Peel Station of his English cousin, Captain William Acland (1847-1924), who was on a tour of duty with the British Navy in the South Pacific and serving out of Sydney from $1882-85 .^{28}$ At the completion of this tour of duty William Acland wrote to his commanding officer to make a request that his return to England be via New Zealand to visit close family who had settled in this country. Beyond establishing that William Acland did make this visit to his uncle J.B.A. Acland at Mt Peel Station there is no other information about his time spent in New Zealand. J.B.A. Acland's diaries are not helpful with regard to the actual dates of his nephew's visit to Mt Peel, but an entry in his account 
ledger from this period lists the purchase of several boxes of glass plates which Acland may have made in anticipation of his nephew's proposed visit. ${ }^{29}$ Subsequent to the visit by William Acland, John Acland is known to have set up a darkroom at the back of the house and probably was responsible for many of the photographs taken of the family up until the early $1890 \mathrm{~s}^{30}$ As far as it can be ascertained, it was during this period that J.B.A. Acland and his wife Emily (1830-1905), and daughters Bessie, Lucy and Rosa were overseas visiting relatives in England. Harriet, who had remained at home with her brother John, began learning to take photographs under his guidance. The portrait studies taken of their father in his study demonstrate that she continued to work closely with her brother after the other members of the family returned from overseas at the end of 1892. Following the return of her sisters, Lucy and Rosa, they too became closely involved in photography and from this time assisted Harriet in the role of picture taking as well as developing and processing the photographic prints. The photograph taken of Harriet (left) and her sister, Rosa (right), in the conservatory at Mt Peel Station working on developing their prints illustrates some of the ways in which the sisters worked together as a social practice.

\section{An interior view}

Among the series of photographs dating from 1893 within Lucy Acland's album is a small selection of interior scenes of the drawing room in the homestead. These provide a nice comparison with the portrait studies of J.B.A. Acland taken by John and Harriet. These images are all identified by Lucy as being the work of Harriet. Since few photographs taken by Harriet are known to survive it is only possible to get an understanding of Harriet as a photographic practitioner in her own right through these photographic studies.

From the photographs in Lucy's album, it is known that Harriet took at least three photographs of the drawing room at Mt Peel Station (figs $13 \& 14) .{ }^{31}$ From these images it is possible ascertain that Harriet set up the family's half-plate camera on its tripod in the middle of the room. She has then turned her apparatus three hundred and sixty degrees in order to survey the room from all vantage points, as if her original intention had been to document every aspect of the highly-decorated room in detail. These images include views taken on either side of the fire place and one of the far side of the room, which features French doors leading out to the verandah and the conservatory. In fact, this series 
of photographs could be interpreted as a portrait of a room, as one of those lived-in spaces which focus on situations and environments.

Sarah Anne Carter says taking photographs of interior scenes within the home was not unusual at the end of the nineteenth century. ${ }^{32}$ Referring to the east coast of America at this period, she claims that many families wanted to have a visual record of their properties. Drawing on a contemporary article written by Clarence Cook which appeared in House Beautiful at the end of the 1870s, Carter explains that, the main reason for recording home interiors was because photography transformed a private space into a distant form that could be critiqued as a bounded cultural object. ${ }^{33}$ It also provided a visual record of intimate spaces and the memories that people associate with them. In other words, the documentation of interiors provided souvenirs of places of association as well as a permanent record of the material history of a particular family and a reflection of their status within the society in which they lived. What is more, by having the home interiors realized in this way, those interiors were also personalized, in much the same way as a souvenir of people and places and a visualization of one's material family history.

As A.K.C. Petersen points out in her historical survey of New Zealand interiors, there was also a demand for house interiors to be extensively documented throughout the late nineteenth and early twentieth century. ${ }^{34}$ Indeed, there seems to have been a steady demand for professional photographers to take photographs of the interiors of people's homes and probably for much the same reasons as Carter outlines. In her research on photographs of New Zealand interiors, Petersen argues how interiors reveal aspects of the character of the inhabitants of the house and therefore come to stand as a unique statement of the identity of a particular family and their interests. ${ }^{35}$ Furthermore, 'home' became a site where these individuals were able express their own identity through the material objects they had acquired, as is demonstrated in the photographs of Acland in his study.

\section{A time to reflect}

Petersen also reminds us that in 1890 New Zealand had been a British colony for fifty years. ${ }^{36}$ It was a time to reflect on this colonial history, and at the same time to compile reminiscences. Many people had been encouraged to immigrate to New Zealand in the 
first place by the prospect of a simpler and healthier future. They were now drawn back to these values of the past. Certainly this is recognized when approaching the three photographs of the interior scenes taken of the drawing room at Mt Peel Station in the album compiled by Lucy Acland. The three pictures of the drawing room at Mt Peel are juxtaposed with a view of the first habitations at Mt Peel taken by Dr Barker, on his visit in 1861, some thirty years before. While Lucy Acland's album is a vehicle for viewing Harriet's photographs, at the same time it also provides an opportunity for Lucy to construct her own interpretation of the context in which they are to be viewed. In so doing we come to understand the mechanisms by which the compiler of albums can assume authority over how images are presented. Perhaps Lucy was reflecting on the early years, not as a simple way of life, but as a way of measuring the progress that this particular family had made in the intervening years. For the colonial families of Canterbury, photographs taken in the home environment were very important to them in terms of how they wanted to be represented and, more importantly, how they wished to be remembered. It is necessary to be always mindful when considering migrant communities of how the concept of belonging is conceived as being grounded within the territory of their lived experience.

\section{The drawing room as a site of absent presence}

Petersen says that of photographs of New Zealand interiors she has examined, there is a preference for drawing rooms or parlours. ${ }^{37}$ These venues were recognized by Petersen as sites of assembly, where public and private spheres within the colonial context met. ${ }^{38}$ In the majority of cases these photographs were taken without people present, so that, as Jane Ussher says, speaking of her own experience in taking photographs of lived-in spaces, pictures such as these can be seen first and foremost as studies, indeed as portraits of situations and environments. ${ }^{39}$

Lady Mary Anne Barker (1831-1911), living in the nearby foothills at Steventon in midCanterbury, in her role as commentator on early station life in New Zealand, describes her idea of an ideal drawing room or sitting room. ${ }^{40}$ Above all, she concludes, the room should have an original character and style of its own, so that a visitor left alone for five minutes could conjure up an idea of the tastes and habits of the people who lived there. In this sense, an image of a drawing room became a representation of a particular family. However Beverly Gordon, drawing from contemporary articles, suggests that the home 
should be seen as a personification of the homemaker. ${ }^{41}$ Gordon says that the home, through the decoration of interior spaces, came to stand for a particular family member, usually the mother in her role as the homemaker. The idea of home as an embodiment of the woman of the house found its fullest outward expression in the public domain of the drawing room, where personal mementos such as the display of selections of photographs could become identified with a particular person. Mary E. Richmond of Wellington, a visitor to Mt Peel Station during the 1880s, could write in a letter to a friend how 'Emily's drawing room is all that could be desired ... I call it extremely pretty and artistic'. ${ }^{42}$

On surveying the room it becomes apparent that this is indeed Emily's room. Note the companion portraits in pastel of J.B.A. Acland and Emily undertaken when they were in England in 1879, the writing desk by the window, the upright piano, (throughout her life, music was important to her), not to mention the many photographs of family arranged on the mantelpiece and on top of book shelves (figs $13 \& 14$ ). Within this context, then, it seems quite reasonable to assume that when her daughter Harriet took the series of photographs in the drawing room, she was thinking of her mother in conjunction with this particular room. If so, these photographs should be seen as personifications of Emily Acland in her role as mistress of the house. Although this may at first seem a rather unlikely conclusion, I suggest that we also look at how Lucy Acland has included a photograph of her own sitting room with her photographs taken of her wedding to Oliver Scott Thomson in January $1896 .{ }^{43}$ It suggests that she chose to place these photographs together to recognize her change in status from daughter to mistress of her own home (fig. 15). ${ }^{44}$ Certainly, Lucy's personal connection with this room is acknowledged. In a similar way, taking account of the images of the drawing room, I believe that Harriet was also acknowledging her mother. Again, Edwards' observations are helpful here. She says that absence from within an image does not necessarily negate an active presence. ${ }^{45}$ The ways in which people invest in objects and the type of interactions they have with their possessions, especially over time, become part of their identity, and by extension, their close association with them is also communicated.

\section{Summary}

In Chapter Three I have examined the circumstances surrounding the production of the portrait studies of J.B.A. Acland in his study at Mt Peel Station as a case study of two 
family members working collaboratively. These photographs are best understood as part of a larger portfolio of images produced by John and Harriet together for their father probably with his forthcoming seventieth birthday in mind. Among those images of the house, church and surrounding farmland there were a number of interior scenes of the drawing room of the homestead taken by Harriet. Just as the portrait study of their father had specific associations, I suggest that these particular images may also have special associations with their mother, Emily. Of particular concern here has been the ways in which the interaction between animate and inanimate objects have been captured and how they combine to produce a culturally-enriched image of J.B.A. Acland, through the representation of him with the things that give him pleasure.

Secondly, I have compared and contrasted the portrayal of their father as sole actor in his private domain with three photographs taken by Harriet within the public space across the hallway from the study in the drawing room, in which the active presence of her mother, Emily permeates every aspect of the room. The photographs of the drawing room and those taken in the study at Mt Peel Station work, I believe, are companion studies of both her mother and father. In this way, as Carter concludes, images of interior scenes have clear metonymic functions offering access to memories of people and places. They were therefore more than documents, but also statements about personal relationships between people and places, so important to settler families. ${ }^{46}$ 


\section{Chapter Four}

\section{The Buckland family and their contribution to photography}

\section{Introduction}

This chapter examines the photographic practices of siblings. However, the focus here is on tracing the special set of circumstances surrounding the photographic collaborations of the three Buckland sisters, Carrie, Susan and Jessie. Although Jessie, who went on to open her own photographic studio in the small town of Akaroa on Banks Peninsula in 1907, is the best known of the sisters today, it needs to be emphasized from the outset that all three sisters were active photographers during the early period of this study. What is more, each received recognition for their individual achievements. As in the previous chapter, I will attempt to establish the background to the production of selected photographs taken by the three sisters, piecing together details gathered from first-hand accounts relating to the production of their photographs. This will include an in-depth analysis of selected images from their personal photograph albums, as well as a close reading of any correspondence from this period that has survived. The aim is to reconstruct as much information as possible concerning their photographic practice. I will begin this discussion by considering the factors which led to the Buckland sisters taking up photography.

The Bucklands were a fine example of a Victorian family that embraced photography as a social activity. From the early 1890s the whole family, including parents Caroline and John, were involved, in some capacity, in the production of photographs. Family biographer, Nancy Buckland, described her relatives as an 'ingenious family'. She continued: 'When it comes to their interest in photography. I cannot imagine that any of them would not want to know the details of the whole process'. ${ }^{1}$ Sisters, Carrie, Susan and Jessie with their eldest brother Harold, were the family members who were most active in the actual picture making and picture taking during this period. Harold's influence was felt mainly in the early phases of their association with the photographic medium. Undoubtedly, it was his initial enthusiasm for photography and his experimentation with a 'pin-hole' camera which was responsible for his sisters also taking an interest in photography. ${ }^{2}$ The interaction between them at this time clearly 
demonstrates how siblings learnt their photographic skills primarily from one another within the family circle, an aspect of photographic production that I will discuss further. ${ }^{3}$

\section{The role of Aunt Bessie Hocken}

It was probably the active intervention of their paternal aunt, Elizabeth Hocken (18461933), who was instrumental in sustaining their initial expressions of interest in the photographic medium. As the wife of Dr Thomas Morland Hocken (1833-1910), a medical practitioner and collector of historical documents which he bequeathed to the University of Otago in Dunedin on his death in 1910, Bessie Hocken held a prominent position in the social and cultural life of colonial New Zealand. She was known as a resourceful woman and widely recognized for her many personal accomplishments, particularly within the field of the visual arts in which she was productively engaged throughout this period as a painter and photographer. ${ }^{4}$ She was therefore in a position to offer her nephew and nieces the timely advice and support which they required in order to advance their photographic practice into the serious pursuit that it became in future years. On a practical level, she would have been able to make some useful suggestions. For instance, she possibly had some input into the choice of camera most suitable to their needs. And what is more, as a woman of independent means, she may have assisted in procuring their first working camera. ${ }^{5}$ A description of the camera, which the family shared during these years, was written by Susan Buckland's son, Geoffrey Orbell. It was an incredibly basic half-plate camera, being manually operated by removing and replacing the lens cap to expose the glass plate negative to the light. ${ }^{6}$ At a time when photographic societies were being established in many centres in this country. Hocken probably also suggested they follow her lead and join the local photographic society which had opened in Dunedin in $1890 .{ }^{7}$ It should be pointed out that most other women photographers studied in this thesis, with the exception of Frances Stoddart, do not appear to have availed themselves of the opportunity to join a photographic society. I suggest this demonstrates the extent to which photography was understood by them as a family activity. ${ }^{8}$ Nevertheless, Harold and Carrie Buckland did act upon their aunt's advice, as both are listed as members of the society in the 1890s. ${ }^{9}$ However, they must have realized, given their relatively isolated situation on the family farm at Taieri Lake Station, near Middlemarch in Central Otago, that attending meetings was not really practicable. In both cases their individual memberships seemed to lapse after only one year. 
As the Bucklands became more competent operators, Bessie, recognizing their growing ability, was again able to use her influence to channel their potential. She encouraged them to submit their original contributions beyond the family circle to a wider audience. Her assistance in this matter was to be of significance to her nieces, who, after their brother Harold moved away from the family farm to make his own way in life and gain farming experience, continued to take photographs in close association. It was as a result of their aunt's active interventions that they began to receive recognition for their photographic work and have it critiqued by qualified judges.

\section{The Buckland family's early attempts}

The first successful images taken by the Buckland family and that have survived date from the early 1890s. Foremost among these images are a series of staged photographs in the form of tableaux vivants taken in the garden of their home showing members of the family, suitably attired, assembled before the camera. ${ }^{10}$ The most frequent themes represented in these early tableaux are of scenes of the kings and queens of England in which the boys dressed up in the costumes of chosen kings from history, with the girls as their female counterparts. This series of images include kings taken alone, queens taken alone, as well as images of kings and queens taken together in a combined staged photograph. A common feature of these costumed dramas is the rather loose arrangement of individual characters, apparently strung out along the picture plane of the photograph (fig. 16). ${ }^{11}$ Their immediate concern at this early stage was to obtain a good photographic impression, and less attention appears to have been given to directorial input with regard to the interaction between a cast of characters. Nonetheless, as both the operators and the performers became better acquainted with the camera's potential and how to handle it, in conjunction with more awareness of the requirements of picture making, the consideration of how to develop a clear storyline within their images becomes evident. One of the first narrative scenes which they produced as a group was their representation of the legendary tale of the future King Charles II hiding in the branches of a large oak tree, to save himself from being captured by the Roundheads at Boscobel Hall near Worcester. This was enacted by the Buckland boys (fig. 17). ${ }^{12}$ And although there is also an ungainliness in the composition of this image, the storyline of the historical event it narrates is clear. In this case, I think that it can be assumed that the scene, prior to being captured on camera, had been re-enacted by the family as part of an amateur theatrical performance. 
Certainly an enthusiasm for staging amateur dramatics was a useful background for the production of this genre of photography. From what we can gather from Gladys Hocken's first-hand accounts of her experiences while staying with her relatives on their sheep station during her school holidays, there was a lot of high spirits involved. ${ }^{13}$ For instance, in a letter to her parents dated 17 May 1897, Gladys described the camaraderie surrounding amateur dramatics staged within the domestic setting. One can only imagine how this crossed over into the production of staged photographs produced at the same time. This demonstrates how at this particular period colonial families like the Bucklands, who lived in rural parts of the country, were reliant on making their own entertainment.

\section{The staged photograph}

The staging of costumed tableaux from themes drawn from history, art and literature before the camera was not an uncommon photographic practice throughout the Victorian period. ${ }^{14}$ However, in much the same way as amateur photography associated with the representation of the family has been generally neglected, the genre of the staged photograph and its history, has also been largely ignored by photo-historians. This is all the more extraordinary considering the emergence of this genre of photography as a recognized photographic practice from the medium's beginnings, with William Fox Talbot, to take but one example, producing a number of such pictures in the $1840 \mathrm{~s} .{ }^{15}$ The fact that staged photography has since become so firmly associated in the minds of many commentators with expressions of artifice has led to a reluctance to acknowledge the popularity of this type of photographic genre during the nineteenth century. Consequently, if it is mentioned, staged photography is often regarded as an 'aberration' within photographic collections under examination. ${ }^{16}$

Marta Weiss is one of the first photo-historians to carry out extensive research relating to the development of the staged photograph. ${ }^{17}$ What comes through in her study are the close links between the pastimes of amateur dramatics and the staged photograph. With Judith Fetterley and Karin Hultunnen, Weiss has demonstrated how amateur theatricals were a popular form of entertainment within many Victorian households in Britain, but also in North America and the Continent. ${ }^{18}$ Amateur theatricals were an integral part of the wider repertoire of parlour games within the domestic sphere in the years prior to the advent of the photographic medium at the end of 1830s. As Douglas Nickel has noted, the 
Victorians had a penchant for recognizing allusions based on literary, visual and historical themes taken from a variety of different sources, and they became extremely adept at taking on the personae of characters other than their own within the setting of the drawing room or parlour. ${ }^{19}$ Thus amateur dramatics filled a void within Victorian society, by providing an outlet for high spirits countenanced even within the confines of more conservative households. Women in particular found amateur dramatics appealing, whether staged before an audience or for that matter before a camera, because the lighthearted antics associated with stage production afforded them the opportunity by posing in costumes of a different class, period or gender, to take on roles that would not normally have been seen as appropriate within their society. ${ }^{20}$

\section{The role of the manual}

As the popularity of staged performances grew within the domestic setting, manuals became available as a guide for amateur players on how to re-enact themes suitable for such performances. Some of these manuals comprised up to several hundred entries. Carol Armstrong cites the example of the extensive volume compiled by Emma and Elizabeth Rook, first published in 1869, which comprised more than 300 entries. ${ }^{21}$ An individual entry could include detailed descriptions of the story lines, as well as helpful suggestions for costuming, lighting and musical accompaniment for the would-be performer. Besides these explicit instructions, stage directions as to appropriate body language and the suitable emotions to be conveyed in order to provide authenticity to any performance were also outlined.

Haltunnen has suggested that, as a result of the publication of these manuals, many of the themes commonly re-enacted in domestic dramas relating to the performance of charades, and subsequently extended to tableaux vivants, became to a large degree prescriptive. ${ }^{22}$ The 'arrested drama' of the tableaux vivants, as a form of staged performance, required the assembled performers to assume a pose from a scene of a play or story. This in turn required some restraint on the behalf of the performers to hold the pose for several minutes. It soon became very much part of the contemporary scene as a favoured form of entertainment throughout the nineteenth century within the home environment. ${ }^{23}$ Furthermore, as a result of their apparent popularity within the home, tableaux vivants were also incorporated into professional theatrical performances of the period. Consequently, following the advent of photography, it was only a matter of time, before 
the obvious connections between the theatrical practices of tableaux vivants and photography were realized in the form of the staged photograph. ${ }^{24}$ In this case, the photograph was sometimes taken at the time of the actual staged performance, but more often than not, owing to the inherent problems of taking photographs in low light, it was taken subsequently.

\section{Staged photographs and family photographs}

Through the Buckland's collections it is possible to witness their growing understanding of the requirements for the production of their photographs and therefore also their development as photographers. As the Bucklands became more proficient with the camera, and as they come to understand what was actually involved in picture making, their images became increasingly sophisticated. Over time, after the initial reliance on the performative aspects of the staged-costumed characters of amateur dramatics, there was a recognizable move towards the construction of a more narrative focus in their imagery. The themes that they now chose to represent in their photographs were drawn from specific scenes from well-known historical, visual and literary sources. This particular emphasis is a distinguishing feature of the Buckland family's extensive photograph collections in comparison with the other collections examined here. To be sure, their personal collections display a full range of family activities. However, in contrast with other collections, the number of scenes in which family members actively role play a prescribed part in the form of a staged photograph or a representation of a well-known narrative theme is remarkable. Therefore, this aspect of their combined production must be recognized as a unique feature of their photograph collections.

Nevertheless, this does not imply that the subject of the family and the expression of unity and togetherness, already identified as a central theme of family photography, might be a lesser consideration for the Bucklands. In fact, this is far from being so. It is more a case of their photographs projecting a clear preference for portraying family togetherness by way of another means of seeing and telling. It illustrates the alternative ways in which people make visual statements about themselves within domestic photography. ${ }^{25}$ Furthermore, if staged photographs taken within the home setting are considered to be constructed by social and cultural factors, which of course they are, then they can be understood, like all family photographs, as visual statements about family. ${ }^{26}$ They also show how staged photographs fit comfortably into the criteria of representations of 
family. In other words, staged photographs taken within the context of domestic photography are also part of a wider category of family photography. Moreover, if comparisons are to be made between family photographs and staged photographs located materially and temporally within familiar surroundings, the apparent differences between them may be considerably less than is commonly imagined. Paradoxically, what is found is that there are striking correspondences between the production of staged photographs taken within the domestic setting and group family photographs, in that they are all representations of ways in which people define themselves in social terms. They are thus both symbolic of our need to demonstrate belonging as visualized through participation in social events. In this sense these photographs also become part of what Clark McPhail has classed as highly complex forms of collective action within a family, action which can only feasibly take place among members of close family groups. ${ }^{27}$

As already described in Chapter Two, Chalfen, among others, maintains that taking a family photograph is seldom random. ${ }^{28}$ Staged photographs are even less so. Rather, like family photographs they are reflective of a collective activity which is both patterned and constructed, and whose sub-text is the representation of family togetherness. In each instance, both photographic genres are carefully orchestrated towards a desired effect, in which everyone involved in the production of the image has a vested interest in the outcome.

The circumstances surrounding the taking of the family photograph and the staged photograph are similarly associated with high points in family life. Perhaps more significantly, these photographs also provide the visual evidence which reinforces the family's sense of itself, in the sense that the more it perceives itself as integrated, the more likely it is to mark these occasions when they are reunited. Bearing this in mind, we have a better understanding of the true import of Gladys Hocken's remark to her parents in her letter dated 18 December 1894, when she described how on Christmas day: 'We are going to take the camera out and we are all going out to take photographs'. ${ }^{29}$ However, as already pointed out in Chapter Two, families often establish their own ritualized photographic practices beyond designated high points in the calendar. One example, highly relevant to the Bucklands, relates to the considerable amount of time they spent in the company of their close friends the Orbells at their home at Raukapuka, near Geraldine in South Canterbury, in the 1890s. These sojourns, which they undertook 
at regular intervals, could be defined as periods of concentrated photographic activity for the Buckland girls, since the number of images they produced while staying with the Orbell family is noteworthy. For example, Carrie produced her well-known series of images entitled 'Baking Day' (but also known as 'Stirring the Christmas Pudding') in 1896 (fig. 18), while Jessie produced her award-winning photograph of 'The Jackeroo' in 1898 (fig. 19), and in the same year Susan took the tranquil scene of 'After the Toil of the Day' (fig. 20). ${ }^{30}$ While it is not possible to ascertain the extent of the Orbell's involvement in photography, there are several photographs included in the albums compiled by Susan and Jessie Buckland of this family. Some are inscribed with the initials of the sisters, Jessie and Eveline Orbell. This suggests that the daughters of the house shared similar interests to those of the Buckland girls, and that photographs were passed between them as objects of social exchange. ${ }^{31}$ One thing is certain: the environment at Raukapuka was one that was conducive to photographic activity.

\section{Working together}

The activity of picture making as opposed to picture taking was certainly an integral part of the whole process of photography for the Buckland sisters. Although we have only limited first-hand accounts concerning this aspect of their photographic production, we can safely assume from our knowledge of contemporary sources, particularly the observations of Gladys Hocken in her letters, that a considerable amount of time was spent in the planning stages for each photograph. An idea had to be thought up, then suitable costumes selected and poses rehearsed, all with the same camaraderie and conviction that rehearsals for an amateur theatrical performance entailed. Everyone involved was well aware that for the successful outcome of the photo-shoot itself, it was paramount that everyone involved co-operated. Here again, the repeated references to photography in Gladys' letters to her mother, so significant in ascertaining the circumstances in which photography was practiced at this time by her cousins, provide some idea of this process. For example, Gladys described how Susan had discussed with her some future plans for subjects for her photographs. In one instance Susan proposed photographing a particular stretch of water. She writes: 'Susan thinks that it would make a very good photo. I think she is going to bring the camera up one day to photograph it'. 32 
What comes through in the brief comments made by Gladys is that working towards taking an actual photograph involved a number of different forms of collective action, and in many respects her description coincides with those outlined by Welsh photographer Thereza Dillwyn Llewellyn in her diary many years earlier once again, ideas for photographs were conceived and thought through over a period of time before they were actually acted upon and photographed. ${ }^{33}$ One of the differences of the point-and-shoot culture that emerged after the invention of the hand-held camera in the late 1880s was that taking photographs became a more spontaneous activity. Yet, as already stated, all practitioners in this study used plate cameras and continued to do so. However after Kodak had opened a wholesale outlet for film cameras in Wellington in mid-1909, film began to dominate the practices associated with amateur photography in New Zealand. ${ }^{34}$

Naomi Rosenblum has discussed how having some knowledge of the visual arts definitely gave women an advantage when they took up photography. ${ }^{35}$ Certainly most of the women in this study are known to have received some art training. What is more, by the 1890s there was a range of choices of such training in New Zealand, from casual classes to advanced courses in the fine arts. These were offered by institutions that had been established by this date in the four main centres of the country, and which women could attend. ${ }^{36}$ The four Stoddart sisters, for instance, were foundation students at the Canterbury College School of Art in Christchurch when it opened in $1882 .{ }^{37}$ Frances and Margaret Stoddart went on to successfully complete their teacher training qualifications from the Department of Science and Art at South Kensington in London, through the School of Art, under the guidance of David Blair and George Herbert Elliot. Margaret Stoddart's beautifully-crafted photograph album, which will be discussed in Chapter Five, provides visible testimony to her prodigious talent as a flower painter and anticipates her later recognition as a leader in this field. However most of the women selected for this study did not necessarily choose to undertake such an intensive course of study and they pursued their art training on a much more informal level. For instance, in the case of the Acland and Buckland girls, they would have received their introduction to art while still quite young at home, either with their mother or under the supervision of their governess. Certainly, all six Acland girls followed the artistic inclinations of their mother Emily. As a recorded artist she would have provided a role model for her daughters. ${ }^{38}$ Furthermore, from the folio of works on paper within the Acland papers, they appear to have acquired a certain proficiency in the handling of water colour. Rosenblum has pointed out that, for 
some women taking up photography could be seen as a natural progression following some previous training in the visual arts. ${ }^{39}$ For them it was a viable alternative pursuit and a more fulfilling and less expensive form of visual expression. For instance, Harriet, Lucy and Rosa Acland took up photography, while their sisters Agnes, Mary and Bessie continued to draw and paint at least until film cameras became more widely available in this country from the 1910s.

The Buckland girls also received an artistic training. Susan Buckland is known to have studied art while attending a private school in Dunedin during the $1880 \mathrm{~s} .{ }^{40}$ She studied under Fanny Wimperis (1840-1925), who had trained at the Slade School in London. It stands to reason that her sisters Carrie and Jessie had similar opportunities. They may have even taken lessons with Wimperis or another member of this artistic family, since Wimperis was well acquainted with their aunt, Bessie Hocken. ${ }^{41}$ Moreover Hocken, as already mentioned, was herself a competent artist. Significantly, she is known to have gone out sketching while staying with her relatives in Central Otago during the early 1890s. ${ }^{42}$ Collected examples of their work in the Hocken Library in Dunedin also demonstrate that all the Buckland girls were artistically able, particularly Susan. ${ }^{43}$ As well as working from direct observation from nature, they copied casts from the antique and reproduced works by well-known artists, which was very much representative of the art curriculum at this period. Importantly, these studies raise the issue of how an interest in the fine arts may have guided their photographic practice and enriched it. It was not just a matter of competency, but more a question of how they used this knowledge in relation to their engagement with photography.

Of course, it is not usually obvious how this art training might manifest itself. However, the insertion in the albums of the Buckland girls' drawings and other reproductions provide a clear indication of how, in a number cases their drawings reflect the close correspondence between the subjects that they selected and those that they subsequently staged before the camera. This suggests that probably the reason these particular drawings were chosen to be included in the albums was for future reference. In this way we are able to trace the sources for some of their photographs, which otherwise may not have been possible. This demonstrates how the subsequent production of photographic images was influenced by a prior interest in images drawn from the fine arts. For example, Carrie Buckland included in her photograph album several sketches that she had carried out in 
black and white or pencil of popular narrative themes of the period. One of these illustrations depicts a woman holding a pitcher, which was probably copied from a picture of some unidentified motif of a classical female figure derived from a pastoral scene (fig. 21). ${ }^{44}$ Subsequently her sister Jessie, dressed in a costume of a peasant girl and carrying a pitcher by her side, re-enacted the scene of a woman with a pitcher in her hand on at least three different occasions for the camera (fig. 22). ${ }^{45}$ Likewise, the rather sentimental subject entitled 'A Sweet Burden', copied by Carrie in pencil and black ink, was also inserted in her album (fig. 23). ${ }^{46}$ This scene is usually represented in narrative form as a young man carrying a young woman over a stretch of water, as described by Carrie in her drawing. Later, this theme was taken up by Susan as a subject for a photograph, in which her future husband Lionel Orbell and Gladys Hocken feature as the actors, and assume similar poses to those of Carrie's drawing (fig. 24). ${ }^{47}$ This clearly demonstrates how material selected by one sister was then taken up by another, and suggests that they were conversant with the contents of each other's albums, and that ideas circulated freely within the family. It is only speculation but surely there was a certain amount of communication between Carrie and Susan prior to the photo shoot. Gladys, commenting to her mother Bessie Hocken in a letter at the time, confirms as much when she described how 'Sue is going to take a photo of Lionel pig-a-backing me across the stream' ${ }^{48}$ From this it may be possible to get some idea of the close correspondence between the themes for the preliminary sketches and those of subsequent photographs, and once again highlights the ways in which ideas for photographs were often thought through over a considerable period of time.

\section{Joint production}

What cannot be underestimated are the benefits for the amateur photographer of working on pursuits within a family unit, as discussed in conjunction with John and Harriet Acland. Collaborations such as these demonstrate how, as a result of working cooperatively on a task, members of the group had the opportunity to pool their resources. For instance, they could learn about processes that they may be unacquainted with by working alongside someone who had more knowledge, or else by actually being mentored by them on a one-on-one basis, as Gladys Hocken was by her cousin, Susan Buckland. Gladys informed her parents, in one of her letters, how Susan was showing her how to use the camera. ${ }^{49}$ She wrote: 'Susan is teaching me how to take photos'. She continued: 'and I am getting to know all about them'. 
As psychologist, L.S. Vygotsky points out, mentoring appears to work particularly well when the individual competency of the group is varied, a situation which is likely to arise within an extended familial unit. ${ }^{50}$ In his article, Vygotsky outlined how junior members of the group gain competence by picking up knowledge while working in association with more experienced members and which they could not necessarily acquire if working alone. As with the Acland family, the more experienced members of the group were frequently responsible for introducing the less experienced members to the various processes. Conversely, in the process of passing on skills, in this type of learning environment, the more competent members of the group also benefit from this close association of working with others. In this way, they develop a better understanding of the processes. Working collaboratively provides the opportunity to combine the collective knowledge of the members and an opportunity for members to spark ideas off onto one another and thus build on them. Added to this, working cooperatively often affects the quantity and the quality of output in a favourable way by honing interpersonal skills, for not only the group as a whole but also for the individual. In this way, the group extends their collective knowledge, which benefits their overall competence, and this input may also foster a higher standard of skills. As is known, this was the outcome for both the Acland and Buckland families.

The mere fact of being a member of a peer-directed activity can also reinforce the overall commitment of the individual to the group. As already mentioned in Chapter Two, when it comes to social interactions, individuals feel more comfortable collaborating in situations where shared cultural values are the norm, as for example, would be the case within a family group. ${ }^{51}$ But equally important is a willingness of the groups' members to combine their skills to maintain a sense of collective purpose within the specific social environment in which they operate. This in turn produces a relatively stable pattern of close socially interactive processes and an underlying sense of cohesiveness. This becomes an important aspect of the group dynamic, as it can create within the membership a sense of fulfillment, or indeed 'rewardedness', which goes a long way to distinguish small family groups from other social units. ${ }^{52}$

One example of how a photograph was produced by the three girls as a joint production is provided by Jessie Buckland's photographic image entitled 'Coming Thro' the Rye' 
taken in late January of 1897 (fig. 25). ${ }^{53}$ The idea for the photograph was based on the traditional Scottish rhyme popularized after its inclusion in the landmark publication of The Scots Musical Museum, to which Scottish poet, Robert Burns (1759-96) was a major contributor. $^{54}$

From the 1780s, Robert Burns worked with Stephen Clarke on compiling a compendium of traditional Scottish airs for Edinburgh music engraver and seller James Johnson. Johnson, like Burns, was concerned at the continuing erosion of aspects of their Scottish heritage since the acts of union between England and Scotland in 1707. In particular, they lamented the loss of the oral traditions of Gaelic-speaking Scots, mainly from the rural areas of the country, realizing how pressing it was that they be fully documented. This enormous task involved collecting and transcribing the original words of 600 traditional songs. It also encompassed indications for the preferred musical arrangements for each song and included notes on the guidance for their performance.

These collections, which were issued by Johnson in six volumes between the years 1787 and 1803, finally gave Scots at home and abroad a better comprehension of the extent of their oral traditions. Their release was all the more poignant, since it coincided with the premature death of Burns in 1796, and the upwelling of nostalgia that followed for the poet in the aftermath. ${ }^{55}$ Although the Bucklands were of English origin, during this period they were residing within a region of this country which had been founded as a Scottish settlement in $1848 .^{56}$ Since that date many Scots had come to settle in Otago, and of course they continued to observe many of their Scottish traditions including those associated with the 'Bard'. This may explain Jessie Buckland's familiarity with Burns' works. It may provide the reason why Buckland's thoughts might have turned to Burns, when many in the local community would have been commemorating the anniversary of the poet's birth on 25 January for a suitable subject for the theme to her forthcoming submission to the photographic competition in the Australasian.

At the same time as the publication of The Scots Musical Museum, individual songs with wide popular appeal, such as 'Coming Thro' the Rye', also began to appear in a variety of widely available pictorial forms within contemporary popular culture. The illustrated covers designed for this sheet music became a formative source for the large repertoire of images that developed in association with the printed versions of this song; also the 
'staged' photographic images produced for the stereograph, to name but two. ${ }^{57}$ The triptych of images reproduced by commercial photographer John R. Hanna in the Auckland edition of Cyclopedia of New Zealand, in 1902, under the headings of 'The Meeting', 'The Proposal', and 'Waiting for the Answer', provides some idea of imagery that had already developed in association with this song (fig. 26). ${ }^{58}$ However, when we review the representations of 'Coming Thro' the Rye' from the numerous examples represented in the library of online images, the most frequent pictorial depiction for this rhyme, whatever interpretation may be given to the storyline, it is usually represented as a the bucolic scene of a young man walking arm in arm with a young woman, through a field at harvest time, positioned close to the picture frame and about to plant a kiss on her cheek. $^{59}$

Jessie Buckland, in her photographic version of the poem, conformed to the established representation of this rhyme. In addition, we also know that Jessie's rendition draws specifically on the lines in the poem: 'Gin a body kiss a body, coming through the Rye' since these lines have been inserted by Susan Buckland under the copy of the photograph in her photograph album (fig. 27). ${ }^{60}$ In choosing to follow the prescribed course for illustrating the verses of this song, Jessie has made no allowances. She obviously understands the requirements in depicting an image and becomes aware of the significance of the verbal text in generating the framework for the production of visual images. Nevertheless, she does make one obvious concession in her pictorial representation, by depicting her figures in the local landscape against the backdrop of the Rock and Pillar Range.

As well as being the originator of the photograph, Jessie was also one of the two principal protagonists, along with her friend, Ini Burnett from a neighbouring farm. ${ }^{61}$ This very fact rather begs the question of who was the person responsible for taking the actual photograph. One can consider how people within a small group share roles in the production. Further, the benefits to the group of individuals combining their skills while working on a common endeavour have already emphasized. ${ }^{62}$ Nevertheless, what is not always taken into account in studies of interactions among peer-groups is the possibility that the individual players will also possess their own natural strengths and weaknesses. For this reason alone, it may be that within the group situation certain individuals become more closely involved in certain aspects of production than others. For example, they may 
have their own special talents which are recognized within the group. Jessie Buckland clearly had a real sensitivity for the portrayal of a variety of character types. For instance, she was prominent within amateur dramatics, both staged and caught on camera. A selection of specifically chosen illustrations inserted into her photograph album demonstrates her interest in understanding how appropriate gestural imagery assists in the realization of the portrayal of character, particularly when it comes to the visualization of the narrative whose meaning has to be clearly understood. Therefore, it is appropriate here to consider how an understanding of illustration may come as one of the benefits of an art training when taking up photography. ${ }^{63}$

The Buckland family decided on how to mete out which family member was best suited to take on a particular role in their collaborative productions. From a survey of the photographs that the sisters are known to have worked on together, it is found that there is a clear division of labour. For example, Jessie is usually the lead actor. Susan, on the other hand, appears to have been rather camera 'shy' in comparison, and for this reason we find very few images of her in any of the girls' photograph albums. The study of her dressed as a gypsy fortune teller is one exception. ${ }^{64}$ However, where Susan appears to have taken personal responsibility within the group situation was in the actual taking of photographs. If the remarks of her son Geoffrey Orbell are anything to go by, right from her first involvement with photography she demonstrated a particular interest in understanding the mechanics of how a camera works. ${ }^{65}$ The subsequent comments of her niece Nancy Buckland also may lead us to the conclusion that Susan is the one who took control of the production of the photograph, from the point of shooting to the processing of the prints. ${ }^{66}$ In the case of 'Coming Thro' the Rye', after preliminary discussions were over and actors were assembled into their designated positions, it was probably she who removed and replaced the lens cap on the camera for this particular photograph. Furthermore, time spent peering through the lens may have given her a particularly accurate view of the setup of the actual photograph, for she is the one sister of the three who provides the most detailed information in her album concerning an individual photograph, including dates, titles and the names of the actors. ${ }^{67}$

What is also known is that Susan was actively involved in the printing out of the plates. Here, the comments from Gladys Hocken again prove useful. Gladys informed her mother on at least two occasions in her letters of May1897, how Susan is working on a 
print of 'Coming Thro' the Rye' to send to her. ${ }^{68}$ Of course 'printing out' is an activity that does not have the same profile as that of the originator of an image, nor, for that matter, as an actor within a photograph - roles in which her sister Jessie took equal prominence.

The photograph of sisters Harriet (left) and Rosa Acland (right) working on photographic prints in the conservatory of their family home in South Canterbury, provides ample evidence of how the printing out was carried out within the domestic sphere (fig. 1). In this photograph Rosa, who is holding a printing-out frame in her hands, is shown opening the frame a fraction, to ascertain how the print she is developing is progressing and to demonstrate the process. What is less apparent from the image and frequently overlooked in commentaries on photographic procedures, in part, due to the work process. This entailed placing the exposed glass-plate into the frame in direct contact with a prepared light-sensitive photographic paper. Although this method of printing was relatively uncomplicated, producing photographic images using this process was essentially reliant on sunlight. It was, therefore, by its very nature, also quite an imprecise business. Even when the prevailing weather conditions were optimal, the time required for the actual printing out of an image employing a printing frame was likely to take approximately five to ten minutes per print. However sometimes, depending on the weather and the time of year, this process could extend from anywhere between thirty minutes to several days. ${ }^{69}$ Therefore this method of printing represents a considerable personal commitment of time and effort by those who engaged in this activity.

\section{Sharing within the extended family}

Given the close relationship between the Buckland and Hocken families throughout the 1890s and early 1900s, it is unsurprising to learn that Bessie Hocken and her nieces exchanged images that they produced. Unfortunately, Hocken's personal albums cannot be located. However, a survey of the Buckland girls' photograph albums does reveal that the sharing of photographic images took place during this period and that all three received photographs from their aunt.

That said, the total number of photographs that actually found their way into the photograph albums appears to be not large. ${ }^{70}$ As might be expected, the images do include portrait studies which celebrate their close family ties. But other images also reveal an 
exchange of a wider range of photographic subjects. Noteworthy among these are copies of the photographs that Hocken was currently working on for submission to the photographic competitions for the Australasian during the second half of the 1890s and early 1900s. For instance, in Susan Buckland's album there is a copy of the first photograph that Bessie Hocken found success with in these competitions, 'Mother's Treasure Box'. In this photograph taken by Hocken, her daughter Gladys, then aged ten years, contemplates her image reflected in the mirror she holds in her hands, draped in jewels drawn from her mother's jewel box open on the dressing table before her (fig. 28). ${ }^{71}$

In October 1894, the Australasian, a weekly paper which was published in Melbourne and had a wide circulation within Australia and New Zealand at this period, announced its intention of running a competition for amateur photographers. ${ }^{72}$ In its announcement the paper noted that in recent years such competitions had been very popular in England. It was stipulated that for the first competition any Australasian scene would be acceptable. However, the paper advised that simple landscape scenes can become somewhat monotonous. Therefore, preference would be given to pictures which depicted an incident rather than simply a scenic view. The paper asked that any photographic print submitted for the competition must not have been published before. All entries were to be sent to the main office in Melbourne in duplicate. The selected winning photographs would be published in the paper and monetary prizes would be awarded to the three photographs judged to be the best. At the time of the closing date for the first competition, the paper announced that it had received over 2000 entries. Carrie Buckland was listed among the entrants from New Zealand, but we have no idea what image she sent to the competition and therefore it is probable that she was not one of the photographers who received commendation. The seventeen-year old Jessie Buckland and her aunt Bessie Hocken successfully contributed to the second competition that was held in the second half of 1895. By this date the Australasian must have decided, as a result of the popularity of the competition, that, rather than having only one open section, it would supply a short list of subject categories for subsequent competitions. Prizes would be awarded for each individual category. Bessie Hocken was the winner of The Human Figure section of the second photographic competition with her photograph entitled 'Mother's Treasure Box'. Jessie received the prize for the runner-up in the same section with her representation of 
'Such a Big Basket and we have caught Nothing'. Reproductions of the photographs they had entered were published on the same page of the Australasian. ${ }^{73}$

For the Buckland sisters these photographic competitions, which were run by the Australasian from early 1895 into the early 1900s, provided them with a welcome outlet in which to circulate their images and to have them critiqued. Furthermore, the competitions also stimulated their creative resources and became a significant catalyst for directing future picture making for the Buckland girls. For instance, Jessie Buckland's 'Coming Thro' the Rye', taken at the beginning of 1897, was more than likely specifically developed with the forthcoming fourth photographic competition organized by the Australasian in mind. The subject for one section of the competition was a photograph on the theme of summer, and Jessie was voted the winner of the section with this entry. ${ }^{74}$ But more than this, as successful participants in these photographic competitions, the Buckland girls would have received a sense of achievement at having received recognition beyond their immediate family circle. It is easy to gloss over the significance this type of recognition might have had on the girls. But the positive feedback they received helped to promote the production of further photographs, which they continued to submit to subsequent competitions.

In conjunction with the discussion above, it is also necessary to take into consideration how history has treated the three sisters. Jessie is the sister who eventually made her living from photography, following the family's move to live in Akaroa on Banks Peninsula in 1902. Here she opened her own photographic studio, which she ran for over twenty years. She is the one whose name is best remembered as a photographer, within the family as well as to a wider audience. In contrast, her older sisters Carrie and Susan, and their early association with photography, have been almost forgotten. Certainly photography is not an activity which is immediately associated with them. However, a close examination of individual photographs in the albums compiled by the three sisters during the 1890s reveals a rather different story. Even from a cursory glance through their individual albums, it becomes evident that all three sisters were active producers of photographs at this date. One photograph that was clearly identified within their albums and again at the time of its publication in the Australasian as taken by Carrie is the photograph under the title 'Baking Day' (fig. 18). ${ }^{75}$ In this photograph, her sister Jessie is shown standing at the kitchen bench, surrounded by fresh baking, adding a few drops of 
vanilla essence to the Christmas pudding, which she is in the process of mixing. As I mentioned, it was taken in the days prior to Christmas of 1896, on one of the Buckland family's visits to the home of the Orbell family at Raukapuka, near Geraldine in South Canterbury. As far as can be ascertained, it was also one of the first successful experiments that the girls undertook employing flash. And as I pointed out in Chapter Three when discussing the photo-sessions involving John and Harriet Acland, their experiments with flash light, are reflective of their serious attitude towards their work and the desire to extend themselves as practitioners. A second photograph of this scene, this time in a portrait rather than landscape format, appears in Jessie's album. This time Jessie is shown in profile, a recipe book open in one hand, as she stirs the mixture in the bowl with the other (fig. 29). ${ }^{76}$ This also suggests that photo-sessions such as this one sometimes resulted in a number of images being undertaken. It is also a reminder of how important the collections of photographs in another sister's album were in assessing the full extent of the photographic images that each sister was responsible for producing.

Although the caption for this photograph in Susan's album clearly states that this photograph was taken by Carrie, in more recent times the photograph has been assigned to her better-known sister Jessie by commentators. ${ }^{77}$ The acknowledgement of Carrie as the true author has been effectively passed over. This is a good example of how the ownership of a particular image, although known at the time of its production and even labelled as such in the captions within their albums, subsequently, often through ignorance can be denied. According to Rosenblum, lack of care with the attributions of photographic images is one of the prime reasons why a woman's contribution to photography might be overlooked or lost. ${ }^{78}$ This situation is all the more bizarre in the case of the Buckland sisters, since during the 1890s, when all three girls were active as photographers, Jessie was all too aware of how images could be easily misappropriated. As a result, Jessie often chose to use a nom-de-plume when her photographs were published, in order to prevent her photographs being confused, in the minds of her prospective audience, with those of her elder sisters, Carrie and Susan. Or perhaps another reason comes to mind, as I have mentioned, she was still a teenager at this time. She may have thought that, if this became known, her work may not be taken seriously. For example, in the caption for her entry entitled, 'Coming Thro' the Rye', which Jessie submitted to the fourth photographic competition run by the Australasian, she went by the name of 'P. Gay' (fig. 30). ${ }^{79}$ 


\section{Summary}

Chapter Four examines the photographic practices of sisters Carrie, Susan and Jessie Buckland. A major concern of this chapter has been to piece together aspects of their close working relationship. Of utmost importance has been developing a comprehensive understanding of their family background. Here, evidence for their photographic practices gathered from contemporary accounts from family members, particularly the observations of their cousin Gladys Hocken, were highly relevant. This chapter also gives a close account of the relationship between the Buckland girls and their aunt, Bessie Hocken. After all, it was Hocken who made it possible for her young relatives to take up photography seriously by furnishing them with their first working camera. In the following years she continued to be a positive influence in their lives, by actively supporting her nieces' aspirations and their developing talent. Then, when the opportunity arose, she also encouraged them to profile their photographic work beyond the family circle and participate in contemporary photographic competitions, where they all received recognition. She also recognized the girls' other cultural interests, in particular their participation in amateur dramatics and the fine arts which, as I have demonstrated, they drew on in the production of their photographs. This brings to this study a more informed understanding of the interactions between these sisters with regard to the production of their photographs and highlights the complexities of these forms of collective action as a social practice. 


\section{Chapter Five}

\section{Seeking out the narrative structures in the photograph album}

\section{Introduction}

In his survey of the photograph collections of Japanese-American immigrant families, Richard Chalfen places considerable emphasis on the photograph album. ${ }^{1}$ In his opinion, the album should be considered a central focus in any study of family photography. After all, he explains, even after the photograph has been taken and printed, further significant decisions concerning the image still remain. ${ }^{2}$ It is in the process of choosing one photograph while rejecting another that the album maker imposes their authority over the images to be included, along with the way those images are presented, and thereby are rendered meaningful.

Studies of photograph albums, such those undertaken by Chalfen, have been responsible for raising the general awareness of their value as a significant material resource within photographic discourse. ${ }^{3}$ What becomes clear on reviewing his contribution, however, is Chalfen's apparent unwillingness to engage in a close analysis of the narrative structures employed within these albums. If he refers to narrative structures at all, it is only in a perfunctory and summary manner; beyond noting sequencing or captioning, he makes little attempt to elaborate further on this aspect of album making. ${ }^{4}$

In contrast, Catherine Kohler Riessman reminds us that an important component of any comprehensive study of textual material should be its narrative structures. ${ }^{5}$ Without an adequate understanding of how these modes of narrative expression function, she argues, there will continue to be fundamental gaps in our knowledge concerning the processes and procedures associated with how information is relayed.

\section{The formative work of Martha Langford}

Martha Langford provides a notable contribution to this area of research. In Suspended Conversations, she tells of examining photograph albums in the Notman photographic archives in the late 1990s, becoming aware for the first time of the correspondence between the structural patterning within photograph albums and those found in other 
forms of textual material. ${ }^{6}$ She describes how confirmation of these observations came after consulting Walter J. Ong and his research on sixteenth-century French philosopher Peter Ramus (1515-1572). ${ }^{7}$ In this research, Ong investigates the impact of the printing press on written texts and considers how texts were subsequently delivered and received within Western society. Ong argues that it was largely as a result of this development that language was transformed from a sound world to a visual world; in other words, from a method of thought to a 'system' of ordering'. ${ }^{8}$ This shift would increasingly become associated with the organization of information on the page.

Martha Langford describes how she incorporated aspects of Ong's findings into her own analysis of narrative structure organization within photograph albums. ${ }^{9}$ In her account of this undertaking, Langford makes a convincing case for the efficacy of introducing an oral-photographic framework. ${ }^{10}$ As she points out, knowledge of oral tradition can assist in restoring albums to their original performative social functions, and thereby transform them, once again, into a meaningful textual experience. ${ }^{11}$ Langford gives considerable attention to the correspondences between the sequencing, repetition and clustering of the structural devices which Ong had shown to be consistent with the oral tradition, demonstrating how similar structural devices are also latent within the organization of visual material in the photograph album. Her study of anonymous photograph albums from the Notman photographic archives reveals patterns of inclusion, organization and presentation. $^{12}$

Although Langford does not deny the oral/literary divide in her analysis of photograph albums, she privileges oral traditions over literary ones. ${ }^{13}$ In taking this position, however, Langford overlooks the fact that both these modes of expression might be present within the structures of the photograph album, and may function in similar ways. However, what cannot be denied, however, is that her method of approach has contributed to a better understanding of the modes of expression used by album makers in the organization of their pictorial material. By identifying the correspondences between oral and visual texts, Langford also draws attention to the commonality of these structural procedures and those in other genres. Thus, through this work, Langford provides a significant precedent, and a point of departure, for future investigations into visual texts. ${ }^{14}$ 
In Chapter Five, I will demonstrate how elements of both oral and literary traditions are present within the narratives in photograph albums. In addition, I will explain how these complementary systems work in concert as a set of interpretative procedures within the structural frameworks of pictorial narratives. To further substantiate these claims, I shall seek support from empirical evidence garnered from recent studies undertaken on both spoken and written narrative discourse. I shall therefore be developing an interdisciplinary methodology for this analysis which has the potential to broaden the scope of our knowledge of album making within the domestic sphere, and, more specifically, to enhance our understanding of the album-making practices of the women in this study.

\section{Precedents from within literary discourse}

In order to acquire a more comprehensive understanding of these narrative structures, I shall review recent studies of literary texts. Of particular significance will be those studies which investigate oral and literary traditions as complementary processes, notably the contributions of linguist Deborah Tannen, in association with William Chafe. ${ }^{15}$ Prior to their studies, it had been generally agreed that literary and oral traditions operated separately. However, Tannen and Chafe have produced conclusive evidence that within social discourse the oral and literate traditions function as integrated processes. ${ }^{16}$ More importantly, they found that features previously associated with one mode or the other were present in both.

Deborah Tannen admits that she was sceptical of their findings, and reluctant initially to accept them. ${ }^{17}$ Only after careful re-consideration did she come to acknowledge that the features associated with both spoken and written texts were freely interchangeable within interpersonal communication and that these features were readily accessible to anyone from within the same cultural background. She concluded that deciding which strategy to use was largely determined by the type of message to be communicated. In support of her argument, Tannen cites this example: writing is time consuming. ${ }^{18}$ There will be times when it is not the most effective mode of communication to employ. Speech is more efficient, and often a more convenient mode through which to convey certain messages.

What Tannen appears to be saying is that both systems are workable and that one form of expression does not necessarily take precedence over the over one. Depending on what 
we wish to communicate, we are able to employ either mode. ${ }^{19}$ In essence, we are free to choose how we communicate, and therefore, how we frame what we wish to communicate. It all comes down to deciding on the most efficacious means to do so.

In relation to album making, the means by which compilers write their captions within the photograph album amply illustrate this point. If the compiler considers it unnecessary to provide all the contextual information, it need not be reiterated in caption form. If provided at all, it is likely to be brief. Alternatively, the compiler may decide on a message-focused caption. In this case, the caption will demand less input from the viewer in terms of filling in the relevant details from the_stock of knowledge at their disposal. And, hence, a detailed caption is more likely to be supplied by the compiler.

The analysis of literary texts has also been a major focus of folklorist Susan Stewart. Over many years she has directed her attention towards documenting the range of interpretative procedures available to the organizers of literary texts in the formation of their narratives. ${ }^{20}$ Tannen and Stewart work within common areas of interest, particularly in relation to the application of textual devices and how they can be deployed, either singly or in combination; however Stewart has specialized in investigating how they function in different genres. ${ }^{21}$ In her survey of narrative structures employed in folkloric and literary texts, Stewart suggests these textural procedures should not be regarded as unique to one particular genre and that each should be recognized as part of a set of equally viable interpretative procedures in the organization of human experience and the generation of meaning. ${ }^{22}$ Stewart goes to considerable lengths to describe each procedure, providing specific examples and describing how they perform within the context of each genre she studies.

Susan Stewart's work on narrative structures and her descriptions of the individual functions of these textual procedures will act as contextual markers for this study. In the discussion that follows, I shall provide a comprehensive overview of how the structural devices identified by Stewart can be applied in the organization of photograph albums. This will include descriptions of the specific structural devices available to album makers and will also outline the characteristics of the narrative devices most frequently used. ${ }^{23}$ 
In order to reach a better understanding of their usage in photograph albums as a whole, this discussion will also cover some so-called idiosyncrasies, which Stewart labelled 'aberrant' devices. ${ }^{24}$ Although less often applied, it is clear that the women in this study employed them, knowingly or otherwise, in arranging their photograph collections. In addition, when deemed necessary, I shall refer to Stewart's inventory of terms for further clarification of the way in which compilers developed these procedures to make information more meaningful to themselves and to others.

The discussion will begin by considering one of the most widely-recognized devices for the organization of textual material - arranging information in chronological order.

\section{Identifying the narrative structures within photograph albums}

\section{Telling in time...}

Telling in time is a favoured method of storytelling which people everywhere naturally turn to, when conveying information. ${ }^{25}$ Its great advantage over other forms of communication is that the temporal nature of the arrangement of its narrative elements makes it possible for the events being described to be followed as they unfold.

Telling in time is a common strategy employed by album makers in the organization of photographs in their albums. In reviewing the albums compiled by the women in this study, we find that several maintain a chronological order. And, as we shall see, it is a style of compilation they often used to recount stories relating to significant life events. Lucy Acland, for instance, who began compiling her photograph album on her return to New Zealand in 1892, devotes the first half of her album to photographs she had collected while travelling overseas. ${ }^{26}$ Significantly, she chooses to introduce the account of her voyage by sea and her stay in England on the first page of her album with a full-plate photograph of an ocean-going steamer (fig. 31). ${ }^{27}$ This image is followed by photographs of Hobart, Colombo and Brindisi, presumably the ports of call on her passage to England..$^{28}$ Lucy also annotates each of these images with a hand-written inscription of the name of the place, and the date of her visit, including details of any return visits. This means it is possible to retrace Lucy's movements throughout that period. In fact, the way in which Lucy organizes her photographic material in her album is comparable to excerpts from personal letters or diaries. It is likely that either Lucy, or her sister Bessie, who accompanied her on this voyage, could have compiled a written account of their 
travels to which Lucy is referring when she began to arrange these photographs into her album on her return to New Zealand.

Sisters Margaret and Laura Bowen apply a similar approach to organizing the photographs in the album they worked on together from the early 1900s (fig. 32). ${ }^{29}$ Margaret and Laura began taking photographs in their mid-teens under the guidance of their older brother, Henry. As with their female counterparts from the Acland and Buckland families, the Bowen sisters soon began practicing photography independently of their male sibling. Over the following decade, using their quarter-plate camera, Margaret and Laura became responsible for documenting their immediate family, as well as those members of their extended family also living in Christchurch.

A characteristic feature of the Bowen sisters' album is their well-developed awareness of how a visual narrative should be constructed in terms of its textual clarity. The full-page spread of photographs taken by the girls of members of their extended family gathered within the grounds of the home of their uncle C.C. Bowen (1830-1917) at Middleton in Upper Riccarton on Christmas day 1901, provides one example (fig. 33). ${ }^{30}$ Under the heading, 'S.S. Discovery', inscribed in ink in large block letters at the top of this page, they announce the presence within the family's midst of the Antarctic hero, Captain Robert Falcon Scott, (figs 34 \& 35). ${ }^{31}$ Both Scott, who was in command of a British National Antarctic expedition, and his English sponsor, Sir Clements Markham, had close family connections with members of the Bowen family. The family acted as congenial hosts to Scott and members of his expedition while they were stationed at the port of Lyttelton from 1901-4 and again from 1910-1913. ${ }^{32}$

Like Lucy Acland and the Bowen sisters, Margaret Stoddart also arranges the images in her album in chronological order (graphs I \& III). ${ }^{33}$ Stoddart, who began compiling her photograph album sometime in the late 1880 s, was therefore a keen collector well before she and her sisters Frances, Mary and Agnes, took up the practice of photography as a serious recreational pastime in the mid-1890s. ${ }^{34}$ At the same time, a considerable number of the photographs in her album were obtained on her travels. For instance, following two extended visits to stay with her childhood friend, Mabel Chudleigh (née Potts) on the Chatham Islands in 1886-87 and again in 1891, she sourced a series of scenic views of the islands by the commercial photographer Alfred Martin (fl.1866-1899). ${ }^{35}$ Similarly, while 
on a trip to Melbourne in the second half of 1894, at the invitation of the Australian flower painter Ellis Rowan (1848-1922), whom she had met earlier that year when Rowan was touring New Zealand, Stoddart purchased photographs of places she had visited in Australia (fig. 36). ${ }^{36}$ These included several images taken by the commercial photographer J.W. Beattie, from Hobart in Tasmania. ${ }^{37}$

Stoddart's album also contains a significant number of photographs received from friends and acquaintances who shared her interests in painting and tramping, and who were also photographers. ${ }^{38}$ To give an example: in August 1892 and 1893 Margaret Stoddart and a party of climbing companions made winter ascents of Mt Torlesse in the Torlesse Range in inland Canterbury. In her album, Stoddart devotes two full-page spreads to photographs documenting both of these winter ascents, presumably received from a member of this party (figs $37 \& 38$ ). ${ }^{39}$

As already mentioned, most of the women selected for this study had undertaken some formal art training. Nevertheless, Margaret Stoddart's photograph album stands out for its exceptional artistic qualities, reflected in the overall standard of presentation, and in her innovative approach to its production. Stoddart put together her own album, unlike the other women selected for this study, whose albums were mass-produced from thick card, the preferred backing-support for the thin photographic papers of the period.

Indeed, if we familiarize ourselves with the contents of her album, we are able to have a better understanding of how she has produced it through attaching individual leaves of fine card into a hinged-bound folder. A close inspection of individual pages also reveals aspects of the working method she employed in the realization of these narratives, and how she combined her artistic skills with those of album making. Prior to arranging each page, it appears that Stoddart sought suitable pictorial motifs from sketches she had previously carried out at the location where the photographs were taken. Then, with a pencil, she has set about the process of tracing the outline of the chosen motifs directly onto the page, before rendering each of these preliminary drawings in water colour. Returning to the sequences of photographs representing the ascents of Mt Torlesse in 1892 and 1893, we see how she has carefully selected specimens of flora native to this particular alpine region, such as bracken, fern and matagouri, for these pages (fig. 39). ${ }^{40}$ Also, what becomes evident as we survey their layout on the page is how these motifs 
become a feature of the overall design. ${ }^{41}$ In addition, and perhaps more significantly, we may come to an appreciation of how these motifs provide the framework onto which the photographic images are to be superimposed.

At the same time that Stoddart was assembling her photograph album, she was also working on a scrapbook of newspaper cuttings and other memorabilia which she was collecting. ${ }^{42}$ Significantly many of the items she includes in her scrapbook refer to activities she describes in her photograph album. Inputs from other textual material, such as letters and diaries, can add immeasurably to the process of understanding the production and organization of photograph collections. Likewise, the written commentaries in Stoddart's scrapbook have also proved to be a useful source in the interpretation of the pictorial material in her album. For instance, from an account written for the New Zealand Alpine Journal by G.E. Mannering, a member of the party of the 1892 ascent of Mt Torlesse, we learn that this attempt was not without incident. ${ }^{43}$ Apparently ice under the snow cover had made conditions treacherous for the climbers, forcing them to use ropes in order to reach the summit. If we refer back to the sequence of images depicting the ascent of 1892 in Stoddart's photograph album, we do in fact find that the 11 members of this party, whom he names, are pictured in a close formation, as if they were roped together (fig. 37 ). ${ }^{44}$ This also highlights the tenacity of the early mountaineering fraternity at this period in this country.

\section{Breaches in narrative continuity}

Although we are able to follow the activities described in the photograph albums compiled by Lucy Acland, Margaret and Laura Bowen, and Margaret Stoddart, even in their well-signposted albums there is potential for considerable fragmentation of the narrative. This situation is most likely to occur when the compiler deviates from a strictly temporal ordering in the placement of their images; for instance, if the compiler decides to commence a new narrative before the one that is already in progress has been satisfactorily concluded. This type of interference in the sequence of the narrative structure tends to have an effect on its continuity. With each inversion or reversal in the sequence of photographs, the headway of the viewer is likely to be impeded, or worse, stalled. As Susan Stewart states in her overview of narrative devices, any structural anomalies can effectively undercut the status of the narrative order and contribute to a loss of meaning. ${ }^{45}$ 
This is precisely what transpires in the extended sequence of photographs of Lucy Acland's trip to England. As the narrative of her travels draws to a close, but before its conclusion, Lucy inserts several photographs into her album with no apparent connection to her trip overseas or to those celebrating the family's homecoming on their return to New Zealand (fig. 40). ${ }^{46}$ In this way, Lucy interrupts the ordering of the photographs in her album in what could otherwise be described as a coherent account of events. By embedding unrelated elements at a critical point into her pictorial narrative, Lucy creates a situation which threatens our ability to make linkages between the photographs relating to the final stages of her trip and the homecoming. This dramatically weakens the conclusion to her extended narrative and its impact on the viewer.

Although the oft-employed device of splitting up a sequence with asides is an inherent property of narrative structures, and is routinely employed within literature and film to good effect, when it comes to the confines of the photograph album, such framing devices have proven to be unwise and can lead to unforeseen consequences. This adds credibility to Barbara Herrnstein Smith's observation that, while there can be permeability within the boundaries of all narrative structures, the way in which these narrative devices perform varies according to the medium. ${ }^{47}$ Certainly, her remarks demonstrate the need for a degree of caution on the part of any album maker when it comes to deciding which structural devices are suitable to be employed. To compensate for any breaches in a narrative sequence, it is left to the individual viewer to restore some semblance of order.

Unsurprisingly, these inversions or 'blips' in temporal organization are also clearly identifiable within a structural analysis of the layout of images in the album. If we refer to the graph compiled from the data gathered on Lucy Acland's album, it becomes obvious that the interruption in the graduated line tracking the chronological organization of photographs in the first half of her album, indicated by a random scattering of points, corresponds to the insertion of unrelated narrative elements between the narrative sequence of the overseas trip and the events surrounding their homecoming (graph I). ${ }^{48}$ As we can see from the graph, this development in the layout of photographs anticipates the rather looser order of photographic arrangement within her album that Lucy will subsequently adopt. 
Likewise, the arrangement of photographs within Margaret Stoddart's album presents several discontinuities in the sequencing of photographs. For instance, Margaret separates the sequences of images associated with her trip to Melbourne in the second half of 1894 by introducing unrelated pictorial material. ${ }^{49}$ As a result, the overall significance of the photographs of her visit to Australia is lessened considerably. Stewart summarizes this situation thus: when it comes to communicating information, understanding is not so much to do with the content, as it is to do with the procedures of communication that are employed. ${ }^{50}$ In considering these examples, it is clear that any interruption in the course of a narrative is also likely to disturb the integrity of the storyline. ${ }^{51}$

\section{Lapses in signposting}

Needless to say, deficiencies in narrative structuring within some of the albums selected for this study are likely to be even more problematic. This raises the possibility that, when it comes to developing a narrative, there may be some resistance on the part of the compiler to providing adequate signposting. What becomes obvious is that several of my album makers appear to begin putting photographs into their albums without consideration for their overall organization. If we compare the way in which Lucy Acland began the narrative sequences of her overseas trip with those album makers whose albums are less structured, the differences between these approaches becomes more obvious. What Lucy does on the first page of her album is set up the narrative of her overseas trip with the image of the steamer that she and her sister will sail on to England (fig. 32) ${ }^{52}$ Even without the inclusion of a detailed commentary, it is understood that she is about to embark on a sea voyage and the viewer's attention is engaged. By contrast, if confronted with pages of photographs that do not follow a rudimentary narrative order, the viewer is likely to experience difficulties in making an immediate connection with these images.

The choice of this type of construction may also lead the viewer to question why one event takes precedence over another as the starting point of such a pictorial archive, or, for that matter, why a compiler might cease to add to the album at a particular point in time. Hayden White and Robert Kellogg provide precedence for such behaviour, citing medieval chronicles. ${ }^{53}$ Both have argued that it is a characteristic of this style of narrative for the chronicler to begin at whatever point he deems 'life' to have begun. Some compilers of photograph albums in this study appear to adopt a similar approach to 
organizing their information - they just begin and then, just cease. David Carr suggests that the notion that sequences of real-life events possess the formal attributes of the stories that people tell, has its origins only in our imagination. In his opinion, the unpretentious narrative elements of medieval chronicles may better reflect reality. ${ }^{54}$

A defining feature of the photograph albums arranged by sisters Jessie, Susan and Carrie Buckland is the random nature of the placement of photographs and a lack of a recognizable structural framework. If we review selected pages from Jessie Buckland's album, which frequently includes the placement of apparently unrelated subject matter onto a single page, we can see how she effectively excludes from understanding all but those involved in their production (fig. 41). ${ }^{55}$ Beyond a lack of sufficient signifying information within the layout of their albums, we also find little indication of the entrance and exit strategies, considered a necessary requirement of a well-formed pictorial narrative.

Although such an informal arrangement for photographs may bring certain individual images into focus, as a general rule this type of formatting also tends to drain intensity from each image - the image has to function in isolation, rather than within a sequence of other images. All in all, there is something decidedly artless about this type of page construction. Once again, Susan Stewart's comments prove helpful here. She defines these types of incongruities in the organization of textual material as consistent with the author abandoning recognized categories and inventing their own. ${ }^{56}$ The distinguishing characteristics of what could be defined as 'rogue' narratives demonstrate how different categories can be put together without consideration for their relationship to each other. Photographs organized in albums in this way appear to be out of place - both in time and space. This may suggest that the Buckland sisters were primarily using their albums as a pictorial archive, rather than to tell a story.

Nevertheless, there are certain situations where there is a better acceptance of inconsistencies in the layout of an album page. For instance, as an album becomes fuller there is a general tendency for the compiler to 'fill in' perceived blank spaces without consideration for the context in which they are placed. Certainly, this is a characteristic of Jessie Buckland's album. Buckland appears to have begun the practice of inserting unrelated photographic images into spaces in her album around 1902. By this date she 
was using a quarter-plate camera and the smaller format of these prints could be easily accommodated into the spaces beside the larger format prints of the half-plate camera she had been working with since the early 1890s. ${ }^{57}$ Again, following at some unspecified but later date, Buckland placed 'snaps' taken on a trip to the Chatham Islands with a handheld camera into spaces on several pages in her album (fig. 42) ${ }^{58}$ This form of visual incompatibility is more easily identified, and therefore more readily accepted, by the viewer.

What is also noteworthy is that such inconsistencies in the arrangement of these photograph collections are reflected by the scatter of points shown in the graphs compiled for each of the photograph albums of the Buckland sisters (graphs IV-VI). ${ }^{59}$ If we compare the graphs plotted for the Buckland sisters' albums with those for Lucy Acland, Margaret Stoddart and the Bowen sisters, the differences between the organizing principles of these women becomes more apparent (graphs I -VI). For instance, when we consider the graphs developed for the Buckland sisters' albums, we are presented with a 'polka dot' effect which underpins the lack of temporal and thematic organization in the general layout of these visual texts. As has been previously shown, these random displays of data contrast with the output gathered for graphs compiled from albums arranged chronologically or episodically, which are expressed as points along a continuous line.

\section{Lack of signification}

According to Stewart, one of the most serious omissions in the narration of any text is a blatant contempt for including factual information. ${ }^{60}$ As Stewart points out, a disregard or lack of adequate textual interpretative procedures acts as an impediment to understanding. Inadequate dating has been a contributing factor in not being able to carry out a detailed analysis of the photograph albums of either Kate Wood or Florence Wright. Wright's photograph album had no annotation originally, and it was only due to the interest invested in this album by subsequent custodians, as I will outline in Chapter Six, which has enabled its stories to continue to be narrated.

Stewart points out that, within small group communication, it is taken for granted that everyone who needs to know already has that knowledge, and the photograph within the album is able to 'speak itself' ${ }^{61}$ At this stage, any accompanying written text can appear to be almost redundant. Yet, over time, what the image had previously announced 
becomes less obvious. The double texts of the visual and the verbal, which had formerly been in a state of flux, will now begin to work in partnership. Gradually, the verbal text, originally appearing to be superfluous, will become more dominant. Finally, it will come into its own, as the stories the visual image once held begin to fade from memory.

Those familiar with the investigations of Patricia Holland will recall her descriptions of vain attempts to negotiate her way through family photograph albums. As she states in the introduction to Family Snaps, our longing to make sense of our present leads us to interpret any traces of information to fill in the gaps in our knowledge of our past, since not to (and this is what makes her quest so poignant) can leave us with a profound sense of loss. ${ }^{62}$ She continues: 'So often, all that family photograph albums can offer to their descendants are tantalizing glimpses of many possible pasts'. ${ }^{63}$ This is certainly the case with many of the albums I am considering here.

\section{Outright removal}

When considering the question of gaps, it is also necessary to address the vexed issue of the outright removal of photographs from a photograph album. As Elizabeth Edwards and Janice Hart argue, the removal of images from an album, for whatever reason and by whatever means, indicates the power that can be exerted by those who come to have authority over it. ${ }^{64}$ What could be the underlying motivation for such action? Is it an attempt to erase any record of them from the collective memory? Certainly, when we survey the pages of the albums in this study, we find that such intervention appears to be more prevalent in those that have been held within the extended family over many years. This demonstrates how subsequent custodians can use their proprietary rights to override the original intentions of the compiler. For instance, as far as can be ascertained, a notable number of images were removed from the albums of Jessie and Carrie Buckland following the transfer of these albums into the care of their brother Harold and his family in the mid-1930s (fig. 43). ${ }^{65}$ When we look at the removal of the image on this page from the album of Jessie Buckland, we find that the initials 'K.W.' and also the name, 'Kate Webber' were inscribed below. While I am unable to comment further, I can confirm that Kate Webber became the wife of the girls' brother, Arthur, and therefore was a member of the family. ${ }^{66}$ 


\section{Surplus of signification}

According to Stewart, a surfeit of information can be potentially as problematic as any perceived deficiencies associated with the signification of an image. She adds that interference with a text, whether in contradiction or not, can take away some of the authenticity from the original text. ${ }^{67}$ Having said this, there is also the possibility that additional information provided by a second hand can be ascribed a more positive role. Certainly, there is evidence for this to be true when it comes to the culture of the photograph album. Take, for instance, the situation where a later inscription endorses what has originally been supplied, and therefore reinforces what has already been stated. In addition, this information may serve to clarify a text that, at a later date, may have been deemed as inadequate or insufficient. As I have already pointed out, the caption supplied by Susan Buckland for the image 'Coming Thro' the Rye' in her photograph album provides information concerning this photograph which her sister Jessie, as the creator of the image, had apparently not considered necessary to include in her own album (fig. 28). ${ }^{68}$

Moreover sometimes this addition can be extremely helpful, as in the case of the Buckland sisters, where the same photographs appear in all their albums, and where similar, but also varying amounts of information, are supplied. This assists the viewer to acquire a more comprehensive understanding of a particular photographic image. In this instance, the captions supplied by these three sisters work together to record in more detail the circumstances of the actual production of this photograph. Nevertheless, I take Stewart's point that additional information may lead to a surplus of signification. As Deborah Tannen reminds us, there are limitations to the amount of textual information that the average person is able to assimilate. ${ }^{69}$ A surfeit of information can actually lead to impairment of understanding in much the same way as a lack of signification. Of course, this is likely to present itself in very different ways. Although not a common occurrence within photograph albums, there are occasions where the compiler finds they have too much information to deal with, or more likely, to be only ordinary information which they feel an obligation to document. In such circumstances the storyline can indeed become 'overloaded' and the message it carries may have less clarity as a result.

A potentially worse situation can materialize when the caption that frames a photographic image encroaches onto the physical margins of the photograph, to the extent 
that it interferes with the pictorial integrity of the image it is intended to anchor. The visual and verbal each vie for common space. Certainly, the captioning of the photograph of the Buckland-Hocken Christmas group taken in 1896 from Jessie Buckland's album comes into the latter category (fig. 44). ${ }^{70}$ When Jessie placed this photograph into her album she included the brief title 'Xmas 1896' in ink, below the image. Subsequently, it appears that Buckland decided she should elaborate on what she had earlier written to include the names of the family members pictured in the photograph. At some later date, however, probably after the album had come into the possession of her brother Harold, a further caption has been added by another hand above the image, this time in biro. ${ }^{71}$ Interestingly, in most particulars this caption repeats Jessie's caption and so can be regarded, at least on the face of it, as not only being superfluous to signification but as also another display of power. Conversely, if we consider the actual process associated with such an act, could it not also be seen as a sign of affirmation?

Deborah Tannen equates displays of solidarity and power as being at opposite ends of a single continuum. In her opinion, they only differ as to interpretation. ${ }^{72}$ In actual fact, the additional caption not only repeats the original inscription; it enlarges on it by supplying details, including changes in the status of family members - in this instance by inserting the married family name of Susan Buckland. Taken from such a perspective, this type of action might be interpreted as a means of endorsing what had already been stated rather than as an attempt to override the authority of the original inscription. It makes the image more relevant to future viewers. Furthermore, and perhaps more significantly, in the very act of retracing the remarks of the first, an added text may also indicate that the inscriber is familiarizing themselves with the names and faces of the people in the photograph. By resorting to a well-recognized narrative device of textual repetition, the writer may acquaint themselves with family members only known to them by reputation. Tannen suggests this activity can also be personally fulfilling. ${ }^{73}$ Cultural anthropologist Takie Sugiyama Lebra defines these types of inscriptions with the interesting concept of 'belonging by memory'. She interprets these actions as the means by which descendants choose to link themselves symbolically to members of their extended family across generations. $^{74}$ 


\section{A Rose is a Rose is a Rose...}

Repetition is a characteristic of many texts and is frequently regarded as a device with the potential to speed up the telling of narratives. Literary theorist Gerard Genette, for example, argues that iterative elements can be employed as a means of accelerating the narrative texts as we assimilate repetitive patterning, already consigned to memory, to future events. ${ }^{75}$ Although this may be the case within a literary setting, Barbara Herrnstein Smith questions whether the same conditions can be applied within the framework of a photograph album. ${ }^{76}$ From my own experience, and also from what can be gathered from others, within the confines of the photograph album repetition often induces a rather different response. ${ }^{77}$ As Langford explains, the repetition of images within a photograph album is deserving of more attention and should not be passed over lightly. ${ }^{78}$ These types of constructs provide compilers with a simple mechanism through which they can emphasize what they want to bring to the attention of others. As William Labov reminds us, such a mechanism also possesses real impact. ${ }^{79}$ Normally, the first time we come across a particular image it may not leave much of an impression. But the reappearance of the same image confirms it is of significance, which may lead to further lines of enquiry. For, although we may not know the reason why the compiler has repeated a particular photographic image, we recognize that by giving space to it again, this image must have a special significance.

Within Susan Buckland's album, includes a candid photograph of the same young man on three separate occasions. ${ }^{80}$ But only one carries an inscription, and this is in the form of initials, so few clues are given to those unacquainted with members of the family circle. What is clear from the repetition of the same image is that this person is of importance to Susan. Appreciating this fact, each time we encounter a copy of the image, a recognition response is triggered. As we become more familiar with the life story of the compiler, the reason that this image appears in her album on several occasions becomes apparent. They picture her 'intended', Lionel Havelock Orbell, whom she married on 22 May, 1901 (fig. $45){ }^{81}$

Similarly, Mary Stoddart also introduces images of those she considered to be important in her life in the two albums she worked on concurrently from 1898. For example, the photograph of the family group of Anna Stoddart and her children gathered on the verandah of their home has been included in both of these albums (fig. 2). ${ }^{82}$ Furthermore 
Mary also introduces this family grouping in cropped versions. In one instance Mary has pared down the image of the family group to reveal just her mother Anna, seated, with her brother James standing behind her (fig. 46). ${ }^{83}$ Although it is impossible to ascertain the reason why Mary has chosen to present them in this way, what becomes apparent on surveying the contents of her albums is that, of all her siblings, it is James who becomes her special focus. He is represented in her albums as a member of the family, a farmer, a miner and a soldier. ${ }^{84}$ Moreover some of these images appear multiple times.

To give one example: a professional portrait study of James, taken some time in the 1890s, appears three times in Mary's photograph albums. Examining these images sheds light on how compilers develop new meanings for an image, simply by reframing its context. For instance, in her first album Mary inserts the portrait study of James, wearing the uniform of the Victoria Rangers, side by side with a companion portrait study of their brother, John (fig. 47) ${ }^{85}$ This pairing of the brothers may be reflective of the pride that Mary and her family felt at the brothers' decision to serve in the South African Wars. When James was killed during active service in 1901, following the siege of Kimberley, Mary placed a second copy of this image of James in uniform in her first album this time inside the front cover of the album (fig. 48). ${ }^{86}$ Next to this image she inserted a newspaper cutting announcing his death. Mary placed yet another copy of the image in her second album and introduced several lines of verse in his memory in the form of a caption. ${ }^{87}$

The inclusion of a carefully chosen text reminds us, as Geoffrey Batchen points out in his studies of photography and remembrance, that if a photograph is to function as a personal memory object within an album, then something more needs to be added to enhance the memorial power of the image. ${ }^{88}$ He suggests that the addition of a text is one way to link the photographic image with the personal. ${ }^{89}$ Mary Stoddart's albums exemplify these remarks, as we witness there the way in which the acts of photography and remembering are brought together. In effect, Stoddart's albums become sites of family reverence and remembrance as well as being ones for mere memories. A sad endnote to this discussion: within a few years of James' death, Mary had also died. ${ }^{90}$ And, as Mary had done for James, a hand-written verse in her memory has been inserted above the large studio portrait of Mary, at the front of her second album (figs $49 \& 50) .{ }^{91}$ Presumably, this epitaph was added by her bereaved husband Richard Farmer, who coincidently had 
presented this album to Mary on the occasion of her thirtieth birthday, some ten years before. $^{92}$

Not only may repetition be employed within photograph albums as a form of duplication, with all the visual impact this possesses, but it can also introduce rhythm into the narrative. Stewart classifies the repetition of subject matter under the general heading of 'digressions and returns'. ${ }^{93}$ She qualifies her statement by explaining how the repetitive patterning of textual elements has the capacity to bring a sense of circularity to a text, which can also generate its own rhythmical effects. ${ }^{94}$ It is a process which the viewer sets in train each time they make their way through the album. The movement resulting from the back and forth motion between the eyes and hands produced during this process should not be considered as contrived, but should more accurately be understood as an attribute of a particular narrative structure. ${ }^{95}$ In Forget Me Not, Photography \& Remembrance, Batchen explains how the processes activated in association with the viewing of the contents of an album effectively 'puts the photograph album back in motion' ${ }^{96}$ In this process, viewing may become transformed into what he describes as a multisensory experience. This is also the reason, I believe, why the 'silenced albums' of which Martha Langford speaks so eloquently in Suspended Conversations appear so forlorn. ${ }^{97}$ It is not solely that the stories in these albums can no longer be called forth; it is that the inherent rhythms of their narrative structures cannot be activated.

\section{Summary}

In Chapter Five an extensive investigation into the structural devices employed in the organization of pictorial material within photograph albums has been undertaken. One concern of this investigation has been to identify the structural devices available to album makers and to outline how they perform within the confines of the photograph album, citing specific examples. Another concern, and no less significant, has been to investigate the means by which these structures facilitate the progress of viewers negotiating their way through the album and its images.

Developing a suitable framework for the evaluation of this textual material has involved going beyond recent contributions concerning photograph albums, and consulting more widely. This has entailed drawing on the expertise of specialists from other genres - in 
particular, those active in the field of literary discourse. I have found the writings of folklorist Susan Stewart to be particularly useful, offering a breadth of knowledge and necessary rigour that an in-depth enquiry into the narrative structures of photograph albums demands. Adopting the framework she developed as a model has enabled a comprehensive analysis of these narrative structures. Such an undertaking has resulted in a better appreciation of the practices of album making as a mode of visual expression for women at the turn of twentieth century. 


\section{Chapter Six}

\section{The culture of image-sharing with others}

\section{Introduction}

Although the image remains central to the act of giving and receiving, Gillian Rose argues that, when it comes to family photography, images cannot be assessed on their visual content alone. ${ }^{1}$ She maintains that what happens subsequently to family photographs is an essential part of their social function. ${ }^{2}$ If this is so, Rose enquires, then, why isn't more effort expended on researching the specific effects brought about as photographs move from the site of their production to the site of their reception? ${ }^{3}$

This chapter will explore the range of practices associated with the distribution of photographic prints in the domestic sphere. By focusing on the circulation of images, the emphasis shifts from a single event to an appraisal of post-production processes. This will provide a fuller account of what happens to photographs in the course of these social interactions, and hence result in a more informed understanding of the underlying behaviour related to these practices, and what is invested in them. This discussion will begin with a review of 'gift-giving' practices.

\section{The photograph as a gift}

When it comes to guidance on gift-giving practices from an historical perspective, attention turns to French anthropologist Marcel Mauss, the scholar who first documented this phenomenon, and who continues to influence our understanding of these processes. ${ }^{4}$ Critical to Mauss' treatise is his premise that, although gifts ('prestations') may appear in theory to be voluntary and disinterested, in practice they are obligated and interested. ${ }^{5}$ Research into the gift economy has broadened since the 1970s, and it is apparent from the findings of more recent studies, such as those of Russell Belk, that the circulation of items does not have to be understood as a form of contractual exchange. ${ }^{6}$ Belk argues that it is a mistake to assume that all behaviour in association with gift-giving results in an obligation to reciprocate. ${ }^{7}$ Indeed, in order to distance himself from Mauss, and to clarify his own position, he proposes that the terms of reference in which such enquiries are framed should be extended beyond the obligation to give, receive and reciprocate. ${ }^{8}$ Belk 
points out that sharing is a form of giving, 'with its origins closely bound up in the history of social relations within the gift-economy. ${ }^{9}$ Yet clearly, as a social phenomenon, it is different from practices associated with the obligations of exchange. Belk maintains that the act of sharing with others, whether family, friends, neighbours or associates, represents a type of interaction that is at the core of social cohesion, performing a fundamental role in the welfare of any functioning society. ${ }^{10}$ As sharing is enacted in everyday situations, it is often overlooked as a social practice, and regarded as so common place as to be taken for granted and passed over as an area of study in its own right.

When examining practices associated with sharing, therefore, it is essential to take into consideration the effects these social transactions can produce. Indeed, failing to do so continues to obscure the subtleties that manifest themselves in association with any act of sharing. This limits a properly informed appreciation of the goodwill such exchanges may occasion, including the feelings of solidarity and bonding created within small group situations.

What Belk claims in general terms for the concept of sharing, Rose has shown to have clear correspondences in relation to photographic distribution. In her survey of housewives in south-east England, Rose reports that a large part of what is ordinarily done with family photographs emerges out of a basic human need to share what we have within the network of people with whom we identify most closely. ${ }^{11}$ She also notes that in sending items such as family photographs to others, the sender does not necessarily consider these as gifts, nor, for that matter, does the recipient perceive them as such. ${ }^{12}$ It is clear from these findings that in certain situations within the bounds of the gift economy, a return in kind is not expected, nor is one always possible. ${ }^{13}$ Such practices distinguish the pro-social behaviours associated with sharing from other gift-giving practices.

\section{Sharing outside the family}

As outlined in Chapters Two and Three, the distribution of photographs was customarily confined to sharing within the established networks of the immediate or extended family. In certain instances, as I have demonstrated in my examination of the photographic practices of the Acland and Buckland sisters, the study of these exchanges can also 
provide a method for reclaiming the photographic work of women whose personal collections still remain unaccounted for. In the case study on Harriet Acland in Chapter Three, it is the surviving album compiled by her sister Lucy Acland which has proved to be so important in supplying incontrovertible evidence of Harriet's contribution to photography at the end of the nineteenth century.

In carrying out this type of research, it may be necessary at times to search beyond the collections of the immediate family, even though establishing connections between the parties involved can pose a challenge. It may, however, prove to be an equally rewarding method for the retrieval of collections of photographs taken by those whose own collections have yet to be located. In these situations, given the length of time elapsed since the original presentation, the search may involve tracing the whereabouts of the descendants of the initial recipients.

It is in this context that the phenomenon of what Belk terms 'sharing out' applies. ${ }^{14}$ As a social practice, 'sharing out' is less common than those practices associated with sharing within a close network of family and friends. With increasing interest in the area of domestic photography as a research topic, however, this method of approach for the recovery of such photographic collections is becoming more widely recognized.

What also needs to be taken into account in such situations, as Richard Chalfen explains in his study of Japanese-American families, is that the original recipients of these photographs are likely to have been regarded as belonging to the extended family group at the time the presentations were made. ${ }^{15}$ In this context then, such presentations between donor and recipient were considered part of normal social interactions, since they would have followed the same prescribed pathways as those for close kin. Chalfen suggests that, within the setting of the workplace, these types of interpersonal relationships were a recognized practice. ${ }^{16} \mathrm{He}$ adds that the families he interviewed recounted instances where loyal employees were often treated as part of the family, and at a certain level, were considered to be part of the circle of intimates. ${ }^{17}$ Work associates were frequently included in family events, appearing in photographs taken of the family group, and could afterwards expect copy prints of the photographs to be distributed to them. This same situation became a feature of social interactions within New Zealand society, especially in 
colonial times, when through necessity there was a greater interdependency between people at different levels in society, particularly in less-populated country regions.

The discussion which follows will examine two separate occasions when presentations of photographs were made in significant numbers beyond the boundaries of the intimate circle of family and friends. In both investigations, close attention will be given to recounting the specific circumstances in which each presentation took place. The discussion will extend to examining the significance of the presentations for the descendants of the original recipients of the photographic images. Indeed, in the course of this study, it will become apparent how influential their role has been in the conservation of these photograph collections up to the present.

I shall begin by describing the background to the presentation of photographs taken by Kate Ivens and given to Elizabeth Colenso, born Fairburn (1821-1904), in $1896 .{ }^{18}$ At the time of this presentation, both women were resident at the Melanesian Mission station of St Barnabas on Norfolk Island. A second study examines the circumstances surrounding the presentation of an album of photographs produced by Florence Wright of Windermere in mid-Canterbury to John Dell, the head gardener on this property from 1894 to 1911, to his wife Eliza, and to their growing family, between December 1902 and June 1904. ${ }^{19}$

\section{Kate Ivens -- her formative years}

Kate Ivens spent her early years at Ashley Bank beside the Ashley River in North Canterbury. Following the death of her father, George Ivens, in mid-December 1878, her mother Caroline moved with her two young children, Walter and Kate, to New Brighton, then a small seaside settlement some ten kilometres east of Christchurch. Here Caroline Ivens opened a children's home. ${ }^{20}$ Given her mother's commitment to the welfare of others, it is perhaps not unexpected that Kate would follow her mother's example when finding her own vocation in life.

From the mid- nineteenth century, first in Europe, then in Britain and North America, orders of deaconesses devoted to the welfare of women and children were founded within several denominations of the Protestant communion, enjoying a growing following in subsequent years. ${ }^{21}$ When an order of deaconesses based on the principles of these earlier institutions was established by Bishop Churchill Julius in Christchurch in 1893, Kate 
Ivens, then in her early twenties, became an associate of the community. ${ }^{22}$ Two years later, in 1895, Ivens was formally accepted into the order as a postulant, and immediately commenced her four-year training in preparation for ordination as a deaconess (fig. 53). ${ }^{23}$ In 1896, in conjunction with her training, Ivens travelled to the Melanesian mission on Norfolk Island, where her brother, the Reverend Walter Ivens, was then stationed, to gain work experience for six months as a teaching assistant. ${ }^{24}$ On 27 March 1896, Ivens set sail from Auckland on the mission vessel, Southern Cross, on the first of its twice yearly supply runs to Norfolk Island. Her travelling companions on this 11-day voyage included Church Missionary Society missionary, Elizabeth Colenso, and her granddaughters, Edith and Christine Simcox, who were returning with Colenso to Norfolk Island after furlough in New Zealand. ${ }^{25}$

\section{Elizabeth Colenso -- a life of commitment}

Elizabeth Colenso had first come to Norfolk Island in the late 1870s at the request of the then Bishop of Melanesia, John Selwyn (1844-1898), for a period of four months. ${ }^{26}$ However, she was persuaded to stay on to supervise an educational programme for girls brought to the mission station from the Pacific Island territories within the diocese of Melanesia. For Kate Ivens, starting out on her own life of Christian service, the opportunity to work under the guidance of Colenso, although by this stage elderly and infirm, is likely to have been an inspiration. Colenso's wealth of experience in the field of missionary work, particularly among Māori in New Zealand, was already widely known and it can be surmised that her knowledge and understanding would have been helpful to Ivens in future years when she was placed in charge of Te Wai Pounamu Māori Girls' College at Tuahiwi, in North Canterbury, and later, when the school moved into Christchurch in the late 1900 s. $^{27}$

Much has been written about Colenso and her full and rewarding life as a missionary, teacher and linguist. ${ }^{28}$ Most of these studies have concentrated on documenting Colenso's earlier years and her association with the Church Missionary Society at mission stations in the upper North Island, as well as her knowledge of Māori culture and her fluency in the Māori language. ${ }^{29}$ The nearly 20-year period of Colenso's association with the Melanesian Mission on Norfolk Island between 1879 and1898 has not received the same level of attention, commensurate with the position she held at the mission and the length of time she spent there. ${ }^{30}$ Yet her years on Norfolk Island represent a significant part of 
her time as a missionary. Admittedly, reconstructing aspects of her life there is no simple matter, since women receive only an occasional mention in dispatches filed by clergy for the Bishop of Melanesia. ${ }^{31}$

Most of the information available to us from this period of Colenso's life comes from the diaries she wrote as a resident, or from typescripts of her recollections put together subsequently by members of her family. ${ }^{32}$ It is notable that some aspects of her activities on Norfolk Island during this period have not been examined, including Colenso's developing interest in album-making late in life which she refers to in these sources. Together with the aforementioned written accounts, the two photograph albums she compiled during these years provide a comprehensive record of life at the mission.

\section{Photography on Norfolk Island}

Photography practiced as a serious recreational pursuit on Norfolk Island originated with the establishment of the mission by John Coleridge Patteson (1827-1871), the first Bishop of Melanesia, in the late $1860 \mathrm{~s}^{33}$ This early interest in photography continued to be widely practiced among the European residents at the mission in the following years, made up at any one time of several clergymen and their families and a number of single colleagues (fig.54). ${ }^{34}$ As Chalfen has already explained, it is often within such close-knit communities that members participate in common activities, allowing a culture of sharing to become an established social practice. ${ }^{35}$

Presumably, the sharing of photographs among members of the European community was already taking place at the time of Colenso's arrival in the late 1870s. Although, as we know, age was no a barrier for women to take up photography, Colenso appears to have preferred to be a collector. ${ }^{36}$ Perhaps it was as a sign of her appreciation for the numbers of photographs she received from her colleagues, which led her to compile her own albums during the few hours set aside each day for recreational practices as her way of meaningfully engaging with those who were active photographers on the island. ${ }^{37}$ Certainly, throughout her residency, Colenso appears to have applied herself conscientiously to this task. In reviewing her albums it is clear that she was assiduous in documenting all the images, including supplying names of the people pictured in each photograph, the name of the photographer and the date the photograph was taken. And 
some of the last images placed into her second album were the series of images presented to her by Kate Ivens when the latter was resident in $1896 .{ }^{38}$

\section{Kate Ivens and her early photographic practices}

Kate Ivens was already a competent photographer when she arrived on Norfolk Island.

During the early 1890s she had attended classes in the rudiments of photography conducted by the Philosophical Institute in Christchurch, in association with the Christchurch Photographic Society. ${ }^{39}$ While attending these popular classes, it is probable that she became acquainted with Kate Wood. Unlike the other women discussed so far in this thesis, for whom working with other family members has been identified as a significant feature of their photographic practice, Ivens did not have a sibling to call upon to share her cultural interests. Meeting Kate Wood, therefore, and then teaming up with her, can be regarded as fortuitous. Certainly it was from this time that the 'two Kates', as they became known within their families, formed a close working alliance (fig. 55). ${ }^{40}$ Even though their lives were soon to diverge following Ivens' decision to commence her formal training as a deaconess at the end of 1895, pictorial evidence from Wood's surviving albums of images taken by Ivens suggests that their friendship extended into the 1900s. ${ }^{41}$

An album compiled by Kate Wood in the early1890's, to which both women contributed, provides an overview of the subject matter they worked on together during this formative stage of attending classes at the Philosophical Institute. ${ }^{42}$ The various photographs of scenes in and around Christchurch suggest they may have been taken by the two women while on field trips conducted by the Institute (fig. 56). ${ }^{43}$ A selection of these photographs was subsequently submitted to photographic exhibitions organized by the Institute in the 1890s. Some of Ivens' images even came to critical attention, suggesting that she had quickly advanced to a serious level of competence. ${ }^{44}$

Kate Ivens was only one of a number of photographers who contributed photographs to Colenso's second album, which Colenso began to compile in $1891 .^{45}$ That said, of the 138 photographs mounted in this album, 36 have been identified as being by Ivens. In comparison with other entries, therefore, Ivens' contribution was far greater and all the more remarkable given the relatively short time she was resident at the mission. ${ }^{46}$ Perhaps the number of images given by Ivens to Colenso may indicate a certain affinity between 
the two women at this time. Perhaps also it would be natural for Ivens to feel somewhat beholden to the older woman. Her gesture, then, could be interpreted as a way of making some kind of return to Colenso.

Apart from several images of scenic views of Norfolk Island recognized for their outstanding beauty, such as Red Rock, the view towards Phillip Island and the Archway and Bird Rock, most of the images taken by Ivens during her sojourn on the island feature the resident community and the routine activities carried out at the mission. She thus provides an overview of day-to-day life there (fig. 57). ${ }^{47}$ A particularly interesting series of photographs documents routine duties undertaken by Melanesians and Europeans together. These activities, broadly based on the Church Missionary Society in New Zealand's organizational blueprint, were the activities both women had been responsible for overseeing at the mission, and this may have been the reason Ivens chose to record and pass on these images to Colenso. ${ }^{48}$ The photographs include scenes of Melanesian women and girls assisting with communal duties associated with the acquiring of life skills such as cooking, sewing, washing and mending (figs 58 \& 59). ${ }^{49}$ There are also images associated with the teaching of the core subjects of reading, writing and the Catechism. One of these images includes a study of Ivens, in her capacity as a teaching assistant, sitting on the verandah steps outside the schoolroom conducting a writing class, surrounded by the young charges in her care, all with writing slates in their hands, apparently eager to learn (fig. 60). ${ }^{50}$

\section{The End of Colenso's Tour of Duty on Norfolk Island}

At the end of 1898, Colenso returned to New Zealand to live permanently with her daughter Frances Simcox and her family at Otaki, north of Wellington. Among the personal items she brought with her were the two photograph albums she had compiled while resident on Norfolk Island. During these final years, Colenso continued to work on her second photograph album.

It is important to bear in mind that the history of a photograph album does not necessarily conclude when the life of the original compiler comes to an end. As noted in relation to the organization of photograph albums, the process of album-making represents an initial phase only, albeit a vital one, in its history. As will be explored in this chapter, the 
developing history of a photograph album is likely to be ever-evolving, encompassing a complex process of 'continual becoming' into the present.

An essential part of any assessment of photograph albums involves extending discussion beyond social interactions between the compiler and contributors, and including the input of those who are subsequently entrusted with the album's care. In most cases, as has already been pointed out, those who do so usually come from the immediate family of the original album maker. Furthermore, their association with a particular album may be a longstanding one. For this reason, it is essential in any study to include the role of those charged with the future care of family archives and their attitudes towards these materials.

Take for instance, the photograph albums of Elizabeth Colenso. The very fact that these albums had been compiled by a cherished relative would have substantially increased their significance for those members of Colenso's family entrusted with their future care. Both out of respect for Colenso and in order to honour her memory, her descendants felt an obligation to care for the items bequeathed to them. Over time, however, a different attitude can emerge. Recipients may come to understand that, although their role is to safe-guard items on behalf of Colenso and her legacy, these items are also part of their own heritage. Therefore their custodial role extends to safe-guarding these items on behalf of the present family. Eventually, as their historical significance increases, they may come to appreciate that these items can be of interest to those beyond their immediate family.

\section{The role of Edith Simcox as custodian of the Colenso photograph albums}

For almost the whole time Colenso was working on her second photograph album in the 1890s, her grand-daughter, Edith Simcox (1871-1958), later Swabey, was also resident at the mission, having travelled from New Zealand to take care of her ailing grandmother (fig. 61). ${ }^{51}$ Given Colenso's declining health throughout this period, it is probable that Simcox may have taken on some of the responsibility for the organization of the photographs in this album, and may also have been responsible for the annotation of some of the photographs. ${ }^{52}$ In addition, Simcox's association with these photograph albums may have continued after Colenso's return to New Zealand at the end of 1898. Certainly, given Simcox's familiarity with the routines of daily life on the island and the people pictured in the photographs, it is reasonable to assume that, of all the members of 
Colenso's immediate family, Simcox might be the one to take over the responsibility for the albums following Colenso's death in 1904. The appearance of Simcox's name on the flyleaf of both Colenso's photograph albums adds credibility to the assumption that the on-going care of the albums devolved to her until her own death in 1954 (fig. 62). ${ }^{53}$ Taking all this into consideration, it is probable that it was also Simcox who was responsible for several additions made to the second album during the period she was a custodian. These additions include a series of photographs taken by the well-known commercial photographer J.W. Beattie of Hobart in Tasmania, who visited Norfolk Island in November 1906. ${ }^{54}$ Coincidently, Beattie's visit to the island coincided with Ivens' second, more extended sojourn between 1901-08, when she was placed in charge of the mission's hospital. In his journal, Beattie describes meeting Ivens. He mentioned how helpful she had been to him during his short stay on the island, putting herself entirely at his disposal and transporting him and his photographic equipment in her dogcart. ${ }^{55}$

\section{The role of photograph collections in establishing an authentic past}

As already emphasized in Chapter Two, photographs which celebrate family performed a significant role for settler families, as they ventured to establish new lives in this country. Images taken of the family together served as a means by which these groups could express their personal identity and the social grouping to which they belonged. At the same time, as John and Jean Comaroff argue, such photographs provided them with essential visual feedback. ${ }^{56}$ But, as suggested by Ann Victoria Bliss in her study of family photographs from the worlds of both fact and fiction, this type of documentary evidence performs an equally critical role in the lives of direct descendants of these families. ${ }^{57}$ She concludes that it is as if a family group cannot function properly without a visual record of its own family history, since such images work to define the family's origins. ${ }^{58}$

I have already referred to the considerable lengths Patricia Holland went to in order to piece together something of her own family history from her family's photograph albums. ${ }^{59}$ However unsatisfactory the outcome may have been for her, from the mounting anecdotal evidence collated thus far her experience is by no means unusual. Rather, it demonstrates, as Bliss maintains, exactly how important archival possessions are for people and the unique role they perform in the formation of identity. ${ }^{60}$ As I pointed out in Chapter Two, the continued use of material objects of specific cultural value from the past carried forward into the present is of extraordinary significance. Human geographer 
Yi-Fu Tuan describes how these types of objects can have a profound effect on determining our sense of who we think we are. ${ }^{61}$ Their role, therefore, in how we come to define ourselves cannot be underestimated. Who we are, is what we possess. If family possessions do not survive, or even if they do but we lose access to the family stories associated with them, this loss of connection to the past will contribute to a diminishment of self-image. The scope of our thoughts and actions will be less rich and meaningful, due in large part to our sense of self needing to be supported. One of the ways we do this states Erich Fromm is through objects. ${ }^{62}$ As the nineteenth-century philosopher William James quipped in relation to his early findings in this area of research, we can be sure of our possessions. ${ }^{63}$ It is of little wonder, then, that people surround themselves with memory-provoking items from our past to bolster perceptions of themselves. And this is why Mihaly Csikszentmihalyi and Eugene Rochberg-Halton advocate so cogently for the need to recognize the relationships that exist between people and things. ${ }^{64}$

Within the context of the present discussion on family photography, the practices of viewing and narrating photograph albums can alter the way in which family histories are told in critical ways. As Elizabeth Siegel points out, an item which may have initially been regarded as valuable in establishing family heritage through making a family's past visible, may come to be regarded over time by later generations of the family as an historical artefact essentially associated with memorial functions. ${ }^{65}$

Fortunately, contrary to Holland's experience, there are family photograph albums which continue to function as living archives. A case in point is the one in the possession of descendants of John and Eliza Dell, formerly of Windermere in mid-Canterbury. ${ }^{66}$ Some four generations on, the descendants still have access to the contents of the photograph album first presented to them in the early 1900s. Perhaps it was due to the paucity of other archival material in their personal possession, or even because of it, that the family has always been aware of the value of this album of photographs. Over the considerable period of time it has been in their possession, the album has continued to operate as a resource for storing the family's pictorial archives. In addition, it has also acted as the vehicle through which family stories can be called forth and retold to future generations of the family. As sociologist Barbara Harrison explains, on the one hand pictorial archives act as evidential support for the story being narrated, and on the other, they provide confirmation of the accuracy of that story. ${ }^{67}$ Thus the visual representations of 
family within this photograph album have served as the means for keeping alive the narratives of the early lived experience of the family, and hence fostering a genuine connection to that colonial past. This is all the more remarkable, given that captioning, limited at best, was only added to the album in recent years. ${ }^{68}$

\section{The Dell family album: A portrait of a family}

The Dell family album opens with a group photograph of John and Eliza Dell and their children (fig. 63). ${ }^{69}$ This photograph was taken on the day of Catherine Margaret Dell's christening by the Rev. T.N. Blakiston at the small church of St John the Evangelist, located at Windermere, on 28 December 1902. After the christening ceremony had taken place, the Dell family was invited to the homestead of their late employer, E.G. Wright (1831-1902). ${ }^{70}$ Presumably refreshments were served, and, as it was the festive season, gifts may well have been distributed to the Dell children. (In the photograph the handsome craft young George Dell holds in his hands is suggestive of this. ${ }^{71}$ It can be surmised that while the Dell family was there, Wright's eldest daughter, Florence Wright, must have set the half-plate view camera onto its tripod in the garden and taken a group photograph of the family to mark the occasion. In this photograph, John Dell and his wife Eliza, with baby Catherine in her arms, are shown seated on a garden seat, with their two other younger children beside them, while their three older children sit at their parents' feet on a rug spread out on the grass. After this photograph had been taken, Wright may have felt there was some urgency to print a copy and present it to the family. What is worth noting in this instance is that, although probably not without precedence, Wright not only gave a copy of this photograph to the Dell family, but also presented a photograph album to them.

In her survey of nineteenth-century photograph albums, Elizabeth Siegel makes the point that an album was considered an appropriate gift for anyone, inasmuch as an album was regarded as a generic item, but, also one that could be easily personalized. ${ }^{72}$ What was unusual in this particular instance is that, when Wright made her presentation to the Dell family, she appears to have done so with the intention of contributing further photographs to their album. Although Wright may have felt she had an obligation to pass on a copy of the christening photograph to the Dell family without delay, there was no reason for her to furnish the family with a further 70 photographs over the following 18 months. As far as can be ascertained from examining the layout of photographs in this album, they have 
been arranged in the order that the Dells received them. From this supposition it may also be assumed that they were arranged in chronological order, commencing with the christening photograph taken at the end of 1902, which also establishes a firm foothold for the dating of this album. ${ }^{73}$

Once this process had been set in motion, Wright must have felt a need to continue. In taking such a course of action, she undoubtedly placed a considerable onus on herself to carry out this task. This brings into focus, once again, the amount of time demanded of anyone working as a photographer within the domestic sphere at this period and contemplating such an undertaking. This is an aspect not often taken into account in relation to the distribution of photographic images at this particular period.

\section{Description of the contents of the Dell family album}

Almost all the photographs Wright presented to the Dell family were of members of this family or some aspect of their life at Windermere. In other words, all have direct links with the Dell family and, apart from the initial photograph taken at the christening ceremony, offer a relaxed view of family life (fig. 64). ${ }^{74}$ The contrast is striking if we compare the composition of the christening photograph, in which members are dressed formally for a special family occasion, and subsequent photographs taken mainly in the yard at Windermere. It is possible to infer from this that, after this initial photographic session, the family had become more accustomed to the camera, and therefore more accepting of its gaze. Furthermore the Dell family may have actively co-operated in the act of picture making during subsequent photograph sessions. Among this collection of images, Wright has produced a sequence of quite delightful studies of the Dell children at play (figs 65,66 ). ${ }^{75}$ These images of the children, shown bare-foot with touselled hair, capture an essentially rustic view of rural life in New Zealand at the beginning of the twentieth century. Whether or not John Dell or his family had input into the original direction of the production of these photographs, it was Wright's decision as to which images she printed to pass on to the Dells. Therefore, it could be argued, Wright had executive rights over the contents of this album, and I believe she did indeed exercise this authority.

One of the ways in which this becomes evident, is that, even though both families were living in close proximity, and might be assumed to be in regular contact, there is almost a 
complete absence of images representing the Wright family in the Dell family album. ${ }^{76}$ From this it is possible to assume that, in her capacity as the authorizing agent, Wright understood the Dell photograph album to refer solely to the Dell family. Only photographs of the Dell family or of activities associated with them were regarded by her as being suitable for the album. Or, perhaps, and this is more difficult to ascertain at this distance in time, it is possible that these decisions reflect the difference in social standing of the two families at this date. To give one example: although Florence Wright had a comprehensive role in the selection of the album's contents she is not represented in any of the photographs contained within the album. Yes, there is a 'snapshot' of Wright leaving the church at Windermere after her marriage to William Morgan, on 3 June 1904, that has been placed at the end of the album (fig. 67). ${ }^{77}$ However, this photograph has been taken with a hand-held camera. The different format of this photograph and the fact that she is in it raises the possibility that it may have come from a source other than Wright. It is also worth noting a newspaper cutting announcing the marriage of Wright inserted next to this photograph by the Dell family. ${ }^{78}$ Additional published material concerning the Wright family also has been added by members of the Dell family over the years. This includes information on E.G. Wright, who came to New Zealand in 1857 to install the light in the Pencarrow lighthouse on the Wellington coast for the British engineering firm of Fox, Henderson and Company on behalf of the Wellington Provincial Government. ${ }^{79}$ The article indicates that, after this project was completed, E.G. Wright decided to settle in New Zealand permanently and went on to make a significant contribution to the Canterbury region in the diverse arenas of engineering, politics and farming.

\section{The significance of the presentation of photographs to the Dell family}

The presentation of an album of photographs to the Dell family by Wright also provides an example of how photographs can be received without recourse to reciprocation. The Dell family's position in life at this particular time precluded any possibility of an exchange in like kind. Although the presentation of the album can be understood in terms of a 'free' gift, however, the classification does not imply that such a gift will be unencumbered. ${ }^{80}$ In fact, John Frow, writing on the subject of gift-giving and its procedures, maintains, drawing on Lewis Hyde in support of his argument, that it is precisely the absence of any suggestion of return which endows what has been given with its authority. ${ }^{81}$ Belk expands on this point when discussing the influence of possessions in 
the concept of the extended self. ${ }^{82}$ When considering the presentation of items of significance to others, the identity of the donor will inevitably become associated with the object(s). Or, to put it another way, the object(s) will continue to be associated with the giver in the mind of the recipient. In other words, the donor retains a certain amount of influence over what has been given. When it comes to the distribution of photographic images, as Rose points out, this is likely to mean that the images will continue to have a connection with the donor as well as the person or persons pictured within the images. ${ }^{83}$ Thus, for the recipient, the photographs will have the capacity to represent more than the traces of those pictured within the actual photograph; they will also contain traces of those associated with their presentation.

Before commercial outlets were widely available for processing, photographs were usually processed with a printing-out frame. Such items produced within the domestic sphere would have been described at this time as 'homemade' items. ${ }^{84}$ An image, therefore, often held added significance for the person who received it, recognizing in it the time and care that had been spent in its production. This was most likely to be the case if the creator and donor was one and the same person as, for example, in the presentations of photographs by Kate Ivens and Florence Wright. Furthermore, depending on the circumstances in which they were presented, the emotional response they might induce could further intensify the affective value of the items. ${ }^{85}$

Many Victorians were, of course, remarkably receptive to these types of gestures and the many nuances they might engender, and deeply affected by them. In his opening statement in Given Time, Derrida offers his definition of the essence of a 'true' gift and how it should be understood. He explains, with reference to the morganatic wife of Louis XIV, Madame de Maintenon, how best to express this, by applying the analogy of giving of one's time to others, which is tantamount, in his opinion, also to a giving of oneself. ${ }^{86}$ Since such acts provide a reason for 'the giver and receiver to celebrate their mutual association', a permanent connection is likely to be forged. ${ }^{87}$ Thus, embodied within such an interaction there is the potential for creating an enduring bond between the parties involved. 


\section{Florence Wright and her legacy}

At the time she presented the album of photographs to the Dell family, Wright probably gave little forethought to the fact that, in doing so, she would be providing the family with a permanent material link to their early life at Windermere. However, what we do know is that, in recognition of Wright's presentation, the descendants of the Dell family have sought to keep her name associated with the photographs she was responsible for producing. ${ }^{88}$ The album of photographs produced by Wright secured a record of the past for this family, and also became a tangible means by which to connect them to that past. Those who receive something from others may also become beholden to them. By keeping Wright's name associated with the photographs, it is clear that the family has continued to acknowledge the gift they received. It is noteworthy that, when limited captioning was added to the album by the present family member charged with its care, a written statement naming Wright as the creator was inserted as an expression of appreciation. ${ }^{89}$ In future, therefore, anyone perusing this album will learn of Florence Wright and her photographs. Thus, the Dell family have formally recognized a gift that was made to the family more than a hundred years ago.

John Frow regards recognition of any kind as a form of return, explaining that this provides the opportunity for the recipients to give back a 'symbolic equivalent' to the donor, even suggesting that this type of response also constitutes an order of exchange. ${ }^{90}$ In relation to the Dell family, the circumstances in which the presentation was first made has since become linked to the family's history and the photographs produced by Wright recognized as her legacy to them. The early association, which began without any pretentions between Wright and the Dell family, is now embedded within a web of association of far greater complexity for this family.

As the time between the initial presentation of the album and its contents to John and Eliza Dell and family lengthens, its significance continues to increase for their descendants. For some members of the family, this photograph album has become an item of intrinsic value, comparable, to all intents and purposes, to an object of inalienable wealth. ${ }^{91}$ The intense interest of the family in the safe keeping of these images and the ongoing care of the overall photograph collection may explain their determination to retain such personal memorabilia within the family, at the same time accepting more recently that the album is potentially also of public interest. 


\section{The Dell family album as an object of inalienable wealth}

Until recently, the term 'inalienable wealth' has been employed almost exclusively in association with anthropology. However, as Carolyn F. Curasi et al. have demonstrated in their study undertaken in the United States, the term is now being extended to apply to everyday items of social and cultural significance. ${ }^{92}$ Curasi describes how certain items, regarded by families as irreplaceable possessions, perform an important role in providing a material trace of their ancestors. By providing evidence of the family's heritage, they perform a continuing role in shaping and sustaining memories, so important for upholding family solidarity. Furthermore, as Grant McCracken reminds us, there is a tacit understanding that, in assuming this role, whoever has been selected (or has elected) to take over the custodial duties of these items will be required to retain them on behalf of the group, and understand themselves as but temporary custodians during their lifetime. ${ }^{93}$

It also needs bearing in mind that some families possessing items of historical significance may be resistant to the idea of these items becoming part of a public collection. ${ }^{94}$ In more recent times, curators of public institutions have implemented policy changes which have finally opened the way for items of historical value that are held in private hands to be integrated into public institutions without compromising the integrity or the intrinsic value of the original items; for instance, by making facsimiles. As these changes have been implemented, custodians of family archives have become more confident in bequeathing their collections to public institutions in the knowledge that they will be made available to a wider audience, rather than sequestered for limited viewing. ${ }^{95}$

The photographs in the Dell family album provide an example of how items of personal significance can be successfully integrated into a public collection. In previous times, the suggestion of the album leaving the family's possession would have been unthinkable. Yet in 1996, out of recognition of the contribution these visual documents could make to a public collection, the present custodian of the Dell family archives allowed copy photographs from the album to be reproduced and accessioned into the photographic archives of the Macmillan Brown Library of the University of Canterbury in Christchurch. ${ }^{96}$ 


\section{Moving into the public sphere}

Those raising questions about the validity of accessioning archival material into public institutions have expressed concern at the considerable loss of meaning that items from private collections may sustain on entering a public archive. ${ }^{97}$ They argue that much of this 'so-called loss' comes from the physical removal of items from their original contextual placement when transferred from private ownership. Also of concern has been the restrictive nature of the archiving procedures that items from private collections must undergo in the process of acquisition into a public institution. This results in what Allan Sekula has described as 'an abstract equivalence' between individual items within a particular collection which often does not take into account the relationship these items had originally with other archival material. ${ }^{98}$

Although, this rather pessimistic outlook carries some weight, there is also good reason to take a more positive view. ${ }^{99}$ While it is true that the nature of acquisition is likely to remove the image from its former context, it can also be argued that the importance of these items being accessioned into public collections overrides any of these expressed objections. Rather than reducing their meaning, such acquisitions have the potential to further enrich our knowledge of the past by extending the range of uses these items go on to possess and the meanings they may accumulate. Such an approach towards items of archival value also acknowledges their capacity to add to our understanding of our history by recognizing the worth of privately-held documents as authentic records in their own right. There is increasing concern, also, for the greater good of these items on the part of custodians of family archives, recognizing the need for such items to be held in a place where they can receive appropriate conservation.

A positive outcome, not fully anticipated prior to the acquisition of the copy photographs from the Dell photograph album, has been the response to these images. Almost immediately, their subject matter was recognized to be of value to social historians at both a regional and national level. As Catherine Keenan states, we do not simply remember with the aid of photographs; rather, our perceptions of the past are often defined by them. ${ }^{100}$ The value of early photographs as a pictorial resource, particularly for local historians, is exemplified in the immediate interest in these images shown by Vaughan Wood and Tom Brooking, whose research lies in the area of early farming practices. Subsequently, for their essay in Rural Canterbury: Celebrating its history, 
released in 2001, they selected a harvesting scene photographed by Florence Wright at Windermere around 1904 as an illustration of such practices (fig. 68). ${ }^{101}$ Of even more significance for her future reputation, Wright was credited as the photographer in the caption which accompanied the reproduced photograph.

The acquisition of copies of photographs from the Dell photograph album by a public institution provides another example of how the Dell family through their actions, have continued to advocate for recognition on Wright's behalf. As a result of the public institution's acquisition, Florence Wright has progressed from being an almost unknown photographer working exclusively within the domestic sphere, to becoming recognized, following the publication of her work, as a photographer associated with the representation of social history. This has effectively redefined her status to that of a documentary photographer.

\section{Public recognition also for Kate Ivens}

Similarly, following the donation of Colenso's albums to public collections on Norfolk Island by her descendants in the late 1970s, these collections have become more accessible to the public. ${ }^{102}$ Added to this, the documentation of the two albums compiled by Colenso undertaken at the time of the donation has brought attention to individual photographers whose photographs within the albums have also been acknowledged. This has had far-reaching implications for women as originators of photographic collections within the domestic sphere. Take, for example, the preliminary research on women photographers in Australia from an historical perspective initiated in the late 1970s by feminist photo-historian Barbara Hall. ${ }^{103}$ As this research progressed, in recognition of the amount of original material being gathered and its significance, the project was expanded into a more comprehensive undertaking for which funding was sought. Subsequently an exhibition was mounted which included a selection of photographs taken by each of the 26 women photographers located for the project, and an accompanying catalogue was published giving biographical details. ${ }^{104}$

It was in the course of this undertaking that Kate Ivens' contribution to Elizabeth Colenso's albums came to the notice of these researchers reviewing the Norfolk Island Museum's photographic archives. Ten photographs from Colenso's second album taken by Ivens while resident on Norfolk Island in 1896 were selected to be reproduced for the 
exhibition. ${ }^{105}$ Among the photographs selected was the study taken of Ivens sitting on the verandah steps with members of her young writing class (fig. 61). Biographical information on Ivens was compiled for the catalogue accompanying the exhibition, thus bringing to public attention the work of Ivens and the photographs she produced concerning life on the Melanesian mission at the end of the nineteenth century. ${ }^{106}$

Official recognition of this type has had important implications for the future reputations of women such as Kate Ivens and Florence Wright as originators of photographic collections within the domestic sphere. As the authors of these collections, they have been accorded recognition they would not necessarily have received if the collections had remained exclusively in private ownership. Today their names are securely linked to the photographic collections they created. In addition, of significance for the development of women and photography in New Zealand, their names have also been added more recently to public databases compiled on New Zealand photographers. ${ }^{107}$ Thus, their names and their photographic work have become integrated into our photographic history.

\section{Summary}

Chapter Six has examined the act of sharing photographic images and how, through this apparently simple act, a connection is likely to have been forged, since such acts provide a reason for the giver and receiver to celebrate their mutual association. In the simple act of sharing with others and preserving their own visual history, the Dell family and their descendants have also secured recognition for Florence Wright and her contribution to photography. Embodied within such an interaction is the potential for the establishment of an enduring bond between the parties involved, as has been demonstrated by the example of John and Eliza Dell, and their descendants. Similarly, the act of Elizabeth Colenso's descendants in placing their albums in a public institution has brought wider attention to Kate Ivens and her photographic collections - recognition which otherwise might not have been given to her. As historical artefacts residing in the present, these pictorial collections have once more become permanently associated with the women who produced them more than one hundred years ago. 


\section{Chapter Seven}

\section{The domestic sphere and beyond}

\section{Introduction}

In this thesis the photographic practices of settler families have been investigated in relation to the production, organization and distribution of their photograph collections, with a particular emphasis on the photographic practices of the daughters of these families. What becomes evident when reviewing these practices is that groups where members share common cultural values have inherent social advantages. As outlined in Chapters Three and Four and demonstrated in the case studies on the Acland and Buckland families, the particular makeup of these groups brought beneficial outcomes for the overall cohesion for each group and for the individuals involved. Scholars specializing in the study of small group networks, including Paul Crosbie, confirm that groups made up of family members positively influence the dynamics of the group. ${ }^{1}$ Their assessment of these types of affiliations goes a long way towards demonstrating the value of family-orientated groups and why they appear to thrive in comparison with other social units.

Crosbie and others also note that the close working relationships which form within these small groups, and which have been shown to be so advantageous to overall group functioning, may eventually be the harbinger of their own demise. ${ }^{2}$ However cohesive a small group might appear to be, they are unlikely to withstand the effects of what are described as naturally occurring 'societal events'. ${ }^{3}$ Dyad and triad groupings, which describes most of the groups examined in this study, are identified as being particularly vulnerable, since any change in numbers can have adverse effects and compromise an ability to continue to function. ${ }^{4}$

Although the women surveyed in this thesis took their photography seriously, it was also an activity which could soon cease due to unforeseen changes in their life circumstances. In spite of the close working relationships initially forged between members of each family, which in several instances extended over a considerable period of time, in almost every case the groups eventually disbanded. ${ }^{5}$ This situation came about either from a 
single life event or from a gradual decline as a result of several contributing factors. Either way, these events had a profound effect on the group and its ability to function in the long term. The research also demonstrates how tenuous their association was with the photographic medium.

One example is the death of Lucy Acland in childbirth on 6 August 1903. ${ }^{6}$ This unexpected event brought to an end what had been a fulfilling working relationship among the Acland sisters throughout the 1890s and into the new century. In the aftermath of the sudden loss of their sister, Harriet and Rosa, as the surviving members of the group, apparently found it impossible to regain their former enthusiasm for photography without their sister's active participation, thereby demonstrating the crucial role of each member within the group.

A review of the working relationship established between members of the Buckland family also provides evidence of how a series of apparently unconnected events conspired to work against its continuation of photography. In this instance, the whole family took up photography as a recreational pastime in the early 1890s. The withdrawal of several members of the family in the following years appeared to have little effect on the group's overall functioning, so long as a working core remained intact. The withdrawal of their brother Harold, for instance, whose early supportive role within the group had been instrumental in its formation, had little effect on the group's continuation. If anything, the reverse was the case; his departure only served to encourage a closer working relationship between his three sisters, Carrie, Susan and Jessie. As I have already argued, this situation appeared to strengthen the girls' determination to take over greater responsibility for all aspects of their photographic practice.

The new century, when all three sisters were receiving recognition for their awardwinning photographic images, and therefore a time when the group was at its most highly productive, was also, paradoxically, the period coinciding with the group's decline. The three women, now all adults, chose to go their separate ways. Again, this has been identified as a potentially critical period for small family groups. Howard Nixon II has explained that, in these circumstances, the close social interaction identified as such a feature of the internal dynamic of a small family group can no longer be sustained, resulting in a gradual fall off in interest within the group. ${ }^{7}$ The eventual break-up of the 
Buckland family group was further complicated by their father's decision not to renew his lease on the farm at Taieri Lake Station in 1899, and to retire from active farming altogether. ${ }^{8}$ This effectively left his three daughters without a permanent home base for several years from which to practice their photography. Moreover, the prolonged period of uncertainty had additional consequences for the ongoing functioning of the group, prior to their father's subsequent purchase and possession of a small holding at The Glen, on the outskirts of the township of Akaroa on Banks Peninsula in 1901.

\section{Jessie Buckland's personal journey and the wider cultural context}

Chapter Seven will trace the personal journey of Jessie Buckland, from the time of her arrival in Akaroa in late 1902 until her decision to turn professional and open her own photography studio in the township of Akaroa in early 1907. ${ }^{9}$ It will review this five-year period in order to construct an understanding of how she was able to make the transition from being an amateur, working in close collaboration with her sisters within the domestic sphere, to being a professional photographer operating a commercial studio on her own account. My study will trace her progress over this critical period and outline some of the initiatives she undertook to establish her reputation as she came to realize the potentially rewarding life open to women deciding to make photography their chosen career. It will also examine some of the challenges faced by a single woman making the decision to go into business at the beginning of the twentieth century.

To a certain extent, the odds were stacked against her. At the turn of the century Akaroa was a town of fewer than 600 inhabitants. The photography studio of T.E. Taylor and Co. was well established, and had been ably serving the community for many years. Buckland was a recent arrival and therefore not known locally. Nevertheless, several factors worked in her favour. Although Akaroa was small, it was a popular holiday destination and an ideal location for anyone anticipating the potential for capturing the burgeoning market in the sale of postcards to tourists. Buckland was able to take advantage of the world-wide craze for postcards with the development of the 'real' photo postcard process, and began producing and distributing postcards through several outlets in the town. ${ }^{10}$ Working independently, she was able to create a much-needed cash flow to establish her business enterprise. She was moving away from operating exclusively within the private sphere and progressively moving towards the public sphere. In spite of her apparent reluctance to acknowledge the possibility of achieving success as a professional photographer, she 
assessed her situation and found it to be conducive to setting up a photographic studio and working as an independent operator.

Of the fifteen women who form this study, Jessie Buckland was one of only two who continued the pursuit of an early interest in photography following the dispersal of the small family group in which they had been situated. Similarly, Kate Wood, whose name has already been mentioned in conjunction with Kate Ivens in Chapter Six, went on to use the skills she had acquired as an amateur during a professional career.

Jabez Hughes, writing in 1873 in Photo News Review, pointed out that, even at this relatively early stage in the development of the photographic medium, most commercial establishments employed several women assistants. ${ }^{11}$ Naomi Rosenblum has added that women were especially valued for their careful approach to all aspects of the work they undertook within a photographic studio, and hence women with the right skill set were in continual demand in all aspects of this business. ${ }^{12}$ Although women in considerable numbers found employment within the industry, the majority of those who did so have largely been forgotten and thus remain unknown. Rosenblum argues that this is one of the reasons why the extent of women's contribution to studio photography during the late nineteenth century and into the twentieth has not been more widely acknowledged. ${ }^{13}$

Kate Wood is representative of the many women drawn attention to by Rosenblum, choosing to use the skills acquired as an amateur to make a living within a photographic studio. In the 1900s, Wood began working in the studio of the portrait photographer, Steffano Webb, located at 252 High Street in Christchurch. Webb was a leading operator within the city during the first half of the twentieth century. Beyond the fact that Wood was employed by Webb, however, little can be ascertained about her 30-year association with his studio. Even those who remember Wood have no exact idea in what capacity she was employed. ${ }^{14}$ As a result, like so many other women engaged in this type of work, Wood's contribution continues to be unrecognized.

Of the numerous women who found work within this rapidly-expanding industry, few actually owned these businesses. Once again Rosenblum's knowledge concerning this area of photographic practice is helpful. Her insights come from research undertaken almost exclusively within North America, yet have parallels with the situation in New 
Zealand at the same period. ${ }^{15}$ When I consulted postal directories compiled for this country in the first years of the twentieth century, for instance, of the more than 150 commercial photographic studios listed, only a handful are recorded as being run by women on their own account. ${ }^{16}$ Furthermore, when each individual case is investigated, one finds that, in nearly all instances, the woman named as the owner had originally entered the business in partnership with a spouse. This fact puts into perspective Buckland's achievement in becoming a long-term owner-operator at this relatively early stage. $^{17}$

Contemporary reports in photographic journals published in New Zealand, such as Sharland's New Zealand Photographer (which came into production in 1892 as a supplement to Sharland's New Zealand Journal), suggest that there were few social barriers to women in New Zealand working in this area of employment. ${ }^{18}$ In an article published by Sharland's in 1905, for instance, it is possible to infer from the tenor of the piece that there was even a degree of encouragement given to women seeking to take up the profession. Under the title 'Lady professionals', Sharland's pointed out to its readership that the photographic business offered worthwhile employment to women, stating: 'There is not an establishment in the colony which does not employ ladies in the reception room and also for retouching, printing and mounting ${ }^{19}{ }^{19}$ The article continued: 'although operating in the studio with the camera which has been for a long time reserved for men only, and who also have the monopoly of running the shop... in centres like Napier and Wellington ladies have for some time been proprietors of the studio' ${ }^{20}$

In her article 'What a woman can do with a camera', published in the Ladies Home Journal in September 1897, Frances Benjamin Johnston, who had successfully made the transition from amateur to professional photographer three years earlier, provided a realistic assessment for any woman contemplating making such a life decision. ${ }^{21}$ 'It goes without saying that any woman who enters this profession, must have the requisite training and all the necessary equipment'. ${ }^{22}$ Having thus begun her article, she continued: 'Before seeking out a suitable space in which to practice, she also should take into account the local demand for such an enterprise as this may influence the field of photography in which to specialize'. ${ }^{23}$ Above all, Johnston concluded, 'Any women considering taking on this profession, must be prepared to work hard' ${ }^{24}$ 
A carefully-composed portrait study shows Buckland at the time she opened her studio in Akaroa in 1907. She is depicted standing at the half-open window of the brick building which she had had converted into a studio and from where she practised for nearly 30 years (figs 69 \& 70). ${ }^{25}$ It was centrally located on Beach Road, behind what at that time was Alex Munro's shoe shop. This particular image of Buckland contrasts with earlier images from the albums of the three Buckland sisters in that Jessie is no longer role playing, but rather representing herself in her capacity as a professional photographer. Consummate actress though she was, by allowing her figure to be partially obscured by the window frame, represents herself as not entirely confident. Rather to the contrary. It is possible that Buckland was reluctant to take herself seriously. As pointed out in Chapter Four, she had often used a nom-de-plume when publishing her photographs before her arrival in Akaroa in 1902. ${ }^{26}$ This could indicate she did not want her photographic work to be confused with the work of her sisters, or it could be inferred that she had a preference for a degree of anonymity.

In their study of autobiographical representations, David Torrance and Nancy Olson make the point that these representations are extremely significant for the way in which we come to understand who we think we are. ${ }^{27}$ Further, as Jerome Bruner and Susan Weisser suggest, these types of images are of critical importance for indicating how people come to understand themselves in the particular role that they are representing. ${ }^{28}$ Such representations become lodged in our memory and create a sense of identification and individualization, becoming an important instrument in shaping and forming our personal identity. As Chalfen points out, the image produced provides essential feedback, in the sense that images of ourselves subsequently become 'us'. ${ }^{29}$ Nevertheless, selfrepresentations are made, not only for our own consumption, but also for the consumption of others.

As Leigh Gilmore argues in her extensive discussion of the representation of gender, it can be difficult for women to express themselves because in so many instances they have been socialized to see themselves only in association with others. ${ }^{30}$ So often this is how women experience identity, and therefore how they naturally choose to self-identify. They regard themselves only in relation to others, whether as a sister, a wife, a mother or a daughter. Rebecca Preston writes, in her study of women photographers working in Britain at the turn of the twentieth century, that this identity was frequently visualized 
within the confines of the 'home' environment. ${ }^{31}$ If this is still true today, as Gilmore would lead us to believe, then how much more so in the past, when women customarily sought to express their identity through relationships, rather than through their individual autonomy. Gilmore concludes that self-representation as a site of identity production for women continues to be a complex and topical issue. ${ }^{32}$ This is due to the lack of suitable role models for women.

One of the reasons why women within Victorian society found amateur dramatics so appealing was the way in which acting allowed them to portray roles not ordinarily open to them. Buckland, of course, is not specifically acting out a theatrical role in the photograph taken at the studio window, but representing herself as a professional woman in which the photographic image has a prominent role in the expression of her personal identity. The manner in which she is presented, standing framed within the half-open window, tends to act as a barrier to a full and unobstructed view of her. This suggests a degree of reticence in a situation where she is probably out of her immediate comfort zone. As in the portrayal of J.B.A. Acland, it becomes apparent that additional textual information needs to be incorporated within a pictorial frame in order to establish the meaning the photograph is intended to signify. In this particular instance it is made manifest through the sign 'PHOTOGRAPHIC STUDIO' written in large block letters, which works in conjunction with the figure of Buckland shown holding a printing out frame. In this case the sign informs the viewer what the photograph is empowered to signify.

\section{The Akaroa period}

Following a period of three years employed as a teaching assistant at Otago Girls' High School in Dunedin, Jessie Buckland joined her parents, who were already residing in Akaroa, in the second-half of $1902 .{ }^{33}$ However, unlike her previous photographic experience working in close collaboration with her sisters Carrie and Susan, Jessie began working entirely on her own account. Susan was now married and living in South Canterbury, and Carrie was occupied with running a small private school she had opened in Akaroa. ${ }^{34}$

Even at this early stage, Buckland appears to have made a conscious decision to move away from photographic subjects based on themes drawn from historical and literary 
sources, as in the work made in the company of her sisters Carrie and Susan. The focus of her attention from now on would be scenes drawn from her new surroundings. In taking this step, she was apparently signaling the chosen direction she wished to pursue in her development as a professional photographer. The first images produced by Buckland from the Akaroa period were mainly taken from the waterfront below the family home at The Glen, looking out across the bay, towards the township of Akaroa (fig. 71). ${ }^{35}$ Over and above the obvious decision to draw on local scenes in her photographs, Buckland also identified certain activities to record which were of specific significance for this region. One such activity, the picturing of which gained her almost immediate recognition and a photographic theme she made her own, was the harvesting of cocksfoot for grass seed.

The harvesting of cocksfoot seed was an important cash crop in this region of New Zealand at the turn of the century. From early in 1904 Jessie Buckland began taking photographs depicting the whole operation of harvesting cocksfoot. These photographs documented each stage in the process, which took place each year over a four to six week period from late January. Most of the photographs were taken on her brother, Harold's farm at Wainui, across the harbour from Akaroa. The photographs began with several scenes of hand harvesting the grass by a team of croppers (fig. 72). ${ }^{36}$ In one photograph, Harold is shown with a sickle in his hand in the paddock, ready to begin harvesting the ripened grass (fig. 73). ${ }^{37}$ The best-known photograph from this initial series of images is that of Fred Keagan's bullock teams, with their wagons piled high with filled sacks of seed, making their way along the waterfront towards the Akaroa wharf for loading onto a waiting steamer (fig. 74). ${ }^{38}$ It was this image which brought Buckland's photographic work to local and national attention.

A selection of half-plate images from this series, featuring each stage in the process of cocksfoot harvesting, was chosen to form part of the pictorial display for the Banks Peninsula Court at the International Exhibition held in Christchurch over the summer of 1906-7. ${ }^{39}$ Significantly, Buckland's father, involved in local government until 1908, was a member of the committee responsible for selecting material for the Banks Peninsula exhibit. $^{40}$

During these initial years in Akaroa, Buckland also continued her earlier practice of sending photographs to photographic competitions organized by newspapers and journals 
especially for serious amateur photographers. Buckland and her sisters, Carrie and Susan, had enjoyed outstanding success in these competitions, particularly in the Australasian during the last years of the 1890s. In early 1907, for instance, immediately prior to turning professional, Buckland had entered a photographic competition organized by the Auckland (Herald) Weekly. For this competition, entrants had to submit a folio of six previously unpublished photographs. Buckland's entry, for which she received the first prize overall, comprised a selection of photographs she had taken of the cocksfoot seed harvesting, including the image of Keagan's bullock wagons. This image was also reproduced in the Weekly on 23 May, 1907 with the caption: 'The patient bullock team: Produce wagons ready for the road at Akaroa, South Island'. ${ }^{41}$

Publicity of this kind also brought Buckland's photographic work to the notice of the Department of Tourist and Health Resorts in Wellington, which had been established in 1901 by Sir Joseph Ward, the then Postmaster General and the minister responsible for tourism within the Ministry of Industries and Commerce. ${ }^{42}$ The department's chief focus at this initial stage, under the directorship of T.E. Donne, was the promotion of New Zealand overseas. An important aspect of this promotional work was the preparation of suitable pictorial material. Photography was to play an integral role in this business. While the department commissioned several photographers to travel to specific locations to take photographs of interest to tourists on its behalf, departmental representatives also regularly travelled the country, seeking out images from local photographers to purchase. ${ }^{43}$ During the $1900 \mathrm{~s}$, representatives from the Department of Tourism visited Akaroa on at least two occasions, and each time purchased a selection of Buckland's photographs for future publicity purposes. ${ }^{44}$

In addition, Buckland began the process of reformatting several of her photographic images so they could be reproduced to regulation postcard size. Particularly well-received was her image of the bullock wagons bringing the bagged seed to the wharf at Akaroa. As a result, almost in spite of herself, Buckland was progressively moving from working exclusively in the private sphere to functioning more consistently in the public arena. In so doing, she was making the transition from amateur status towards recognition within the community as a professional photographer. Through each of these small acts, she was eventually able to transform what had been a recreational pastime with her sisters into an enterprising business with all that such a development would entail. 
As noted, Buckland's arrival in Akaroa coincided with the phenomenal rise in popularity of the picture postcard industry in New Zealand. From the introduction of the first postcards in the mid-1870s until the early 1900s, the Post Office held a monopoly over the production and distribution of postcards within this country. ${ }^{45}$ With the introduction of the photographic postcard, or the 'real photo' postcard, however, the local postal authorities recognized, as in other countries, that they could no longer deny independent operators the right to produce their own cards. As a result, the Post Office relaxed its control, thus taking postcard production away from large commercial operations to allow for more localized production to take place. Alan Jackson, reviewing the situation in New Zealand at this period, makes the point that the manufacture of postcards became an important aspect of photographic production in this country in what was considered the heyday of the postcard, from the early 1900 s until World War I. ${ }^{46}$

The Eastman Kodak company was at the forefront in facilitating developments in the production of 'real photo' postcards world-wide. In 1903 Kodak introduced a hand-held camera which incorporated, as a standardized feature, a film negative that was the same dimensions as the regulation postcard. ${ }^{47}$ Although, as I pointed out in Chapter One, Kodak had not yet established an outlet in New Zealand at this date, cameras, such as their $3 \mathrm{~A}$ folding camera, could be purchased through agencies such as Sharland and Company in Auckland. ${ }^{48}$ In addition, Kodak had also developed a card that was both durable and affordable, the front side of which was chemically sensitized to accept a contact negative photographic print with a customized pre-printed back, thus facilitating the production process. Further developments soon followed, including a camera featuring a combination back with a glass plate adapter for the production of images to the correct size.

What is particularly salient here, with regard to small operators such as Buckland, is that although costs were involved, no large outlay in equipment or materials was required for those producing postcards by the 'real photo' process. ${ }^{49}$ These developments opened the way for keen amateurs with the right skills to produce their own cards and distribute them through local outlets. In her study of postcard production by amateur women practitioners living in England during the early years of the twentieth century, Rebecca Preston suggests that such production should be recognized as a significant aspect of women's 
visual cultural production during this period. ${ }^{50}$ The introduction of the 'real' postcard found particular currency among women, at the height of its popularity encouraging those women who were already photographers to become involved in postcard production. In Preston's opinion, this brought these women a sense of agency over the entire process of the production and distribution of the postcards they produced and accounted for a significant aspect of women's visual cultural production in the years before World War I. $^{51}$

Within a relatively short space of time Buckland was producing an ever-increasing number of photographic images for distribution as postcards. In most cases the postcards produced at this early period were franchised through selected retail outlets within the town and beyond. This developed into a sophisticated commercial operation as the popularity of postcards grew during the 1900s. Postcard production became a significant aspect of her output as a photographer during these years and central to her viability as a small-time operator. Geoffrey Orbell, her nephew, remembered stopping off on his way to Akaroa at the hotel at Hilltop where a selection of his aunt's postcards was always available for sale. $^{52}$

Before procuring a film camera designed specifically for this purpose, Buckland had been reproducing a selection of her half-plate photographs for distribution as view cards. Copies of these images Buckland subsequently tipped into her photograph album make it possible to follow her progress over this critical period. Although a larger format than the regulation postcard, these first view cards may be understood as prototype postcards, suggesting, even at this early stage, a firm intention to extend production beyond a cottage industry.

The first of the view cards Buckland produced was inscribed with the letter ' $\mathrm{B}$ ' directly onto the glass negative and therefore before printing had taken place. As an example, the early photograph taken from below the family home at The Glen is inscribed with a capital 'B' on the lower right (fig. 75). ${ }^{53}$ Soon, she also included a title in her caption. On an image dating from 1903, for instance, she inscribed, in addition to the capital 'B' on the lower right, the identifying title of 'Akaroa' on the lower left (fig.76). ${ }^{54}$ Her titles became progressively more specific. On the undated view of Akaroa, taken from Rue 
Jolie, she has inscribed 'Jolie St Akaroa' on the lower left of the image and once again the ' $\mathrm{B}$ ' for Buckland on the lower right (fig. 77). ${ }^{55}$

Sometime in the period 1905-06, Buckland seems to have realized that, if she was to continue working in this area and capitalize on her progress so far, it would be necessary to take a more professional approach and invest in a film-camera, purpose-designed to facilitate in the production of postcards. This change can be observed in the way in which she addressed other aspects of their production. One clear indication is the attention she now devoted to the way in which she inscribed her images. From this period on she did so with her name in full and a title, and also included the word 'protected', required by law to recognize a photographer's copyright over an image. Copyright laws had been passed in New Zealand in 1896 and were expressly designed to give photographers certain rights over their images. ${ }^{56}$ It is for this reason, the date of first distribution and copyright was also usually applied.

Also, it was from this time that Buckland began selecting certain photographs taken previously and began resizing them to conform to the specifications of the postcard pictorial format. In August 1906, for example, Buckland reproduced her by now wellknown image of 'Bullock Waggons' [sic], from her series of scenes on cocksfoot harvesting taken with her half-plate camera, and reduced the image to the smaller standard postcard format of 3 x 5 inches (fig. 78). ${ }^{57}$ Buckland probably reformatted this image in anticipation of successful sales at the International Exhibition held in Christchurch over the summer of 1906-07. As has already been mentioned, a selection of Buckland's cocksfooting images were to be on display at the Banks Peninsula stand. ${ }^{58}$

Initially her postcards were limited to scenes of Akaroa and nearby environs. Soon, in order to enlarge her inventory of suitable images, Buckland introduced a selection of images she had taken previously in collaboration with her sisters during the 1890s. These she requisitioned, resized and reformatted to the required size. The best known images reproduced as postcards from her earlier period in Central Otago included 'Coming Thro' the Rye, Akaroa' taken in 1897 (fig.79) and the pastoral scene of sheep being driven through an open gate taken in 1899, formerly entitled 'Evening, June', now reprinted and issued as 'Sunset'. ${ }^{59}$ In her selection she also included anecdotal subjects such as, 'Why the mail bag was late?' taken in the same year (fig. 80). ${ }^{60}$ And although these scenes were 
not photographed in Akaroa, Buckland chose to inscribe them as if they had been photographed locally. This fact demonstrates some of the liberties she took with captioning and how in such ways she also set out to misinform or misrepresent.

This brings us to consider, once again, the role words play in relation to visual images. The caption's principal role may be to provide meaning, or as Barthes states, to anchor the image or to relay a particular message. ${ }^{61}$ The captioning of photograph albums was usually for a limited audience. Therefore, as Susan Stewart points out, captions within the context of a closed network may appear to be almost redundant. ${ }^{62}$ In the case of the postcard, which is intended for public consumption, the caption has an integral role and is an accepted part of its presentational form. As Robert Bogdan explains, the permanent text on the picture side of the card has become one of its defining features. ${ }^{63}$ This is a process which entails imprinting the caption in reverse in dark ink on the lower edge of the negative so as not to interfere with the image. An inscription made in this way becomes permanently laminated on to the emulsion side of the negative and, when printed, resulted in a clearly legible caption in white lettering on the finished postcard.

By this means, the producer of the postcard can impose editorial rights over the caption at the time of production, limiting any further interpretation of an image. The caption, therefore, is usually accurate, since its primary function was to securely anchor the meaning of the photograph at a denotational level in order to counter the potential for any future uncertainty. ${ }^{64}$ As a result, unlike photographs in an album, which can be subjected to additions or erasures, a postcard's caption is less likely to be interfered with. If there is to be any conflict in relation to inscriptions on the postcard, this almost always arises when a message is added on the reverse side of the postcard by the purchaser.

A sample of the messages written on the backs of postcards produced by Buckland from the collections in the Akaroa Museum suggests what is more likely to be the case. Rather than additional messages being in conflict with the original caption, the messages written on these postcards often supply additional information with the intention of initiating further storytelling. Certainly, a case can be made for the caption on the front side of the postcard to be understood as a starting point for directing the personalized messaging of the sender written on the back. A case in point is a comparison of the inscriptions on the front and back of a postcard produced by Buckland in December 1907 illustrating the 
annual regatta at Akaroa. On the front is a photograph of crowds attending the festivities gathered on the wharf at Akaroa. On the lower front of the postcard, Buckland has recorded the title 'Regatta Akaroa' and the date the photograph was taken and copyrighted (fig.81). ${ }^{65}$ On the back of the postcard, however, the purchaser of the postcard and in this instance, also the sender, has added his own written comments (fig.82) ${ }^{66}$ The regatta is not referred to at all by the writer. (Presumably he/she was not present at the time of the event.) Having said this, the purchaser chose this particular postcard from those available for a reason. In this case, the pictorial image on the postcard acts to introduce the message on the reverse.

The message reads: 'Wharf in Akaroa where we spend a lot of our time. Saw a big conger eel \& a skate caught off here last night but we only caught one cod. Cannot get any pipis here only mussels $\&$ they are not any good. The people that had the luck baited [their hooks] with pipis from town'. The person forming the message on the postcard has needed to replace the collective experience, inscribed at the time of the postcard's production, with personal comments. This clearly demonstrates a desire to share personal experiences with friends and family.

Is a postcard an item of public consumption or private communication? Walter Benjamin argues that the process of mass-producing photographs for public consumption reduces their uniqueness because it takes away the 'aura' of authenticity from an art object. ${ }^{67}$ This assessment overlooks any appreciation of the social processes that can take place once a mass-produced object such as a postcard is purchased. Accordingly, the following section of this chapter will concentrate on investigating what postcards do while in circulation. Central to this discussion will be the identification of the specific processes they may prompt between the sender of the postcard and the receiver.

It is important to note, as Stewart reminds us, that, although a product of massproduction, the postcard leaves the commercial sector at the time of its purchase and enters the private sphere. ${ }^{68}$ Speaking from her own experience, Stewart found that the postcard as a souvenir of place also carries with it an implicitly private experience for the purchaser. In this way, the postcard becomes something that it previously was not. She recounts how this is made manifest. ${ }^{69}$ First, the postcard is purchased. Next the purchaser vests in it their own personal experience by the act of handwriting a message alongside 
the more social caption. Then, in a gesture of giving, by which the subject is positioned between the places of production and reception, the postcard is sent to a significant other. This also validates the experience of the writer at the site of encounter at the time of its purchase. Therefore, the postcard can no longer be said to be representative of a massproduced item of sale. Rather, as a result of this action, it has become an item purchased for private consumption. This emphasizes the way in which the purchaser is not necessarily dependent on the generic title of the producer, but can also provide the point of view of the individual. In this way the postcard is subject to a well-understood set of social practices. The principles which formerly governed the economic exchange value of this item will now be suspended and replaced with other values associated with more subjective motivations.

Once it is realized that visual materials such as postcards can be examined as commodities or viewed as materials removed from intended exchange into private possession, it becomes apparent that these distinctions will also have implications on how these objects are assessed and the social life of an image is documented. What matters in such cases, as Gillian Rose stresses, are the specific affordances of these items as they become mobilized and the social practices associated with visual objects as they travel into domestic spaces. ${ }^{70}$

So far in this thesis the focus has been on what are termed 'non-commodity circuits' of the visual economy. Images circulating in these spheres are almost entirely produced and consumed within domestic spaces. The final section of Chapter Seven will investigate what mass-produced images, in this case picture postcards, do as they circulate; that is, it will consider the specific social effects pictorial items may attract as they travel from the public spaces in which they were purchased to the domestic sphere in which they find personal meaning. Once purchased, the postcard, which began in the commercial world, passes into private hands. Here, the principles governing economic exchange are replaced by other values drawn from subjective motivations. They may also develop an interior significance or sentimental value, which gifted items so often come to possess. The many forms and directions in which photographs are sent travelling, and the various spaces in which they may come to rest, places the focus on the practices which made them mobile. A significant part of this process depends on the specific places where they are 
encountered, since these can make a difference to their performance and also determine the effects that may result from such performances.

When objects circulate, Arjun Appadurai and Igor Kopytoff observe, they inevitably become something different. ${ }^{71}$ The postcard is a perfect example of how photographic images can move effortlessly from one context to another. It is as if they become recontextualized as they morph from one use to another. In the course of this change they are transformed from one context to another. Viewing the movement of postcards in terms of a visual economy is a useful way to gain an understanding of them as items of mobility, as they weave beyond the public sphere in which they were distributed and into the domestic sphere. One can further extend the framework of study to include the public spaces from which they emanate and the domestic spaces in which they will subsequently come to reside. Certainly, if the postcard is to be fully understood, there is a need to take into consideration their consumption as well as their production, including taking into accounts the effects these changes might also illicit.

Assigned different roles to perform as it moves away from the point of production, a postcard can be looked at differently, and can also appear to be different. Shifts in ways of seeing are influenced by where visual objects are encountered. In this respect, postcards can take on many of the properties of other forms of visual media circulating in the domestic sphere. For this reason, they may require consideration in relation to other forms of photographic representation which to date have been left out of discussions. Considering such items as visual commodities that are bought and sold, and then circulated, allows for a more expansive analysis than might otherwise be possible. This then provides a better measure of the rich diversity of certain material objects, and of the forces shaping them, as well as a better appreciation of the correspondences between them as they circulate.

In Doing Family Photography, Gillian Rose draws attention to the similarities between the uses of family photographs and emails as objects of communication. ${ }^{72}$ As they move within private spheres, both family photographs and emails can elicit similar displays of attachment, making them both representative of that special category of visual item which elicits feelings of closeness, and which are motivated by the initial desire to share. Rose's analogy provides a helpful way to consider postcards. ${ }^{73}$ Similar to the family photo or the 
email with a pictorial attachment, the postcard is an item of communication specifically designed to have a diverse journeying function, a function that is personal, but also carries with it an emotional component. The function of postcards, therefore, has parallels with the function of family photographs. When such items circulate to family and friends, they are communicating personal information with the intention of maintaining links between people. As part of their activities they are also sent within recognized social networks as an act of reaching out to make contact with those who are known to us and are sent to family and friends elsewhere as a way of keeping in touch. Picture postcards, therefore, need to be included as a vital part of this culture enacted within everyday visual practices associated with photography.

Rose's study of housewives in South East England demonstrates that the process of sending and receiving family photographs, first and foremost, comes from the intrinsic need to communicate with loved ones. ${ }^{74}$ As with the sharing of family photographs, sending postcards to others stems from a desire to share personal experiences and is also directed towards a limited, but clearly defined network of people. The act of sending and receiving photographs, as with other forms of communications within the boundaries of a closed social circle, is seen as a way of keeping in touch. Furthermore, the sending of photographs to another family member or a close friend can be understood as demonstrating a desire to continue to bond within a pre-existing relationship. When used in this way, the postcard may also assume a role that the producer may not have necessarily foreseen.

John Tagg points out that, although photographic meaning is partly determined at the moment of production with reference to choice of subject matter, meaning is also extensively influenced by the particular situation of its reception. ${ }^{75}$ Postcards are not only sent, but also received. Chris Barker has written extensively on how such transactions can be enacted. ${ }^{76}$ Rather than passive recipients, in Barker's opinion, consumers should be regarded as active in this formation of meaning, and as such that the moment of consumption is also a moment of meaningful production. The act of consumption brings a sense of completeness. In this way, Paul du Gay concludes, the circle of production and consumption is brought full circle. ${ }^{77}$ Moreover, the textual entity added to it as another way of keeping in touch may also induce a variety of 'affects'. 
As has already been established, 'affect' is a complex term which has quite distinct origins. Rose goes to some lengths to emphasize the importance of emotion and feelings in relation to family images as a social practice. ${ }^{78}$ An inherent quality of family photographs is the capacity to engender deeply felt conditioned responses in the beholder. Although researchers may have few facts to go on, the responses they observe can be described as patterns of evidence which can be evaluated in relation to other information available. David Sanjek, for example, explains how texts and artefacts connect with our lives, emotions and assumptions, and produce certain effects. ${ }^{79}$ For these effects to take place, the information has to be interpreted as authentic by the recipient. ${ }^{80}$ Although the postcard does not normally incorporate displays of the indexical presence of other family members within the image, it incorporates the trace of the person who has done the sending. In his studies in relation to possessions and the extended self, Belk says that one of the valuable functions of items sent '... is that they also become associated with the sender and with it their identity is extended to include the recipient who retains an identity with the object as a self-extension'. ${ }^{81}$

These similarities may carry over to other aspects of these closed networks. Nor can the impact for the recipient receiving a message through the post be overestimated. Of significance here, and also a powerful motivation for sending photographs to family, is that the very act of thinking of them when they are not present is an important aspect of the articulation of family relations. In this gesture, which recapitulates the social articulation of the self, the postcard as gift surrendered to a significant other carries the feeling of being remembered in one's absence. This flatters the self's capacity to generate worthiness when someone we know remembers us when they are away from us and wants to share their experiences. This is what marks these messages as noteworthy events within human experience.

In the context of a contemporary craze for postcards, the sending of a postcard in the late nineteenth and early twentieth century would have heightened its novelty value, further intensifying responses in the receiver at this period. Thus, like the family photo, the postcard celebrates close associations, precisely because of its references to people we know. Although of little material worth, once sent to a recipient, the postcard becomes an item of interior significance or sentimental value. The postcard, once received, assumes a role that the producer of the postcard may not have foreseen, a role that embodies within 
it an emotional component. What is invested in these objects, and a significant aspect in the actual motivation to send them is in the anticipation that they will be received in a like manner. It is these meanings, which the recipient then associates with a particular item that may result in it being pulled from circulation, at least for the lifetime of the owner.

\section{Summary}

Chapter Seven began by looking into reasons for the eventual breakdown of what had been a successfully forged and apparently close working relationship between sisters, which in some cases had lasted over many years. It also outlined how several of these women went on to use the skills they had acquired while working in the domestic sphere to make their living in the commercial sector, in particular Jessie Buckland, who had already received recognition as a photographer. This chapter recounts her early attempts as a producer of postcards. This proved to be sufficient incentive to open a commercial studio in the township of Akaroa. The chapter also traces the development of the postcard within New Zealand at this period. As with photographs, the culture of postcards is subject to a well-understood set of social conventions, including a specific set of integrated practices and involves knowledge of well-defined ground rules in which they are embedded. 


\section{Chapter Eight}

\section{Conclusion}

In this thesis I have examined the photograph albums created at the turn of the twentieth century by women living in the Canterbury region of New Zealand. These photographic collections originate within the provincial landscape, and represent a significant form of feminized visual culture. My intention has been to raise awareness of the value of visual items produced within the private world of the family, and to acknowledge their unique contribution to the photographic medium at a formative period in this country's history.

Within New Zealand, the study of women and album-making from an historical perspective has attracted little interest. In other parts of the world, however, this form of photographic practice has been increasingly recognized as a significant subject of investigation, especially by those who understand the importance of orientating studies around personally produced cultural artefacts. This body of research has been instrumental in the development of a deeper contextual understanding and approach towards the analysis of the photographic collections of the women in my study, placing particular emphasis on the social and cultural practices associated with the production, organization and distribution of their photographs. The separate studies of Richard Chalfen and Gillian Rose on family photography have been significant providing a suitable framework in which to situate the present analysis and in shaping the direction of my discourse. ${ }^{1}$ Rose gave a detailed account of women's photographic practices. Chalfen's work also sheds light on the way in which the women's experiences would have influenced their engagement with the photographic medium as a means of expression, learning and communication. His knowledge of immigrant groups, for instance, has been crucial in helping develop an understanding of the concerns of the women in my study, whose attitudes and expectations in life would have been informed by the wider narratives of the British Empire. ${ }^{2}$ 
Throughout my extensive investigations into the production of family photographs, I have emphasized the important role photography performed for these settler families as they ventured to make new lives in this country. In developing my discussion, I have endeavoured to show how these visual representations, which celebrate the family grouped together mediated through the domestic spaces in which they were constituted, have provided essential visual feedback for settler families. These photographic images, then, foster in them a sense of connection to their surroundings and maintain a sense of continuity while they go through processes of social change and transformation. And as I have also demonstrated the ways in which they also came to define themselves in terms of the photographic medium. The photograph of the Stoddart family of Diamond Harbour, for instance, gathered on the front verandah of their home taking afternoon tea, illustrates how these colonial families employed photography as a means through which they could express their social standing within colonial society (fig. 2 ). ${ }^{3}$ More significantly for this study, the images have become the means by which they reveal themselves to us, and thereby how they can convey an understanding of their world.

My investigations reveal that, by the mid-1890s, when many of the images in this study were taken, photography was already a recreational pastime in many of these settler families. Furthermore, it was a practice which had become integrated into the activities associated with their family gatherings. In looking closely into these practices, it is found that it was often the women, usually working in collaboration, who were most involved in the organization of these occasions. Moreover, if the women were not directly responsible for taking the photographs, they were likely to be engaged in overseeing the photographic operations. It is important, therefore, to investigate the circumstances which characterized the gendered nature of domestic photography at this period, and what it was that distinguished these small family groups, practising so productively within the confines of the home environment, from other social units at this time. Thus it is possible to come to a better understanding of how these women came to assume the position of designated cultural and social producers within the family circle.

Beyond examining the patterns of engagement relating to the production of family photographs and establishing the significance of these practices for settler families, my thesis has also investigated practices associated with the organization of these photographic images in photographic albums, and their distribution to family and friends. 
Certainly, if the practices associated with family photography as a gendered activity are to be adequately evaluated, it is necessary to develop an understanding of what happens to photographs following their production, so as to establish the role the women in these families performed in their care of photograph collections. Of particular significance has been the need to determine the important social and cultural functions carried out through the distribution of such photographic images, their capacity to elicit certain conditioned responses from their audiences, and their role in the generation and recovery of meaning.

The study of photograph albums has been responsible for drawing attention to their value as a significant material resource within photographic discourse. Chalfen's work, for instance, demonstrates the advantages of examining photographs within an album, and how this can enhance our understanding of such collections, especially when other archival material is limited, as is the case for most of the women selected for this study. ${ }^{4}$ At the same time, while Chalfen's work on albums provides an important precedent to my discussion of album making in colonial Canterbury, his approach also reflects a widespread reluctance to engage in a close analysis of the narrative structures employed in the presentation of images within such photograph albums. By contrast, I have argued that in order to develop a fuller appreciation of the meanings that album makers impose on their images an understanding of narrative structures must be an integral part of the study of such pictorial material.

As explained in Chapter Five, undertaking such a study has entailed developing a suitable method of approach beyond previous contributions in this area of visual culture. This included the otherwise fertile method developed by Martha Langford. It has led me to seek alternative forms of analysis. ${ }^{5}$ Of significance in developing this discussion on narrative structures has been the examination of those already active in the field of literary discourse. Here the findings of folklorist Susan Stewart have been highly formative. ${ }^{6}$ Stewart's work on narrative structures has offered a constructive way to engage in a critical analysis of the organization of material in other genres, including photograph albums. Using her approach has enabled a productive evaluation of some of the more frequently occurring narrative structures employed by album makers in the arrangement of images in photograph albums, providing insights into the working practices of the women selected for this study. This also expands our understanding of their album making. Ultimately, this has led to a comprehensive review of album making 
practices as a significant mode of visual expression, and a better understanding of their usage by album makers in the organization of their pictorial material.

As noted in this study, women were closely associated with the practices allied with the distribution of photographs within the domestic sphere. As Rose outlined in her comprehensive studies of contemporary practices, this activity has been and is customarily confined to immediate or extended family networks. ${ }^{7}$ Putting aside developments in methods of communication, her studies demonstrate how remarkably similar such practices are to those carried out by the women in this study at the turn of the twentieth century. My case studies of the Buckland sisters, for instance, have provided the opportunity to consider image-sharing practices within the home environment of small family groups as a significant aspect of photographic practice. As I outlined in the discussions developed in relation to the production of the photograph, 'Coming Thro' the Rye,' the images the sisters worked on together were also freely shared within the group. Furthermore, on examining each sister's photograph albums, one discovers that copies of these images found their way into the personal collections of all three, sometimes in duplicate. As Maggie Humm concluded in her survey of the albums of the Stephen sisters, this indicates how important certain images were for the whole group. ${ }^{8}$

The survey of the practices of the Buckland sisters also provides evidence of imagesharing beyond the immediate family. In undertaking my study, I examined the mutuallyproductive exchanges between members of the Buckland and Hocken families during this period. Particularly noteworthy are the exchanges that took place between the sisters Carrie, Susan and Jessie Buckland and their aunt Bessie Hocken, who had been formative in encouraging an interest in the photographic medium in her young relatives. Moreover, on reviewing the nature of these exchanges, it is found that the images they chose to circulate within their extended family were images celebrating the family, emphasizing how important it was for these families to acknowledge family ties.

This study's close consideration of the circulation of photographs as objects of social exchange also has led to a comprehensive understanding of the history of these photograph collections up to the present. In this context, making contact with the current custodians of these family archives has been vital in forming an understanding of recent interactions with their family photographs. From these custodians I have learned that the 
real value of their collections has been to provide tangible means by which their descendants are able to connect to their colonial past. Photographs which originally served as an evidentiary record for their pioneering forebears now offer the present generation a means of keeping alive the narratives and early experiences of these families. The custodians indicate that, although the images are important because of what they represent, the circumstances surrounding their provenance are no less significant. In their experience, this could intensify the connection felt towards these items. In addition, custodians also raised their concerns for the future of the albums in their possession. For instance, they were highly aware of the fact that these collections were becoming of increasing historical interest.

In reviewing the albums selected for this study, I find there has been a progressive movement of private family archives into public collections. ${ }^{9}$ Critical attention, therefore, needs to be given to the underlying reasons that such transfers occur, highlighting why families with heritage items come to these decisions. These developments highlight the continuing transfer of photographic images into settings beyond the family. Although these images remain pictorially the same, they almost certainly acquire additional significance as they assume new roles, reminding us that, while the meaning of an image is partly determined at the moment of production, that attribute is by no means all of its history. An image's meaning is better understood as evolving through real time and social space, continually being negotiated, and likely to be subjected to the influences of history, culture and power. This, then, puts paid to any notion of a constant reading for any visual image. Rather, it demonstrates the absurdity of even contemplating this idea. Of course, this is precisely what makes family photography such a fascinating genre and why, as an area of research, it is increasingly recognized as an infinitely rewarding field of study.

\section{One final note}

In undertaking research into the photograph albums of women from the Canterbury region at the turn of the twentieth century, my aim has been to acknowledge the unique contribution of these women to the photographic medium at a formative period in New Zealand's history. My hope is that this endeavour will in some small way contribute to the growing body of literature recognizing the photograph album as an important object of study in the recovery of women's history from the colonial period, thereby giving these women their rightful place within the history of photographic discourse. More broadly, 
my intention has been to bring to wider attention the early collections of photographs of New Zealand colonial life and to underline their importance as a pictorial resource for historians active in the area of New Zealand social and cultural history. My research suggests there is a degree of urgency for studies such as this one, but extended so as to include women photographers from other regions of the country. Such an undertaking would enhance history's purview of what can only be, at present, a limited understanding of the extent of the unique visual legacy left to us by these women, born into the age of Victoria. 


\section{Notes}

\section{Chapter 1}

1) During the period under discussion, the term 'amateur', in the broadest sense of the word, was defined as a person who pursued an activity that had neither commercial applications nor a supporting institutional structure. As Sieberling and Bloore state, social interchange was implicit in the amateur tradition. Activities were shared with friends and family and the participants learnt from one another. Nor did the term 'amateur' carry with it implications of lesser standards of quality. An amateur simply meant someone who engages in photography in pursuit of a pastime as opposed to a profession. Grace Seiberling and Carolyn Bloore, Amateurs, Photography and the Mid-Victorian Imagination (Chicago, University of Chicago Press, 1986): 3.

2) This emphasizes why without the services of 'you push, we do the rest', that Kodak offered as a marketing ploy, their use of hand-held film cameras was limited. For further discussion on the establishment of Eastman Kodak, Australia, in this country including the opening of Kodak's first commercial outlet in New Zealand by J.J. Rouse, Eastman Kodak, Australia, see 'Photography', Evening Post (Wellington), 18 May 1909, p. 8; also Evening Post, 1 June 1909.

3) The diaries of J.B.A. Acland, Acland papers (MB44), Macmillan Brown Library, University of Canterbury, Christchurch.

4) For more information on the Lucy Dyke Acland photograph album, see Appendix I, p. 198. For a complete list of the photograph albums selected for discussion in this thesis, also see Appendix I, pp. 198-201.

5) See Figure 1, [Harriet and Rosa Acland in the conservatory, Mt Peel Station], Lucy Acland photograph album, LA56, private collection, Christchurch, Appendix II, p. 203.

6) Naomi Rosenblum, A History of Women Photographers (New York, Abbeville Press, 1994). 
7) Rosenblum, (1994): 10.

8) Peter Gibbons, 'A Note on Writing Identity and Colonisation in Aotearoa', Sites, 13, (Spring 1986): 32-38; 'Cultural Colonization and National Identity', 36, 1, (2002): 5-10; 'Non-fiction', in the Oxford History of New Zealand Literature in English, Terry Sturm (ed.), (Auckland, 1999): 31-118; 'The Far Side of the Search for Identity': Reconsidering New Zealand History', New Zealand Journal of History, (37, 1, 2003): 38-49. Philippa Wilson, 'We are still English at Heart: Constructions of Englishness by Englishwomen in nineteenth-century New Zealand', (Master of Arts in History, Auckland, University of Auckland, 1997).

9) Peter Gibbons, Sites, 13 (Spring, 1986): 33. An in-depth discussion with regard to what a settler society comprises is well between the scope of this thesis. Nevertheless, it is simply not enough to state that settler people are non-indigenous. For the purposes of this thesis settler societies are those in which Europeans have settled and become politically dominant over the indigenous people and where a heterogeneous society has developed in relation to class, ethnicity and race. As Catherine Hall emphasizes men and women defined their lives in very different ways. The focus of women's lives was within in the home and their families. Therefore, some of the arguments put forward in recent analysis of women in Victorian society are not necessarily representative of women and their position within in early settler societies. See Leonore Davidoff and Catherine Hall, Family Fortunes: Men and Women of the English Class, 1780-1850 (London, Routledge, 2002): 117, 165-166. For a well-researched analysis of settler societies, see Adam Joseph Barker, 'Being Colonial: Colonial Mentalities in Canadian Settler Society and Political Theory', Master of Arts in Indigenous Studies Governance Program (Victoria, BC, Canada, University of Victoria, 2006).

10) Patrizia di Bello, Women's Albums and Photography in Victorian England, Ladies Mothers and Flirts (London, Ashgate, 2006): 72.

11) For examples of research studies undertaken on specific regions, see Pierre Bourdieu et al, Photography: A Middle-Brow Art, trans. by Shaun Whiteside (Stanford, CA, Stanford University Press, 1992); Richard Chalfen, Turning Leaves: The Photograph Collections of Two Japanese American Families (Albuquerque, University of New 
Mexico, 1991); Monique Berlier, 'Picturing Ourselves: Photographs of Belgian Americans in Northeastern Wisconsin, 1888-1950', PhD in Mass Communications (Iowa City, University of Iowa, 1999); Deborah Chambers, 'Family as Place: Family Photograph Albums and the Domestication of Public and Private Space', in Joan M. Schwartz and James R. Ryan, eds, Picturing Place: Photography and the Geographical Imagination (London, L.B. Tauris and Co. Ltd, 2006): 96-114; Orla Cronin, 'The Meaning and Psychological Significance of Family Photographic Collections', $\mathrm{PhD}$ in Psychology (Southhampton, University of Southampton, 1996); Saundra Lee Gardner, 'Exploring the Family Album: Social Class Differences in Images of Family Life', Sociological Inquiry, 61, 2 (1993): 242-51; Nadia Joanne Gush, 'Cultural Fields of the Canterbury Plains: Women and Cultural Citizenship in Canterbury c.1890-1940', PhD in History (Victoria University of Wellington, 2007). Daniel James and M.Z. Lobato, 'Family Photos: Oral Narratives, and Identity Formation: The Ukrainians of Berisso', Hispanic American Historical Review, 84, 1 (2004): 5-36; Marilyn F. Motz, 'Visual Autobiography: Photograph Albums of Turn-of-the-Century Midwestern Women', American Quarterly, 41,1 (1989): 63-92; Armando Silva, 'The Family Photo Album: The Image of Ourselves', $\mathrm{PhD}$ In Comparative Literature (Irvine, University of California, 1996); Sarah McNair Vosmeier, 'The Family Album: Photography and the American Family since 1860', PhD in History (Bloomington, University of Indiana, 2003).

12) W. Main and J.B. Turner, New Zealand Photography from 1840s to the present - Nga Whakaahua o Aoteroa mai 1840 ki nainei (Photoforum/Agfa-Gevaert, 1993). While the editor of Photoforum, John Turner printed the following: Linda Gair, 'Women in Photography: A selected bibliography', PhotoForum (December1975/January 1976): 9; L. Cleveland, 'The Tyrees: Notes towards a critical assessment', PhotoForum Supplement (Spring, 1979): 6-9; Rosemary Bevan, 'Early Women Photographers of NZ', PhotoForum Supplement (1980): 5; Tim Walker, 'Margaret Matilda White', PhotoForum, 56 (1986). John Turner also supervised a number of research essays on New Zealand women photographers including Anton Stolte, 'George and Elizabeth Pulman, early Auckland photographers' (Auckland, Elam School of Fine Arts, Auckland University, BFA, 1989). 
13) Luit Bieringa, 'New Zealand Photography from the 1840s to the present: Nga Whakaahua o Aoteroa mai I mai 1840 ki naianei', Journal of New Zealand Photography, 4 (February, 1994): 9-10.

14) Main and Turner (1993): 27.

15) Hardwicke Knight, Photography in New Zealand: a social and technical history (Dunedin, John McIndoe, 1971); Hardwicke Knight, New Zealand Photographers: a selection (Dunedin, Allied Press, 1981).

16) David Eggleton, Into the Light: A History of New Zealand Photography (Nelson, Craig Potton, 2006).

17) Paul Thompson, 'Into the Light: A History of New Zealand Photography', Journal of New Zealand Photography (2007): 63.

18) For the reference to the Acland sisters, see Eggleton (2006): 36.

19) Angela Wanhalla and Erika Wolf, Early New Zealand Photography: Images and Essays (Dunedin, University of Otago Press, 2011).

20) Chris Brickell, 'At the borders of colonial masculinity: Robert Gant's photographs of men together', in Angela Wanwalla and Erika Wolf, eds, Early New Zealand Photography: Images and Essays (Dunedin, University of Otago Press, 2011): 66-71. See also Chris Brickell, Mates \& Lovers: A History of Gay New Zealand (Auckland, Random House, 2008): Chapter One; Chris Brickell, Manly Affections: The Photographs of Robert Gant1885-1915 (Dunedin, Genre Books, 2012). Robert Gant photograph albums (PAI-q963); (PAI-q-962), Alexander Turnbull Library, Wellington.

21) Chris Brickell, 'Badness Personified: Nola Pratt's Photograph Album', in Annabel Cooper, Lachy Paterson and Angela Wanhalla, eds, The Lives of Colonial Objects (Dunedin, Otago University Press, 2015): 262-267. Nola Pratt photograph album (PAI-o883-1), Alexander Turnbull Library, Wellington. 
22) Julie King, Flowers into Landscape: Margaret Stoddart 1865-1934 (Christchurch, Robert McDougall Art Gallery \& Hazard Press, 1997).

23) King (1997): $54 \& 58$.

24) See reference 11.

25) Bourdieu (1992).

26) Gillian Rose, Doing Family Photography: the domestic, the public and the politics of sentiment (Farnham, England, Ashgate Publishing Ltd, 2010): 1. Although a number of different terms have been used by researchers to define in this area of photography: for instance, Pierre Bourdieu employed the term, 'ordinary,' see Bourdieu, 1992: 4; Richard Chalfen, 'home-mode,' see 'Introduction to the Home mode of Visual Communication', 13, Folklore (1975): 19; Barbara Harrison, 'everyday,' see 'Photographic visions and narrative inquiry', in Michael Bamberg and Molly Andrews, Considering counternarratives: Narrating, resisting, making sense (Amsterdam, John Benjamin, 2004): 113; and Maggie Humm, 'domestic photography', Snapshots of Bloomsbury: The private lives of Virginia Woolf and Vanessa Bell (New Brunswick, Rutgers University Press, 2006): 3. I prefer the term 'family photography' adopted by Gillian Rose, is the most useful and also self explanatory, since these photographs are taken by family, of family and ultimately, for family viewing. See Rose (2010): 1.

27) See Chalfen (1991); (Chalfen's project was entitled: 'The Japanese American Family Album Project', see Chalfen (1991): xix.) In this project Chalfen and his colleagues studied the photograph albums produced by 3 generations from 2 Japanese immigrant families. See also Rose, 2010. But in addition, also see Gillian Rose, 'Practising photography: an archive, a study, some photographs and a researcher', Journal of Historical Geography, 26, 4 (2000), 555-71; Gillian Rose, 'Family Photographs and Domestic Spacings: A Case Study', Transactions of Institute of British Geographers; New Series, 28, 1 (2003): 5-18; Gillian Rose, “"Everyone's cuddled up and it just looks really": an emotional geography of some mums and their family photos', Social \& Cultural Geography, 5,4 (2004): 549-564. 
28) Gillian Rose, Visual Methodologies: An Introduction to the Interpretation of Visual Materials (London, Sage Publications Ltd, 2001): 33.

29) See Chalfen (1991): 8.

30) See Rose (2010): 1.

31) Andreas Reckwitz, 'Toward a theory of social practices: a development in culturalist theorizing'. European Journal of Social Theory, 5 (2002): 243-63; Theodore Schatzki, Social practices: A Wittgensteinian Approach to Human Activity and the Social (Cambridge, Cambridge University Press, 1996).

32) Erving Goffman, Presentation of Self in Everyday Life (London, Allen Lane, 1969); Erving Goffman, Frame Analysis: An Essay on the Organization of Experience (New York, Harper Colophon Books, 1974).

33) Hester Dibbits, 'Furnishing the Salon: Symbolic ethnicity and performance practices in Moroccan-Dutch domestic interiors', International Journal of Consumer Studies, 33 (2009): 550-557; Divya Tolia Kelly, 'Materializing post-colonial geographies: examining the textural landscape of migration in the South-Asian home', Geoforum, 35 (2004): 314319; Divya Tolia-Kelly, 'Mobility/stablity: British Asian cultures of "landscape and Englishness"', Environment \& Planning, A38 (2006): 341-358; Katie Walsh, 'British Expatriate Belonging in Dubai: Foreignness, Domesticity, Intimacy', $\mathrm{PhD}$ in Geography (Royal Holloway, University of London, 2005); Deborah Chambers, 'Family as Place: Family Photograph Albums and the Domestification of Public and Private Space', in Joan M. Schwartz and James R. Ryan eds, in Picturing Place: Photography and Geographical Imagination (London, I. B. Tauris \& Co Ltd, 2003): 96-114; Greg Noble, 'Comfortable and relaxed: furnishing the home and nation', Continuum: Journal of Media and Cultural Studies (2002): 53-66; Greg Noble, 'Home, Comfort and banal Nationalism', in Alison Blunt and Robyn Dowling, eds, Home (Oxford, Routledge, 2006): 167-169. Note: the term 'transnational' has recent origins. It is applied to workers who choose to leave their country of birth to seek work elsewhere for a short-term, rather than as a permanent life change. Nevertheless, when they move for their work, like permanent migrants, they bring with them carefully selected items which reflect their social and cultural background. 
34) Elizabeth Siegel, 'Galleries of Fame and Friendship: the history of nineteenth-century American photograph albums', $\mathrm{PhD}$ in Art History (Chicago, University of Chicago, 2003); Sarah McNair Vosmeier, 'The Family Album: Photography and American Family Life since 1860', PhD in History, (Bloomington, University of Indiana, 2003); Monique Berlier, 'Picturing Ourselves: Photographs of Belgian Americans in Northeastern Wisconsin, 1888-1950', PhD in Mass Communications (Iowa City, University of Iowa, 1999).

35) Martha Langford, Suspended Conversations: The afterlife of memory in photographic albums (Montreal, McGill-Queens University Press, 2001). Langford's special study was on anonymous album (MP035/92), in the Notman Collection of the McCord Museum in Montreal, Canada. Also, Martha Langford, 'Speaking the album: an application of oralphotographic framework', in A. Kuhn and K. McAlister, eds, Locating Memory: Photographic Acts (Oxford, Berghahn, 2006): 223-246.

36) The text which Langford refers to the most is, Walter J. Ong, Orality and Literacy: The Technologizing of the Word (London, Methuen, 1982).

37) di Bello (2006); Marta Weiss, 'Dressed Up and Pasted Down: Staged Photography in the Victorian Album', PhD in Art History, (Princeton, N.J., Princeton University, 2008); Maggie Humm, Modernist Women and Visual Cultures: Virginia Woolf, Vanessa Bell, Photography and Cinema (New Brunswick, Rutgers University Press, 2003); Maggie Humm, 'Virginia Woolf and Vanessa Bell: the same pair of eyes, only different spectacles', in Woolf and the Real World: Selected papers from the thirteenth International Conference on Virginia Woolf (Clemson, SC, Clemson University Press, 2005).

38) Not surprisingly there is an extensive literature available on Queen Victoria and her life and times. The publications listed below deal with aspects of her interest in photography and associated photographic practices and her influence on their development, particularly in relation to family photography. This will be discussed in more detail in Chapter Two. Frances Dimond and Roger Taylor, Crown \& Camera: The Royal Family and Photography, 1842-1910 (Harmondsworth, England, Viking, Penguin Books Ltd, 1987): 11-22; Margaret Homans, Royal Representations: Queen Victoria and 
British Culture 1837-1876 (Chicago, University of Chicago Press, 1998); www.billjayonphotography.com/QnVictoria2ndpassion.pdf; Andrew King and John Plunkett, Victorian Print Media: a reader (Oxford, Oxford University Press, 2006); Elizabeth Langland, Nobody's Angel's: Middle Class women and domestic ideology in Victorian Culture (Ithaca, Cornell University Press, 1995); Elizabeth Longford, Queen Victoria: born to succeed (New York, Harper and Row, 1964); Anne M. Lyden, A Royal Passion: Victoria and photography (Los Angeles, CA, J. Paul Getty Publications, 2014). A number of Victoria's children also had an interest in photography and in compiling photograph albums. Alexandra, Princess of Wales, was also a keen photographer. Unlike the women selected for this study she used a hand-held Kodak camera. See Frances Dimond, Developing the Picture: Queen Alexandra and the Art of Photography (London, Royal Collections Enterprises Ltd, 2004). Women of the Queen's bedchamber who had an interest in the photographic medium included Caroline Augusta Feilding, later Lady Mount Edgcumbe, and Lady Frances Elizabeth Cowper, later Lady Jocelyn. For information on Jocelyn, see Isobel Crombie, 'The Work and Life of Viscountess Frances Jocelyn: Private Lives', History of Photography, 22, 1 (1998): 40-51. To this group of women I also include Clementina Elphinstone Fleeming, later Lady Hawarden, who was also from the aristocracy and who came to critical attention during her life time. Her photographic work has recently become the subject of in depth studies. See Virginia Dodier, Clementina, Lady Hawarden, Studies from Life 1857-1864 (London, Victoria and Albert Publications, 1997).

39) Since the 1940s a number of publications on Julia Margaret Cameron have appeared. More recent publications include: Colin Ford, Julia Margaret Cameron: $19^{\text {th }}$ century photographer of genius (London, National Portrait Gallery, 2003); Victoria Olsen, From Life: Julia Margaret Cameron \& Victorian Photography (London, Arum Press, 2003).

40) di Bello (2006): 4.

41) Humm (2006): 6.

42) Stuart Hall, of the Birmingham Centre for Contemporary Cultural Studies from19681979, has been credited as influential in the emergence of cultural studies as an identifiable field of analysis. See David Morley and Kuan-Hsing Chen, eds, Stuart Hall: Critical dialogues in cultural studies (London, Routledge, 1996). Those who have been formative in this area since the 1990s, include Mieke Bal, Stuart Hall, Sarah Pink and 
Gillian Rose. See Stuart Hall, Representation: Representations and Cultural Signifying Practices (London, Sage Publications, 1997); Mieke Bal, 'Visual essentialism and the object of visual culture', Journal of Visual Culture, 2, 5 (2003): 5-32; Sarah Pink, Amateur photographic practice, collective representation and the constitution of place, Visual Studies, 26, 2 (2011): 92-101; Gillian Rose, Visual Methodologies: An Introduction to the Interpretation of Visual Materials (London Sage Publications, 2002); Gillian Rose, 'On the relation between "visual research methods" and contemporary visual culture', Sociological Review, 62, 1 (2014): 24-46.

43) 'Lived experience' is the term Paula Saukko uses in her analysis of cultural of studies. See Paula Saukko, Doing Research in Cultural Studies: An Introduction to Classical and New Methodological Approaches (London, Sage Publications, 2003): 3.

44) Gillian Rose, Visual Methodologies: An Introduction to the Interpretation of Visual Materials (London, Sage Publications Ltd, 2001): 33.

45) Susan Stewart, Nonsense: Aspects of Intertextuality in Folklore and Literature (Baltimore, The Johns Hopkins University Press, 1979). Susan Stewart, On Longing: Narratives of the Miniature, the Gigantic, the Souvenir, the Collection (Baltimore, The Johns Hopkins University Press, 1993). Although I do not refer to this book directly in this chapter, Stewart's analysis throughout this book provides good background reading for this chapter. However, I do refer to this book in Chapter Seven.

46) Chris Gosden and Yvonne Marshall, 'The cultural biography of objects', World Archaeology, 31, 2 (1999): 169-178.

\section{Chapter 2}

1) Edward Merson Templar (1820-1897), and Mark Pringle Stoddart (1819-1885), Macdonald Dictionary of Canterbury Biographies, Canterbury Museum Christchurch; M.P. Stoddart, 'Reminsciences', Canterbury Museum, Christchurch. For further details of the early years of the Stoddart family in New Zealand, see Julie King, Flowers into Landscape: Margaret Stoddart, 1865-1934 (Robert McDougall Art Gallery and Hazard Press, 1997). 
2) On the 14 August 1852 Stoddart purchased 50 acres (RS246) from the Canterbury for 150. He added to his original purchase a further 173 acres in 1859 (18D 498); 80 acres in 1860 (18D 81) and 58 acres in 1862 (RS2404) from the Crown. In addition, from 1858, for a period of 21 years, he leased100 acres from the Church Property Trustees (RS 234c). I am grateful to John Wilson and Julie King for this information. For more details see King (1997): 36.

3) King (1997): 20.

4) See fig. 2, [Stoddart family, Diamond Harbour], c. 1897, Mary Stoddart photograph album 1, MS 1 , Canterbury Museum, Christchurch, Appendix II, p. 204.

5) See the photograph album of Mary Stoddart (MOS 232), Canterbury Museum, Christchurch. Although there is no confirmation of the date when this photograph was taken, it was taken presumably prior to Margaret Stoddart's departure for an extended stay in England to continue her art studies, in early 1898. See King (1997): 19, 62.

6) These realities are well expressed in an excerpt from a letter written by Agnes Mildred Hall (1851-1919), to her aunt, Grace Neall (born Hall) in London, England, dated 7 February, 1869. 'I think I am happier on the whole, but it will of course be a long time before I get accustomed to all the colonial ways'. Reprinted in Kate Foster and Jean Garner, Letters to Grace: Writing home from colonial New Zealand (Christchurch, Canterbury University Press, 2011): 43. For biographical details of Hall's life, see Foster and Garner, pp. 40-44.

7) Philippa Wilson, 'We are still English at Heart: Constructions of Englishness by Englishwomen in nineteenth-century New Zealand', Master of Arts in History (Auckland, University of Auckland, 1997). Women included in this study are Maria Atkinson, Marianne Williams and her daughter, Kate Hadfield, Jane Williams, Anne Chapman, Mary Martin, Caroline Abraham, Mary Hobhouse, Mary Taylor, Mary Swainson, Hannah Richardson, Elizabeth Colenso, Laura Taylor. But, as Wilson notes, Mary Hobhouse (née Brodick) is identified by her biographer, Shirley Tunnicliff, as descended from the gentry. For Philippa Wilson's description of the process of finding a place to continue to carry out these practices, see Wilson (1997): 6, 57. 
8) Excerpt from a letter written by Kate Williams to Marianne Williams, dated from 29 April 1851, and quoted in Wilson (1997): 58. For a full transcript of this letter see Octavius Hadfield papers 1846-1912 (Ms copy Mirco-190) (Ms papers-139), folder 41, Alexander Turnbull Library, Wellington. For the full list of primary sources which Philippa Wilson consults, see Wilson (1997): 198-201. Wilson does not draw on any photograph albums in her discussion. However, Elizabeth Colenso, for example, was a conscientious album maker for many years. I will look at her contribution in Chapter Six in conjunction with the discussion of woman photographer, Kate Ivens.

9) Wilson (1997): 58.

10) Wilson (1997): 76.

11) Frances Porter and Charlotte Macdonald came up with the term 'unsettlement' as a way to describe how settlers felt about the often uneasy situations in which they found themselves, and as Wilson points out, this is a constant theme in their narratives. See Frances Porter and Charlotte Macdonald, My hand will write what my heart dictates: 'The unsettled lives of women in nineteenth century New Zealand as revealed to sisters, family and friends' (Auckland, University of Auckland Press, 1996): 3, 4, 7.

12) Jean and John Comaroff, 'Introduction', in Jean and John Comaroff, eds, Modernity and its Malcontents, Ritual and Power in Postcolonial Africa (Chicago, University of Chicago Press, 1993). The contributions to this area of research by Clifford Geertz, Peter Gibbons and Marshall Sablins also should not be overlooked. See Clifford Geertz, 'Deep Play: Notes on the Balinese Cockfight', in Clifford Geertz, ed., Myth, Symbol, and Culture (New York, Norton, 1972): 165-185; Peter Gibbons, 'A Note on Writing Identity and Colonisation in Aotearoa', Sites, 13 (Spring, 1986): 32-38; Eric Hobsbawm, Nations and Nationalism since 1780: Programme, Myth, Reality (Cambridge, Cambridge University Press, 1992); Thomas C. Holt, 'Marking Race, Race-making, and Writing of History', The American Historical Review, 100, 1 (February, 1995): 1-20; Marshall Sahlins, Historical Metaphors and Mythical Realities: Structure in the Early History of the Sandwich Islands Kingdom, (Ann Arbour, University of Michigan Press, 1981).

13) Claudia Knapman, White Women in Fiji, 1835-1930: The Ruin of Empire? (Sydney, Allen \& Unwin, 1986). 
14) Richard Chalfen, Turning Leaves: The Photograph Collections of Two Japanese American Families (Albuquerque, University of New Mexico, 1987): 17-18, 164.

15) The researchers that I have found useful in the field and consulted most include: Hester Dibbits, Divya Tolia Kelly and Katie Walsh. See Hester Dibbits, 'Furnishing the Salon', International Journal of Consumer Studies, 33 (2009): 550-557; Divya Tolia Kelly, 'Materializing post-colonial geographies', Geoforum, 35 (2004): 314-319; Divya Tolia-Kelly, 'Mobility/stablity', Environment \& Planning, A38 (2006): 341-358; Katie Walsh, 'British Expatriate Belonging in Dubai: Foreignness, Domesticity, Intimacy', PhD in Geography (Royal Holloway, University of London, 2005).

16) Dibbits (2009): 2; Hester Dibbits draws our attention to the major concern of many new arrivals from Morocco was finding a suitable living space that was large enough to accommodate the traditional sofa. For an Australian perspective also see Greg Noble, 'Comfortable and Relaxed', Continuum: Journal of Media and Cultural Studies, 16 (2002): 54.

17) Katie Walsh, 'Expatriate Belongings', in Alison Blunt and Robyn Dowling, eds, Home (Abingdon, Oxford, Routledge, 2006): 248-249.

18) Wilson (1997): 76.

19) Erving Goffman, Interaction Ritual: Essays in Face to Face Behavior, Joel Best, ed. (New Brunswick, NJ, Transaction Publishers, 2005); Jeffrey C. Alexander, Bernhard Giesen, Jason L. Mast, Social performance: Symbolic Action, Cultural Pragmatics and Ritual (Cambridge, Cambridge University Press, 2006): 13.

20) Elizabeth Edwards, 'Negotiating Spaces: Some Photographic Incidents in the Western Pacific, 1883-4', in Joan M. Schwartz and James R. Ryan, eds, Picturing Place: Photography and the Geographical Imagination (London, I.B. Tauris \& Co. Ltd, 2006): 271.

21) Joan M. Schwartz and James R. Ryan, 'Introduction', Picturing Place: Photography and the Geographical Imagination (London, I.B. Tauris \& Co. Ltd, 2006): 7-8. 
22) Letter from Jane Maria Atkinson to Margaret Taylor, 31 August 1867, Richmond Atkinson family papers (Ms-Papers-4298, folder 55), Alexander Turnbull Library, Wellington.

23) Letter from Mary Taylor to Charlotte Brontë, 1852, in Joan Stevens, ed., Mary Taylor, Friend of Charlotte Brontë, Letters from New Zealand and Elsewhere (1972): 109.

24) King (1997): 31. Robert Peden, in his carefully researched study of Canterbury runholders in the $19^{\text {th }}$ century, Making Sheep Country, concluded that many experienced early highs, but also the subsequent lows of land owning. For instance, he described how for J.B.A. Acland his precarious financial situation from the 1860s triggered in him a deep emotional and spiritual despair (p. 228), which by the 1890s meant that he had to make increasing economies. These affected not only the management of the farm, but also the household. Acland explained the situation in a letter dated 4 February to his brother-in-law, Arthur Mills, in England, writing that there were almost no staff, and that his daughters were doing all they can in the way of housework (Letterbooks, 13, 17 March 1893 - 2 April 1895, Acland papers (MB44). See Robert Peden, Making Sheep Country: Mt Peel Station and the Transformation of the Tussocklands (Auckland, Auckland University Press, 2011).

25) The term 'Home' was already in common parlance by 1886 . See letter from J.B.A. Acland to his brother, Sir Thomas Acland, dated 14 May 1886, in the Devon Archives, Exeter City Library, Exeter, England. (typescript in Canterbury Museum, Christchurch).

26) Deborah Chambers, 'Family as Place', in Joan M. Schwartz and James R. Ryan, eds, Picturing Place: Photography and the Geographical Imagination (London, I.B. Tauris \& Co. Ltd, 2006): 96-114.

27) Chambers, (2006): 97.

28) Barbara Harrison, ‘Snap Happy: Toward a Sociology of "Everyday” photography’, in C.J. Pole, ed., 'Seeing is Believing? Approaches to Visual Research', Studies in Qualitative Methodology, 17 (2004): 30; Susan Sontag, On Photography (New York, Farrar, Strauss and Giroux, 1977): 8-9, 28. 
29) For biographical details on Barker see John B. Turner, Barker, Alfred Charles, 18191873; URL:http//www.TeAra.govt.nz/en.biographies/1b4/barker-alfred-charles; also:

C.C. Burdon, Dr A.C. Barker, 1819-1873, photographer, farmer, physician (Dunedin, McIndoe, 1972).

30) Diary of M.P. Stoddart 1862-1871 (Micro Ms 24), Alexander Turnbull Library, Wellington.

31) Fig. 3, The Stoddart family, Diamond Harbour, 1871, Dr A.C. Barker collection, Canterbury Museum, Christchurch, Appendix II, p. 204. Barbara Stoddart and her children, Frances, Margaret and James, appear in both figs $2 \& 3$.

32) Diary of J.B.A. Acland, May 1871-April 1873, Acland papers (MB44), Macmillan Brown Library, University of Canterbury, Christchurch.

33) See fig. 4, A.C. Barker, [Acland family, Mt Peel Station], 1872, Appendix, II, p. 205. Acland photographs collection (MB44), Macmillan Brown Library, University of Canterbury, Christchurch,

34) See commentaries of Pierre Bourdieu et al, in Photography: A Middle-Brow Art, trans. by Shaun Whiteside (Stanford, CA, Stanford University Press, 1992): 19, and Richard Chalfen, Snapshot Versions of Life (Ohio, Bowling Green State University Press, 1987).

35) Goffman (2005): 7.

36) Bourdieu (1992): 19.

37) Ann Victoria Bliss, 'Fixing the Family: The Function of the Family Photograph in Albums and Literature', $\mathrm{PhD}$ in English (University of California at Davis, 2006): 5.

38) Gillian Rose, Doing Family Photography: The Domestic the Public and the Politics of Sentiment (Farnham, England, Ashgate Publishing Ltd, 2010): 20.

39) Reckwitz (2002): 249.

40) Goffman (2005): 1. 
41) Letter from J.B.A. Acland to Sir Thomas Acland, Killerton, Devon, dated April 1887, Devon Archives, Exeter City library, Exeter, England. (typescript in Canterbury Museum, Christchurch, n. p.). For an informative account of the development of Mt Peel Station since 1856, see Peden (2011).

42) Photograph album of Lucy Acland, LA54, private collection, Christchurch.

43) See fig. 5, Appendix II, p. 205, [Acland family, Mt Peel Station], May 1895, Acland photographs collection (MB44), Macmillan Brown Library, University of Canterbury, Christchurch.

44) See figs 6 \& 7, Appendix II, p. 206 'Xmas I', Lucy Acland photograph album, LA40, private collection, Christchurch; 'Xmas II', Lucy Acland photograph album, LA40, private collection, Christchurch.

45) Richard Chalfen, 'Interpreting Family Photography as Pictorial Communication', in Image-based research: a sourcebook for Qualitative Researchers, Jon Prosser, ed (London, England, RoutledgeFawler, 1998): 214-234.

46) Chalfen (1991): 6-7; Bourdieu (1992): 23.

47) Clark McPhail, The Myth of the Madding Crowd (New York, De Gruyter Series of Texts and Monographs (1991): xiii.

48) Chalfen (1991): 7; also Goffman (2005): 11.

49) Alexander, Jeffrey C., Bernhard Giesen and Jason L. Mast, Social performance: Symbolic Action, Cultural Pragmatics and Ritual (Cambridge, Cambridge University Press, 2006): 54.

50) Erving Goffman, Presentation of Self in Everyday Life (London: Allen Lane, 1959): 32.

51) Chalfen (1991): 6.

52) Edwards (2006): 266. 
53) Geoffrey Batchen, Forget me not: Photography and Remembrance (Princeton, NJ, Princeton Architectural Press, 2006): 12, 14.

54) Geoffrey Poister, 'A Cross-Cultural Study of Family Photographs in India, China, Japan and the United States', PhD in Communications (Syracuse, NY, New York State University, 1998): 53.

55) Fig. 8, Ghémar Frères, Queen Victoria and Princess Beatrice, 1863. Appendix II, p. 207.

56) Chambers (2006): 98; Anne M. Lyden, A Royal Passion: Victoria and photography (Los Angeles, CA, J. Paul Getty Publications, 2014).

57) Chambers (2006): 98; Lyden (2014).

58) See Chapter One, reference 37; also: www.billjayonphotography.com/QnVictoria2ndpassion.pdf.

59) For instance, Victoria and Albert publically acknowledged their deepening interest in photography by becoming the first patrons of the fledging Photographic Society founded in England in 1853. See Frances Dimond and Roger Taylor, Crown \& Camera: The Royal Family and Photography, 1842-1910 (Harmondsworth, England, Viking, Penguin Books Ltd, 1987): 11-22. These authors also provide a comprehensive background to the subject of photography and the association of the royal family with the medium during the second half of the nineteenth century.

60) John Plunkett, Queen Victoria: First Media Monarch (Oxford, Oxford University Press, 2003): 2.

61) See the comments of Margaret Homans, Royal Representations: Queen Victoria and British Culture 1837-1876 (Chicago, University of Chicago Press, 1998). Margaret Homans and Adrienne Munich, Remaking Queen Victoria (Cambridge, Cambridge University Press, 1997): 2.

62) During Victoria's lifetime this painting hung in the dining room at Osborne. Marina Warner, Queen Victoria's Sketchbook (London, Unwin Hyman, 1987): 112; Margaret Homans, 'Victoria's Sovereign Obedience: Portraits of the Queen as Wife and Mother', 
in Victorian Visual Imagination, Carol T. Christ and John O. Jordan, eds (Berkeley, University of California Press, 1995): 179.

63) Pierre Bourdieu, The Logic of Practice, Richard Nice, trans. (Stanford, CA, Stanford University Press, 1990): 69-70; Elizabeth Longford, Queen Victoria: Born to succeed (New York, Harper and Row, 1964): 34.

64) Longford (1964): 567.

65) Longford. (1964): 64; Elizabeth Langland, Nobody's Angel's: Middle Class women and domestic ideology in Victorian Culture (Ithaca, NY, Cornell University Press, 1995): 132.

66) www.billjayonphotography.com/QnVictoria2ndpassion.pdf.

67) www.billjayonphotography.com/QnVictoria2ndpassion.pdf.

68) www.billjayonphotography.com/QnVictoria2ndpassion.pdf.

69) See fig. 9, Leonida Caldesi, [The royal family at Osborne House], 1859. Appendix II, p. 207.

70) The Liverpool and Manchester Photographic Journal, 15 June1858, p. 153.

71) Plunkett (2003): 148.

72) London Illustrated News, 6 June 1859, p. 540; Harper's Weekly: Journal of Civilisation, 25 June 1859, New York, p. 1.

73) Plunkett (2003): 152. For a reproduction of the complete leather-bound accordion folio, see Lyden (2014): 136-37. Lyden says that there was a premium paid for these images. For example, she says, Charles Asprey of Bond St, London was charging four guineas for a portfolio. (In today’s money this is the equivalent of $£ 200$ or \$US300.) Individual items sold for one shilling and six. Lyden also notes that this was three times the cost for a non-royal card. Also see further comments in Plunkett (2003): 153. 
74) For instance, advertisements were placed for these photographs by local agents, such as Swan and Wrigglesworth, in the Wellington Independent and the Hawkes Bay Herald, during the months of May and June, 1864. See 'Advertisements', Wellington

Independent, 28 May, 1864, p. 1, and the Hawkes Bay Herald, 11 June 1864, p. 1. AnneMarie Willis, also refers an advertisement in Walch's Literary Intelligence, November 1863 advertising photographs of the royal family by J.E. Mayall available from an outlet in Hobart, Tasmania. See Anne-Marie Willis, in Picturing Australia: A History of Photography (North Ryde, NSW, Australia, Angus \& Robertson, 1988): 47, 72.

75) Andrew King and John Plunkett, Victorian Print Media: a reader (Oxford, Oxford University Press, 2006).

76) King and Plunkett (2006): 376.

77) In the 1870s Burton Bros in Dunedin reproduced photographs taken in 1863 by J.E. Mayall of the Queen with members of her family after the death of Prince Albert at Windsor. For one example see the image from the Photographic archives of Museum of New Zealand, Te Papa Tongarewa (O034217), from album AL000214. See http://collection.tepapa.govt.nz/Object/1183689.

78) See The Lady's Newspaper and Pictorial Times, 14 March 1863, p.1. Reproduced in Patrizia di Bello, Women's Albums and Photography in Victorian England (2006): 141.

79) Gillian Rose, 'Everyone's cuddled up and it just looks really nice', Social and Cultural Geography, 5 (2004): 549-64; also, Rose (2010): 43.

80) See Rose (2010): 41; also Chalfen (1991); P. Hunt, 'Gender and the construction of home life', in G. Allan and G. Crow, eds, Home and Family: Creating the Domestic Sphere (London, Macmillan, 1989): 66-81； R. Madigan and M. Munro, 'Negotiating Space in the Family Home', in I. Cieraad, ed., At Home: An Anthropology of Domestic Space (Syracuse, Syracuse University Press, 1999): 107-117; P.J. Pennartz, 'Home: the experience of atmosphere', In I. Cieraad, ed., At Home: An Anthropology of Domestic Space (Syracuse, Syracuse University Press, 1999): 95-106.

81) Rose (2010): 557. 
82) Reckwitz (2002): 259.

83) Edwards (2006): 266, 271.

84) Howard L. Nixon, II, The Small Group (Englewood Cliffs, NJ, Prentice and Hall Inc., 1979).

85) Rose (2010): 41, 46.

86) Rose (2010): 2.

87) Rose (2010): 2; Chalfen (1991): xiv.

88) Rose (2010): 45.

\section{Chapter 3}

1) Fig. 10, Harriet Acland, 'Father in Study, March, 1893', Appendix II, p. 208, Acland photographs collection (MB44), Macmillan Brown Library, University of Canterbury, Christchurch, and fig. 11, John Acland, [Father in Study], 1893, Appendix II, p. 208, Acland photographs collection (MB44), Macmillan Brown Library, University of Canterbury, Christchurch.

2) The Acland papers (MB44), Macmillan Brown Library, University of Canterbury, Christchurch.

3) See Chapter One, p. 5.

4) See J.B.A. Acland's diary for the years 1893-97, Acland papers (MB44), Macmillan Brown Library, University of Canterbury, Christchurch.

5) Letter from J.B.A Acland to Henry Acland, dated 3 April 1893, Letterbook 18, p. 10, Acland papers (MB44), Macmillan Brown Library, University of Canterbury, Christchurch.

6) Jane Fletcher, 'The Way She Looks: Robert Thompson Crawshay's Photographic Portraits of his daughter Rose Hariette', PhD in Photography History and Theory (Derby, University of Derby, England, 2002): vi. 
7) Brad Jackson, 'Killing Time: Life in the Arkansas Penitentiary', in H.S. Becker, ed., Exploring Society Photographically (Chicago, Chicago University Press, 1981): 40.

8) See J.B.A. Acland's diary entry for 20 March 1893, and also the letter to his son, Henry, dated 3 April 1893, Letterbook 18, p. 10, Acland papers (MB44), Macmillan Brown Library, University of Canterbury, Christchurch.

9) Sarah Anne Carter, 'Picturing Rooms: Interior Photography 1870-1900', History of Photography, 34, 3 (2010): 253, 255; Rebecca Preston, 'Hope you will be able to recognize us': the representation of women and gardens in early twentieth-century British domestic "real photo" postcards', Women's History Review, 18, 5 (2009): 782. Preston also comments on the technical difficulties hampering photographs of interior scenes being taken.

10) Interview between photographer, Jane Ussher and Findlay MacDonald, Kim Hill Show, Radio NZ, 15 October 2010.

11) See the letter from J.B.A Acland to Henry Acland, dated 3 April 1893, Letterbook 18, p.10, Acland papers, Macmillan Brown Library, University of Canterbury. Judging by the times of exposure described by Acland, it is possible that two appararti were used for these sessions. The long exposure time of 3 minutes is suggestive of a quite basic camera; on the other hand, the second exposure time of 30 seconds is suggestive of a more sophisticated apparatus.

12) Conversation with John Goddard, of the Canterbury Centre for Historic Photography and Film at the Ferrymead Trust in Christchurch, 23 June 2015. For a concise history of the development of the composition of early flashlight compounds, see Leggat, Robert, $A$ History of Photography: From its beginning till the 1920s (1999). (http://www.rleggat.com.photohistory/index.html); Robin Lenman, The Oxford Companion to the Photograph (Oxford, Oxford University Press, 2005): 234-35.

13) Elizabeth Edwards, 'Negotiating Spaces: Some Photographic Incidents in the Western Pacific, 1883-4', in Joan M. Schwartz and James R. Ryan, eds, Picturing Place: Photography and the Geographical Imagination (London, I.B. Tauris \& Co. Ltd, 2006): 266. 
14) Theodore Schatzki, Social practices: A Wittgensteinian Approach to Human Activity and the Social (Cambridge, Cambridge University Press, 1996): 83; Andreas Reckwitz, 'Toward a theory of social practices', European Journal of Social Theory, 5 (2002): 249.

15) Maurice Merleau-Ponty, Phenomenology of Perception, trans. C. Smith (London, Routledge and Kegan Paul, 1962).

16) Mihaly Csikszentmihaly and Eugene Rochberg-Halton, The Meaning of Things: Domestic symbols and the self (Cambridge, Cambridge University Press, 1981): 173.

17) Csikszentmihaly (1981): 139.

18) Letter from J.B.A. Acland to Sir Thomas Acland, Killerton, Devon, dated April 1887, Devon Archives, Exeter City library, Exeter, England. (typescript in Canterbury Museum, Christchurch, n. p.) Elsewhere J.B.A. Acland had expressed similar sentiments. For instance in another letter to his brother, Thomas, dated 14 May 1886, he wrote that, 'I do indeed continue to take an interest in Home matters as many or most of us colonists call England. Although we are endeavouring to start new homes here for the next generation long I hope to be bound by the closest ties to the homes of their parents albeit the Globe in between us'. Devon Archives, Exeter City Library, Exeter, England. (typescript in Canterbury Museum, Christchurch, n. p.).

19) Goffman (1959): 2.

20) For a short biography of J.B.A. Acland, see An Encyclopaedia of New Zealand, A.H. McLintock, ed. (Wellington, New Zealand, R.E. Owen, Government Printer, 1, 1966): 6.

21) Stuart Hall, Representation: cultural representations and signifying practices (London, Sage Publications Ltd, 1997).

22) Edwards (2006): 263.

23) Celia Lury, Prosthetic Culture: photography memory and identity (London, England, Routledge, 1998): 6. 
24) Fig. 12, Lucy Acland photograph album, LA37, private collection, Christchurch, Appendix II, p. 209.

25) Description of photographic images dating to 1893 in photograph album compiled by Lucy Acland include: views of Peel Forest and Mt Peel taken by John, LA37; 3 views of the interior of the house taken by Harriet, LA44; the church exterior and lagoon, hayshed, Mt Somers, LA45; 2 scenes of the Lynn River, Parson's Rock taken by John, LA46; Walter's cottage, Pigeon's Flat and 3 scenes of Peel Forest taken by John, LA47; Bishopscourt, Christchurch, Mt Peel garden and Mt Peel views, LA53, Lucy Acland photograph album, private collection, Christchurch.

26) Euan Duff, 'Working World', in H.S. Becker, ed., Exploring Society Photographically (Chicago, Chicago University Press, 1981): 76.

27) A list photographers that visited Mt Peel Station, and mentioned in the diaries of J.B.A. Acland, include Dr A.C. Barker, 25-27 January, 1872 (Diary May 1871-April 1873); (Barker's first visit in mid-October 1861 is not recorded in his diary for that year as Acland was in England at the time of Barker's visit.) C.P. Sealy, 29 April 1866, (Diary 1 March 1865-29 June 1867); 16 March 1871 (Diary 28 March 1869-123 May 1871); Phillips 2 December 1878 (Diary June 22 1878-Dec 12 1879); D.L. Mundy, 10 November 1865 (Diary 1 March 1865-29 June 1867). Acland papers (MB44), Macmillan Brown Library, University of Canterbury, Christchurch.

28) For a background of Captain Acland's photographs taken while on his tour of duty in Australia and the Pacific Islands, see James Alison Acland, 'Admiral Sir William A.D. Acland, Royal Navy', Aclands - and the sea (Henry Ling, London, Dorset Press, Dorset, 1976): 147-179. Picturing Paradise: Colonial Photography in Samoa 1870-1920, Casy Blanton, ed. (Daytona Beach Community College, 1995): 49-58. See the 'Shipping Telegrams' for the Christchurch Press, for 12 September, 1885, p. 2 with notification of his arrival on the Hawea bound for Lyttelton. Several glass plates of New Zealand scenes are known to be among the contents of a William Acland's overall photographic collection in the Pitt Rivers Museum in Oxford. These plates remain unidentified. It should be noted that Acland's sister Sarah Angelina Acland (1849-1930), took up photography in 1891. She went on to receive recognization for her early experiments with 
colour photography. See Giles Hudson, Sarah Angelina Acland: First Lady of Colour Photography, 1849-1930 (Oxford, Bodleian Library, 2012).

29) According to an entry in J.B.A. Acland's diary for 1884, 4 dozen glass plates were purchased from Kempthorne's on 2 July of that year. See the accounts section for diary, 1 January 1883-14 February1885, Acland papers (MB44), Macmillan Brown Library, University of Canterbury, Christchurch.

30) Letter from J.B.A. Acland to Henry Acland, 3 April1893, Letterbook 18, p. 10, Acland papers (MB44), Macmillan Brown Library, University of Canterbury.

31) Photographs of drawing room by Harriet Acland in Lucy Acland photograph album, LA44, private collection, Christchurch. See figs 13 \& 14, Appendix II, p. 2010 \& 211.

32) Sarah Anne Carter, 'Picturing Rooms', History of Photography, 34, 3 (2010): 251252.

33) Carter (2010): 251-52; Clarence Cook, House Beautiful (Croton on Hudson, NY, The North River Press, 1878): 48.

34) A.K.C. Petersen, New Zealanders at Home: A Cultural History of Domestic Interiors 1814-1914 (Dunedin, University of Otago Press, 2001).

35) Petersen (2001): 66.

36) Petersen (2001): 99.

37) Petersen (2001): 61.

38) Petersen (2001): 39.

39) Jane Ussher with Nigel Watson, Still life: Inside the Antarctic Huts of Scott and Shackleton (Sydney, N.S.W., Murdoch Books, 2010).

40) Lady Barker, Station Life in New Zealand (London, 1874): 64, 103. Lady Barker lived in New Zealand between1865-68. At this date she was married to her second 
husband, Frederick Napier Broome. However, she continued to style herself as Lady Barker.

41) Beverly Gordon, 'Women's Domestic Body: The Conceptual, Conflation of Women and Interiors in the Industrial Age', Winterthur Portfolio, 31, 4 (1996): 281.

42) Letter from Mary E. Richmond to Connie Dillon, dated 6 March, 1882, Richmond family papers ca 1870-1950,( Ms77-173-16), Alexander Turnbull Library, Wellington. Quoted in Frances Porter and Charlotte Macdonald, eds, 'My Hand will write what my heart dictates', The unsettled lives of women in nineteenth-century New Zealand as revealed to sisters, family and friends (Auckland, Auckland University Press, 1996): 177178.

43) See Lucy Acland photograph album, LA61, private collection, Christchurch.

44) Fig. 15, Lucy Acland photograph album, LA61, private collection, Christchurch, Appendix II, p. 211.

45) Edwards (2006): 263.

46) Carter (2010): 255.

\section{Chapter 4}

1) Letter from N.M. Buckland to W. Main, dated 15 March1983, private collection, Wellington. For additional information on the Buckland family see N.M. Buckland, The Bucklands: a continuation of C.M. Gordon's story and revision of the Buckland and Taylor trees (Christchurch, New Zealand, 1975).

2) Letter from Dr G.B. Orbell to W. Main, 16 April 1980, private collection, Wellington.

3) ibid.

4) Bessie Hocken became a member of the Dunedin Photographic Society in 1892, the year that women were first admitted. She was one of 2 women who were elected to the committee at this time. See T. Maguire, The Lantern was Lighted: A History of the 
Dunedin Photographic Society Inc. 1890-1990 (1990). Both Harold and his sister, Carrie became members, but only for one year each, in 1892 and 1899 respectively. Bessie was also a working member of the Otago Art Society from 1887-1914. For additional information on Elizabeth Hocken (née Buckland), see Annette Facer 'Mrs Hocken requests...' in Rosemary Entwisle, ed., Women's contributions to the Hocken Library (Dunedin, Hocken Library, 1993): 7-10.

5) Vickie Hearnshaw, 'A Study in Black and White: The Life and Work of Photographer Jessie Buckland', Women's Studies Journal, 12, 1 (1997): 41-62.

6) Letter from Dr G.B. Orbell to W. Main, 1980.

7) By the 1890s photographic societies were established in Auckland, Wellington Christchurch and Dunedin, also Nelson and Wanganui. Some were not open to women. For example, the Auckland society did not allow women entry until 1921. See minutes of the Auckland Photographic Society for 10 September 1921, Auckland War Memorial Museum, Auckland.

8) Frances Stoddart was a member of the Nelson Camera Club in the late 1890s. She moved to Toi Toi, in the Rai Valley near Nelson, to take up a teaching position in 1897. See Rosalina McCarthy, 'Women and the Nelson Camera Club 1888-1900', New Zealand Journal of Photography (November, 1994): 16. Certainly, the next generation of women photographers benefitted from their association with photographic societies. Of particular note are Una Garlick (1883-1951), Auckland, and Thelma Kent (1899-1946), Christchurch. See Gordon Maitland, 'Garlick, Eunice Harriett', Dictionary of New Zealand Biography, Te Ara - The Encyclopedia of New Zealand, 2013;

URL:http//www.TeAra.govt.nz/en/biographies/4g7/garlick-eunice-harriett and Joan McCracken, 'Kent, Thelma Rene', Dictionary of New Zealand Biography, Te Ara - The Encyclopedia of New Zealand, 2013;

URL:http://www.TeAra.govt.nz/en/biographies/4k9/Kent-Thelma-Rene.

9) Harold Buckland was listed as a member of the Otago Photographic Society in 1892 and Carrie Buckland in 1899. 
10) See the Susan Buckland photograph album, private collection, Louisville, Kentucky. For copy photographs from this album see the Photographic Archives of the Hocken Library, University of Otago, Dunedin (copy album 121).

11) Fig. 16, [Kings and Queens of England], c. early 1890s, Susan Buckland photograph album, SB15, private collection, Louisville, Kentucky, Appendix II, p. 212.

12) Fig. 17, 'King Charles hiding in a tree...', c. early 1890s, Caroline Buckland photograph album, CB9, Hocken Library, University of Otago, Dunedin, Appendix II, p. 212.

13) Typescripts of the letters written by Gladys Hocken (later Le François), to her parents, Dr T.M. Hocken and Bessie Hocken c.1894-1899, private collection, Christchurch.

14) Marta Weiss is one exception. See Marta Weiss, 'Dressed Up and Pasted Down: Staged Photography in the Victorian Album', PhD in Art History (Princeton University, 2008).

15) William Fox Talbot, The Pencil of Nature (New York, Dulapo Press, 1969), reprint of the 1844-1846 edition with introduction by B. Newhall.

16) Helmut Gernsheim, Lewis Carroll, Photographer, revised ed. (New York, Dover Publications 1969): 22.

17) Weiss (2008).

18) Weiss (2008): 11. Judith Fetterley, 'Little Women: Alcott's Civil War', Feminist Studies, 5, 2 (1979): 369-83; Karen Haltunnen, 'Impersonating Little Women: Domestic Drama', Feminist Studies, 10, 2 (1984): 233-254.

19) Douglas R. Nickel, Dreaming in Pictures: The Photography of Lewis Carroll (San Francisco, San Francisco Museum of Modern Art, 2002): 39-43.

20) For further confirmation of this see Mary Megan Chapman, 'Living Pictures: Women and Tableaux Vivants in the Nineteenth Century American Fiction and Culture', Wide 
Angle, 18, 3 (1996): 22-52; Fetterley (1979): 369-83 and Haltunnen (1984): 233-254. Also Weiss (2008): ii.

21) Carol Armstrong, Scenes in a Library: Reading the Photography in the Book, 1843 1875 (Cambridge, MA, MIT Press, 1998): 363; Emma Cecilia Rook and Elizabeth Jane Rook, Tableaux, Charades and Pantomines (Philadelphia, Bibliobazaar for The Penn Publishing Co., 1914); Sub-title: 'For children of 12 years, Young folks entertainment, comprising many new and novel motion songs, charades, pantomimes, tableaux, concert'.

22) Haltunnen (1984): 227.

23) Haltunnen (1984): 227.

24) Weiss (2008): 27-28.

25) John Berger and Jean Mohr (with the help of Nicholas Philibert), Another Way of Telling (Vintage Books, New York, 1996).

26) Richard Chalfen, Turning Leaves: The Photograph Collections of Two Japanese American Families (Albuquerque, University of New Mexico Press, 1991): 5.

27) Clark McPhail, The Myth of the Maddening Crowd (New York, De Gryter series of Texts and Monographs, 1991).

28) Chalfen (1991): 6; Ann Victoria Bliss, 'Fixing the Family: The Function of the Family Photograph in Albums and Literature', PhD in English (University of California at Davis, 2006).

29) Gladys Hocken, letter dated 18 December, 1894, private collection, Christchurch.

30) Figs 18, 19, 20, Appendix II, pp. 213-214. See Susan Buckland photograph album, SB18, private collection, Louisville, Kentucky and Jessie Buckland album, JB33, Hocken Library, University of Otago, Dunedin.

31) See the photograph albums of Jessie Buckland, JB54, JB59, JB60, Hocken Library, University of Otago, Dunedin, and Susan Buckland, SB17, SB23, SB59, private 
collection, Louisville, Kentucky,. Following the marriage of Susan Buckland to Lionel Orbell on 22 May 1901, these close ties were formalized.

32) Gladys Hocken, letter dated December 1894, private collection, Christchurch.

33) Thereza Dillwyn Llewellyn, Diary entries, 2 and 4 July 1857, Richard Morris, trans., Swansea, Wales.

34) For information on the opening of a commercial outlet at Mercer Street in Wellington, by J.J. Rouse, Eastman Kodak, Australia, see 'Photography', Evening Post (Wellington),18 May 1909, p. 8; also Evening Post, 1 June 1909.

35) Naomi Rosenblum, A History of Women Photographers (New York, Abbeville Press, 1994): 61.

36) Art schools had been established in the 4 main centres of New Zealand by the 1890s, Dunedin (1870); Christchurch (1882); Wellington (1885); Auckland (1890).

37) For more detailed information concerning the Stoddart girls attendance at the School of Art in Christchurch, see Julie King, Flowers into Landscape: Margaret Stoddart 1865 1934 (Christchurch, Robert McDougall Art Gallery, 1997): 10, 32, 38.

38) Una Platts, Nineteenth century New Zealand artists: a guide and handbook (Christchurch, Avon Fine Arts), 1980: 118.

39) Rosenblum (1994): 81.

40) Platts (1980): 186. Platts states that Susan Buckland attended Miss Duke's School. She may have meant Miss Dick's School, which Jessie was purported to have attended. When I asked Nancy Buckland, in January 1996, about the girls' education, she said that they had been tutored by a governess. For further information on Fanny Wimperis, see Platts (1980): 258-59, and Entwisle, Mrs Hocken requests...' (1993): 35.

41) Entwisle (1993): 17, 35.

42) For example, in 1893 Bessie Hocken exhibited a painting no. 234, 'On the Rock and Pillar Range', at the Otago Art's Society annual exhibition in Dunedin. The location of 
this painting suggests that Hocken was staying with the Bucklands while she was working on this painting. See also Hearnshaw (1997): 45.

43) See Carrie Buckland photograph album (album 211); Jessie Buckland photograph album (album 210); Susan Buckland photograph album (copy print album 121), and folio 26,767, Hocken family archives, Hocken Library, University of Otago, Dunedin.

44) See fig. 21, Appendix II, p. 215, and the photograph album of Caroline Buckland (album 211), CB35.

45) See fig. 22, Appendix II, p. 215. See the photograph albums of Caroline Buckland (album 211), CB4: Susan Buckland (album 121), SB16, SB88; and Jessie Buckland (album 210), JB6.

46) See fig. 23, Appendix II, p. 216. See the photograph album of Caroline Buckland (album 210), CB35.

47) See fig. 24, Appendix II, p. 216. See the photograph album of Susan Buckland SB60 (copy album 121).

48) Gladys Hocken, undated letter to her parents, Dr T.M. Hocken and Elizabeth Hocken.

49) Gladys Hocken, letter to her parents, Dr T.M. Hocken and Elizabeth Hocken, dated 18 December 1894.

50) L.S. Vygotsky, Mind in society: the development of higher psychological processes (Cambridge, MA, Harvard University, 1978).

51) Jeffrey C. Alexander, Bernhard Giesen and Jason L. Mast, Social performance: Symbolic action cultural pragmatics and ritual (Cambridge, Cambridge University Press, 2006): 54; Jonathan Turner, Face to Face: Toward a Sociological Theory of Interpersonal Behavior (Stanford, Stanford University Press, 2002).

52) Chalfen (1991): 6; Bliss (2006): 5.

53) See 'Coming Thro' the Rye', fig. 27, Appendix II, p. 217. Susan Buckland photograph album, SB72, private collection, Louisville, Kentucky. 
54) James Johnson, The Scots Musical Museum of Six Hundred Songs: Proper basses for the pianoforte (Edinburgh, Wm Blackwood \& Sons, 1787-1803). 'Coming through the Rye was included in volume 5; see pp. 430-431. Additional notes were supplied on p. 377. Suggested tunes for 'Coming Thro' the Rye' were given as 'Common' Frae the Town' and 'Auld Lang Syne'. 'Coming Thro' the Rye', was subsequently included in the repertoire of acts compiled by the Rooks. Emma Cecilia Rook and Elizabeth Jane Rook, Tableaux, Charades and Pantomines (1914): 51.

55) Burns died on 21 July 1796.

56) The first settlers from Scotland arrived at Port Chalmers in Otago, on the John Wickliffe and the Philip Laing on 23 March1848.

57) See Internet sites such as Images of 'Coming Thro' the Rye'. Of particular note, are the images from early to mid-nineteenth century include engravings (see for example, Harper's Weekly, 22 May 1858, p. 224), but also sheet music published in a number of different countries, and also the extensive repertoire of staged images produced for the stereograph. The first stereographs were produced by Sir Charles Wheaton in the 1830s. They became increasingly popular from the 1850 s with the introduction of a small handheld apparatus developed by Wendell Holmes.

58) See fig. 26, Appendix II, p. 218; also J.R. Hanna, 'Art Pictures by Hanna, Artists and Photographers', The Cyclopedia of New Zealand: Industrial, Descriptive, Historical, Biographical Facts (Christchurch, 2 (1902): 319.

59) There are other interpretations for this song. One version locates the scene as a couple crossing a ford; another locates the scene as in an alley or 'rye'.

60) See fig. 27, Appendix II, p. 219, Susan Buckland photograph album, SB72, private collection, Louisville, Kentucky.

61) Lilias Hārata te Aho Burnett was the daughter of William Burnett and Raiha Eliza Keo Keo Alexander of the Ngāti Te Ūpokoiri tribe from Hawkes Bay. William Burnett became the manager of Hawkdun Station near St Bathans in Central Otago in 1878. Ini, as Lilias was known, married Charles Statham in 1905. Statham entered parliament in 
1911. He was speaker in the House of Representatives between the years 1923-1935 and was knighted for his services.

62) J.R. Hackman, Groups that work (and those that don't): Creating conditions for effective teamwork (San Francisco CA, Jossey-Boss, 1990); Noreen M. Webb, 'Group Collaboration in Assessment: Multiple Objectives, Processes and Outcomes' Educational Evaluation and Policy Analysis, 17, 2 (Summer 1995): 241-243.

63) Photograph album of Jessie Buckland, JB8, JB10, JB42, JB58, JB65, JB68, Hocken Library, University of Otago, Dunedin.

64) Photograph album of Susan Buckland, SB48, private collection, Louisville, Kentucky.

65) Letter from Dr G.B. Orbell to W. Main, 1980.

66) Letter from N.M. Buckland to W. Main, dated 15 March1983, private collection, Wellington.

67) Photograph album of Susan Buckland, SB5, private collection, Louisville, Kentucky.

68) Gladys Hocken, letters to her parents, Dr T.M. Hocken and Elizabeth Hocken, dated, 17 May [1897], and [21 May1897], re: Susan sending copies of prints of 'Coming Thro' the Rye' to her Aunt Bessie Hocken.

69) James M. Reilly, The Albumen and Salted Paper Book: the history and practice of photographic printing 1840-1895, Chapter Seven (New York, Rochester, Light Impressions Corporation, 1980).

70) Susan Buckland photograph album, private collection, Louisville, Kentucky, see SB17, SB19, SB20, SB60, SB68a, SB76. Also, Carrie Buckland photograph album, Hocken Library, University of Otago, Dunedin, CB26, CB27. Also, Jessie Buckland photograph album, Hocken Library, University of Otago, Dunedin, JB3, JB15, JB30, JB31.

71) Fig. 28, Appendix II, p. 220. Susan Buckland photograph album, SB19, private collection, Louisville, Kentucky. 
72) See the Australasian, for 5 January 1895: 20, and Australasian, 2 February1895: 212.

73) Australasian, 24 August 1895: 359.

74) Australasian, 29 May 1897: 1097.

75) Fig. 18, Appendix II, p. 213, Susan Buckland photograph album, SB18, Hocken Library, University of Otago, Dunedin.

76) Fig. 29, Appendix II, p. 220, Jessie Buckland photograph album, JB5, Hocken Library, University of Otago, Dunedin.

77) W. Main, The New Zealand Listener (Wellington, 27 April, 1985); W. Main and J. Turner, New Zealand Photography from 1840s to the Present (1993): 27.

78) Rosenblum (1994): 7.

79) Jessie Buckland used a number of nom-de-plumes. An early one that she used in the Australasian was P. Gay. See the Australasian, 29 May 1897, p. 1079. Without further conclusive evidence, it is not possible to speculate on her choice of nom-de-plume. See Fig. 30, Appendix II, p. 221.

\section{Chapter 5}

1) Richard Chalfen, Turning Leaves: The Photograph Collections of Two Japanese American Families (Albuquerque, University of New Mexico Press, 1991).

2) Chalfen (1991): 8-9, 130.

3) Richard Chalfen, Snapshot versions of life (Madison, University of Wisconsin, 1987;

Richard Chalfen, 'Interpreting family photography as pictorial communication', in Image-based Research: A Sourcebookfor Qualitative Researchers, Jon Prosser, ed. (London, RoutledgeFalmer Press, 1998): 214-234; Richard Chalfen, 'Redundant Imagery: Some observations on the use of Snapshots in American Culture', Journal of American Culture, 4, 1 (1981): 106-113; Richard Chalfen, 'Snapshots 'r' us: the evidentiary problematic of home media', Visual Studies, 17, 2 (2002): 141-144. 
4) Chalfen (1991): 2, 22.

5) Catherine Kohler Riessman, Qualitative Research Methods (Newbury Park, CA, Sage Publications, 1993): 15.

6) Martha Langford, Suspended Conversations: The afterlife of memory in photographic albums (Montreal, McGill-Queens University Press, 2001): 122-123.

7) W.J. Ong, The Presence of the Word: Some Prolegomena for Cultural and Religious History (New Haven, CT, Yale University Press, 1967); W.J. Ong, 'Media transformation: The Talked Book', in W.J. Ong, Interfaces of the Word: Studies in the evolution of Consciousness and Culture (Ithaca, NY, Cornell University Press, 1977a): 82-91; W.J. Ong, 'Typographic rhapsody: Ravisius Textor, Zwinger and Shakespeare', in W.J. Ong, Interfaces of the Word: Studies in the Evolution of Consciousness and Culture (Ithaca, NY, Cornell University Press, 1977b): 146-188; W.J. Ong, Orality and Literacy: The Technologizing of the Word (London, Methuen, 1982); W.J. Ong, 'The Presence of the Word', in Religion and Literature: a reader, Robert Detweiler and David Jasper, eds (Westminster, John Knox Press, 2000). For biographical information on Ong see, Paul A. Soukup, S.J., 'Walter J. Ong, S.J.: A Retrospective', Quarterly Review of Communication Research, 23, 1 (2004): 3-23.

8) Ong (1977b): 161-166.

9) Langford (2001): 18, 124-126.

10) Langford (2001): 124-126.

11) Langford (2001): 21 .

12) Langford (2001): 139, 151, 175.

13) Langford (2001): 123.

14) For instance, Martha Langford's research has already had an influence on the work of Lynn Berger. See Lynn Berger, 'Snapshot's, or: Visual Culture's Clichés’, Photographies, 4, 2 (2011): 175-190. 
15) Wallace Chafe and Deborah Tannen, 'The Relation between Written and Spoken Language', Annual Review of Anthropology, 16 (1987): 383-407. See also Deborah Tannen, 'Relative focus on involvement in oral and written discourse', in D.R. Olson, Nancy Torrance, Angela Hidyard, eds, Literacy, Language and Learning: the nature of Consequences (Cambridge, University of Cambridge Press, 1985); Deborah Tannen, 'Oral and Literate Strategies in Spoken and Written Narratives', Linguistic Society of America, 50, 1 (1982): 1-21; Deborah Tannen, Talking Voices (Cambridge, Cambridge University Press, 1989).

16) Tannen (1985): 124. Tannen's observation about shared social conventions also found a resonance with Mieke Bal. See Mieke Bal, A Mieke Bal Reader (Chicago, University of Chicago Press, 2006): 270.

17) Tannen (1985): 127.

18) Tannen (1985): 130-131.

19) Tannen (1985): 130.

20) Susan Stewart, Nonsense: Aspects of Intertextuality in Folklore and Literature (Baltimore, The Johns Hopkins University Press, 1979). Also, Susan Stewart, On Longing: Narratives of the Miniature, the Gigantic, the Souvenir, the Collection (Baltimore, The Johns Hopkins University Press, 1993).

21) Stewart (1979): ix, 13.

22) Stewart (1979): ix.

23) Stewart (1979): 3-46.

24) Stewart (1979): 47-195.

25) For a discussion on this topic see: Mein Steinberg, 'Telling in Time (1): Chronology and Narrative Theory', Narratology Revisited II, 11, 4 (Winter 1990): 901-948.

26) See Lucy Acland photograph album, LA1-35; LA41-42, private collection, Christchurch. 
27) Fig. 31, Appendix II, p. 222, Lucy Acland photograph album, LA1, private collection, Christchurch.

28) See Lucy Acland photograph album, LA2-8, private collection, Christchurch.

29) Fig. 32, Appendix II, p. 223. Margaret and Laura Bowen photograph album, MLB9, Canterbury Museum, Christchurch.

30) Fig. 33, Appendix II, p. 223. Margaret and Laura Bowen photograph album, MLB3, Canterbury Museum, Christchurch.

31) Also see figs $34 \&$ 35, Appendix II, p. 224. Detail of MLB3, Margaret and Laura Bowen photograph album, Canterbury Museum, Christchurch.

32) Scott's cousin, Robert Julian Scott (1861-1930) married Margaret and Laura Bowen's cousin, Gertrude Elizabeth Bowen on 22 October, 1889. There were more close connections. Georgiana Markham, sister of Clements Robert Markham (1830-1916) who was the English sponsor of the Antarctic expeditions, was the wife of C.C. Bowen. Ernest Shackleton (1874-1922) was also entertained by the C.C. Bowen and his family when he was at Lyttelton under Scott in Discovery, in1901; Morning, in 1903, Nimrod, in 1907 and1909, and with the Aurora in 1917. For example, both men appear together in one of photographs taken by Margaret and Laura Bowen at Middleton c. 1903. See Margaret and Laura Bowen photograph album, MLB23, Canterbury Museum, Christchurch.

33) See graphs I-III, Appendix III, p. 255-256.

34) The only photographs that can be firmly identified as being taken by Frances Stoddart are 'Richmond, Nelson' and 'Rai Valley, Nelson' whole-plate prints in the Mary Stoddart photograph album, Canterbury Museum, Christchurch; see $\mathrm{MS}_{1} 48$ and $\mathrm{MS}_{1} 50$. These images were probably produced by Frances when she was a member of the Nelson Photographic Society in the late 1890s. For information on Frances and her association with the Nelson Camera Club, see: Rosalina McCarthy, 'Women and the Nelson Camera Club 1888-1890', New Zealand Journal of Photography (November, 1994): 16. 
35) Alfred Martin was practising photography in Christchurch at this period. He later moved to Wanganui where he took over the studio of Denton. He travelled to the Chatham Islands in March 1877. For a short commentary on Martin, see Joan Woodward, A Canterbury Album (Christchurch, Te Waihora Press, 1987): 104-108. Margaret includes photographs by Martin in her album, see Margaret Stoddart photograph album, MOS1-MOS6, Canterbury Museum, Christchurch. Mabel Potts was the daughter of Thomas and Emma Potts. The Potts lived at Ohinetahi, Governor's Bay, at the western end of Lyttelton Harbour.

36) Fig. 36, Appendix II, p. 225. Margaret Stoddart includes photographs that she purchased on her trip to Australia in her album. See Margaret Stoddart photograph album, MOS17, MOS18, MOS19, MOS20, MOS26 and MOS27.

37) See Chapter Six, p. 98 for further information on Beattie.

38) Margaret Stoddart received copies of photographs from M.J. Dixon. See Margaret Stoddart photograph album, MOS14. But in relation to the ascents of Mt Torlesse in 1892 and 1893 , it is not possible to ascertain from which of her friends or acquaintances Stoddart received these photographs. G.E. Mannering would seem to be the most likely person as he was known to have been an enthusiastic amateur photographer. But, it should also be noted that other members of the party were also photographers. For instance, James and Janet Westland who were from Britain and India and resident in Christchurch for about two years, c.1892-3, were both enthusiastic amateurs. For a recent survey of the Westland's expeditions in Canterbury-Westland, see Graham Langton, 'The Westland family at large in the Rakaia and Westland', New Zealand Wilderness, (February, 2003): 6-8.

39) See figs $37 \&$ 38, Appendix II, pp. 226-227. See Margaret Stoddart photograph album, MOS9, MOS10, MOS15, MOS16, Canterbury Museum, Christchurch.

40) Fig. 39, Appendix II, p. 228, Margaret Stoddart photograph album, (MOS16), Canterbury Museum, Christchurch.

41) See Margaret Stoddart photograph album, MOS9, MOS10, MOS15 and MOS16, Canterbury Museum, Christchurch. 
42) Margaret Stoddart, scrapbook 55/66, Canterbury Museum, Christchurch.

43) G.E. Mannering, The New Zealand Alpine Journal (Christchurch, Whitcombe and Tombs Ltd, 1 (4), 1893): 190-96. According to Mannering the party comprised of Mr and Mrs A.M. Olliver, Mr James and Mrs Janet Westland, Margaret Stoddart, Miss Harper, Miss Lean, Mr Harman, Messrs, Graham, Black, and George Mannering. The climb took up to seven hours.

44) Margaret Stoddart photograph album, MOS10, Canterbury Museum, Christchurch.

45) Stewart (1979): 69.

46) Fig. 40, Appendix II, p. 229; also Lucy Acland photograph album, LA36-40, private collection, Christchurch.

47) Barbara Herrnstein Smith, 'Narrative Versions, Narrative Theories, On Narrative', Critical Inquiry, 7, 1 (1980): 213-236.

48) Lucy Acland photograph album, LA1-35; LA41-42, private collection, Christchurch; also see graph I, Appendix III, p. 265.

49) Margaret Stoddart photograph album, MOS17-MOS19, MOS26, \& MOS27, Canterbury Museum, Christchurch.

50) Stewart (1979): 202.

51) Stewart (1979): 208.

52) Lucy Acland photograph album, LA1, private collection, Christchurch.

53) Hayden White, The Content of the Form: Narrative Discourse and Historical Representation, Baltimore, Johns Hopkins University Press, 1987): 27; Robert Kellogg, in Robert Scholes, James Phelan and Robert Kellogg, The Nature of Narrative: Fortieth Anniversary Edition (New York, Oxford University Press, 2006): 211. 
54) David Carr, 'Narrative and the Real World: An Argument for Continuity', in P. Hinchman and S. Hinchman eds, Memory, Identity, Community: The idea of narrative in the human sciences (Albany, State University of New York Press, 2001): 8.

55) Fig. 41, Appendix II, p.230. Jessie Buckland photograph album, JB44, Hocken Library, University of Otago, Dunedin.

56) Stewart (1979): 61.

57) Also Jessie Buckland photograph album, JB7, JB14, JB16, JB17and JB21, Hocken Library, University of Otago, Dunedin.

58) Fig. 42, Appendix II, p. 231. Jessie Buckland photograph album, JB21, Hocken Library, University of Otago, Dunedin; also see JB19, JB60, JB68.

59) See graphs IV-VI, Appendix III, pp. 256-257.

60) Stewart (1979): 103.

61) Stewart (1979): 86.

62) Patricia Holland, 'Introduction', in J. Spence and Patricia Holland, Family Snaps: The Meanings of Domestic Photography (London, Virago, 1991): 1.

63) Holland (1991): 1.

64) Elizabeth Edwards and Janice Hart, 'Introduction', Photographs, Objects, Histories: On the materiality of images (London, Routledge, 2004): 12. The term 'damnation memorize' has its origins in Classical times. See: Robert Draper, 'Rethinking Nero', National Geographic (September, 2014): 82-111.

65) See fig. 43, Appendix II, p. 232. Jessie Buckland photograph album, JB43, JB64; Caroline Buckland photograph album, CB17, CB22, CB25, CB26, CB31, CB38, Hocken Library, University of Otago, Dunedin, and also Susan Buckland photograph album, SB19, SB41, private collection, Louisville, Kentucky.

66) Nancy Buckland, The Bucklands: a continuation of C.M. Gordon's story and revision of the Buckland and Taylor trees (Christchurch, New Zealand, 1975): 37. 
67) Stewart (1979): 108.

68) See Chapter Four and images in Susan Buckland photograph album, SB5, private collection, Louisville, Kentucky, and Jessie Buckland's album, JB5, Hocken Library, University of Otago, Dunedin.

69) Deborah Tannen, 'How is conversation like literary discourse? The role of imagery and details in creating involvement', in Pamela Downing, Susan D. Lima, Michael Noonan, eds, The Linguistics of Literacy (Amsterdam, The Netherlands, John Benjamin Publishing Co., 1992): 31-46.

70) Fig. 44, Appendix, p. 233. Jessie Buckland photograph album, JB30, Hocken Library, University of Otago, Dunedin.

71) Lászlo' Biŕo'(1899-1985) invented the biro pen in 1931. It was first patented in 1938, but it was not although the late 1940s that ball point pens become widely available.

72) Deborah Tannen, 'The sex-class-linked framing of talk at work', in Gender and Discourse (Washington, Georgetown, 1994).

73) Tannen (1989): 144.

74) Takie Sugiyama Lebra, Japanese Patterns of Behaviour (Honolulu, University of Hawaii, 1976): 23.

75) Gerard Genette, 'Fictional Narrative, Factual Narrative', Poetics Today: Narrotology Revisited II (Winter, 1990): 755-774. For his comments on the frequency of acceleration, see p. 761.

76) See reference 44; also Herrnstein Smith (1980): 213-236.

77) Langford (2001): 140.

78) Langford (2001): 140. 
79) William Labov, Language in the Inner City: Studies in Black English Vernacular (Philadeplphia, University of Pennsylvania Press Inc., 1972): 378.

80) See Susan Buckland photograph album, SB41, SB53, SB63, private collection, Louisville, Kentucky.

81) Fig. 45, Appendix II, p. 233, Susan Buckland photograph album, SB41, private collection, Louisville, Kentucky.

82) See fig. 2, from Mary Stoddart photograph albums $1 \& 2, M_{1} 4 ; M_{2} 27$; also see discussion in Chapter Two, p. 16.

83) Fig. 46, Appendix II, p. 234. Mary Stoddart photograph album 2, $\mathrm{MS}_{2} 29$, Diamond Harbour Historical Society, Diamond Harbour.

84) See Mary Stoddart photograph album $1, \mathrm{MS}_{1} 12$. For images of James as a farmer see Mary Stoddart photograph album $2, \mathrm{MS}_{2} 34, \mathrm{MS}_{2} 54$. Images of James as a hunter; see Mary Stoddart photograph album, $\mathrm{MS}_{2} 33$. For images of James mining; see Mary Stoddart photograph album 2, $\mathrm{MS}_{2} 3 ; \mathrm{MS}_{2} 5 ; \mathrm{MS}_{2} 7 ; \mathrm{MS}_{2} 10$. Also for images of James as a soldier see James with group of soldiers of Victoria Column taken in 3 October, 1893, Mary Stoddart photograph album 1, $\mathrm{MS}_{1} 10$, Canterbury Museum, Christchurch.

85) Fig. 47, Appendix II, p. 235. See Mary Stoddart photograph album 1, MS 12.

86) Fig. 48, Appendix II, p. 235. See Mary Stoddart photograph album 2, $\mathrm{MS}_{2} 34$.

87) Mary Stoddart photograph album $1, \mathrm{MS}_{1} 1$. James Stoddart died on 17 January 1901. See 'Deaths', The Star (Christchurch), 12 March 1901, p.3. See also an interview with James Stoddart in The Press (Christchurch), under the title 'A Christchurch Man in Rhodesia', Topics of the Day, The Press, 27 November, 1896, p. 4; the report 'Christ's College Old Boys' in South Africa', in The Star (Christchurch), 2 May, 1900, p. 1.

88) Geoffrey Batchen, Forget Me Not, Photography \& Remembrance (Amsterdam, Van Gogh Museum, 2004): 48.

89) Batchen (2004): 41. 
90) Mary Stoddart died following childbirth on 27 October, 1909. In addition, it is worth noting that a published obituary for Margaret Stoddart, after her death in 1934, was added to the inside the back cover of Mary's second album.

91) Figs $49 \&$ 50, Appendix II, p. 236, Mary Stoddart photograph album 2, $\mathrm{MS}_{2} 2$.

Excerpt from 'Whisperings in the Wattle Boughs', from an anthology entitled Sea Spray and Smoke Drift, by Australian poet, Adam Lindsay Gordon (1833-1870).

'Oh! Whisper buried love, is there rest and peace above!

There is little hope and comfort here below.

On your sweet face lies the mould

And your bed is straight and cold.

Near the haven where the sea-tides ebb and flow'

For more information on Gordon, see Leonie Kramer, The Australian Dictionary of

Biography (Melbourne, Melbourne University Press, 4, 1972).

92) The inscription inside the front cover of Mary Stoddart's second album reads: 'With love to "May" From “Dick," June 27 1898'.

93) Stewart (1979): 208.

94) Stewart (1979): 30.

95) With references to Susan Buckland and Mary Stoddart, see notes 78 and 84. I would like to add to these examples, one from the album of Lucy Album where she includes a series of images of 'Lucy with her dog, Tor', LA51, LA60. See figs 51 \& 52, Appendix II, p. 237.

96) Batchen (2004): 95.

97) Langford (2001): 5.

\section{Chapter 6}

1) Gillian Rose, Doing Family Photography: The Domestic the Public and the Politics of Sentiment (Farnham, England, Ashgate Publishing Ltd, 2010): 9, 20.

2) Rose (2010): 25-26. 
3) Rose (2010): 1, 9, 59-60.

4) Marcel Mauss, The Gift: The form and reason for exchange in archaic societies, foreword by Mary Douglas (London, Routledge Classics, 1990).

5) Mauss (1990): 42.

6) Russell Belk, 'Sharing', Journal of Consumer Research, 36, 5 (2010): 727; Yochai Benkler, 'Sharing Nicely: On Shareable Goods and the Emergence of Sharing as a Modality of Economic Production', Yale Law Journal, 114, 11 (2004): 273-358; Jonathan Parry, 'The Gift, The Indian Gift and The "Indian Gift”, Man, 21 (1986): 466-471. Price was the first to write on this subject. See: John A. Price, 'Sharing: The Integration of Intimate Economics', Anthropologica, 17, 1 (1975): 3-37.

7) Belk (2010): 727; Benkler (2004): 273-358; Markus Giesler, 'Consumer Gift System: Netnographic Insights from Napster', Journal of Consumer Research, 33, 2 (2006): 283290.

8) Russell Belk, 'Why Not Share Rather Than Own?' Annals of the American Academy of Political and Social Sciences, 611, 5 (2007): 126-140.

9) Belk (2010): 727; Giesler (2006): 283-90; John F. Sherry, 'Gift-Giving in Anthropological Perspective', Journal of Consumer Research, 10, 9 (1993); 157-168; B.S. Frey and S. Meier, 'Social comparisons and pro-social behavior: Testing conditional cooperation in a field experiment', American Economic Review (2004): 2; James Woodburn, 'Sharing is not a Form of Exchange: An Analysis of Property Sharing in Immediate-Return Hunter-Gatherer Societies', C.M. Hanm, ed., in Property relations: Renewing the Anthropological Traditions (Cambridge, Cambridge University Press, 1998): 48-63.

10) Belk (2010): 126-40. See also Cele Otnes, Yina M. Lowrey \& Young Chan Kim, 'Gift selection for Easy and Difficult recipients: a social role interpretations', Journal of Consumer Research, 20, 2 (1993): 232; Sherry (1993): 159; Giesler (2006): 20; Frey and Meier (2004): 2, 16; Parry (1986): 457. 
11) Rose (2010): 59, 61. Also see Richard Chalfen's account of the sharing of photographic images among Nisei or second generation families living in America in Turning Leaves: The Photograph Collections of Two Japanese American Families (Albuquerque, University of New Mexico, 1991): 124-125; Sherry (1993): 159.

12) Rose (2010): 63. When it comes to sending photographs to friends and family, Rose makes a clear distinction between the practices of a photo sent in the post and one that is sent electronically. Of course, sending an image electronically was not possible in the 1890s. Also, see Rose (2010): 64, 67-68 and Otnes et al. (1993): 232.

13) The ultimate 'free gift' must be the gift of blood or of a bodily organ. For further discussion on this subject see: Monica Konrad, Nameless Relations: Anonymity, Melanesia and Reproductive Gift Exchange between British Ova Donors and Recipients (Oxford, Berghahn, 2005): 71-75; also, Thomas Widlock, 'Sharing by default: Outline of an Anthropology of Virtue', Anthropological Theory, 4, 1 (2004): 61.

14) Belk (2010): 726.

15) Chalfen (1991): 129.

16) Chalfen (1991): 129.

17) Chalfen (1991): 138.

18) Kate Ivens, Appendix I, p. 199.

19) Florence Wright, Appendix I, p. 201.

20) Caroline Ivens children's home was the precursor of the Cholmondeley Children's Home which was permanently established at Governor's Bay in 1925 with funding from local benefactor, Hugh Heber Cholmondeley. Its mission was to provide short-term quality care for children aged between 3-12 years.

21) For a comprehensive background to the history of Deaconess movement see, Rev. C. Golder, History of the Deaconess Movement in the Christian Church (Cincinnati, Jennings and Pye, 1903). 
22) For the history of the Deaconess community in Christchurch see Ruth Fry,

Community of the Sacred Name: A Centennial History (Christchurch, The Community of the Sacred Name, 1993).

23) Fig. 53, Appendix II, p. 238. Kate Ivens commenced her training as a deaconess on 5 November1895. She was ordained on 16 November 1899. See Fry (1993): 105. Also see Kate Ivens, Appendix 1, p. 196.

24) See Fry (1993): 105; also see Kate Ivens, Appendix 1, p. 196.

25) The departure date from Auckland was 27 March, 1896 (see 'Shipping', New Zealand Herald, 27 March 1896, p. 4.) She travelled to Norfolk Island on the mission yacht, Southern Cross, in the company of Elizabeth Colenso and her granddaughters Edith and Christine Simcox, arriving 9 April 1896. Ivens returned to New Zealand in September 1896 with her brother. She arrived in Auckland on the Southern Cross, 'Shipping', New Zealand Herald, 23 September 1896, p. 4.

26) Catherine R. Ross, 'The Legacy of Elizabeth Fairburn Colenso', International Bulletin of Missionary Research, 30, 3 (2006): 148-152.

27) Ruth Fry (1993): 100; also see Kate Ivens, Appendix 1, p. 196.

28) See Janet Murray, Elizabeth Colenso, 1821-1904, Dictionary of New Zealand Biography, 1 (Wellington, Department of Internal Affairs, 1990): 86-7; Catherine R. Ross, “More than 'Wives' 'Helpmeets' 'Heroines' or 'Partners'," Mission Studies, 20, 2 (2004): 140-68; Ross (2006): 148-152.

29) See Murray (1990): 87. Her knowledge of Māori led to Colenso taking an active part in assisting the Reverend Robert Maunsell in the overseeing the publication of the translation of the Bible into Māori, when she was in England in the 1860s. While she was on Norfolk Island, Colenso also translated the Bible into Mota, the language spoken among the Melanesians at the mission.

30) There is also little mention of her contribution to the Melanesian Mission on Norfolk and certainly not her developing interest in photographic practices. 'Elizabeth Colenso on Norfolk Island', Auckland-Waikato Historical Journal, 29 (1976): 9-12. 
31) See Rev. Michael Blain in collaboration with the Right Reverend Dr Terry Brown Historical Notes on the Diocese of Melanesia and the mandated Territory of New Guinea (1885-1949), 2008, Project Canterbury).

32) Diaries and Notebooks of Elizabeth Colenso, 1862-1895 (Ms-0557-0577), Alexander Turnbull Library, Wellington. This archival material was bequeathed to the library by Francis S. Simcox in 1958; also the diary for 1889 (Ms-papers-4176). Transcriptions of Frances Edith Swabey (1870-1954) made by Francis Selwyn Simcox in 1955, were also bequeathed to Alexander Turnbull Library in 1958 (Ms 1940).

33) Also, David Hilliard, God's Gentlemen: A History of Melanesian Mission 1849-1942 (Brisbane, University of Queensland Press, 2013). According to Raymond Nobbs, in 1896, 647 persons were living on Norfolk Island on an area of 400 hectares of land. See Raymond Nobbs, Norfolk Island and its First Settlement: The First Hundred Years (Sydney, Library of Australian History, 2006): 107. Raymond Nobbs, St Barnabas and the Melanesian Mission (Sydney, Macquarie University, Australian History Resources Centre, 1990).

34) Fig. 54, Appendix II, p. 238, Elizabeth Colenso photograph album, EC15. The single residents were usually billeted with married residents on the island. Ivens may have lodged with Colenso. Colenso had in her possession one of the larger houses on the island. See Blain and Brown (2008).

35) Chalfen (1991): 129.

36) Age was not necessarily a barrier to taking up photography. After all, Julia Margaret Cameron was 48 when she began taking her first photographs.

37) Elizabeth Colenso: Her work for the Melanesian Mission by her eldest grand daughter, Frances Edith Swabey, 1956. Transcribed by Right Reverend D. Terry Brown, Bishop of Malaita church of the province of Melanesia (2007), section 3. Here Colenso specifies the daily routine on the island. The only free time for residents within the highly-regulated structure of the mission, was from $3.30 \mathrm{pm}$ until $6 \mathrm{pm}$ daily. 
38) Elizabeth Colenso photograph album, EC40 (NIM 1841), Norfolk Island Museum, Norfolk Island.

39) 'Philosophical Institute', The Press, 3 May 1894, p. 3; The last 12 months associates admitted at for a subscription of five shillings. The Press, 4 May 1893, p. 3. 'Canterbury Photographic Society', Sharland's Photographic Journal, 8 October 1894, p. 75.

40) Fig. 55, Appendix II, p. 239. Kate Wood album 2, KW 27 . Anecdotal account from Dave Stewart, direct descendant of Kate Wood, April 2010, Martinborough, Wairarapa.

41) For details of these albums, see Kate Wood photograph albums 1-3, Appendix I, p. 201.

42) Kate Wood, photograph album 1, private collection, Martinborough. Kate Ivens contributed 18 photographs to Wood's album. See Wood photograph album 1, KW $15-7$, $\mathrm{KW}_{1} 12-17$, private collection, Martinborough.

43) Fig. 56, Appendix II, p. 240, Kate Wood Album 1, KW 113 \& KW 14.

44) 'Photographic Exhibition', The Press, 10 October1894, p. 5; 'Photographic Exhibition, 8-15 September, 1894 at the art gallery in Armagh Street, 600 photographs', 10 September 1894, p. 5. 'Sharland's New Zealand Photographer', in Sharland's New Zealand Journal, November, 1894.

45) At least 8 other people contributed photographs to Colenso's second photograph album which she worked on from the early 1890s up until her death in1904. They were Miss Anne Firmstone, Rev C.W. Browning, Mrs Browning, Rev. L.P. Robin, The Simcox family, Mr Laing, J. W. Beattie, Rev. W.C. O'Ferrall.

46) Elizabeth Colenso photograph album, EC6-EC11, EC13-EC15, EC17, EC18, EC20, EC28, Norfolk Island Museum, Norfolk Island.

47) Fig. 57, Appendix II, p. 241, Elizabeth Colenso album, EC8, Norfolk Island Museum, Norfolk Island. 
48) This followed the curriculum established by Colenso when she was in charge of a boarding school for Maori girls at the Taupiri mission in the Waikato with Benjamin Ashwell and his family, from 1854-1861. See Ross (2006): 148-152.

49) Figs 58 \& 59, Appendix II, p.241-242. Elizabeth Colenso photograph album, EC14, EC 6, Norfolk Island Museum, Norfolk Island. Also see EC48, EC52 and EC55.

50) Fig. 60, Appendix II, p.242, Elizabeth Colenso photograph album, EC7, Norfolk Island Museum, Norfolk Island.

51) Fig. 61, Appendix II, p. 243, Elizabeth Colenso photograph album, EC9, Norfolk Island Museum, Norfolk Island.

52) The Comins assisted Colenso in assembling her second photograph album. Colenso notes this in entries in her diary dated 10 and 21 November, 1891 (Ms-0557-0577), Alexander Turnbull Library, Wellington.

53) Fig. 62, Appendix II, p. 243. Elizabeth Colenso photograph album, flyleaf, Norfolk Island Museum, Norfolk Island.

54) Elizabeth Colenso photograph album, EC47, EC49, EC50, EC51, EC53, Norfolk Island Museum, Norfolk Island.

55) J.W. Beattie, Journal of a Voyage to the Western Pacific in the Melanesian Mission Yacht Southern Cross, 25 August-10 November, 1906, Royal Society of Tasmania (MSS RS 29/3).

56) Jean and John Comaroff, 'Introduction', in Jean and John Comaroff, eds, Modernity and its Malcontents, Ritual and Power in Postcolonial Africa (Chicago, University of Chicago Press, 1993): xvi.

57) Ann Victoria Bliss, 'Fixing the Family: The Function of the Family Photograph in Albums and Literature', PhD in English (University of California, Davis, 2006): 3.

58) Bliss (2006): 3. 
59) Patricia Holland, 'Introduction', in Jo Spence and Patricia Holland, eds, Family

Snaps: the Meanings of Domestic Photography (London, Virago Press Ltd, 1991): 1.

60) Bliss (2006): 139.

61) Yi-Fu Tuan, 'The Significance of the Artefact', Geographical Review, 70, 4 (1980): $462-472$.

62) Erich Fromm says, 'If I am what I have and if what I have is lost, who then am I'. See Erich Fromm, To Have or To Be (New York, Harper \& Row, 1976): 76.

63) William James, The Principles of Psychology (New York, Henry Holt, 1, 1890): 291292.

64) Mihaly Csikszentmihalyi and Eugene Rochberg-Halton, 1981, The Meaning of Things: Domestic Symbols and the Self (Cambridge, Cambridge University Press, 1981): 53; also see Parry (1986): 457.

65) Elizabeth Siegel, 'Galleries of Fame and Friendship: The history of nineteenthcentury American photograph albums', PhD in Art History (Chicago, University of Chicago, 2003): 15.

66) Florence Wright, the Dell family photograph album, Appendix I, p. 201.

67) Barbara Harrison, 'Snap Happy: Toward a Sociology of 'Everyday’ photography' in C.J. Pole, ed., 'Seeing is Believing? Approaches to Visual Research', Studies in Qualitative Methodology (2004): 26.

68) Captions were only added to the Dell photograph album in the mid-1990s by the present custodian of the album, Clive Morriss. The information for the captions came from his mother, Rhonda Mary Dell (later Morriss) b.1900. She is pictured on the seat between her parents in the group photograph of the Dell family taken by Florence Wright in 1902; see fig. 63, Appendix II, p. 244.

69) Fig. 63, Appendix II, p. 244, the Dell family photograph album, FW1, private collection, Christchurch. 
70) For further information on E.G. Wright see

http://www.TeAra.govt.nz/en/biographies/2w34/wright-edward-george

71) See George Dell, sitting on the rug with a handsome boat, fig. 63.

72) Siegel (2003): 116.

73) The Morriss family considered that the album had a longer timeline. However, the evidence is against such a conclusion, for the first photograph in the photograph album and one of the last photographs in the album can be securely dated.

74) Fig. 64, Appendix II, p. 244, the Dell photograph album, FW2, private collection, Christchurch.

75) Figs 65, 66, Appendix II, p. 245, the Dell photograph album, FW29 \& FW27, private collection, Christchurch.

76) Wright's brother, Douglas, does appear in the images in association with his horses. See the Dell photograph album, FW15.

77) Snapshot of Florence Wright after the marriage ceremony on 3 June 1904. See fig. 67, Appendix II, p. 246, the Dell photograph album, FW30, private collection. Christchurch.

78) Loose cuttings in the Dell photograph album p. 30.

79) For further information on E.G. Wright see http://www.TeAra.govt.nz/en/biographies/2w34/wright-edward-george

80) Rose (2010): 63; Parry (1986): 457. (Parry and Rose use the word lien to describe the particular type of agency that the donor carries.)

81) John Frow, Time \& Commodity Culture: Essays in Cultural Theory and Postmodernity (Oxford, Clarendon Press, 1997): xvii, 103.

82) Belk (1988): 150.

83) Rose (2010): 63-64. 
84) See Rose (2010): 63-64; Otnes et al (1993): 33.

85) See Rose (2010): 7; Russell Belk, Melanie Wallendorf, and John Sherry, 'The Sacred and The Profane in Consumer Behaviour', Journal of Consumer Research, 15, 6, 1989): 18.

86) Jacques Derrida, Given Time: I. Counterfeit Money, Trans by Peggy Kampf (Chicago, University of Chicago Press, 1992): 1, 58. The philosophical position that Derrida proposed in Given Time drew comprehensively on a series of five lectures that Derrida had originally presented at the Ecole Normal Supérieur in Paris from 1977-78. In April 1991, Derrida gave the same series of lectures at the University of Chicago. The following year they were published by the University of Chicago Press.

87) See Derrida (1992) : 24, 37. Otnes, et al. (1993): 233.

88) Interview with Clive Morriss, custodian of the Dell photograph album from the mid1990s.

89) This information was supplied by Rhoda Mary Dell, later Morriss, who passed on much of this information to her son, Clive Morriss of Christchurch.

90) Frow (1997): 107.

91) Carolyn F. Curasi, Linda L. Price, and Eric J. Arnould, 'How Individuals' Cherished Possessions Become Families' Inalienable Wealth’ Journal of Consumer Research, 12 (2004): 609-22; Belk (1988):150; Harrison (2004): 25.

92) Curasi et al. (2004): 609-622.

93) Grant McCracken, 'Culture and Consumption: A Theoretical Account of the Structure and Movement of the Cultural meaning of Consumer Goods', Journal of Consumer Research, 13, 6 (1987): 71-69.

94) See comments in L.A. Bennett, S.J. Wolin and K.J. McAvity, 'Family Identity ritual and myth: A Cultural perspective on life cycle transitions, in Family Transitions: Continuity and Change over the Life, Celia Jaes Falicov, ed. (New York, Guilford Press, New York, 1988): 211-234. 
95) These were the sentiments expressed by Clive Morriss in relation to the Dell photograph album, in an interview conducted in 1996.

96) Acquisition of copies of photographs from this album by the Macmillan Brown Library at the University of Canterbury, 1996.

97) Allan Sekula, 'Reading an archive: photography between labour and capital', in P. Holland, J. Spence and S. Watney, eds, Photography/Politics Two (London 1986): 153161. Rose believes that here Sekula is relying on what is an over-simple distinction between a more authentic, previous use of the photographs and a less authentic reuse in the archive. However, his point that there is a change in use when a photograph enters an archive is nevertheless important. See Gillian Rose, 'Practising photography', Journal of Historical Geography, 26, 4 (2000): 569.

98) See Sekula (1986): 153-161.

99) Rose (2000): 558.

100) Catherine Keenan, 'On the relationship between personal photographs and individual memory', History of Photography, 22 (1998): 60-61.

101) Fig. 68, Appendix II, p. 246, see Vaughan Wood and Tom Brooking, 'Canterbury farming intensifies', in Garth Cant and Russell Kirkpatrick, eds, Rural Canterbury: Celebrating its history (Christchurch, University of Canterbury Press, 2001): 81-100. These authors have decided on a later dating for this photograph, placing it in the 1920s rather than the early 1900 s.

102) Descendants of the Simcox family donated both the albums that Elizabeth Colenso had compiled while she was living on Norfolk Island to the Norfolk Island Historical Society in the late 1970s. The albums were subsequently transferred to the Norfolk Island Museum where they were given their accession numbers by which they are now known by.

103) Barbara Hall initiated this research. Later, she was joined by Jenni Mathers. Their partnership resulted in an exhibition and an accompanying catalogue. 
104) Jenni Mathers, Christine Gillespie and Barbara Hall, Australian Women Photographers, 1890-1950 ( Melbourne, George Paton Gallery, Melbourne University Union, 1981).

105) For the list of photographs by Ivens selected for the exhibition, see Mathers et al. (1981): 30 .

106) There are inaccuracies in the biographical notes compiled by Mathers for Kate Ivens. For example, Ivens' name is listed with the group of women 'who married and subsequently found support for continuing as photographers from their husbands'. See Mathers et al (1981): 8.

107) See, The Photographers' Database (Auckland, Auckland City Library archives). http://www.aucklandcity.govt.nz/inmagic.Browse/Index browseaaspx?TN=PHOTOGRA $\underline{\mathrm{PH}}$

\section{Chapter 7}

1) Paul V. Crosbie, Interaction in Small Groups (New York, Macmillan, 1975): 2. See also Georg Simmel, Sociology of Georg Simmel (trans by K.H. Wolff) (Glenco, Illinois, Free Press, 1950); (Reprinted with permission of Macmillan Publishing Co., Inc. 1978): 135-136; Kingsley Davis, Human Society (New York, Macmillan,1948): 300; Howard L. Nixon II, The Small Group (Prentice-Hall Inc, Englewood Cliffs, New Jersey, 1979): 6.

2) See Crosbie (1975): 2. Also see Simmel (1950): 135-36 and Nixon (1979): 16.

3) See Nixon (1975): 7; also Crosbie (1975): 2.

4) According to Nixon a small group numbers between 2-20 members. See Nixon (1975): 7.

5) It is almost impossible to give a timeline here. However, the Buckland girls, for instance, worked together from the early 1890s until the early 1900s. 
6) Lucy Dyke Acland (1869-1903). Lucy also left two dependent children which the Acland women living at home initially took on the care of. In Chapter Five I mentioned that Mary Stoddart (1868-1909) also had died five weeks after giving birth to a daughter, on 16 October 1909. Likewise, her sisters, Margaret and Agnes became responsible for this child's upbringing.

7) Nixon (1979): 13. In drawing attention to this aspect of the makeup of small groups, Nixon draws on the earlier research of Dexter Dunphy. See Dexter Dunphy, The Primary Group: A Handbookfor Analysis and Field Research (New York, Appleton-CenturyCrofts, 1972): 3.

8) For information on J.C. Buckland's public life, see A Dictionary of New Zealand Biography, Guy Hardy Schofield, ed. (Wellington, Department of Internal Affairs, 1 (1940): 114.

9) For more on the background of the Buckland family during these years, see Vickie Hearnshaw, 'A Study in Black and White, The Life and Work of Photographer Jessie Buckland,' Women's Studies Journal, 13, 1 (1997): 47.

10) The 'real' postcard came into production with the introduction of the Kodak A3 in 1903. And with the development a special light-sensitive backed piece of cardboard the same size as a postcard in the printing process and became the postcard also facilitated this production.

11) Jabez Hughes, 'Photography as an Industrial Occupation for Women,' Anthony's Photographic Bulletin, 4 (1873): 162-166. Reprinted by Peter M. Palmquist, in Camera Fiends and Kodak Girls II: 60 Selections by and about Women in Photography, 1855 1965 (New York, Midmarsh Arts Press, 1995): 29-36. Jabez states that in any successful photographic studio in the later part of the nineteenth century there would be between 5 10 assistants. Most of them would have been women.

12) Naomi Rosenblum, A History of Women Photographers (New York, Abbeville Press, 1994): 74.

13) See Rosenblum (1994): 12. 
14) Wood is reputed to have worked for Steffano Webb from c. 1910-1940. On consulting members of Wood's extended family little additional information concerning Wood and her employment with Webb was gained.

15) Rosenblum (1994): 59. For a list of photographers active at this period in America, see Rosenblum (1994): 291-327.

16) List of the numbers of professional women photographers taken from Wise's and NZPO directories from 1900-1910. 1900: 1779, 165 photographers; 4 women: Cobb Hermann, Pulman, Robottom.1901:1886-7, 190 photographic studios; 6 women: Cobb, Craig, Hermann, Labatt, Pulman, Robottom.1905: 1494, 218 photographic studios; 5 women: Cobb, Cook, Craig, Hermann, Humphrey.1910: 1494, 251 photographic studios; 8 women: Buckland, Cobb, Davys, Greenwood, Humphrey, Smith, Moore sisters. Hermann, Pulman, Robottom, are known to have worked initially in partnership with their spouses. After the deaths of their husbands these women took over the studio management of the photographic studios on their own account.

17) Jessie Buckland worked as a professional photographer in Akaroa from 1907 until the early 1930s. She left Akaroa permanently in 1935. She travelled to England. She died at sea on the return voyage in 1939. For more on the background of the Buckland family during these years, see Hearnshaw (1997): 57-62.

18) The photographic supplement of Sharland's New Zealand Journal began in 1892 under the editorship of Auckland photographer, Josiah Martin. It continued to be published until 1911. This supplement is a useful contemporary reference for the development of photography in New Zealand. Over these years, numbers of articles were printed, including reprints from overseas publications. One example is the reprint of an article by English photographic enthusiast, Snowden Ward on 'The prospect of photography for the employment of women...' and published in Sharland's New Zealand Photographer on 7 February, 1895: 76.

19) 'Lady Professionals,' Sharland's New Zealand Photographer, 8 May, 1905: 19.

20) ibid. 
21) Frances Benjamin Johnston, 'What a Woman can do with a camera,' Ladies Home Journal (September, 1897): 6-7.

22) ibid.

23) ibid.

24) ibid.

25) Figs 69, Appendix II, p. 247, private collection, Christchurch. Also see fig. 70, Appendix II, p. 243, an advertisement in the Akaroa Mail, from March-May 1907.

26) Nom-de-plumes used by Jessie Buckland in the Australasian include P. Gay. See fig. 30, Appendix II, p. 221.

27) David Olson and Nancy Torrance, eds, Literacy and Orality (Cambridge, Cambridge University Press, 1991): 4.

28) Jerome S. Bruner and Susan Weisser, 'The invention of self: autobiography and its forms,' in David Olson and Nancy Torrance, eds, Literacy and Orality (Cambridge, Cambridge University Press, 1991): 129-148.

29) Richard Chalfen, "Snapshots "r" us: the evidentiary problematic of home media', Visual Studies, 17, 2 (2002): 142.

30) Leigh Gilmore, Autobiographies: A Feminist Theory of Women's Self-Representation (Ithaca, New York, Cornell University, 1994): xiii.

31) Rebecca Preston, 'Hope you will be able to recognize us': the representation of women and gardens in early twentieth-century British domestic 'real' photo postcard, Women's History Review, 18, 5 (2009): 794-795

32) Gilmore (1994): 10.

33) Otago Girls' Schools Letterbooks, 1890-1899, 6 March, 1899, p. 115 (AG266), Hocken Library, University of Otago, Dunedin; Otago Girls' Schools Letterbooks, 18901899, 3 May, 1902, p. 258 and 3 June, 1902, p. 114 (AG266), Hocken Library, University of Otago, Dunedin. Buckland was paid for $£ 30$ pounds a year. 
34) Susan married Lionel Orbell of Raukapuka, South Canterbury in 1901. Carrie began a small private school in Akaroa in the early 1900s. However, this venture was short-lived.

35) Fig.71, Appendix II, p. 248, Jessie Buckland photograph album, JB27 \& JB55, Hocken Library, University of Otago, Dunedin.

36) Fig. 72, Appendix II, p. 248. Also, Jessie Buckland photograph album, JB69, JB70 \& JB71, Hocken Library, University of Otago, Dunedin.

37) Fig. 73, Appendix II, p. 249, Jessie Buckland photograph album, JB69 Hocken Library, University of Otago, Dunedin.

38) Fig. 74, Appendix II, p. 249, Jessie Buckland photograph album, JB70 Hocken Library, University of Otago, Dunedin.

39) Banks Peninsula display title: A picture-land and story-land "Peninsula's story dairying and agricultural wealth in form of prime butter and big cheese and the cocksfootgrass-seed crop that brings its settlers in hundreds of thousands of pounds annually for Akaroa supplies a large proportion of the world's supply of cocksfoot seed - there were a number of exhibitions that drew attention to the important place the Peninsula occupied in the early history of New Zealand. Official record of the NZ International exhibition (1906/7): 203.

40) For information on J.C. Buckland's public life, see Schofield (1940): 114.

41) Auckland Weekly News, Pictorial supplement, 23 May 1907, p. 1.

42) 100 years Pure Progress, 1901-2001, Tourism NZ.

43) Thomas Pringle (1858-1931) was an amateur photographer from Wellington who was given assignments to undertake on behalf of the Government from 1901.

44) Akaroa Mail, 30 March, 1906, p. 2; Akaroa Mail, 4 March, 1910, p. 2.

45) Stephanie Cape, 'The history of the Pictorial Postcard in New Zealand', Research essay, for Stage III History of Design (Christchurch, School of Fine Arts, University of 
Canterbury, 1978): 10, 18; Alan Jackson, NZ Postcards: Rates and regulations to 1939 (Postal History Society of NZ, 1984): 9; Alan Jackson and W. Main, 'Wish you were here': The story of the New Zealand postcard (New Zealand Postcard Society, 2005); Robin McGill, Start up Postal History of New Zealand (Postal History Society of NZ Inc, 1966); R.D. Samuels, NZ Postal Stationery Catalogue, pt 1, Postcards, 1976; Frank Staff, The Picture postcard and its Origins (London, Lutterworth Press, 1966).

46) See Cape (1978): 3; Jackson and Main (2005): 23, 37. Jackson stated that postcards sold for $1 \mathrm{~d}$ or $2 \mathrm{~d}$ and the number sold increased. See pp. 9, 14. (1902: 1,239,004; 1906: 5,109,754) 1912: 12,255,477). A.P. Bates, Postcards, Post office statistics, 1903: $1 \mathrm{~m}$ cards; 1907: $7 \mathrm{~m}$ cards; 1909: $14 \mathrm{~m}$ cards.

47) The production of the 'real' postcard was greatly facilitated by the introduction of the Kodak 3A in 1903. The Kodak 3A took a 122 film which was 3 x 5 inches and therefore approximately of the regulation postcard. It came in 4, 6 and 10 exposure film. A variation of the Kodak $3 \mathrm{~A}$, of which there were quite a number, came with a combination back which could take glass plates.

48) See Chapter One, p. 1; Sharland's, 7 January1901, p. 22.

49) Rosenblum (1994): 76.

50) Preston (2009): 781-800.

51) Preston (2009): 781.

52) Letter from G.B. Orbell to W. Main, 12 April, 1980, private collection, Wellington.

53) Fig. 75, Appendix II, p. 250.

54) Fig. 76, Appendix II, p. 250, Jessie Buckland photograph album, JB55, Hocken Library, University of Otago, Dunedin.

55) Fig. 77, Appendix II, p. 251, Jessie Buckland photograph album, JB64, Hocken Library, University of Otago, Dunedin. 
56) For more information on the laws around copyright, see New Zealand Parliamentary Debates, House of Representatives, 22 July, 1986, pp. 400-01; also Geoff McLay, 'New Zealand and the Imperial Copyright Tradition,' in Uma Suthersanen and Ysolde Gendrean, eds, A Shifting Empire: 100 Years of Copyright (Cheltenham, England, Edward Edgar Publications Ltd, 2013): 30-51. The approximate size for a standard postcard was $70 \times 130 \mathrm{~mm}$.

57) Fig. 78, Appendix II, p. 251, Adolf Mortizson papers, Hocken Library, University of Otago, Dunedin. Note: Adolf Mortizson of A. Moritzson \& Co. Dunedin, was a. grain merchant who visited Akaroa on a regularly during the 1900s. On these visits he acquired postcards produced by Jessie Buckland which he compiled into a handmade scrapbook (Arc-0023; Ms-1143/01).

58) Stephanie Cape has suggested that the International Exhibition in Christchurch 1906/7 encouraged an increased production of postcards. See Cape (1978): 22. Jackson also makes the claim that there was a vending machine for the sale of postcards set up at the exhibition proved very popular. See Jackson and Main (2005).

59) Fig. 79, Appendix II, p. 252, Adolf Mortizson papers, Hocken Library, University of Otago, Dunedin. Also see 'Sunset' and 'Evening, June', Jessie Buckland photograph album, JB 8, Hocken Library, University of Otago. Dunedin.

60) Fig. 80, Appendix II, 252, Adolf Mortizson papers, Hocken Library, University of Otago, Dunedin.

61) Roland Barthes, 'Rhetoric of the Image,' in Image-Music-Text, Stephen Heath (trans.) (London, Fontana Press, 1977): 38-41.

62) Susan Stewart On Longing: Narratives of the Miniature, the Gigantic, the Souvenir, and the Collection (Durham, NC, Duke University Press, 1984): 132-169.

63) Robert Bogdan and Todd Weseloh, Real Photo Postcard Guide: The People's Photography (Syracuse, N.Y., Syracuse University Press, 2006): 41.

64) Barthes (1977): 38-41. 
65) Fig. 81, Appendix II, p. 2453. The inscription on the postcard reads: 'Regatta Akaroa Prot 16.12.07 J L Buckland' A later development and an alternative method of captioning which Buckland adopted was to use a custom-made lettering kit especially designed for commercial operators which could stamped onto the emulsion side of the negative prior to printing leaving a permanent impression. This method was adopted by Buckland as a profession photographer when she also had an impression manufactured especially for applying to the matt of photographs produced within her studio.

66) Fig. 82 (reverse of fig. 81), Appendix II, p. 253, Akaroa Museum, Akaroa.

67) Walter Benjamin, 'The Work of Art in the Age of Mechanical Reproduction', Illuminations, Hannah Arendt, ed. (trans. Harry Zohn) (New York, Schocken Books, 1968): 220 .

68) Stewart (1984): 78.

69) Stewart (1984): 79.

70) Gillian Rose, Doing Family Photography: The Domestic the Public and the Politics of Sentiment (Farnham, England, Ashgate Publishing Ltd, 2010): 71.

71) Arjun Appadurai, "Introduction: commodities and politics of value", in A. Appadurai ed., The Social Life of Things: Commodities in Cultural Perspective (Cambridge, Cambridge University Press, 1986): 3-63; Igor Kopytoff, 'The Cultural Biography of Things: Commoditization as process', in A. Appadurai ed., The Social Life of Things: Commodities in cultural perspective (Cambridge, Cambridge University Press, 1986): 6494.

72) Rose (2010): 71.

73) Rose (2010): 64-65.

74) Rose (2010): 59.

75) John Tagg, The Burden of Representation: Essays on Photographies and Histories (London, Macmillan, 1988): 93-94. 
76) Chris Barker, Making Sense of Cultural Studies: Central Problems and Critical Debates (London, Sage Publications, 2002); Chris Barker, Cultural Studies: Theory and Practice (Los Angeles, California, Sage Publications, 2008): 51.

77) Paul du Gay, The Production of Culture/Cultures of Production (London, Sage and Oxford University Press, 1997). Du Gay's circuit of culture is reproduced on p.10.

78) Rose (2010): 67; Rose defers to Andreas Reckwitz for a definition. See Andreas Reckwitz, 'Toward a theory of social practices,' European Journal of Social Theory, 5 (2002): 243-263.

79) David Sanjek, 'A Department of their Own: A Modest Proposal for the Design of Music and Business Technology Programs,' Popular Music and Society, 16, 4 (Winter, 1991): 41-60.

80) See comments of Jeffrey Alexander in Jeffrey C. Alexander, Bernhard Giesen and Jason L. Mast, Social performance: Symbolic Action, Cultural Pragmatics and Ritual (Cambridge, Cambridge University Press, 2006): 55.

81) Russell Belk, 'Possessions and the Extended Self,' Journal of Consumer Research, 15, 2 (1988): 150.

\section{Chapter 8}

1) Richard Chalfen, 'Redundant Imagery: Some observations on the use of Snapshots in American Culture,' Journal of American Culture, 4, 1 (1981): 106-113; Richard, Chalfen, Snapshot Versions of Life (Ohio, Bowling Green State University Press, 1987); Richard Chalfen, Turning Leaves: The Photograph Collections of Two Japanese American Families (Albuquerque, University of New Mexico, 1991); Richard Chalfen, 'Interpreting Family Photography as Pictorial Communication' in Jon Prosser, ed, Imagebased research: a sourcebook for Qualitative Researchers (London, Routledge Fawler, 1998): 214-34; Richard Chalfen, 'Snapshots 'r' us: the evidentiary problematic of home media', Visual Studies, 17 (2002): 141-149; Gillian Rose, 'Practising photography: an archive, a study, some photographs and a researcher,' Journal of Historical Geography, 26, 4 (2000), 555-571; Gillian Rose, 'Family Photographs and Domestic Spacings: A 
Case Study,' Transactions of Institute of British Geographers; New Series, 28, 1 (2003): 5-18; Gillian Rose, “"Everyone's cuddled up and it just looks really”: an emotional geography of some mums and their family photos,' Social \& Cultural Geography, 5, 4 (2004): 549-564; Gillian Rose, Doing Family Photography: the domestic, the public and the politics of sentiment (Farnham, England, Ashgate Publishing Ltd, 2010).

2) Chalfen (1991).

3) Fig. 2, Appendix II, p. 204.

4) Chalfen (1991).

5) Martha Langford, Suspended Conversations: The afterlife of memory in photographic albums (Montreal, McGill-Queens University Press, 2001).

6) Susan Stewart, Nonsense: Aspects of Intertextuality in Folklore and Literature (Baltimore, The Johns Hopkins University Press, 1979).

7) Rose (2010): 59-68.

8) Maggie Humm, Snapshots of Bloomsbury: The private lives of Virginia Woolf and Vanessa Bell (New Brunswick, Rutgers University Press, 2006): 6.

9) See Appendix I, Notes on photograph albums pp. 198-201. Of the 15 albums listed, 8 albums have been accessioned into public collections; 6 albums remain in private hands. 


\section{Appendix I}

\section{List of Compilers and their photograph albums}

The 15 photograph albums described and listed below are arranged alphabetically by the family name of the compiler.

Lucy Acland Album, c. 1892-1898

Creator: Lucy Dyke Acland (1869-1903)

Description: maroon linen cloth cover inscribed in gold 'L.D.A.'

Size: $310 \times 410 \mathrm{~mm}$

Photographs: 208 , mostly $1 / 2$ plates

Collection: private collection, Christchurch.

The Bowen Album, c. 1901-1912

Creators: Margaret Letitia (1885-1978) and Laura Catherine Bowen (1886-1967)

Description: cover in black imitation leather linen cloth with corners reinforced in black Inscription in ink inside front cover: 'The photos have all been taken by Margaret and Laura Bowen who developed them all. I still find photos in old books which they have left to "straighten out" CB [Chrystobel Bowen]

Size: $280 \times 370 \mathrm{~mm} ; 100$ pages

Photographs: 307 mainly $1 / 4$ plate,

Collection: Album 229, Canterbury Museum, Christchurch.

Carrie Buckland Album,_c. 1892-1935

Creator: Caroline Marianme Buckland, (1868-1930)

Description: Green vinyl covered album inscribed 'Photographs' centre front; Inscription inside front cover, top centre: 'Carrie Buckland' in ink her hand; left: 'W.H. Buckland Wainui B.P. - 1934'

Size: $270 \times 400 \mathrm{~mm}$; 40 pages 
Photographs: 118 ; mainly $1 / 2$ plates

Collection: Album 211, Hocken Library, University of Otago, Dunedin.

Jessie Buckland Album, c.1892-1910

Creator: Jessie Lillian Buckland (1878-1939)

Description: Brown-vinyl covered album with sprig of oak leaves and an acorn on top right corner

Size: $280 \times 360 \mathrm{~mm}$; condition: foxed inside front leaves

Photographs: $206,1 \frac{1}{2}, 1 / 4$ glass plates and snapshots

Collection: Album 210, Hocken Library, University of Otago, Dunedin.

Note: There are also extensive collections of Buckland's photographs and those of her sisters in the photograph collections of Akaroa Museum, Akaroa, and the Macmillan Brown Library, University of Canterbury, Christchurch.

Susan Buckland Album, c. 1892-1901

Creator: Rachael Susan Christobel Buckland (1873-1946)

m. Lionel Orbell 1901, 1 child

Description: Red linen cloth album, reinforced with leather at corners. Spine inscribed 'Album'.

Size: $300 \times 240 \mathrm{~mm}$; pages: 105

Photographs: 280; mostly $1 / 2$ plates

Collection: Original album, private collection, Louisville, Kentucky.

Facsimile copy album: Album 121, Hocken Library, University of Otago, Dunedin.

Elizabeth Colenso Album, c. 1895-1900

Creators: Elizabeth Colenso and others, including contributions

from Kate Spencer Ivens (1869-1942).

Album: rose-coloured cloth board cover.

Size: $370 \times 292 \mathrm{~mm}$

Photographs: 138 in total; 31 of these by Kate Ivens.

Collection: Elizabeth Colenso album, (NIM1841), Norfolk Island Museum, Norfolk Island. 
Agnes Stoddart Album,_c. 1897-98

Creator: Agnes Stoddart (1869-1956)

Album: red leather cover: inscribed in gold leaf in centre 'A.S.'

Size: $250 \times 340 \mathrm{~mm}$

Photographs: 18

Collection: Diamond Harbour and Districts Historical Association Inc., Diamond Harbour.

M.O. Stoddart Album, c. 1893-1897

Creator: Margaret Olrog Stoddart: (1865-1934)

Description: red leather cover: inscribed on the front cover in gold leaf in centre. 'M.O.

Stoddart.'

Size: $500 \times 340 \mathrm{~mm}$

Photographs: $80 ; 53$ pages

Collection: Album MOS 322, Canterbury Museum, Christchurch.

Mary Stoddart Album 1, c. 1894-1909

Creator: Mary Stoddart: (1868-1909)

m. Richard Farques Farmer, 4 September 1908; 1 daughter, Frances, b. 16 October 1909.

Description: bound in dark red leather;

front cover inscribed in gold leaf the centre, 'M. Stoddart'

Size: $250 \times 320 \mathrm{~mm}, 52$ pages

Photographs: $149,1 / 2$ plate and $1 / 4$ plates

Collection: Album MOS 232, Canterbury Museum, Christchurch.

Mary Stoddart Album 2, c. 1898-1909

Creator: Mary Stoddart: (1868-1909)

Description: bound in dark red leather. Front cover inscribed in gold leaf in centre, 'May

Stoddart', lower left: 'Diamond Harbour 1898'

Dedication inside front cover: 'With love to "May" From "Dick," June 27 1898'

Size: $330 \times 405 \mathrm{~mm}$

Photographs: $176,1 / 2$ plates and $1 / 4$ plate

Collection: Diamond Harbour and Districts Historical Association Inc., Diamond Harbour. 
Kate Wood Album 1, c. 1890-1897

Creator: Kate Selima Wood (1871-1961)

Description: blue-green leather cover with 'ALBUM' inscribed on the spine in gold Size: $275 \times 220 \mathrm{~mm}$

Photographs: 125 mostly $1 / 2$ plates

Collection: private collection, Martinborough.

Kate Wood Album 2, c. 1895-1905

Creator: Kate Selima Wood (1871-1961) and Kate Ivens (1869-1942)

Description: black leather cover

Size: $185 \times 260 \mathrm{~mm}$

Photographs: $45 \frac{1}{2} 2$ plates and $2 \frac{1}{4}$ plates

Collection: private collection, Martinborough.

Kate Wood Album 3, c. 1895-1905

Creator: Kate Selima Wood (1871-1961)

Description: black leather cover (repaired spine)

Size: $185 \times 260 \mathrm{~mm}$

Photographs: 33 , all $1 \frac{1}{2}$ plates

Collection: private collection, Martinborough.

Dell Family Album, c. 1902-1904

Creator: Florence Jenny Myra Wright (1868-1929)

m. W.A. Morgan 3 June 1904; 2 children

Description: untreated cardboard; condition: poor.

Size: $300 \times 210 \mathrm{~mm}, 20$ pages

Photographs: $75 \frac{1}{2}$ plates

Collection: private collection, Christchurch. 
Appendix II

Gallery of Photographic Images 


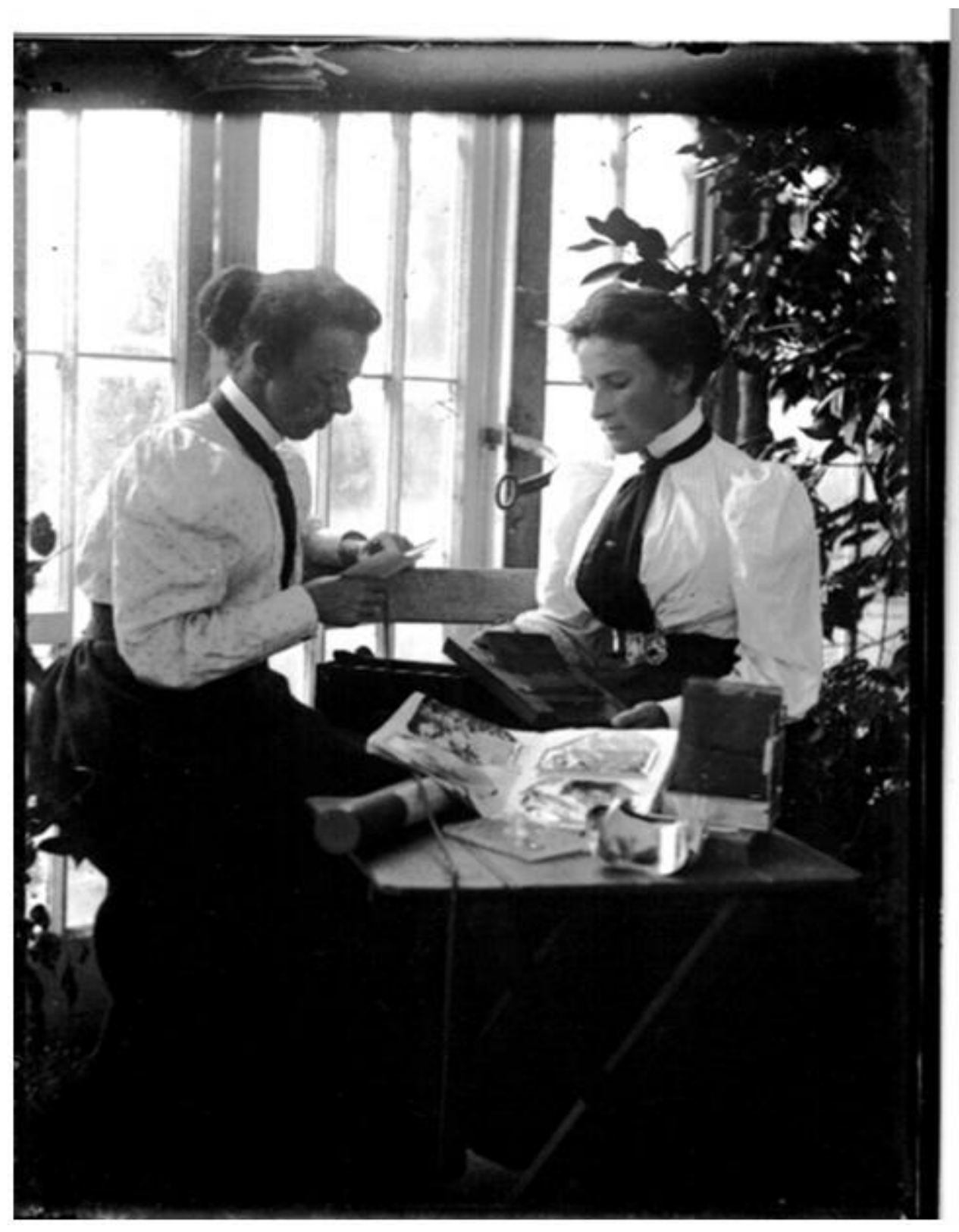

Figure 1: [Harriet and Rosa Acland in the conservatory, Mt Peel Station], Lucy Acland album, LA56, private collection, Christchurch. 


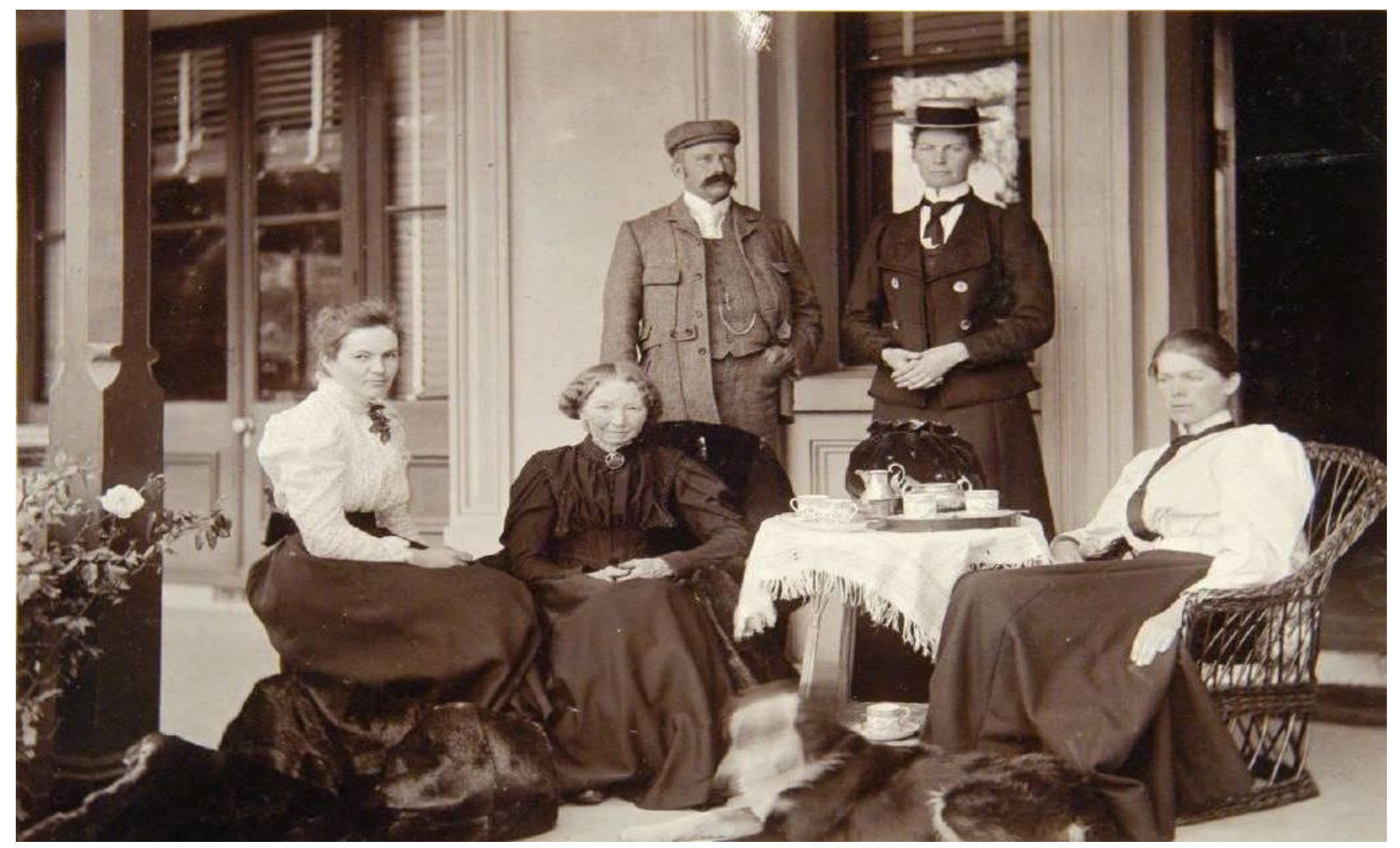

Figure 2: [The Stoddart family, Diamond Harbour], Mary Stoddart album, $\mathrm{MS}_{1} 4$, Canterbury Museum, Christchurch.

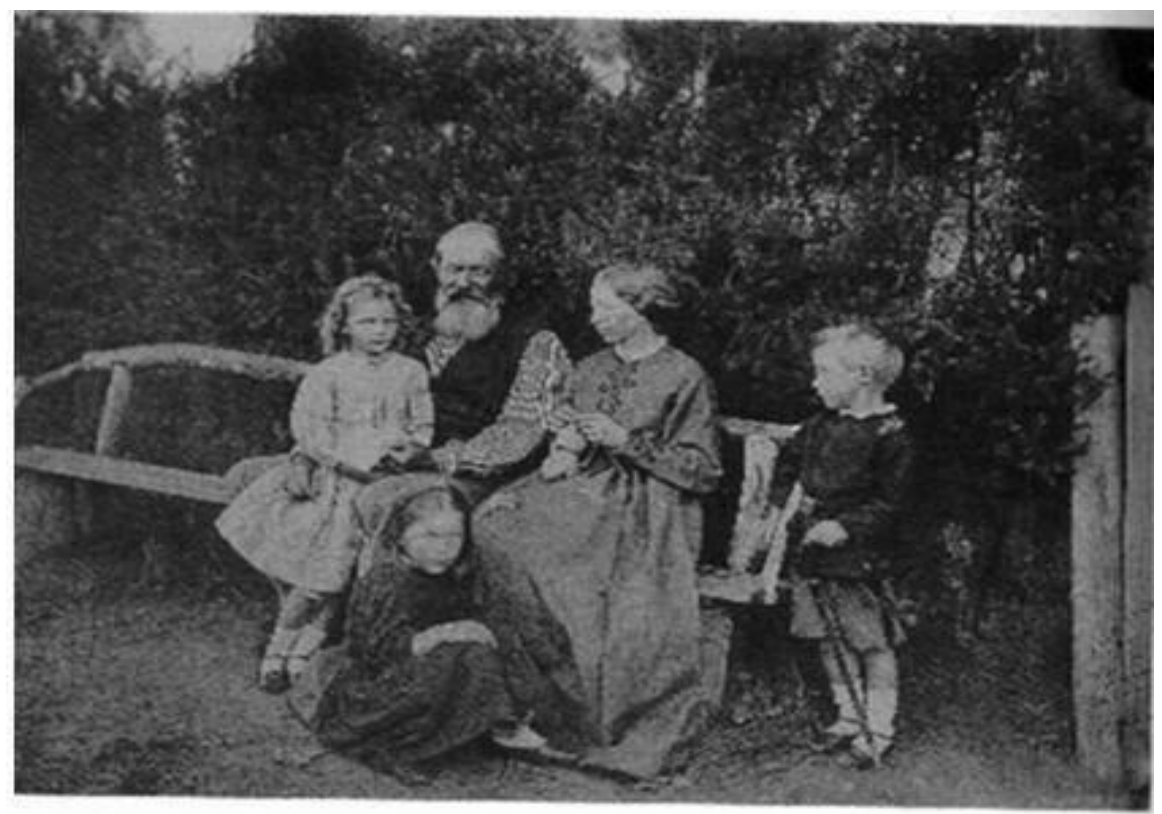

Figure 3: A.C. Barker, [The Stoddart family, Diamond Harbour], 1871, Dr A.C. Barker collection, Canterbury Museum, Christchurch. 


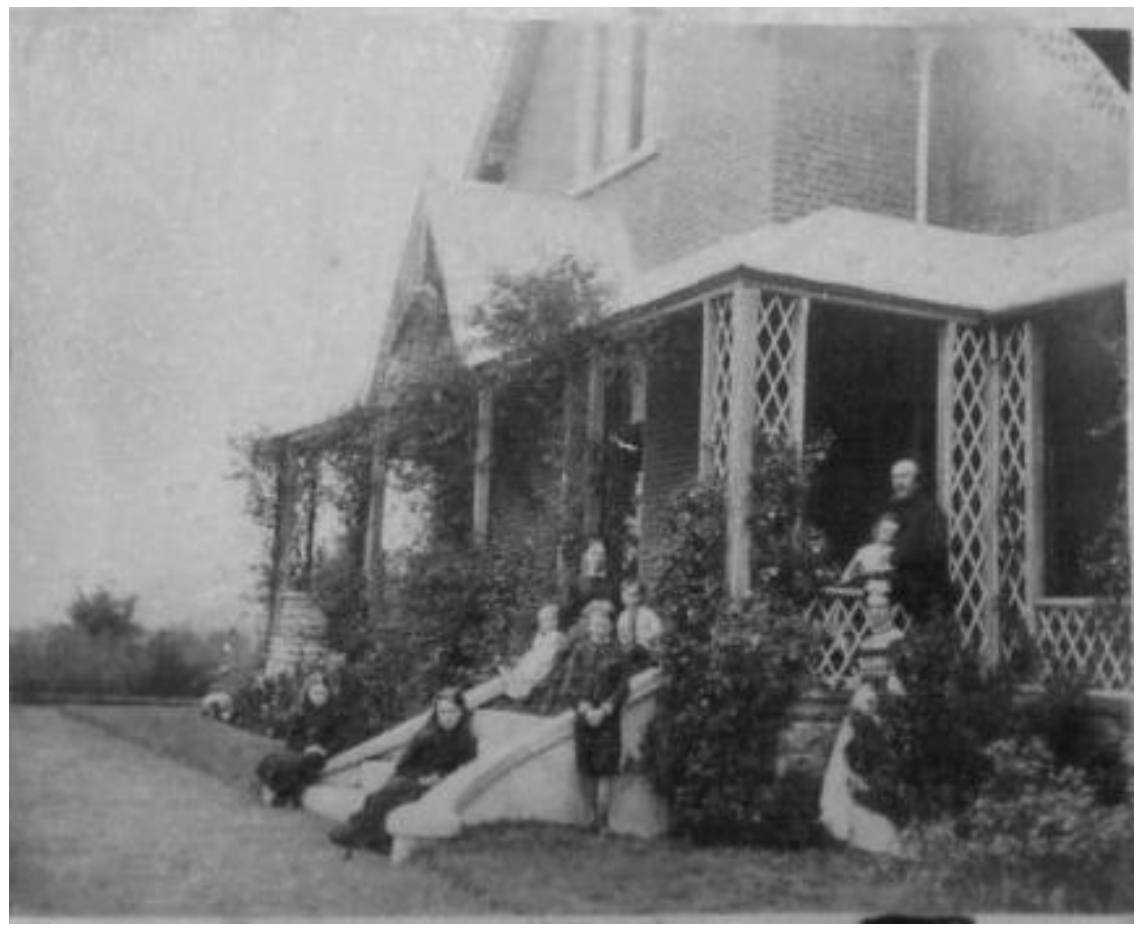

Figure 4: A.C. Barker, [Acland family, Mt Peel Station], 1872, Acland photograph collection, Macmillan Brown Library, University of Canterbury, Christchurch.

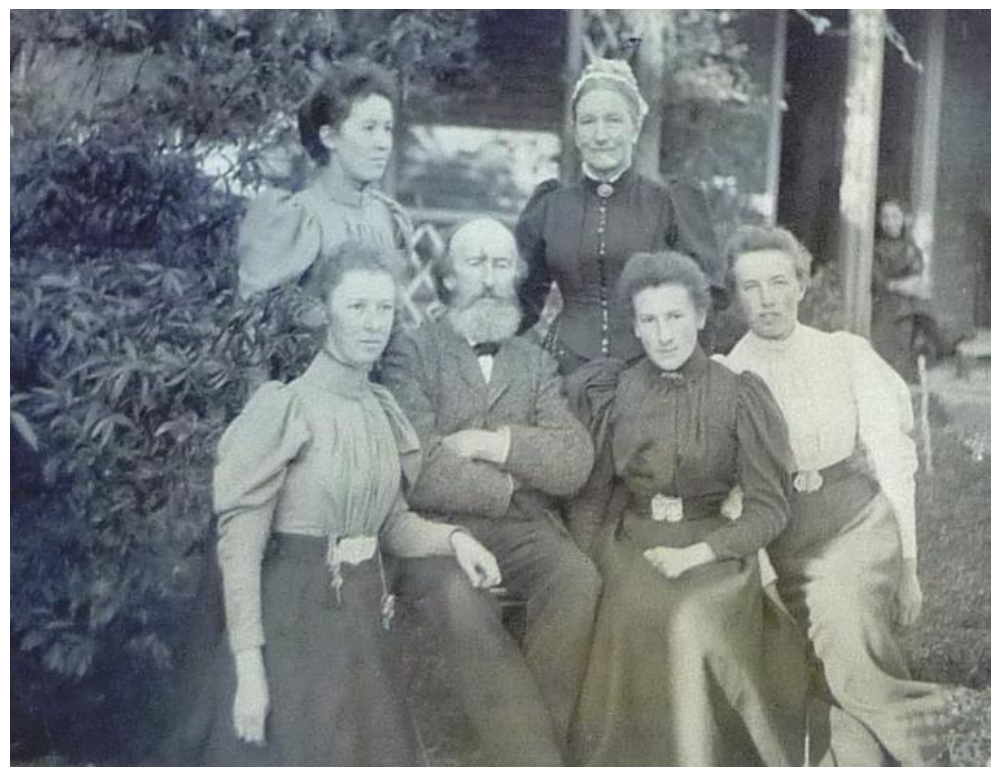

Figure 5: [Acland family, Mt Peel Station], May, 1895, Acland photograph collection, Macmillan Brown Library, University of Canterbury, Christchurch. 


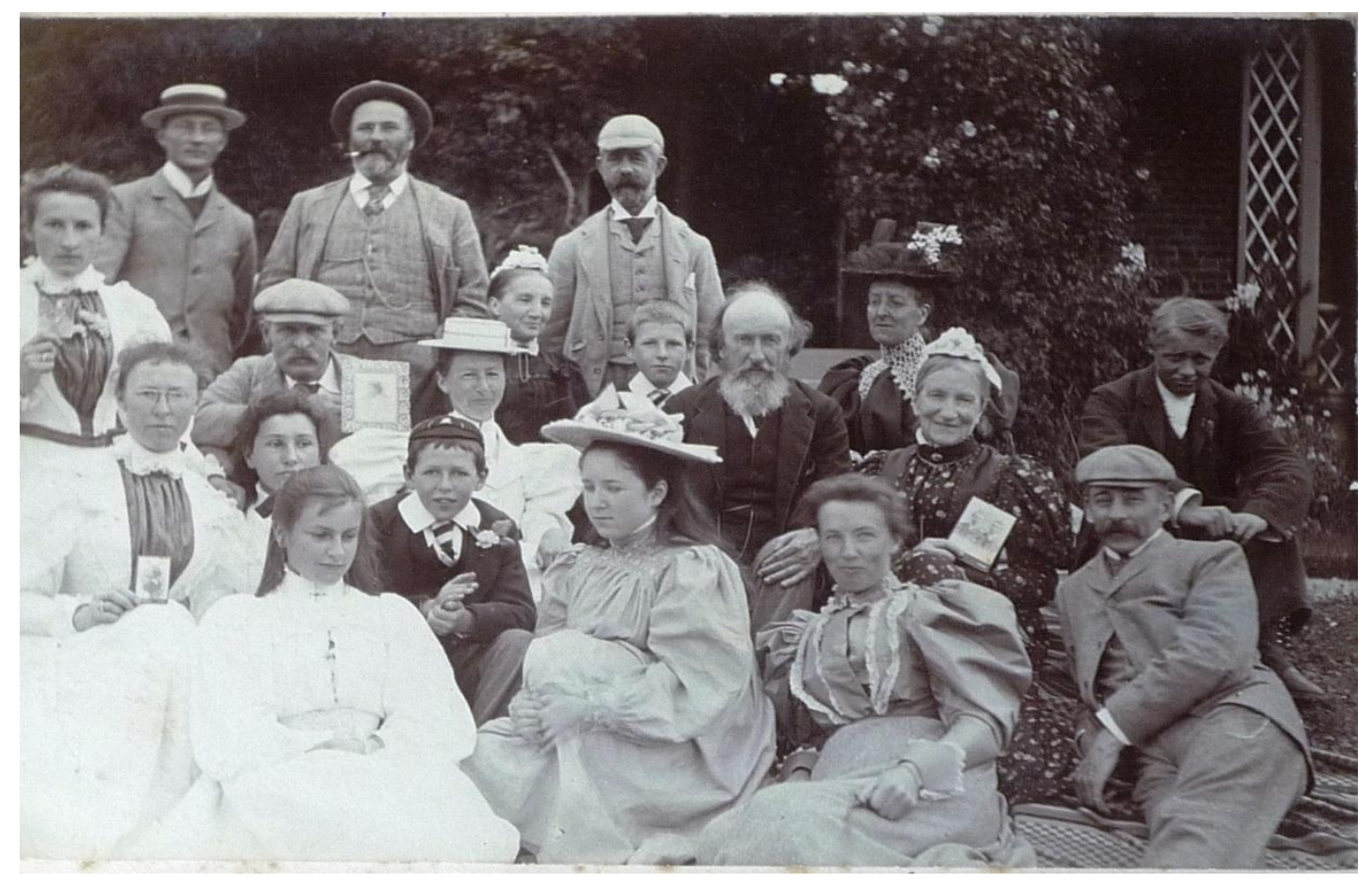

Figure 6: 'Xmas I', Lucy Acland album, LA40, private collection, Christchurch.

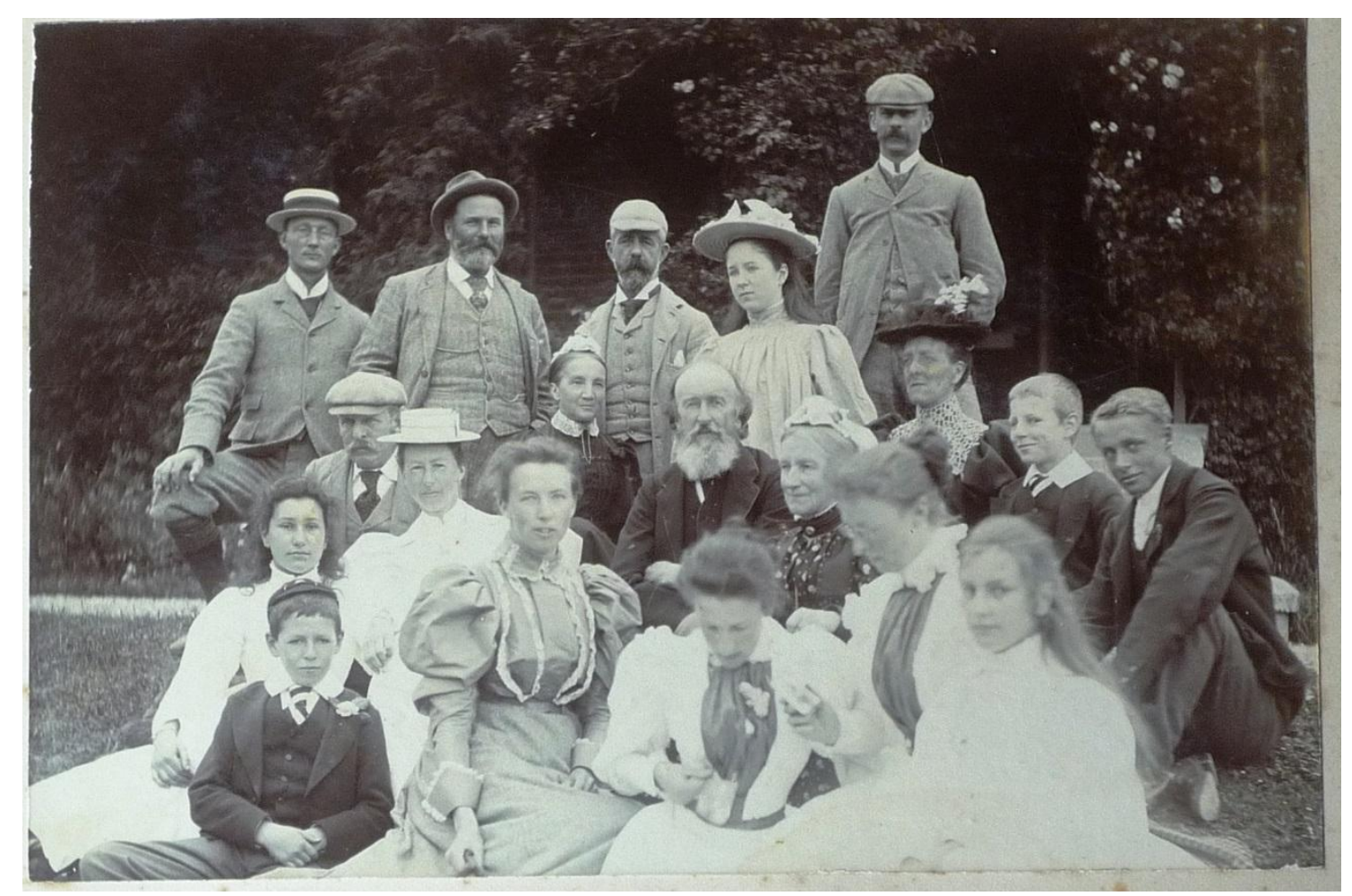

Figure 7: 'Xmas II', Lucy Acland album, LA40, private collection, Christchurch. 


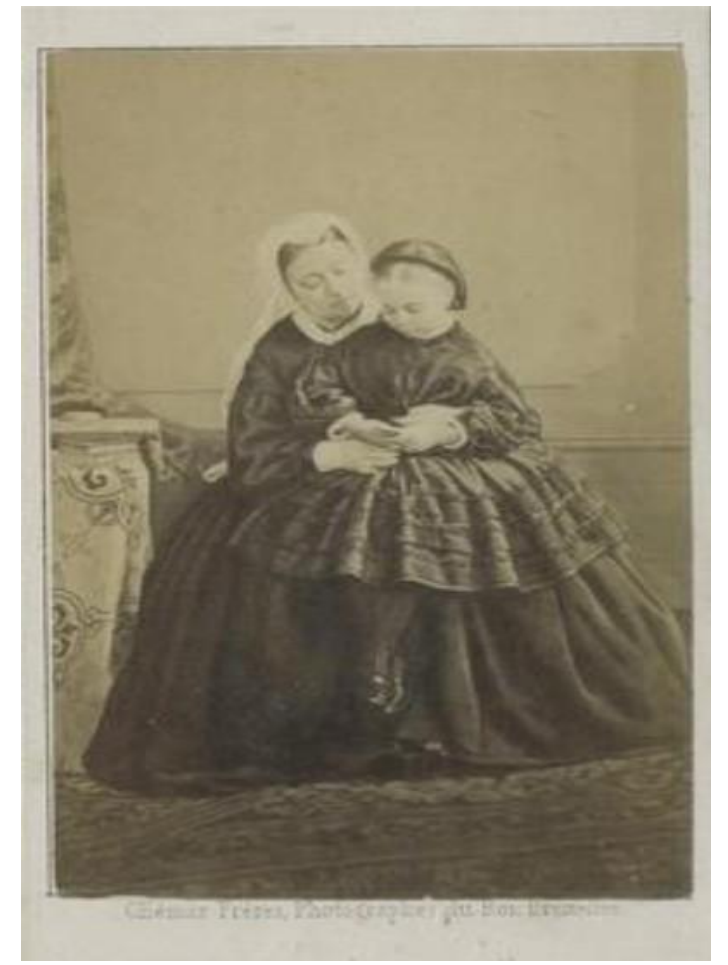

Figure 8: Ghémar Frères, Queen Victoria and Princess Beatrice, 1863.

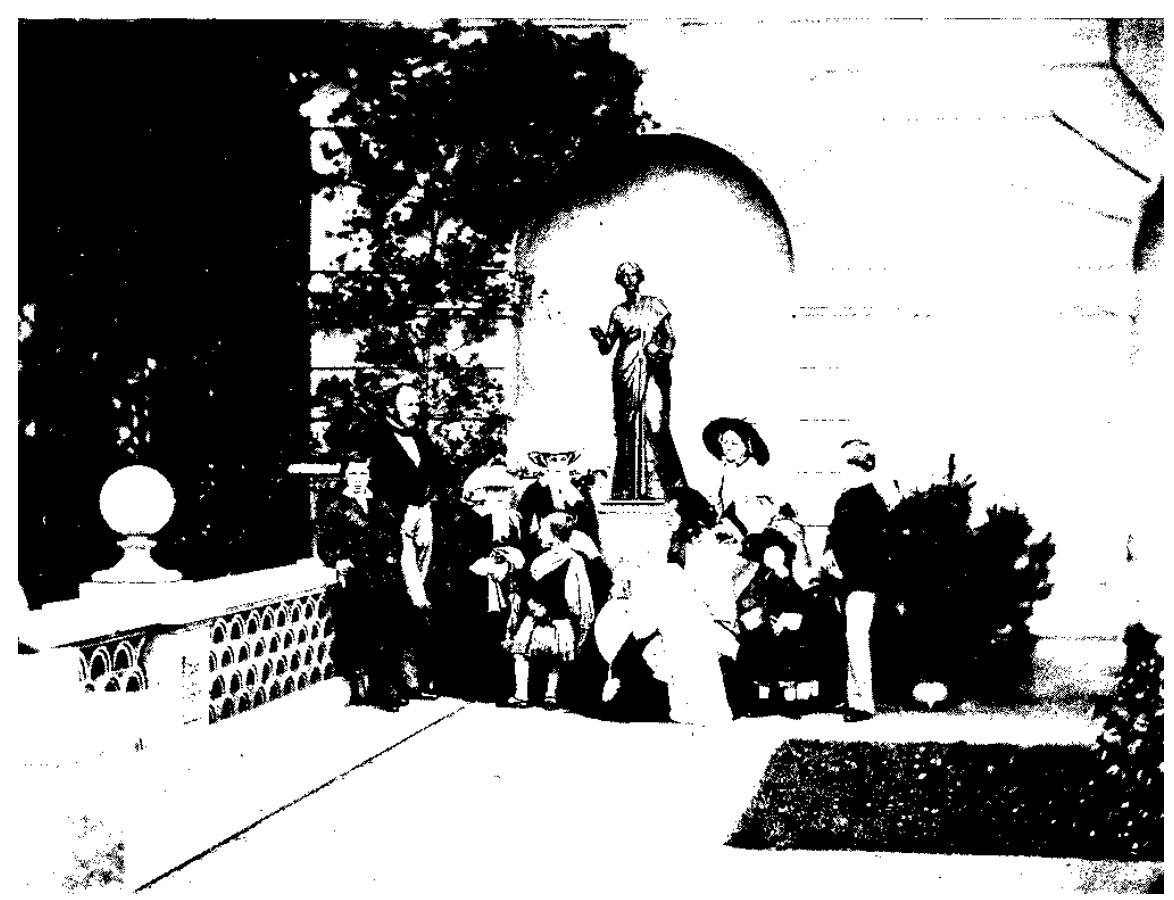

Figure 9: Leonida Caldesi, [The royal family at Osborne House], 1859. 


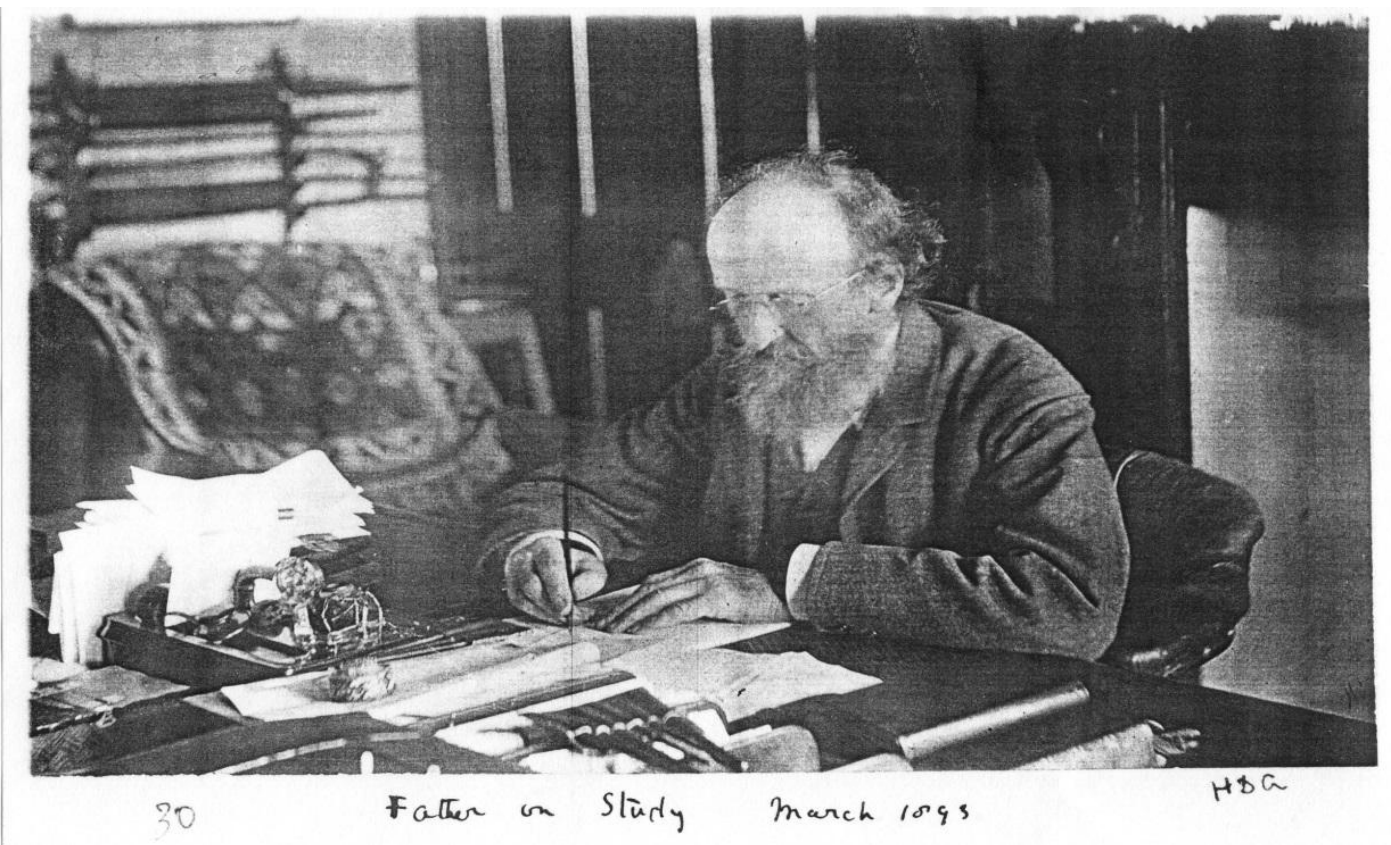

Figure 10: Harriet Acland, 'Father in Study, March 1893', Acland photographs collection, Macmillan Brown Library, University of Canterbury, Christchurch.

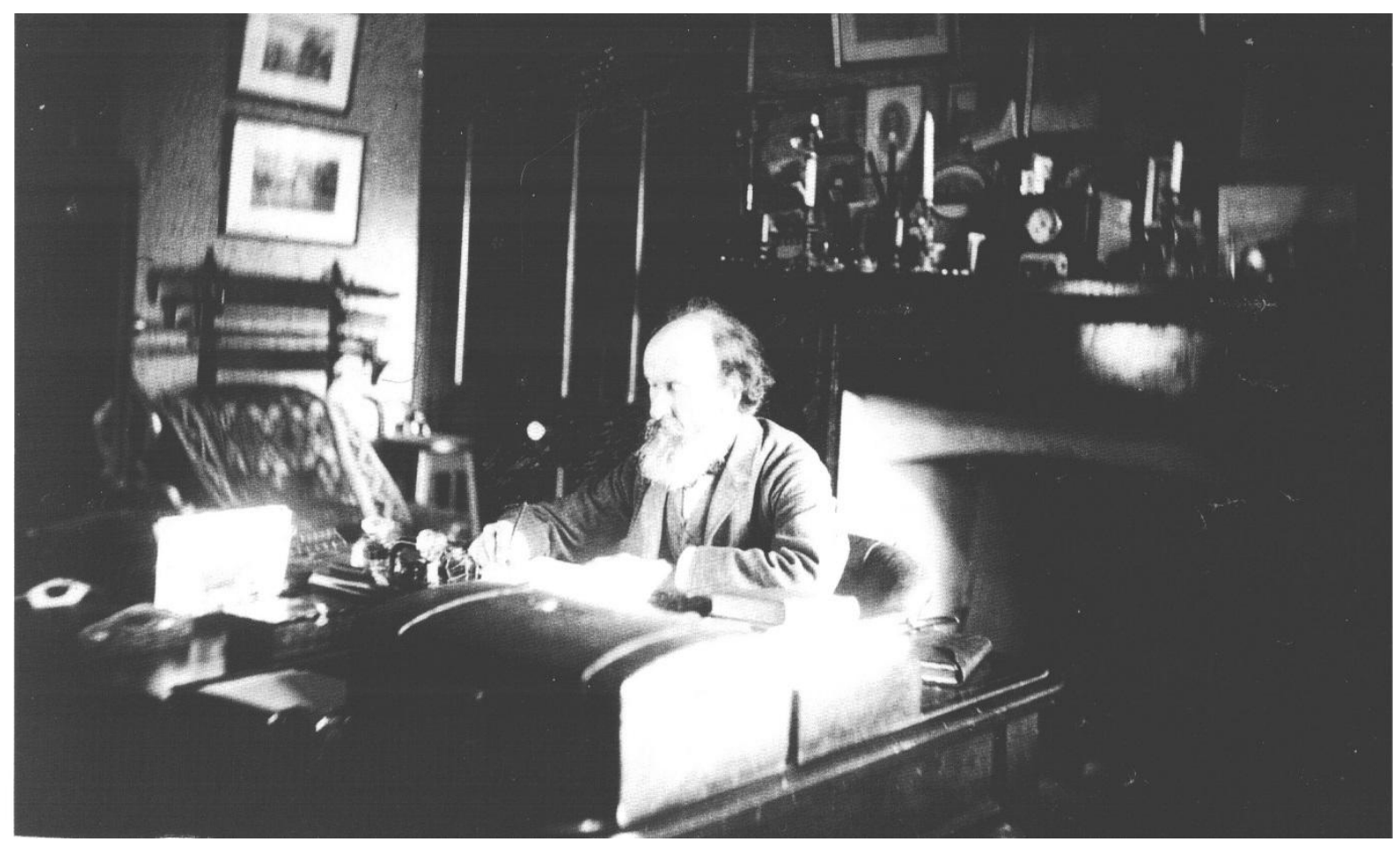

Figure 11: John Acland, [Father in Study], 1893, Acland photographs collection, Macmillan Brown Library, University of Canterbury, Christchurch. 


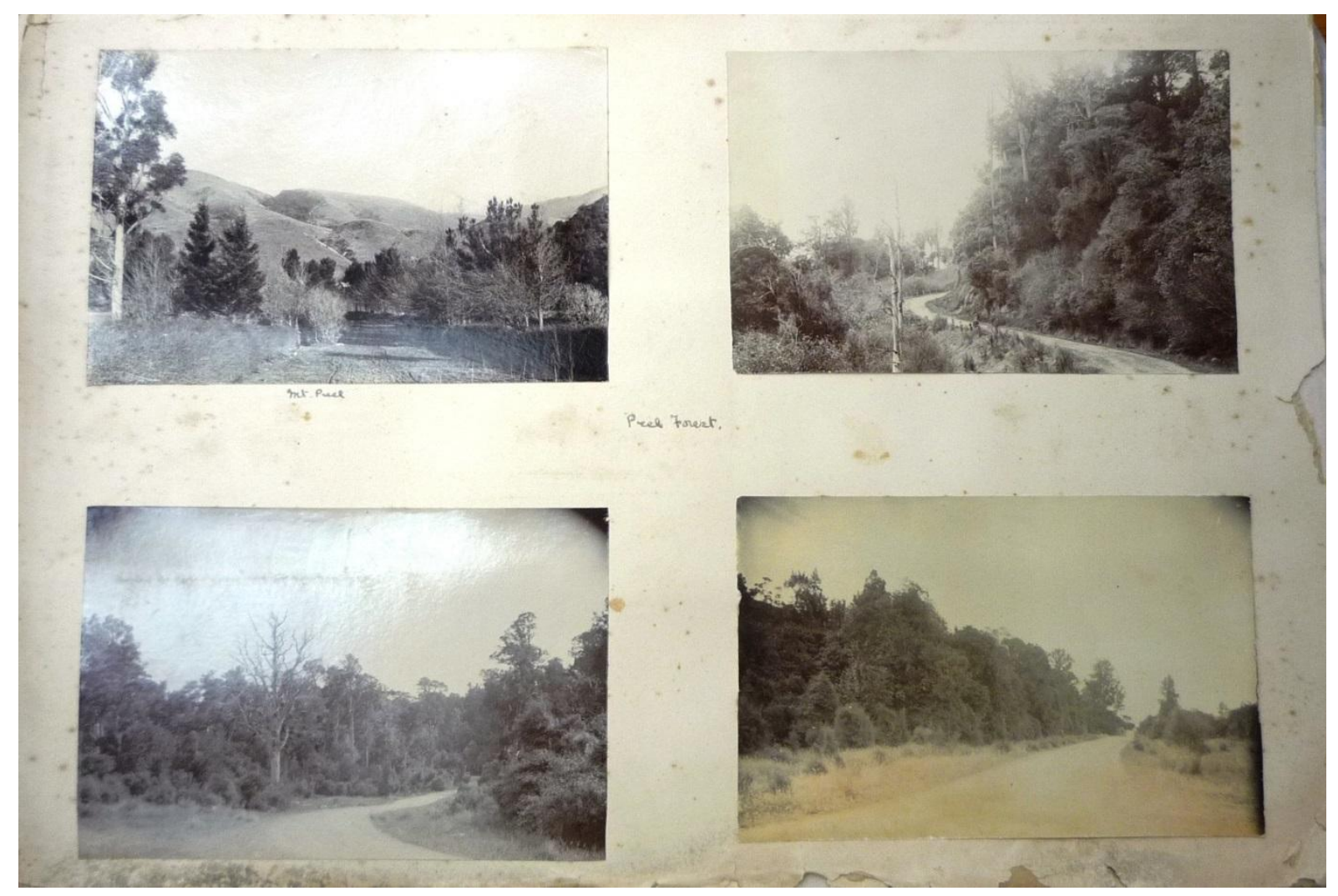

Figure 12: [Views of Peel Forest], 1893, Lucy Acland album, LA37, private collection, Christchurch. 


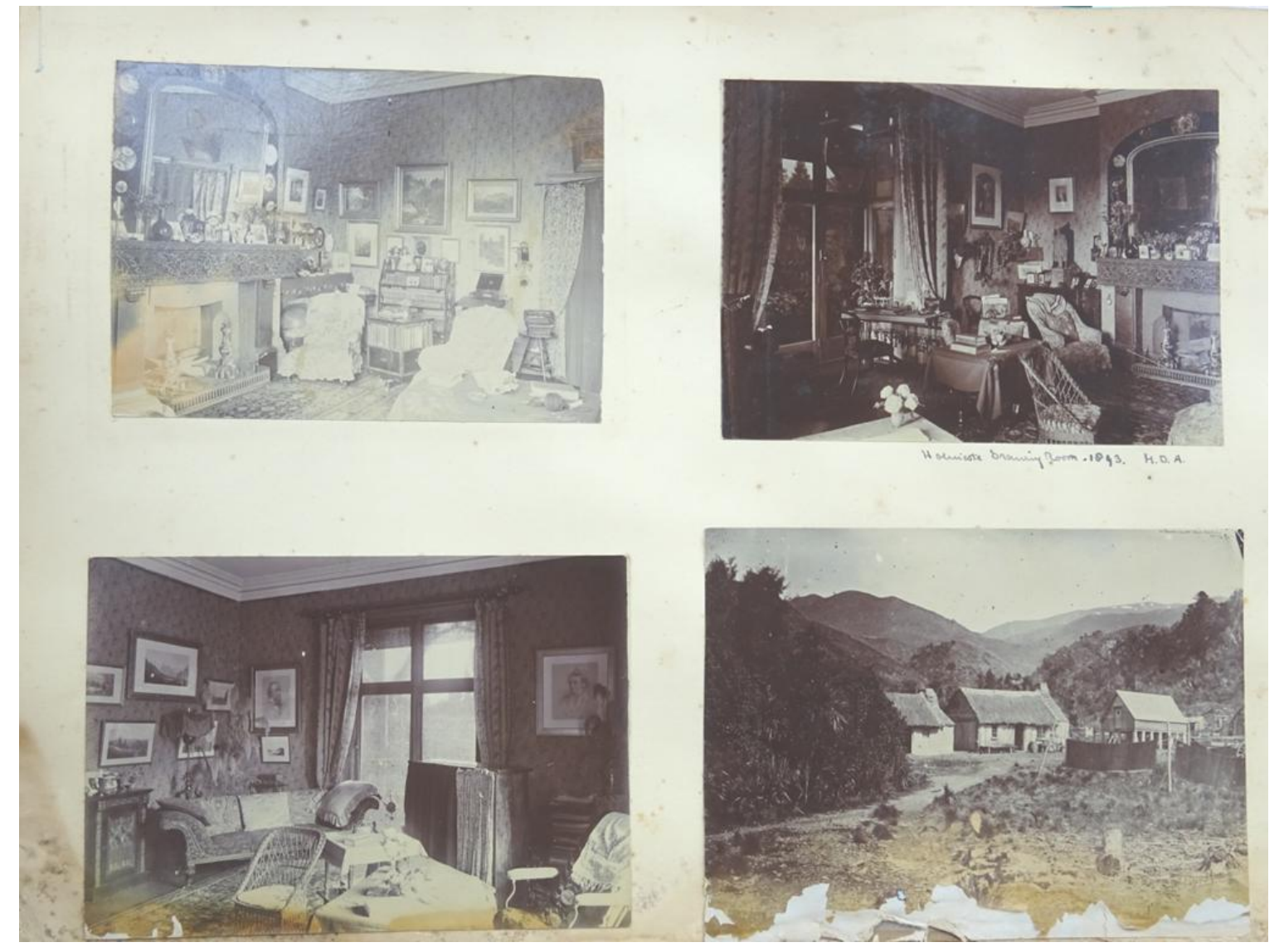

Figure 13: Harriet Acland, [3 photographs of the drawing room at Mt Peel homestead], 1893, Dr Barker, [First habitations at Mt Peel Station], 1861, Lucy Acland photograph album, LA44, private collection, Christchurch. 


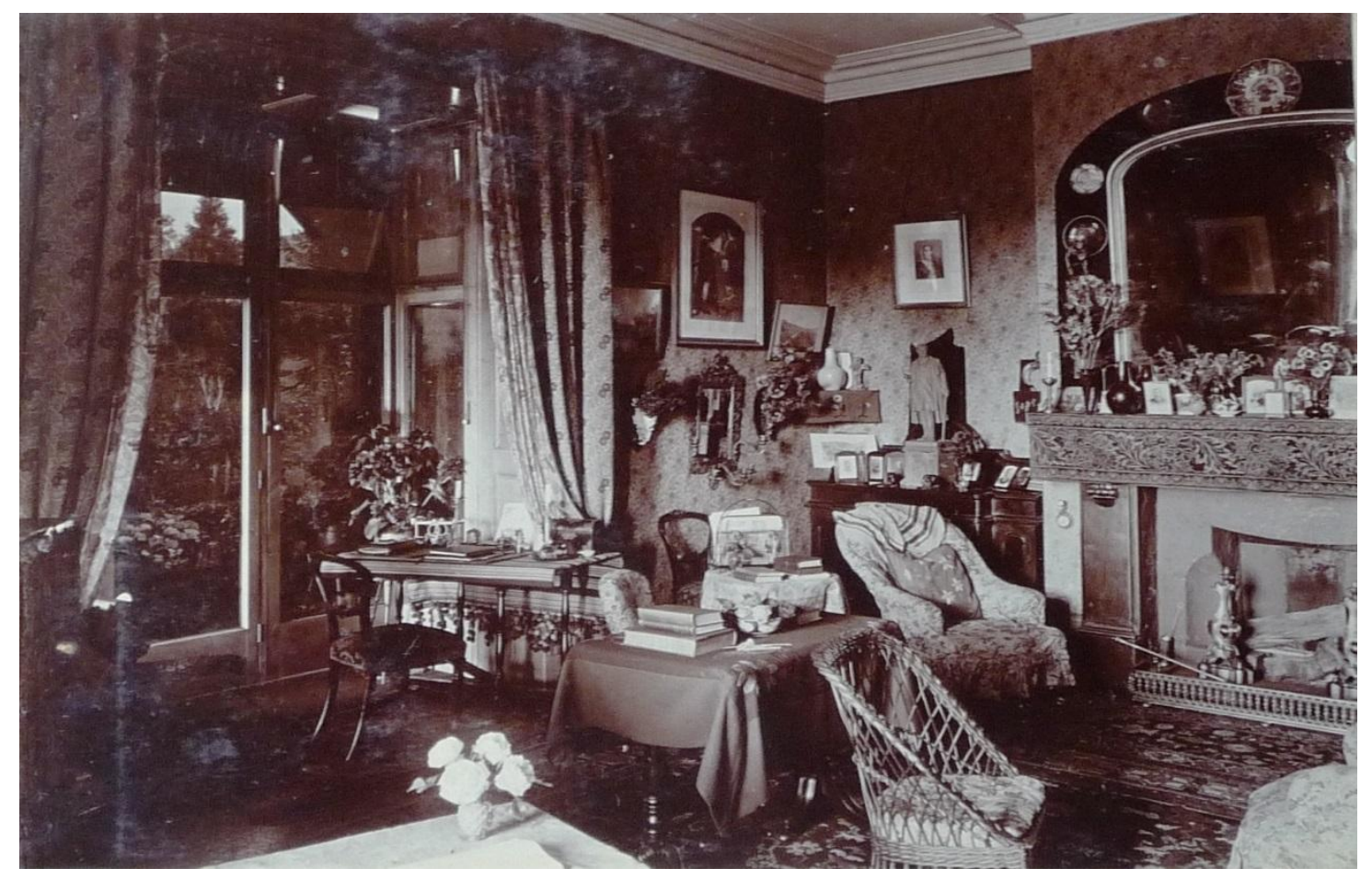

Figure: 14: Harriet Acland, [Drawing room Mt Peel homestead], 1893, Lucy Acland album, LA44, private collection, Christchurch.

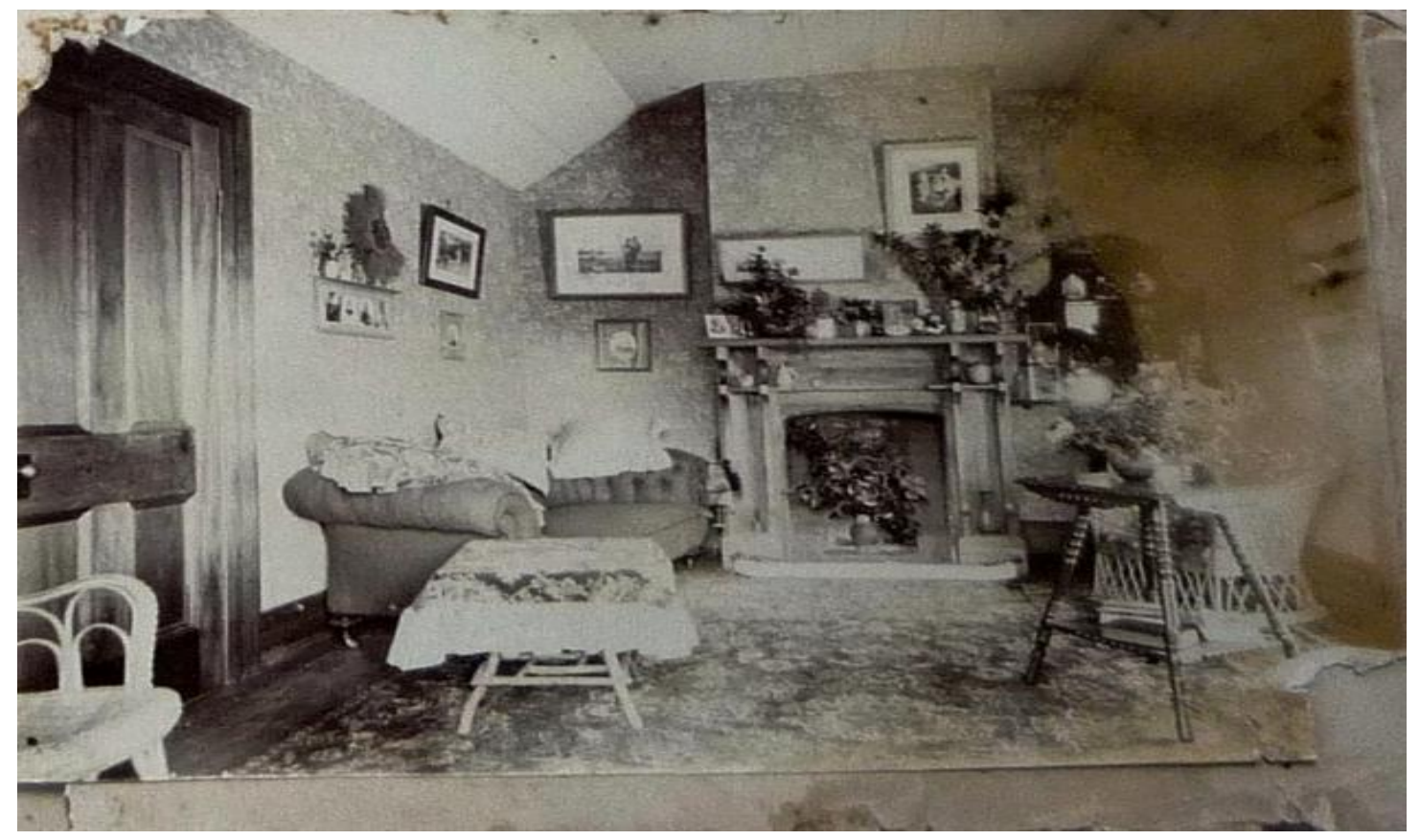

Figure 15: Harriet Acland, [Sitting room of Lucy Acland], Lucy Acland album, LA61, private collection, Christchurch. 


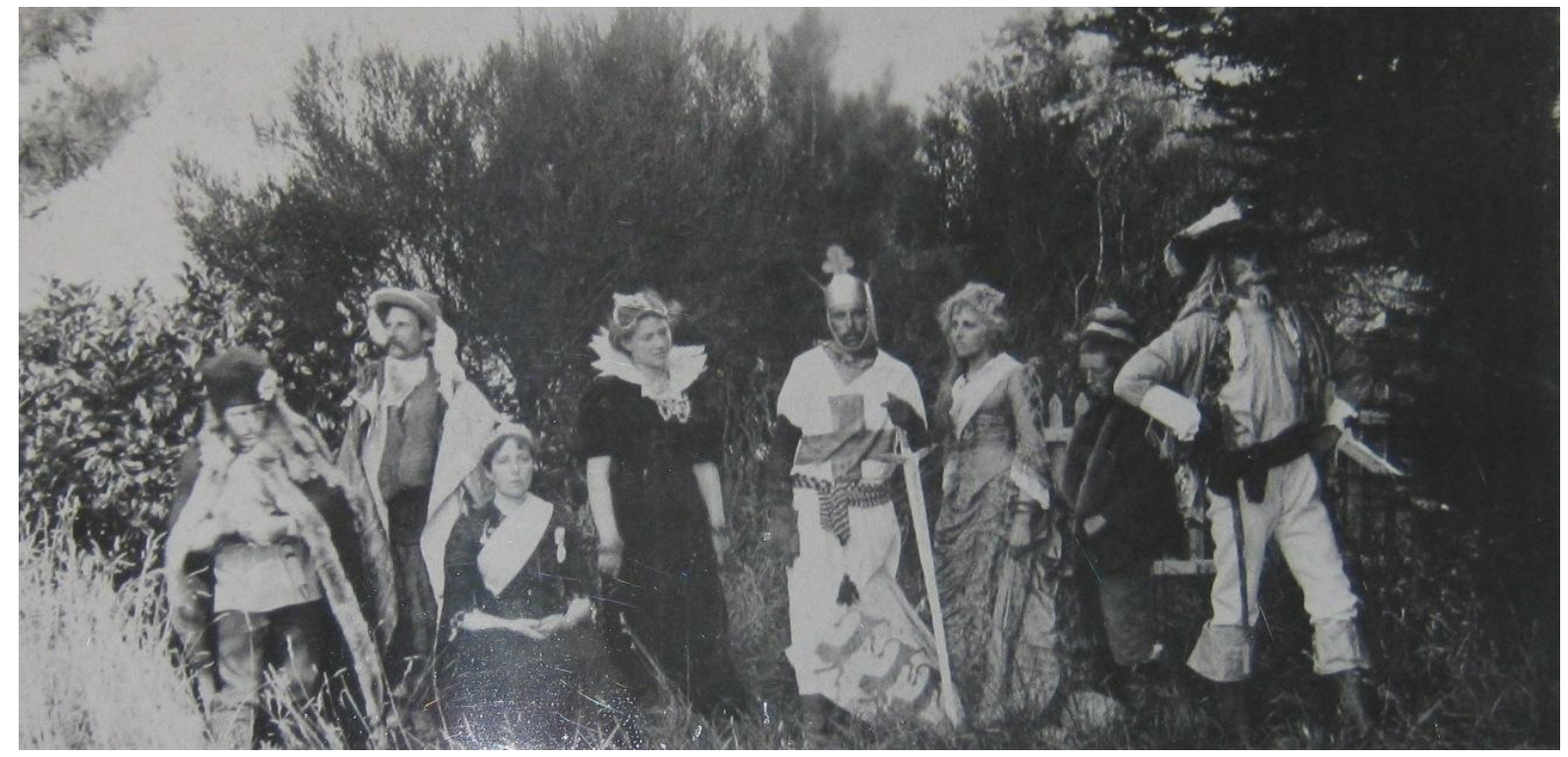

Figure 16: [Kings and Queens of England], Susan Buckland album, SB15, private collection, Louisville, Kentucky.

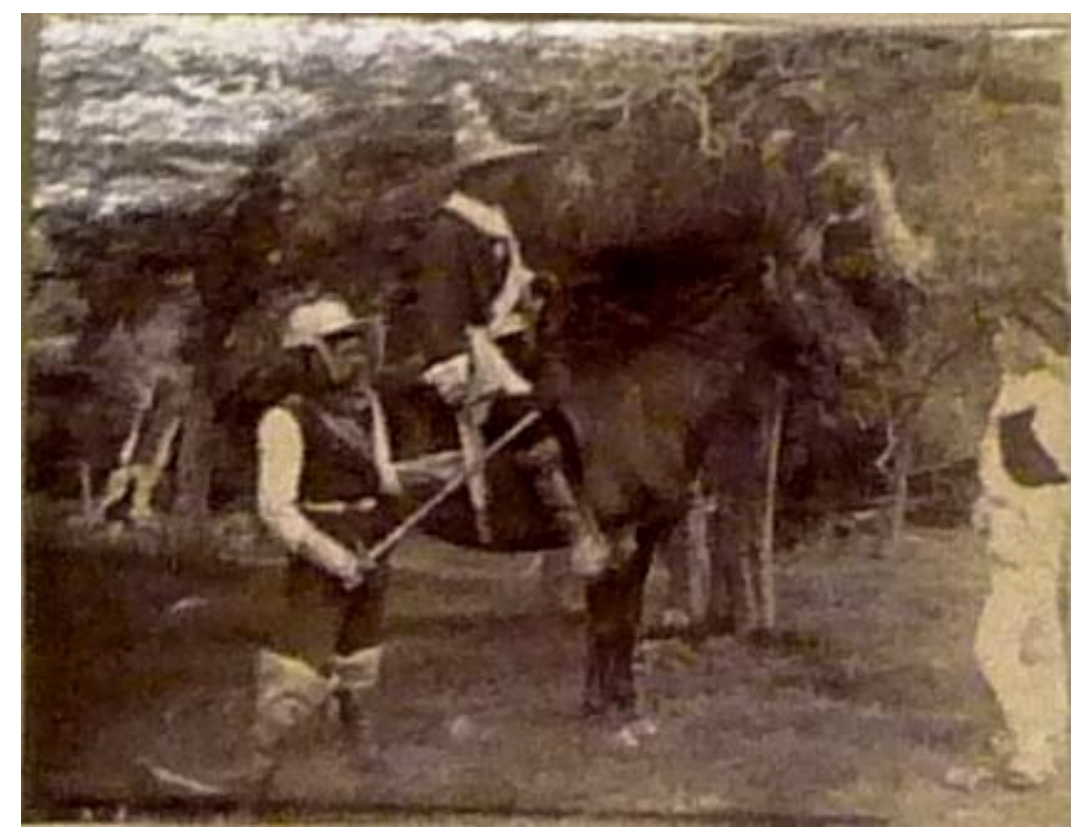

Figure 17: 'King Charles hiding in a tree...', Caroline Buckland album, CB9, Hocken Library, University of Otago, Dunedin. 


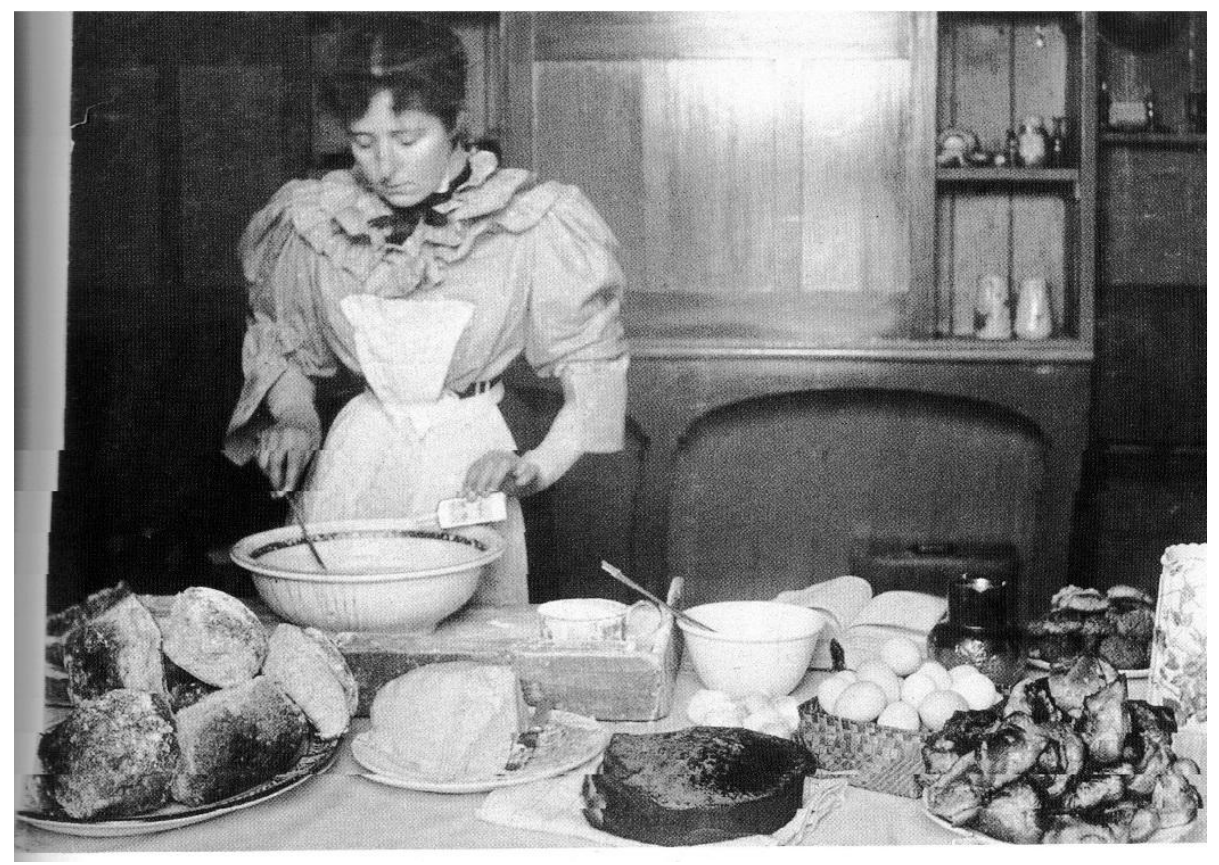

Figure 18: Caroline Buckland, 'Baking Day', 1896, Susan Buckland album, SB18, private collection, Louisville, Kentucky.

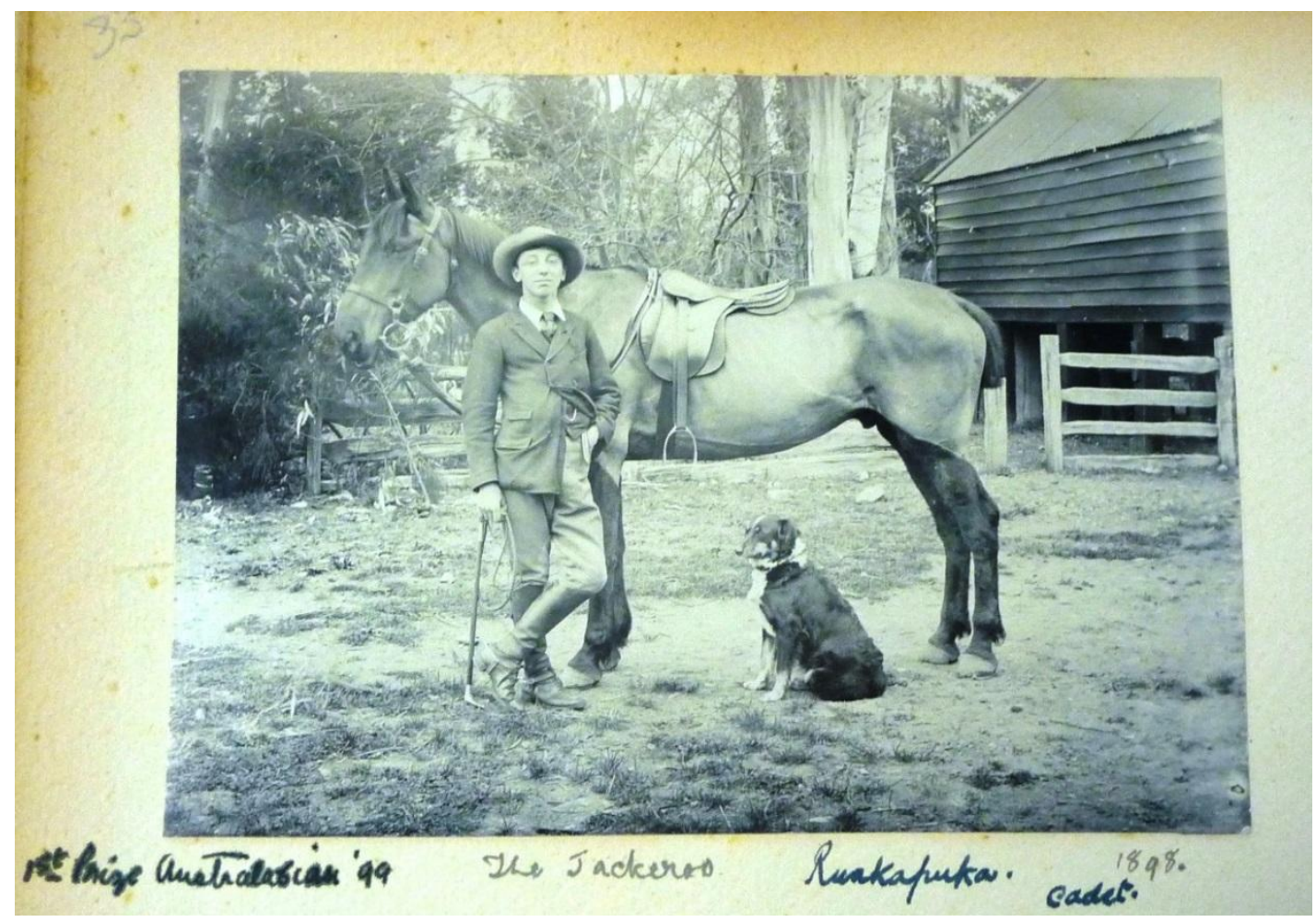

Figure 19: Jessie Buckland, 'The Jackeroo', 1898, Jessie Buckland album, JB33, Hocken Library, University of Otago, Dunedin. 


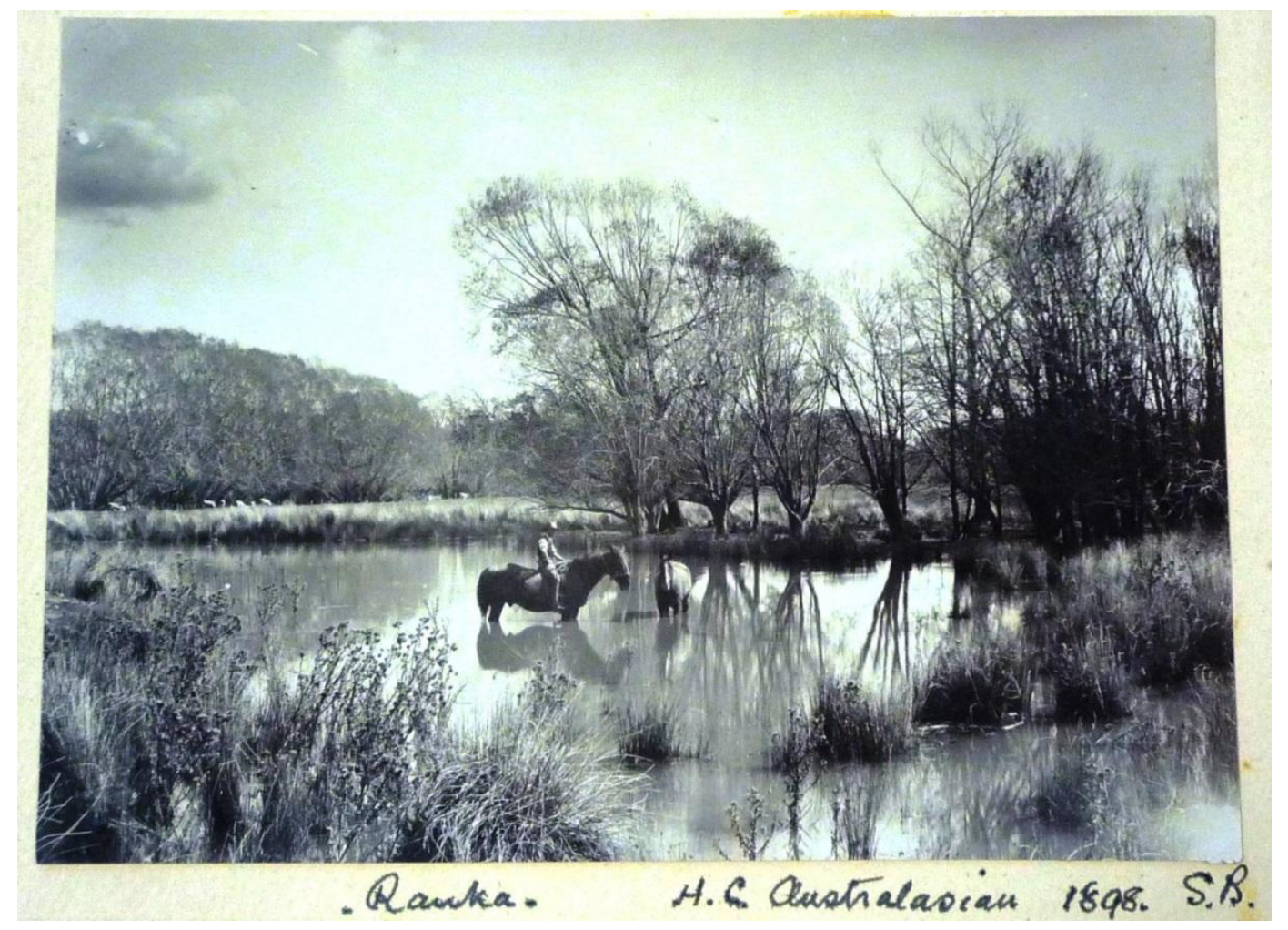

Figure 20: Susan Buckland, 'After the Toil of the Day', 1898, Jessie Buckland album, JB33, Hocken Library, University of Otago, Dunedin. 


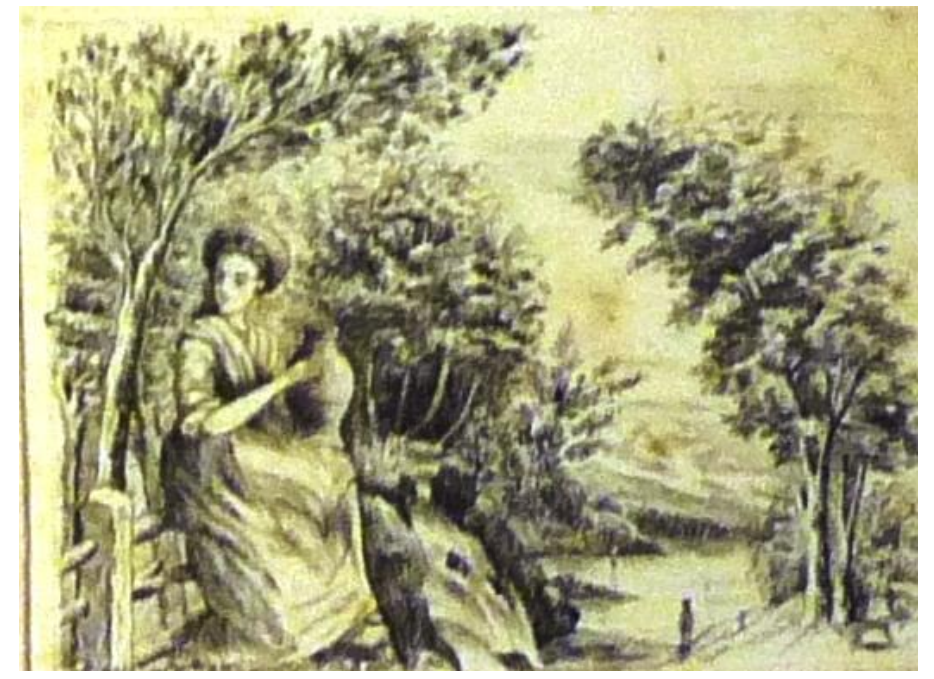

Figure 21: [The Water Carrier], Caroline Buckland album, CB35, Hocken Library, University of Otago, Dunedin.

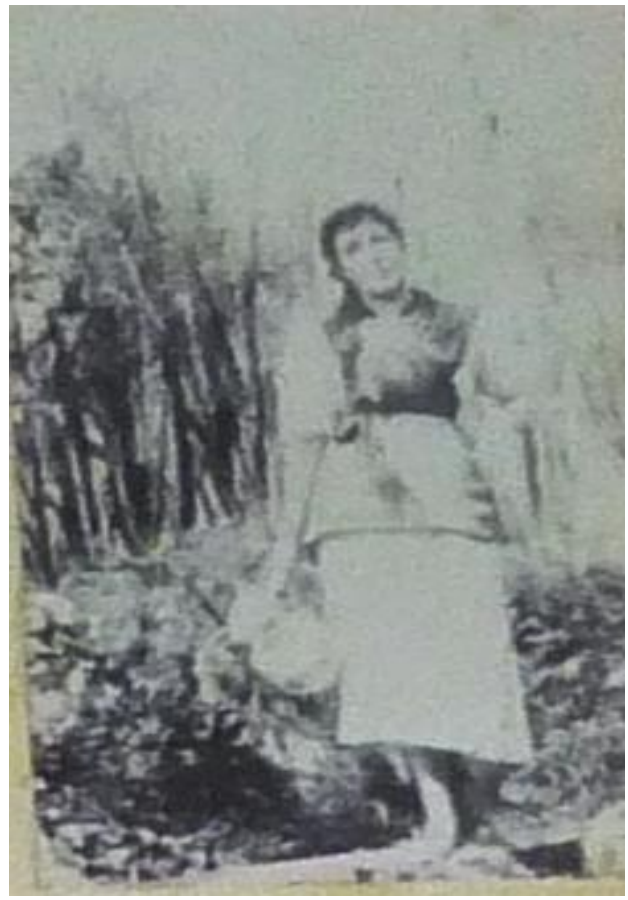

Figure 22: [The water carrier], Jessie Buckland album, JB16, Hocken Library, University of Otago, Dunedin. 


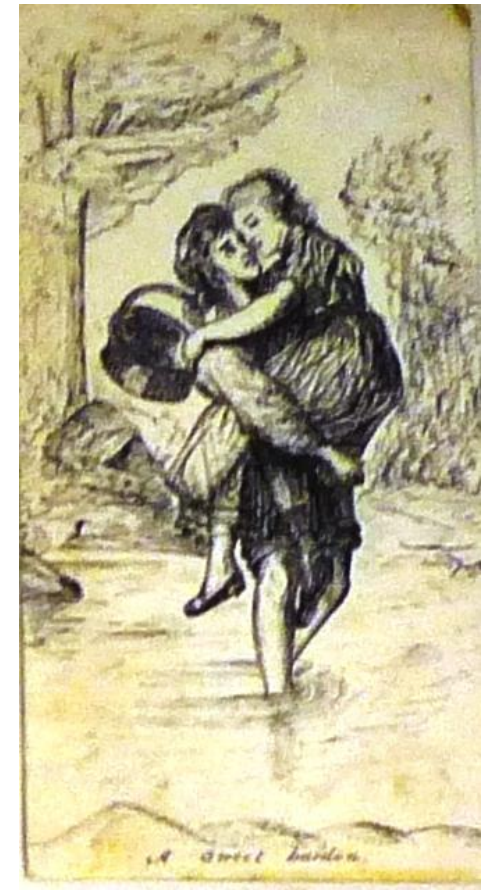

Figure 23: 'The Sweet Burden', Caroline Buckland album, CB35,

Hocken Library, University of Otago, Dunedin.

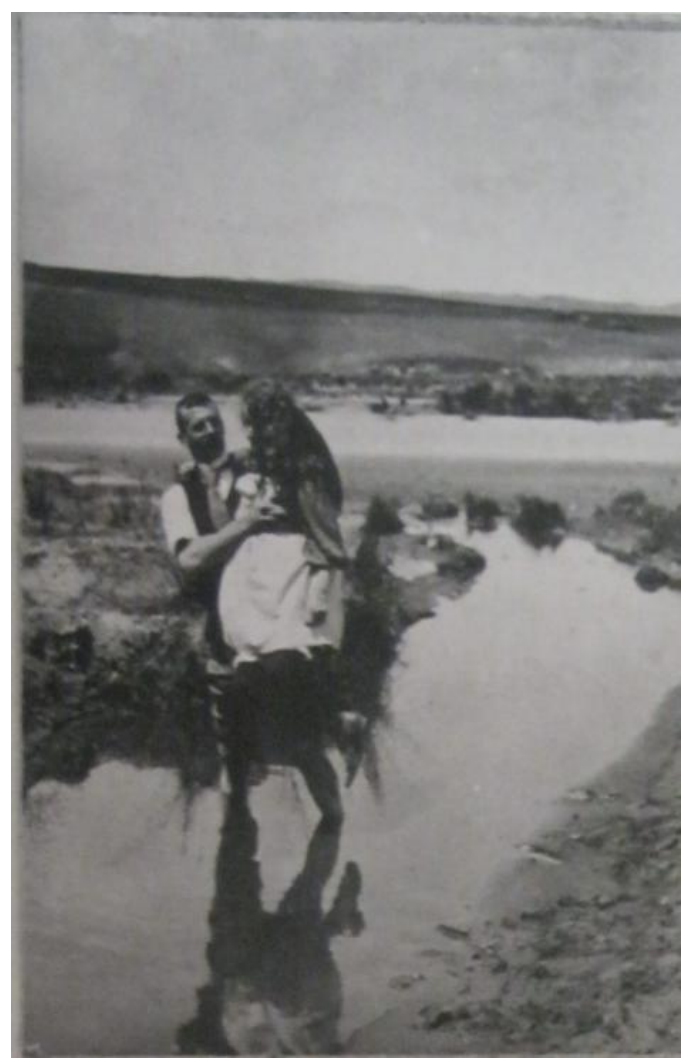

Figure 24: Susan Buckland, 'The Sweet Burden', Susan Buckland album, SB60, private collection, Louisville, Kentucky. 


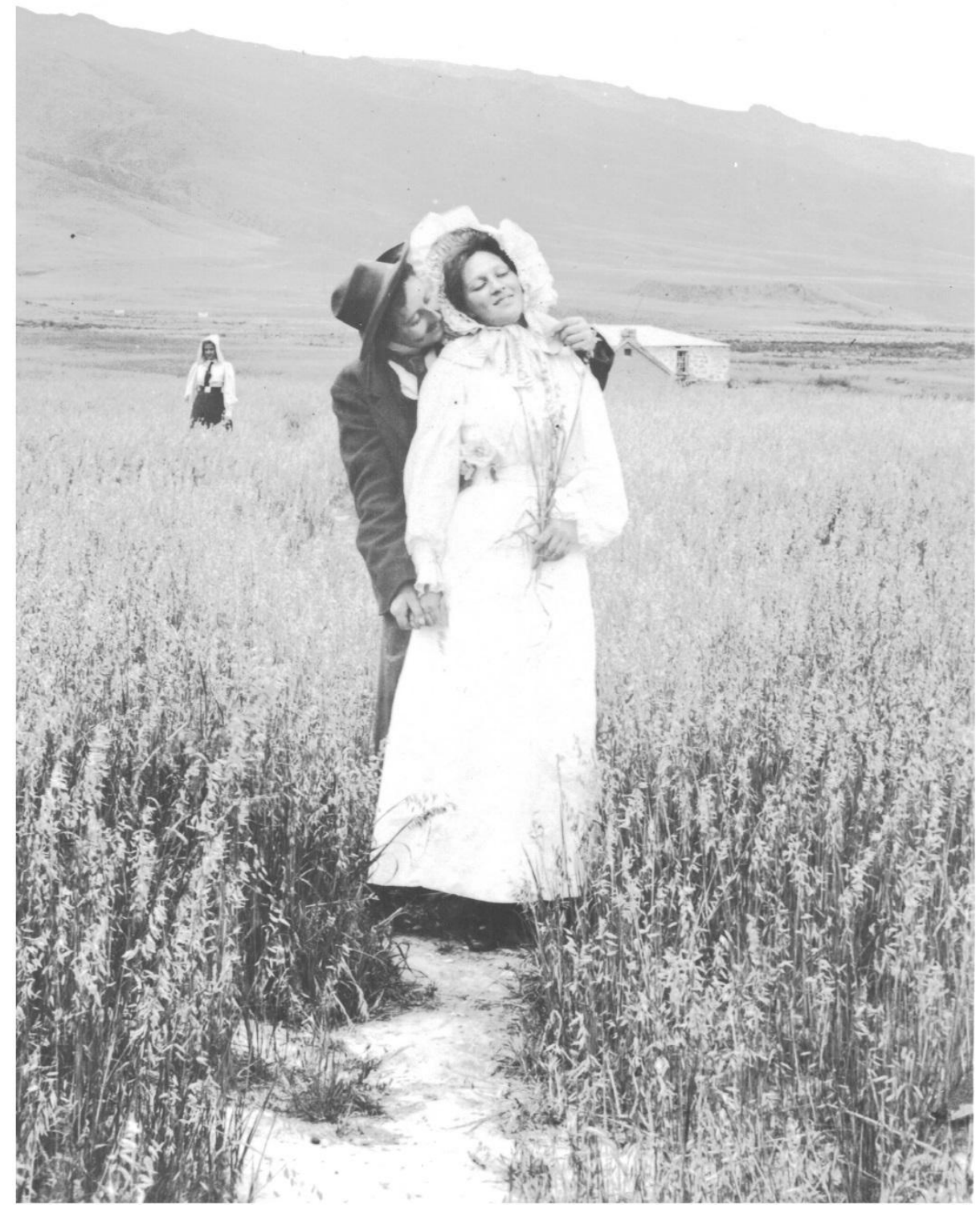

Figure 25: Jessie Buckland, 'Coming Thro' the Rye', 1897, Jessie Buckland album, JB8, Hocken Library, University of Otago, Dunedin. 


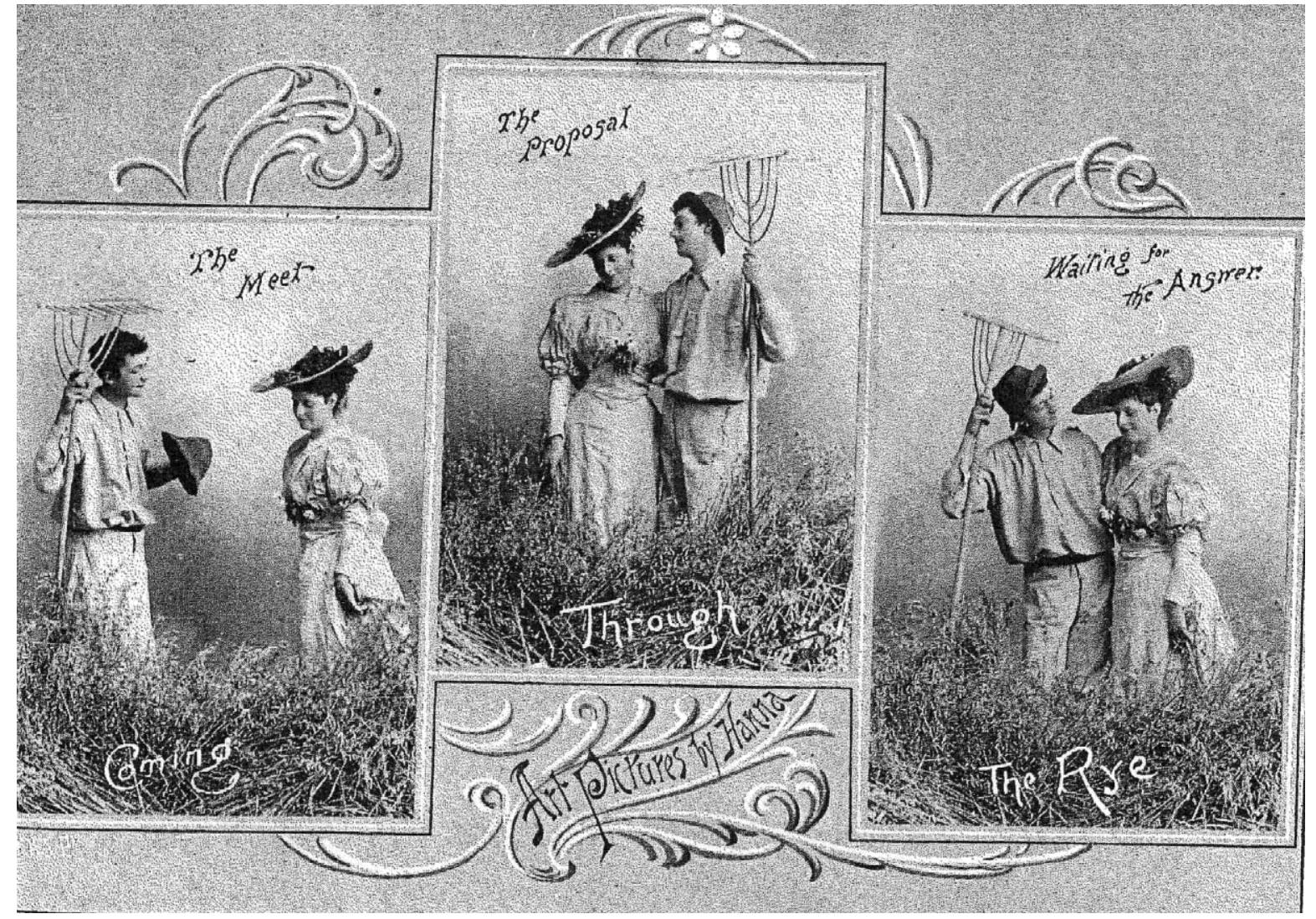

Figure 26: J.R. Hanna, 'Coming Through the Rye', in the Auckland edition of the Cyclopedia of New Zealand, (Christchurch, 1902): 319. 


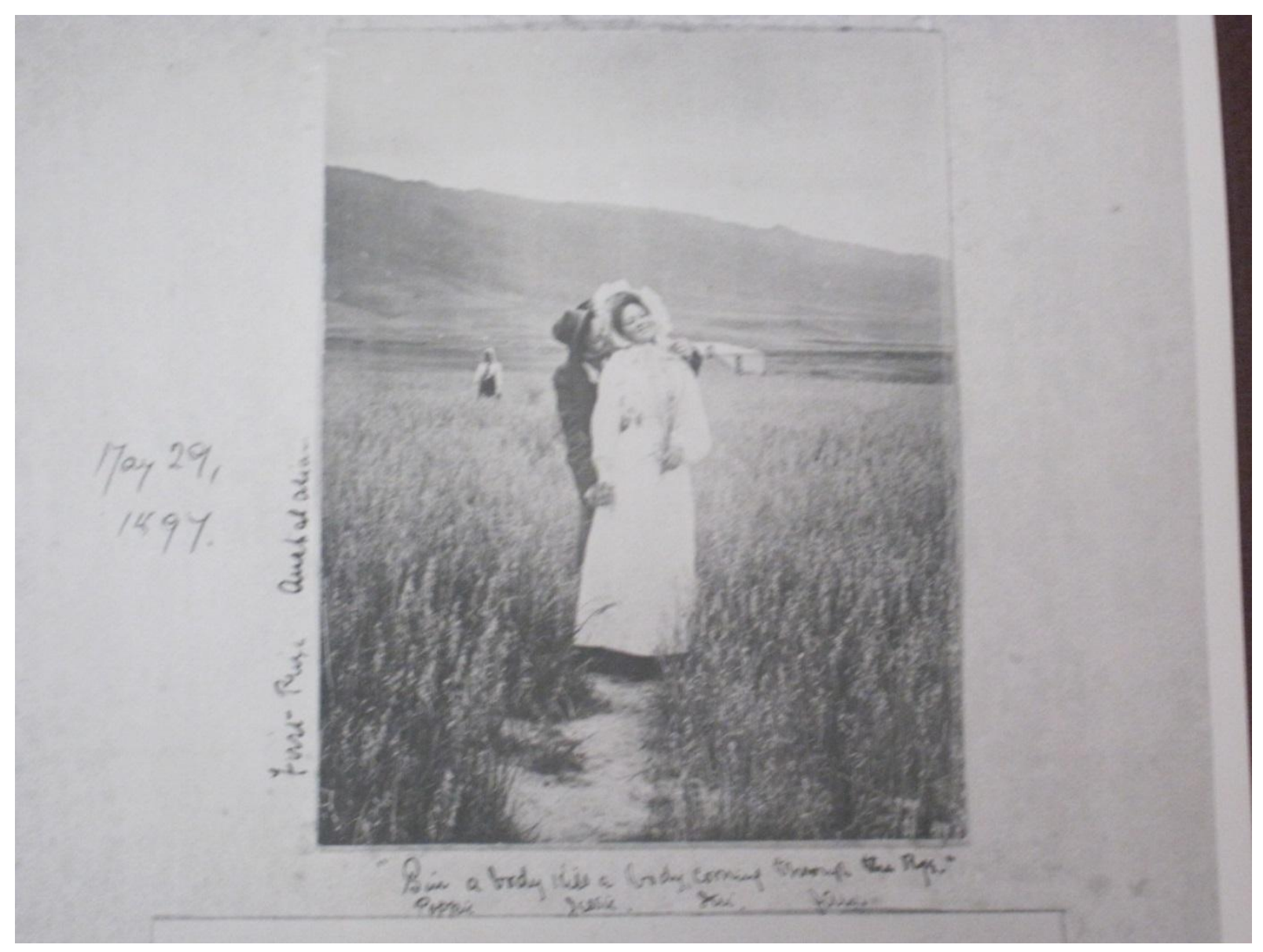

Figure 27: Jessie Buckland, 'Coming Thro' the Rye', 1897, Susan Buckland album, SB72, private collection, Louisville, Kentucky. 


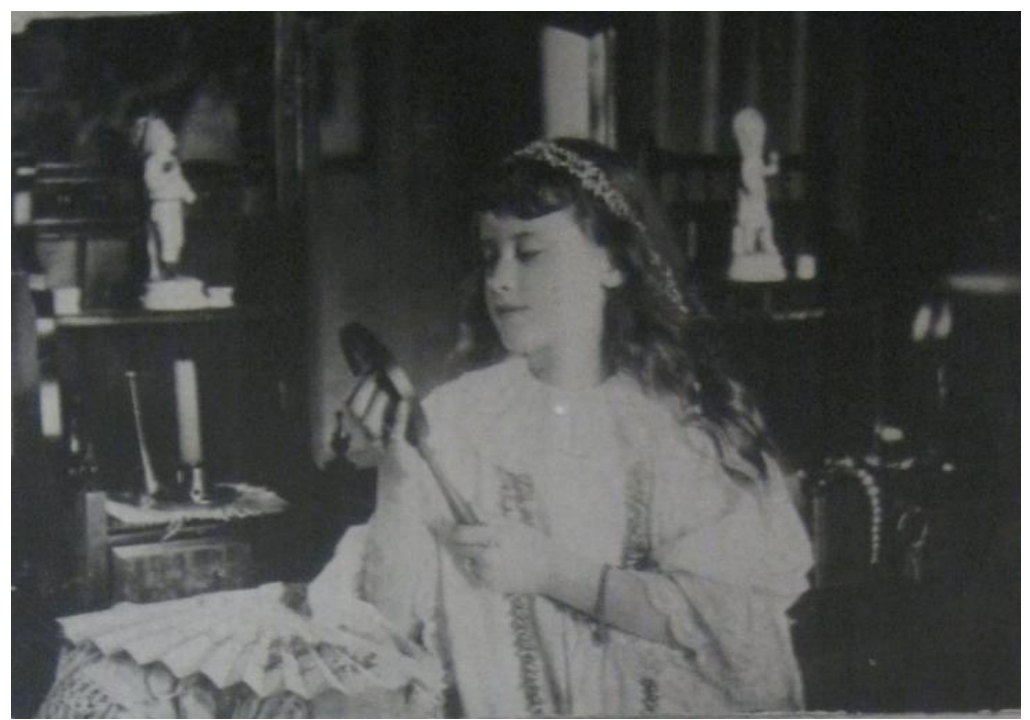

Figure 28: Elizabeth Hocken',Mother's Treasure Box', 1895, Susan Buckland album, SB19, private collection, Louisville, Kentucky.

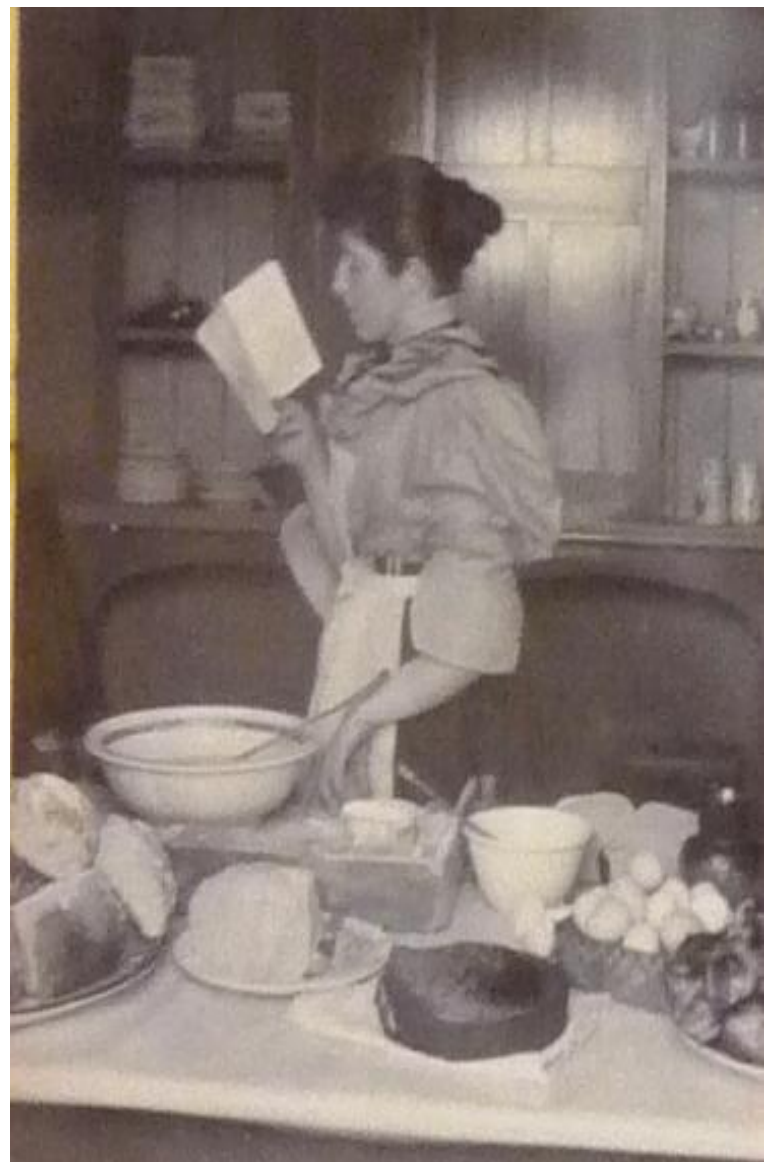

Figure 29: Caroline Buckland',Baking Day', 1896, Jessie Buckland album, JB5, Hocken Library, University of Otago, Dunedin. 


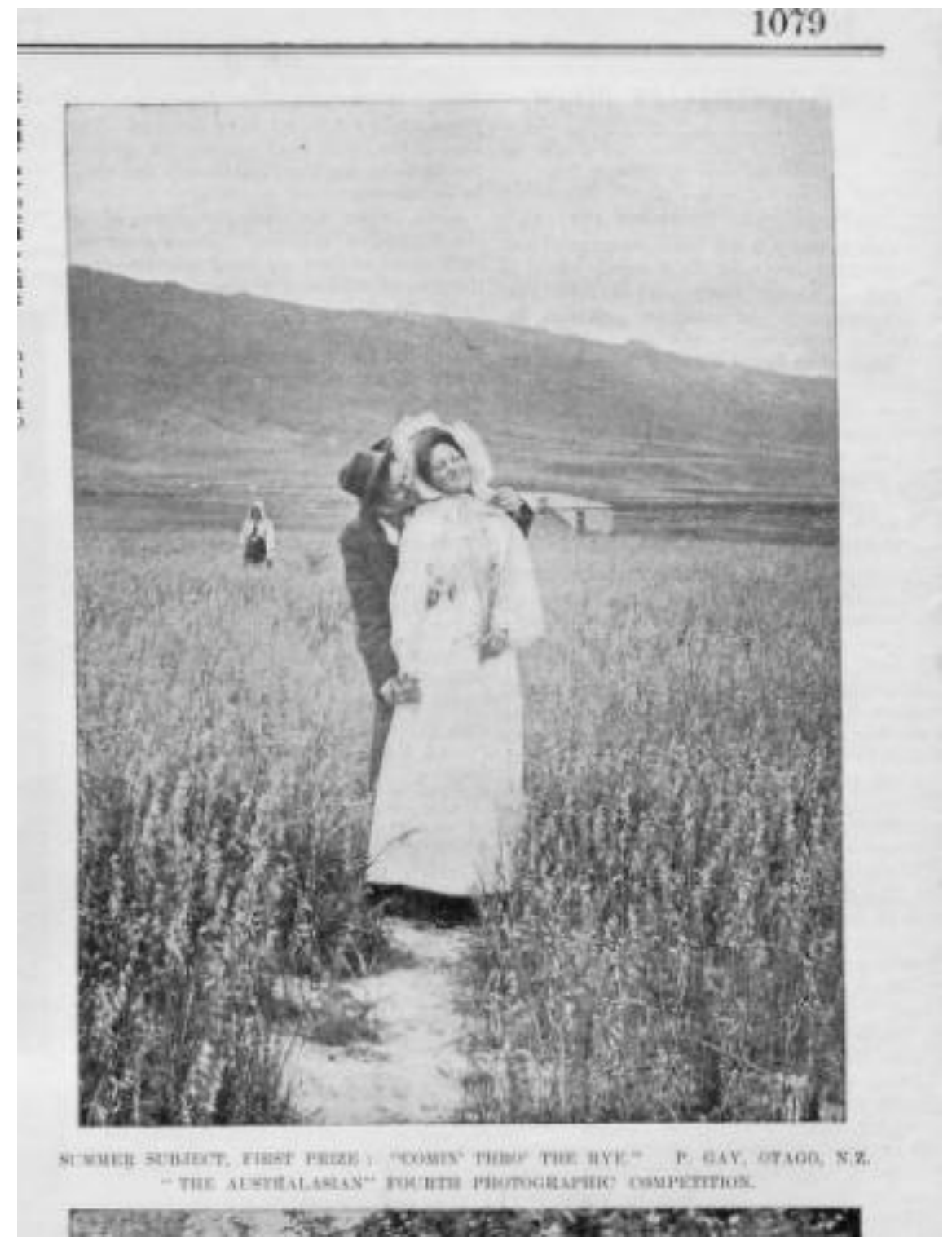

Figure 30: Jessie Buckland, 'Coming Thro' the Rye', Summer Scene, the Australasian, 29 May, 1897, p. 1079. 


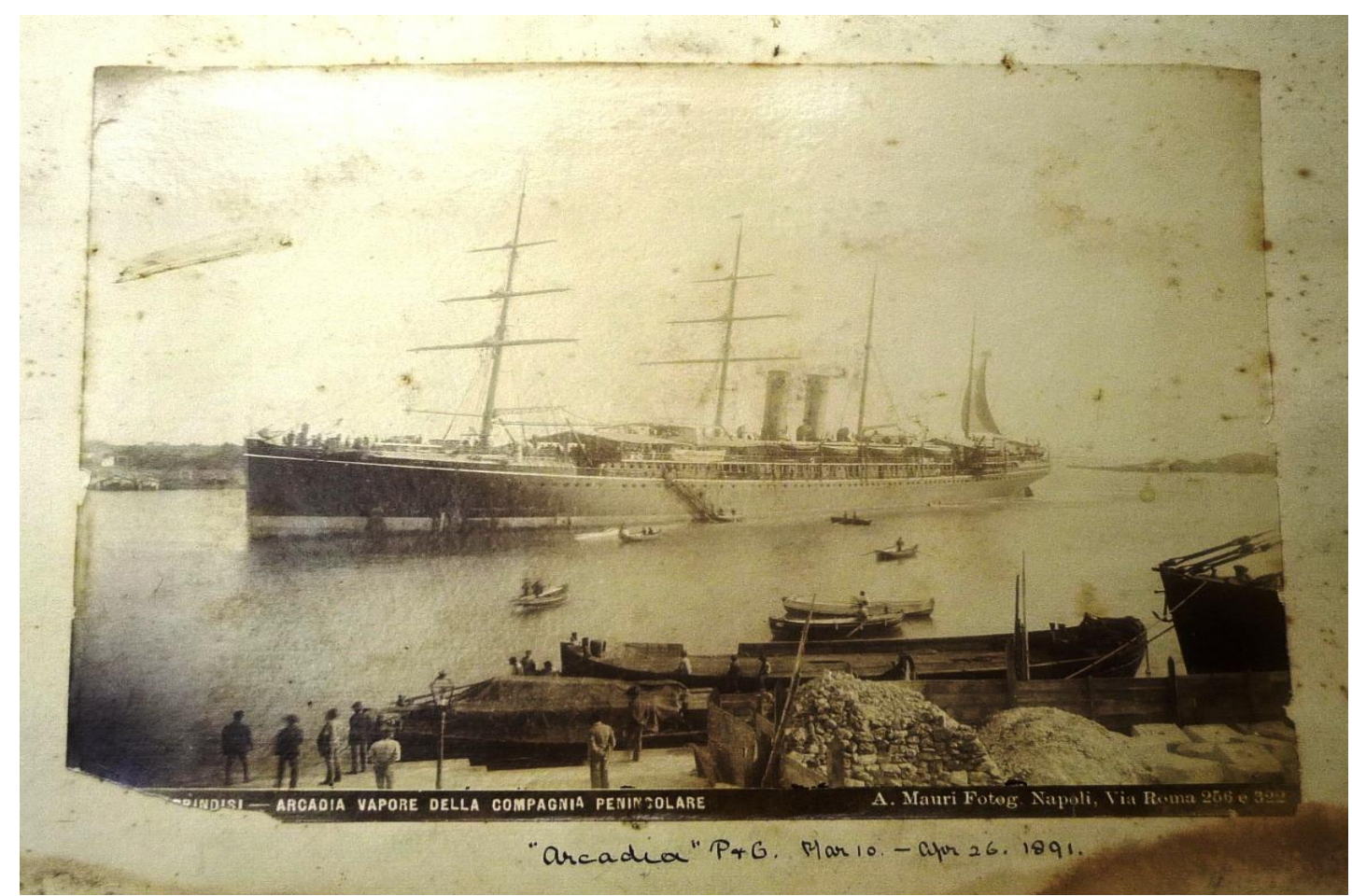

Figure 31: 'The Arcadia', Lucy Acland album, LA1, private collection, Christchurch. 


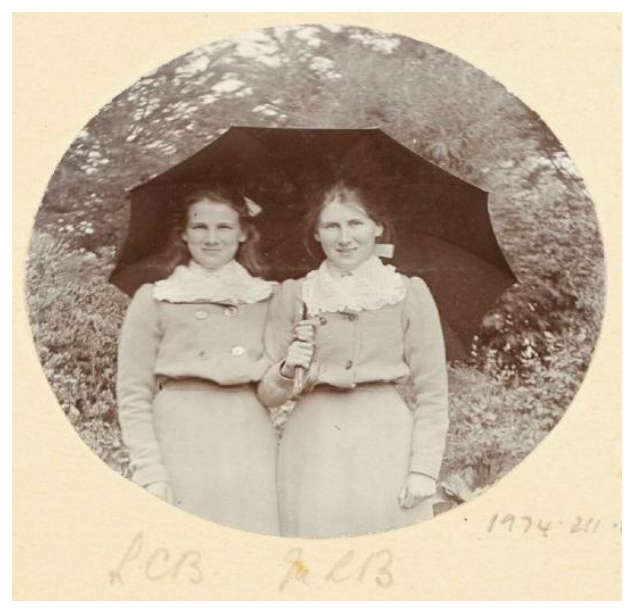

Figure 32: 'LCB MLB', [Laura and Margaret Bowen], The Bowen album, MLB9, Canterbury Museum, Christchurch.

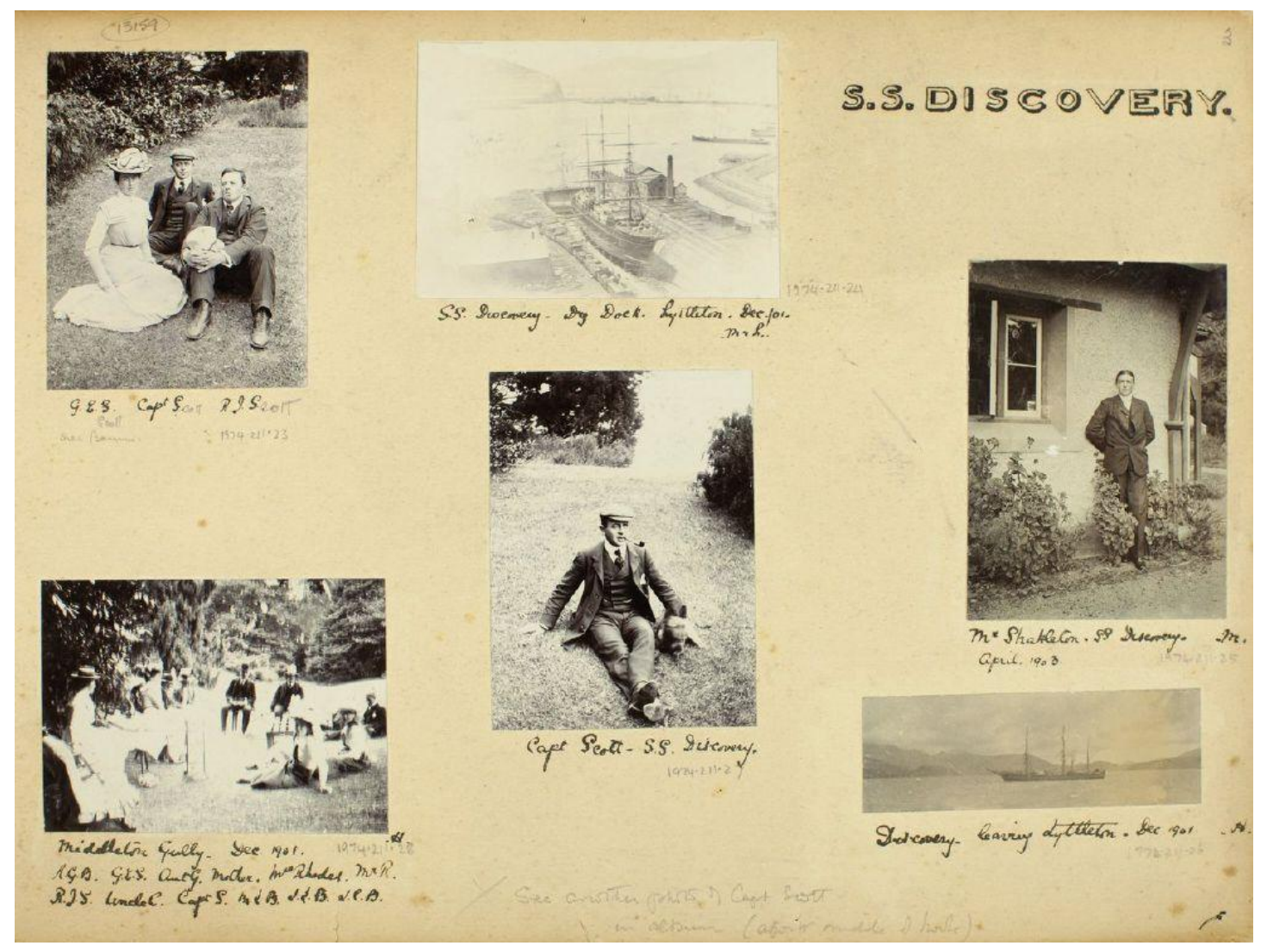

Figure 33: Margaret and Laura Bowen, 'S.S. Discovery', 1901, The Bowen album, MLB3, Canterbury Museum, Christchurch. 


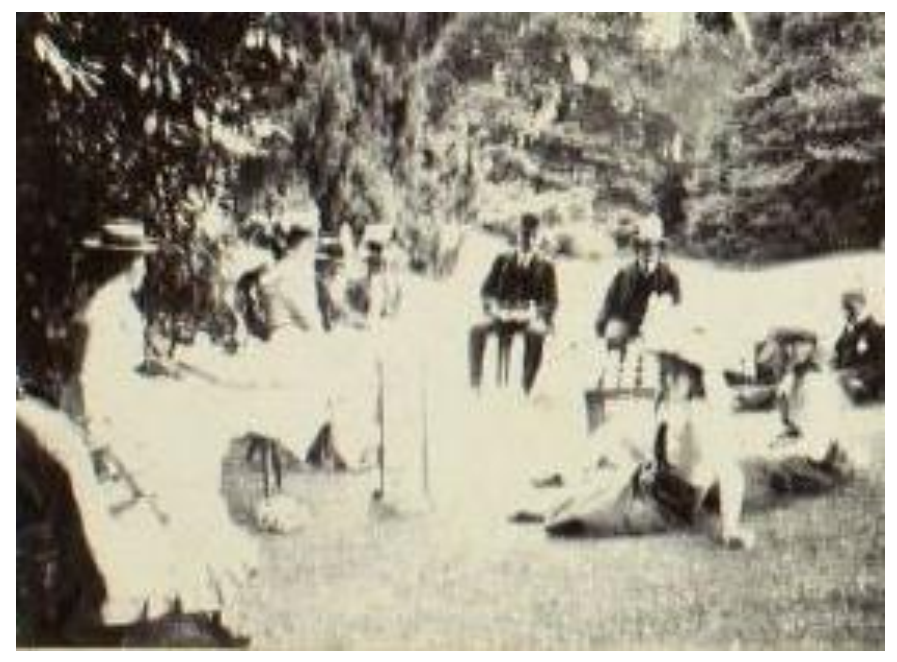

Fig. 34: Margaret and Laura Bowen, [The Bowen family gathered at Middleton], Canterbury Museum, Christchurch. Detail of Fig. 33. MLB3.

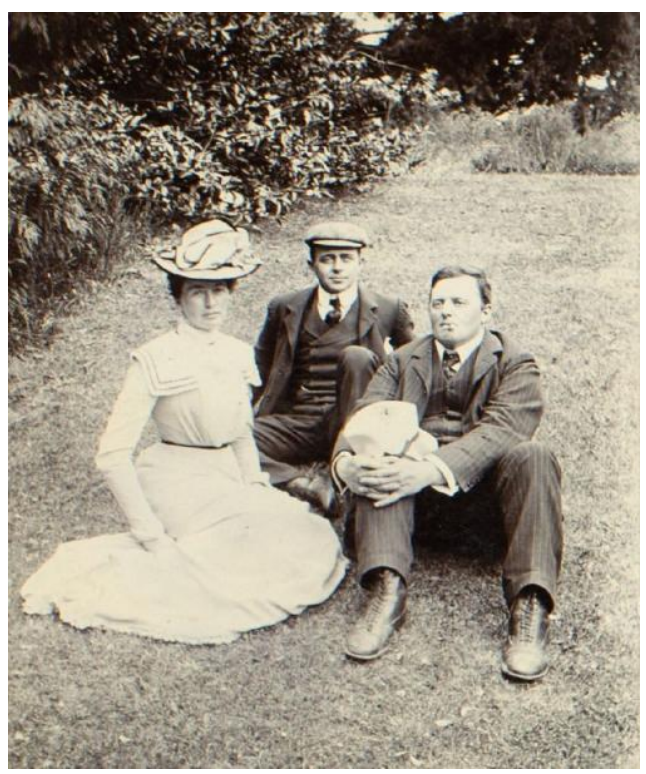

Figure 35: [Captain Scott at Middleton, Christchurch with his cousin, Robert Julian Scott and his wife, Gertrude Elizabeth Scott, née Bowen]. Detail from Fig. 34, MLB3. 


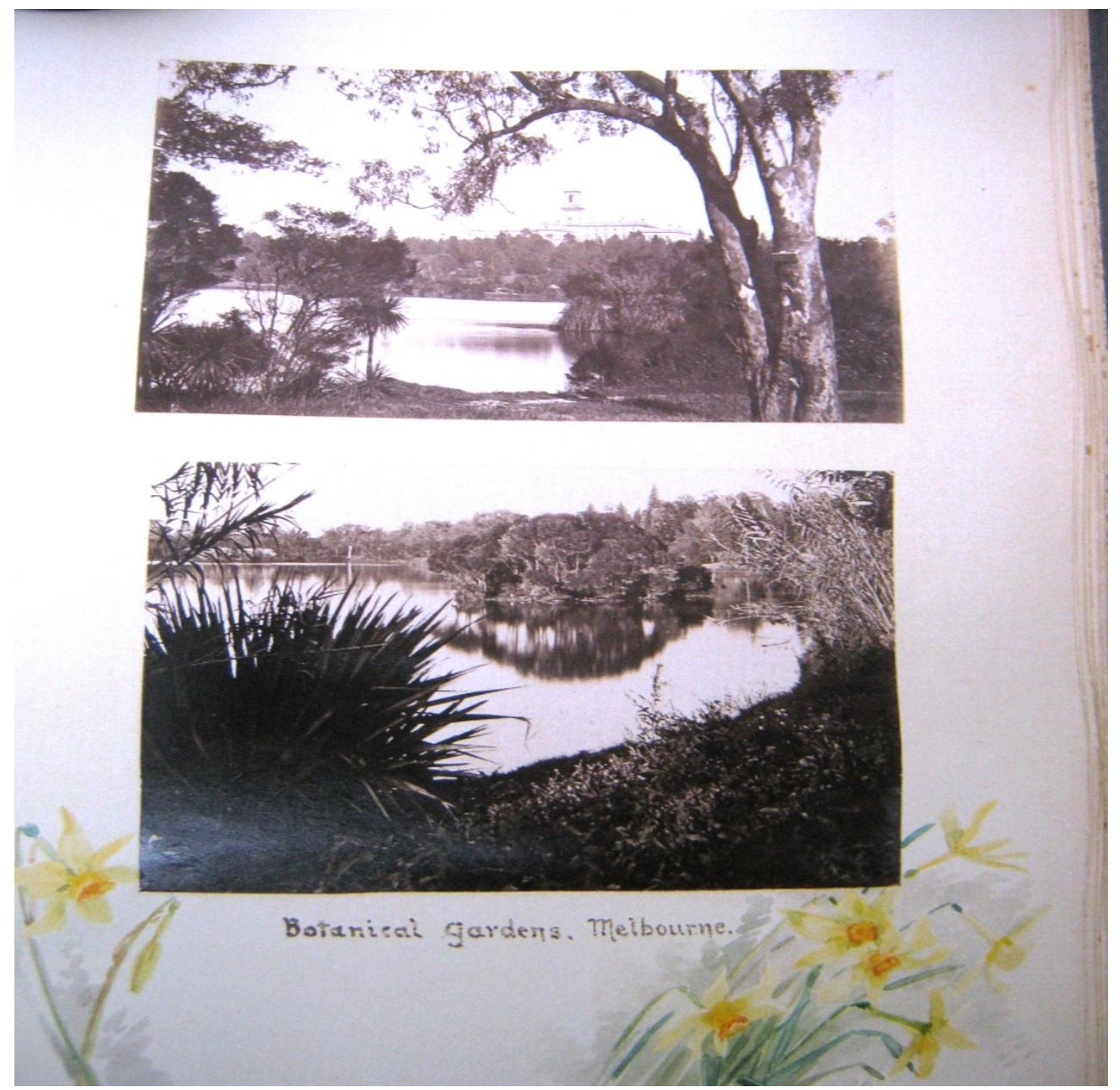

Figure 36: 'Botanical Gardens, Melbourne', Australia, Margaret Stoddart album, MOS26, Canterbury Museum, Christchurch. 


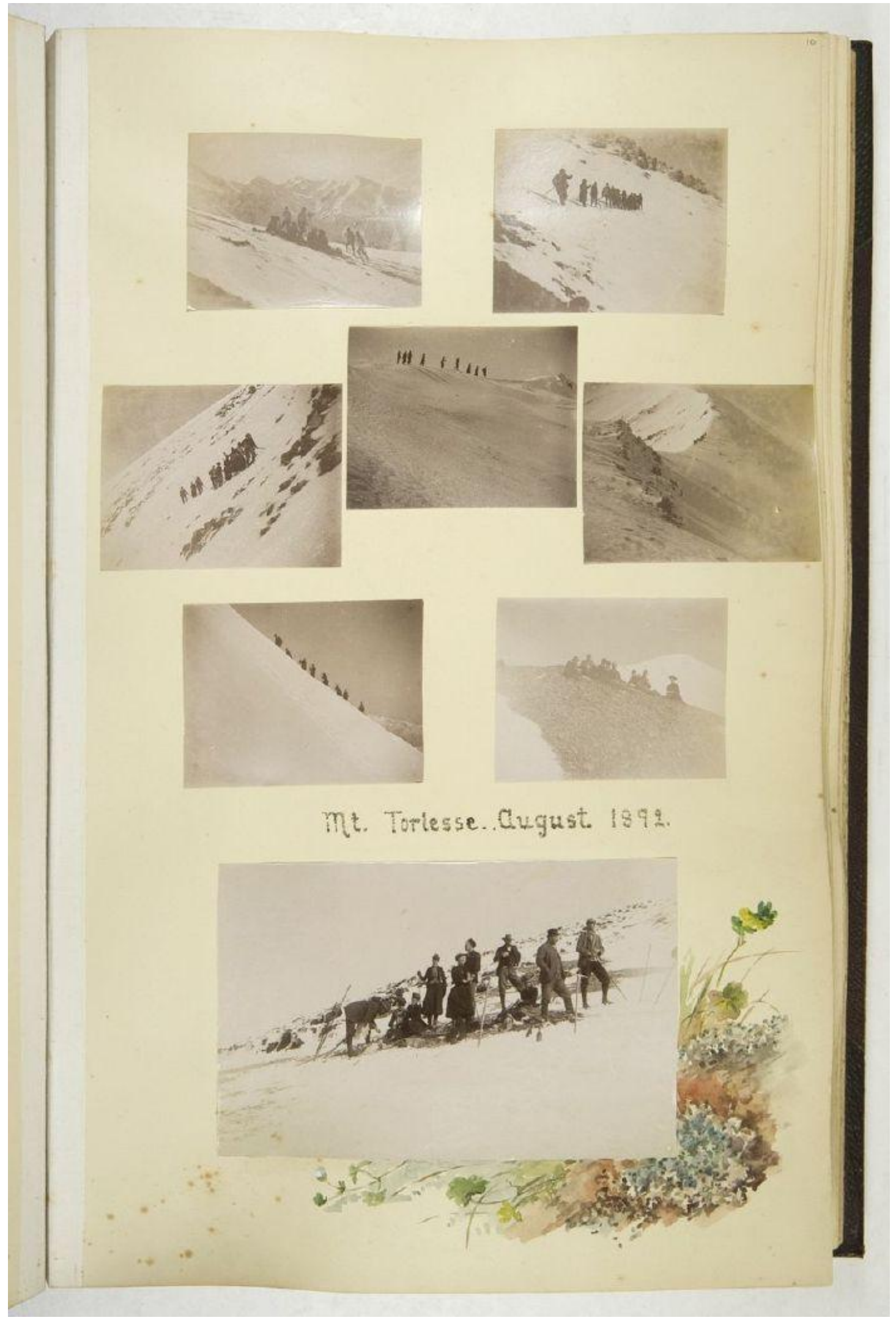

Figure 37: 'Mt Torlesse, August 1892', Margaret Stoddart album, MOS10, Canterbury Museum, Christchurch. 


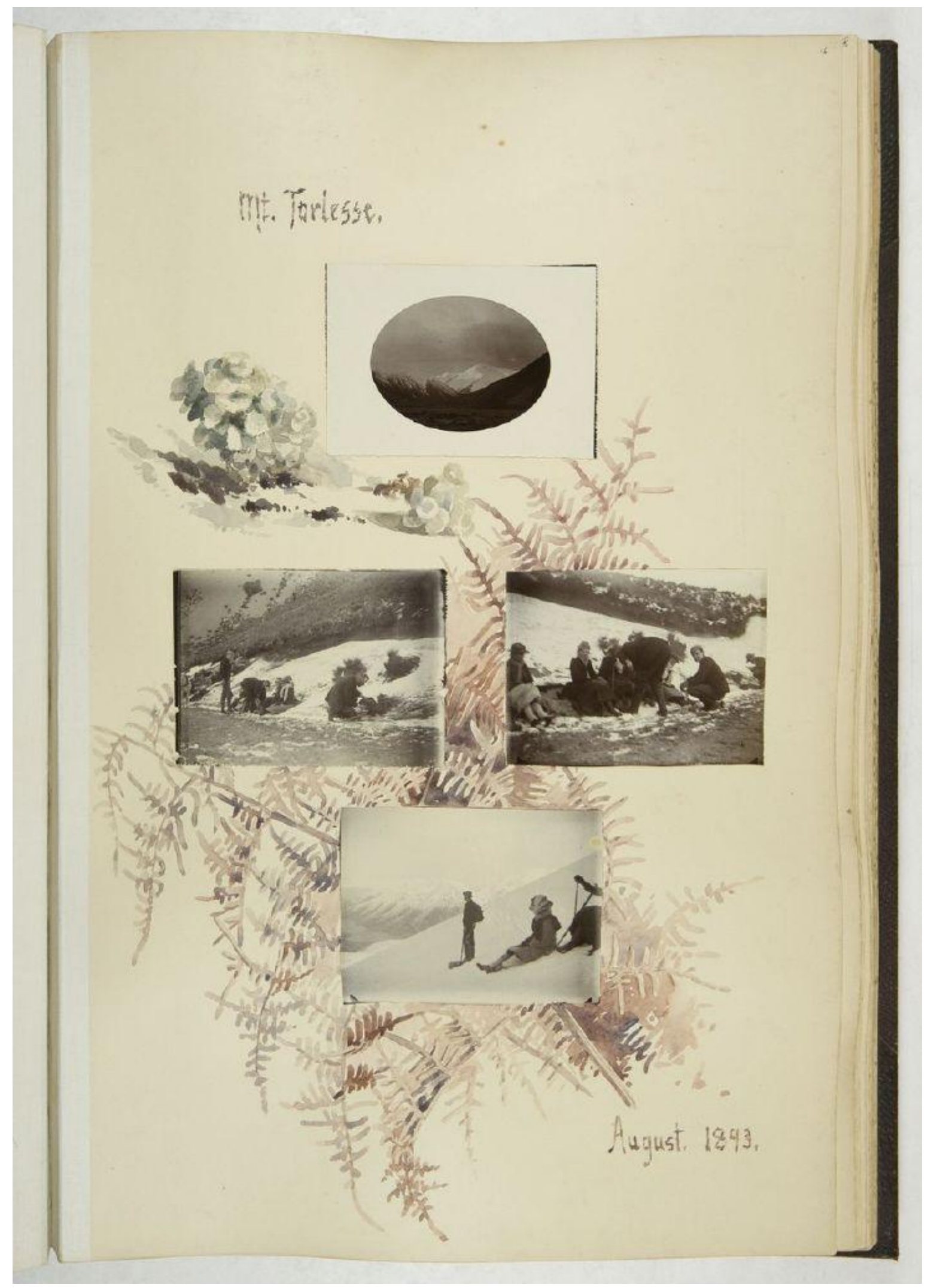

Figure 38: 'Mt Torlesse, August 1893', Margaret Stoddart album, MOS16, Canterbury Museum, Christchurch. 


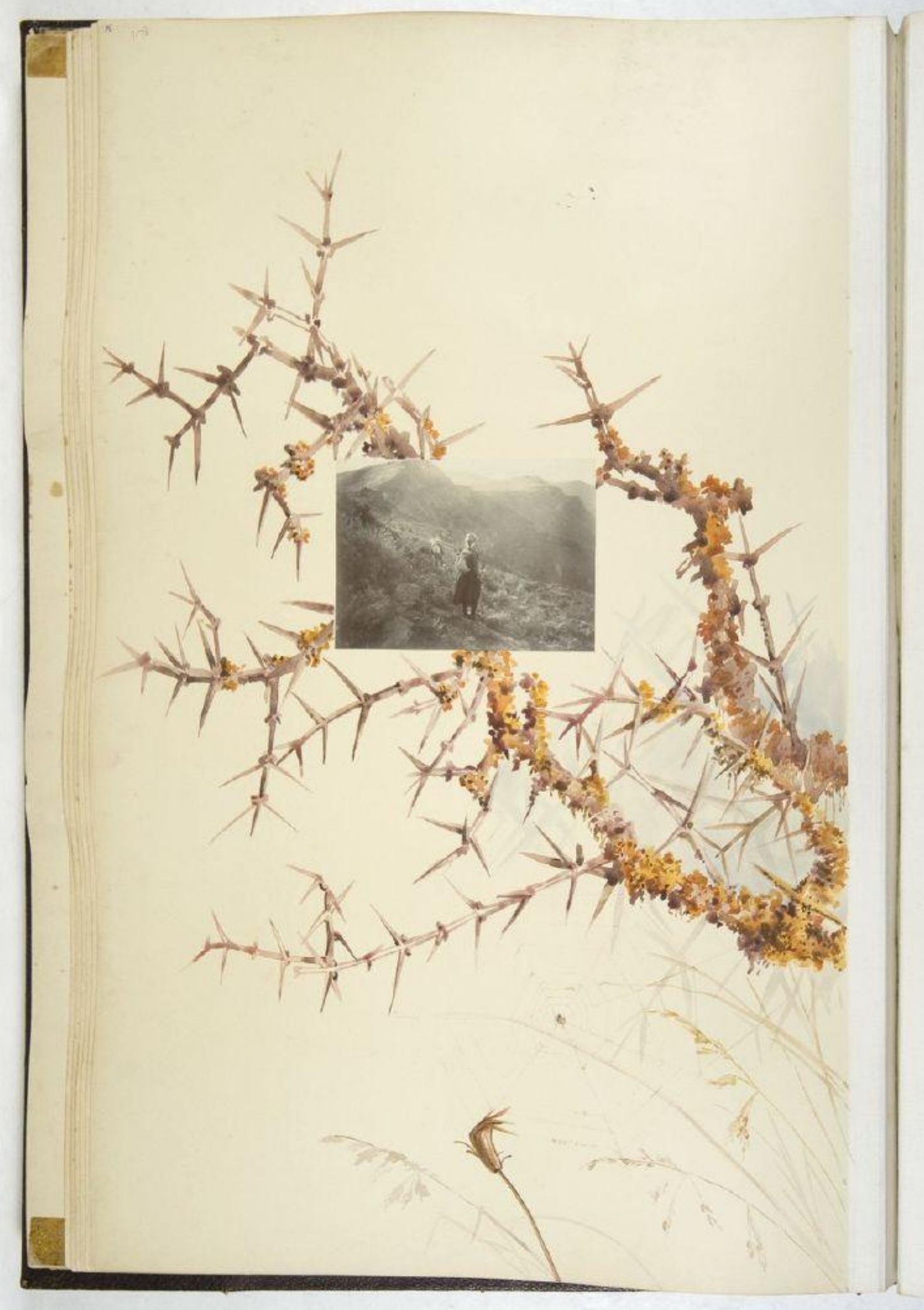

Figure 39: [Matagouri], Mt Torlesse, 1893, Margaret Stoddart album, MOS15, Canterbury Museum, Christchurch. 


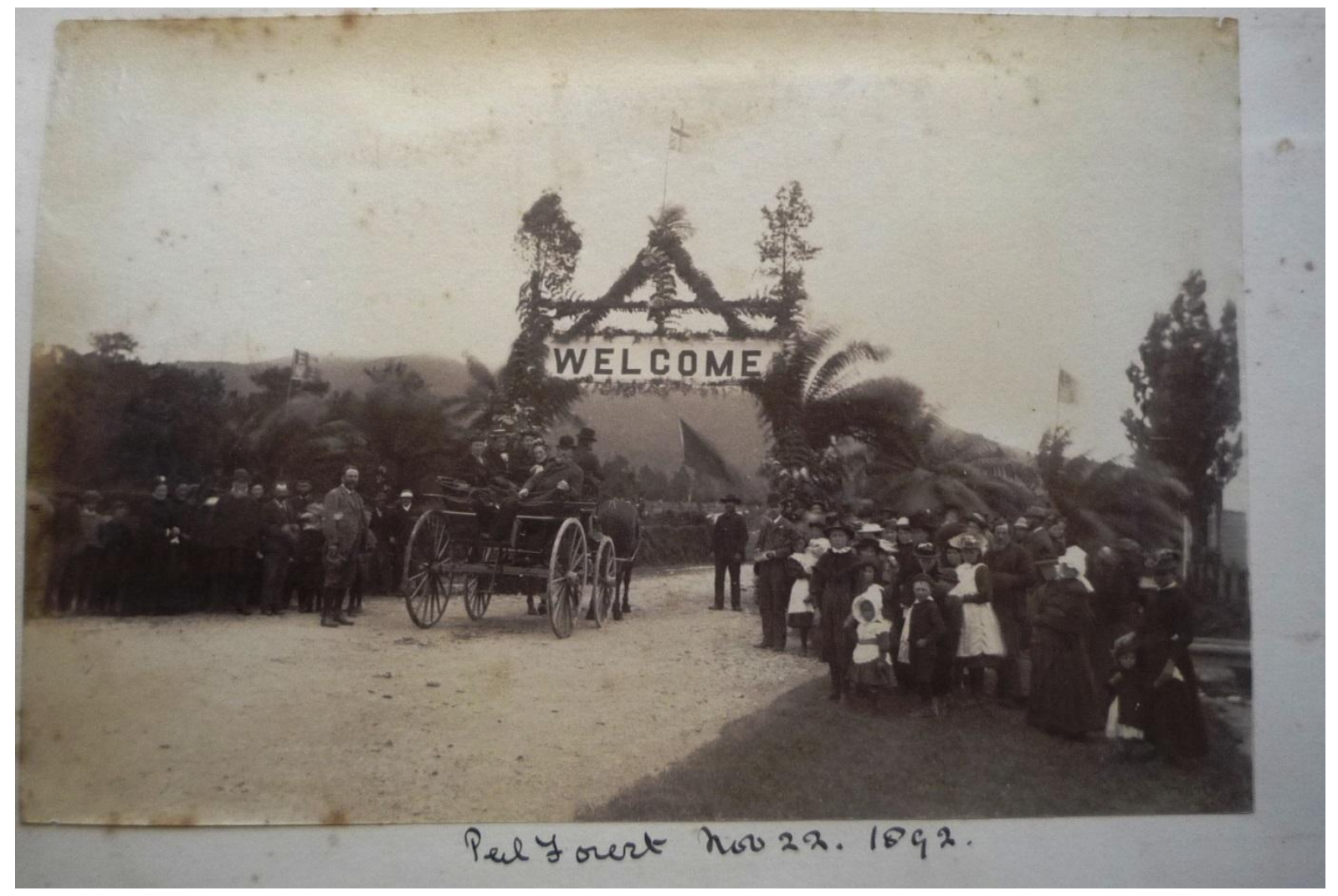

Figure 40: [Homecoming], Peel Forest, 1892, Lucy Acland album, LA42, private collection, Christchurch. 


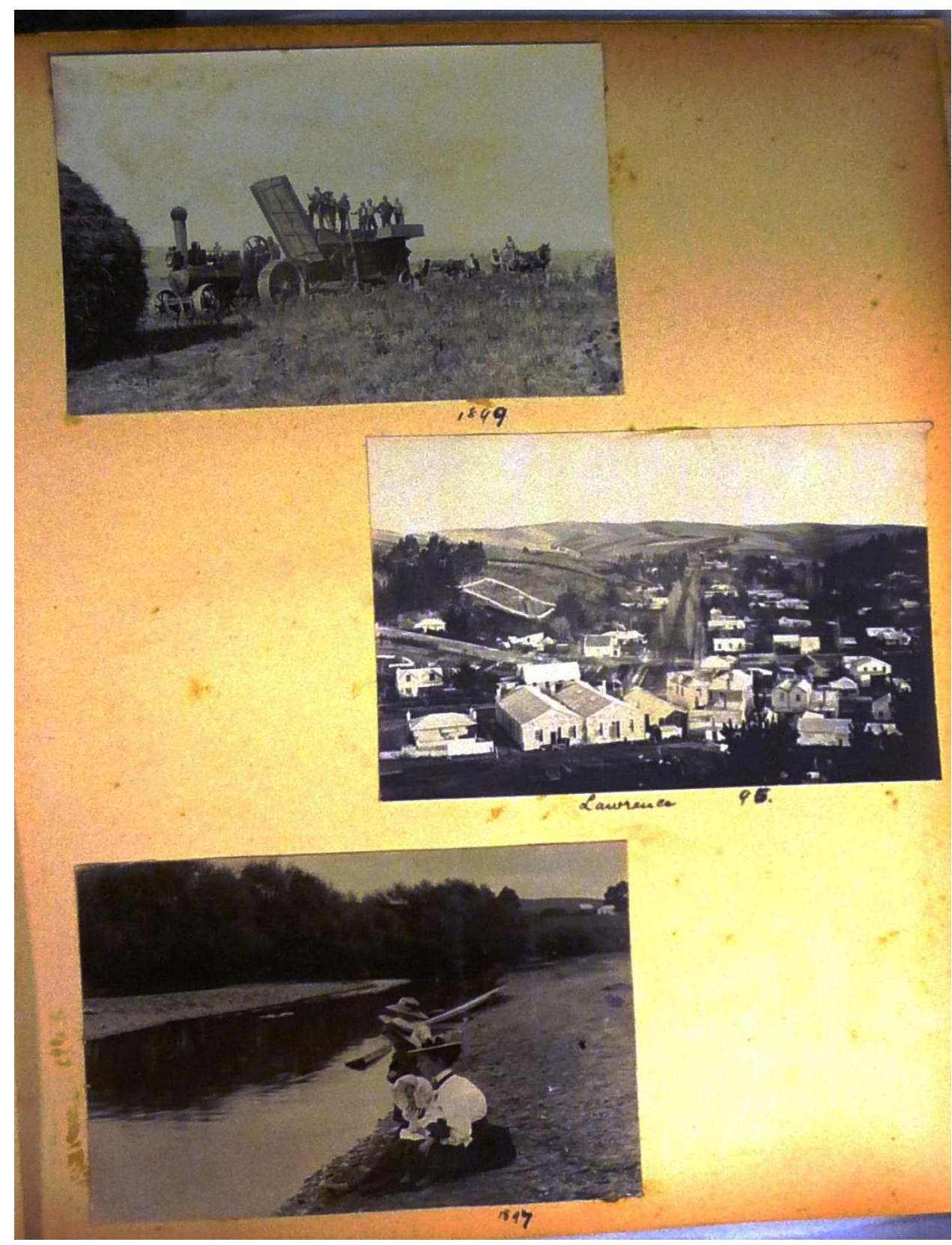

Figure 41: Sample page from Jessie Buckland's album, JB44, Hocken Library, University of Otago, Dunedin. 


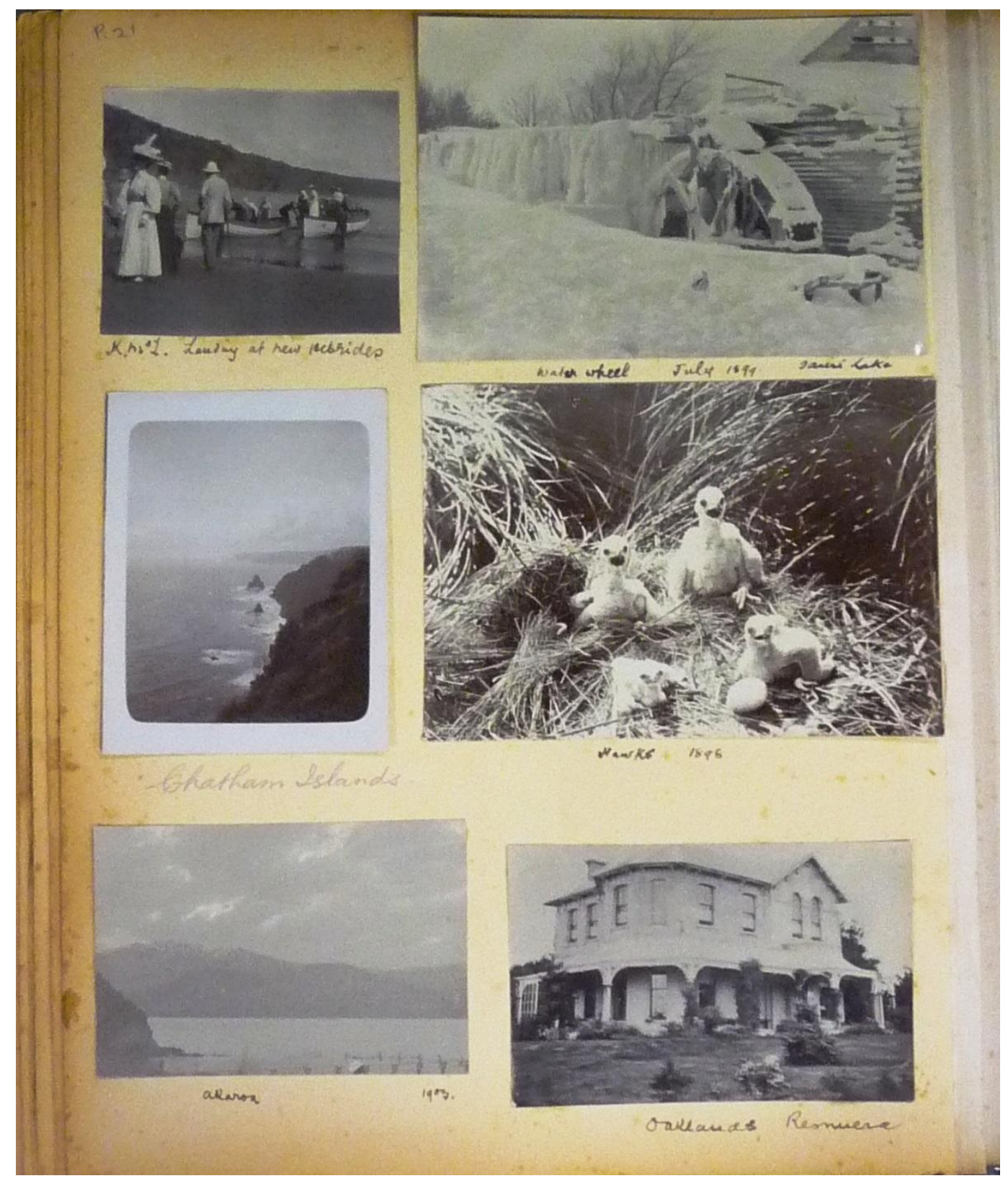

Figure 42: Sample page from Jessie Buckland's album, Jessie Buckland album, JB21, Hocken Library, University of Otago, Dunedin 


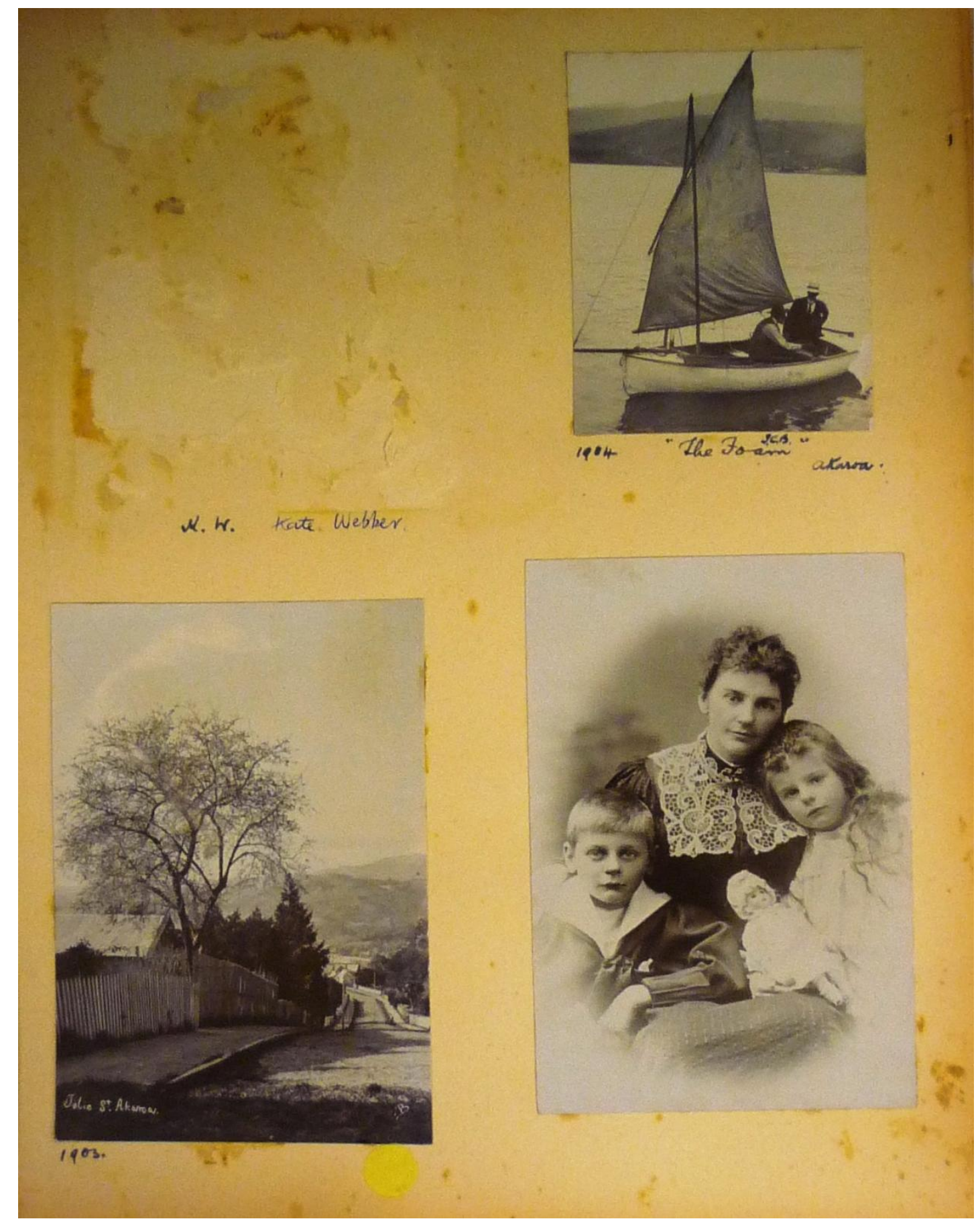

Figure 43: Sample page from Jessie Buckland's album, Jessie Buckland album, JB64, Hocken Library, University of Otago, Dunedin. 


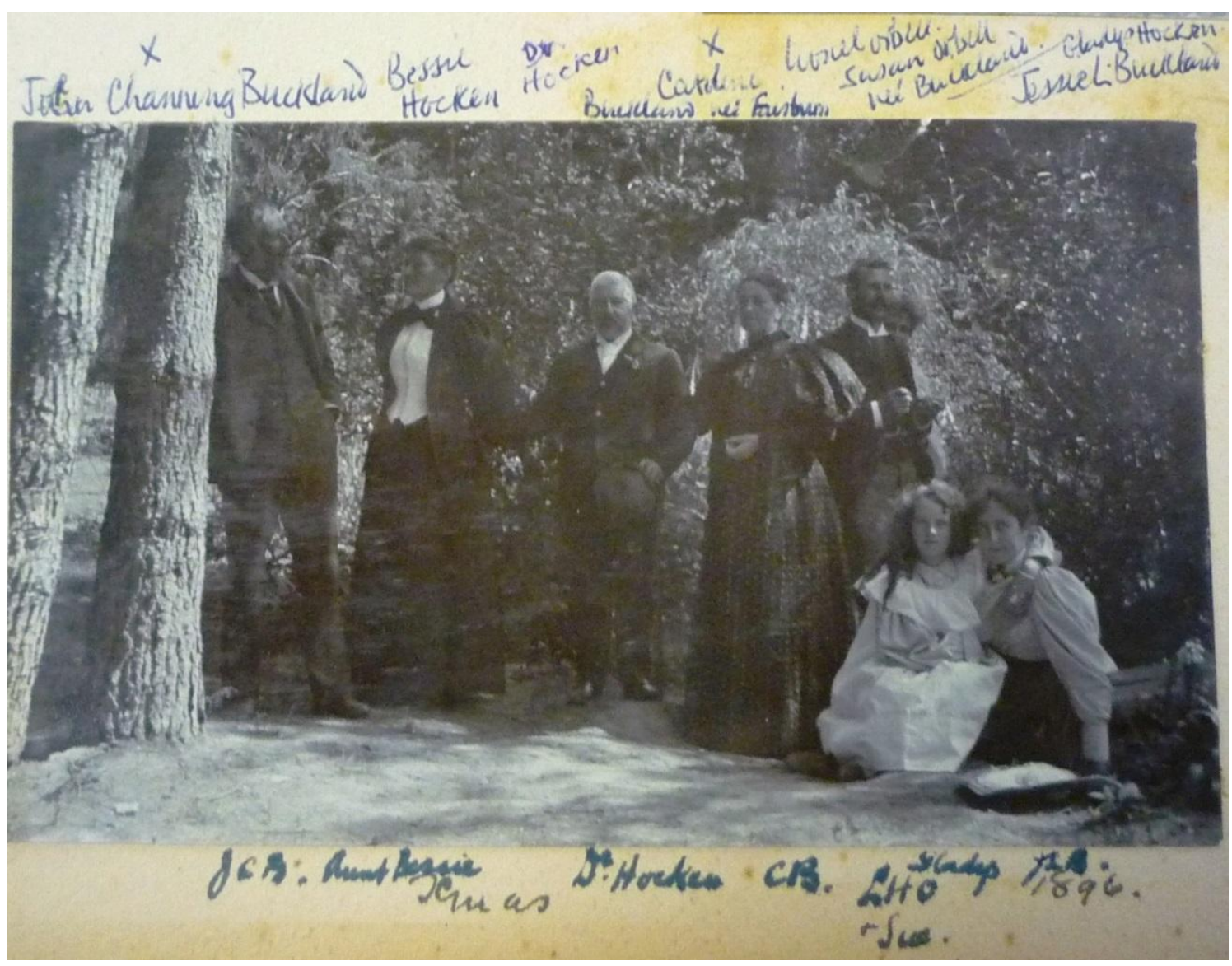

Figure 44: 'Xmas 1896', [The Buckland/Hocken families], Jessie Buckland album, JB30, Hocken Library, University of Otago, Dunedin.

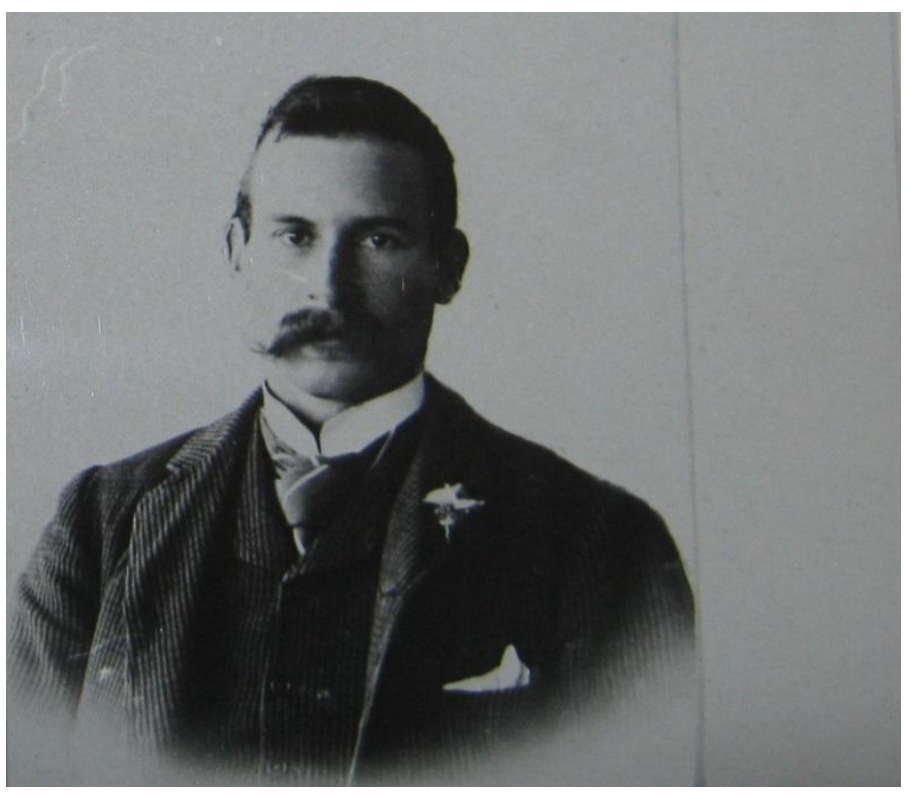

Figure 45: [Lionel Orbell], Susan Buckland album, SB41, private collection, Louisville, Kentucky. 


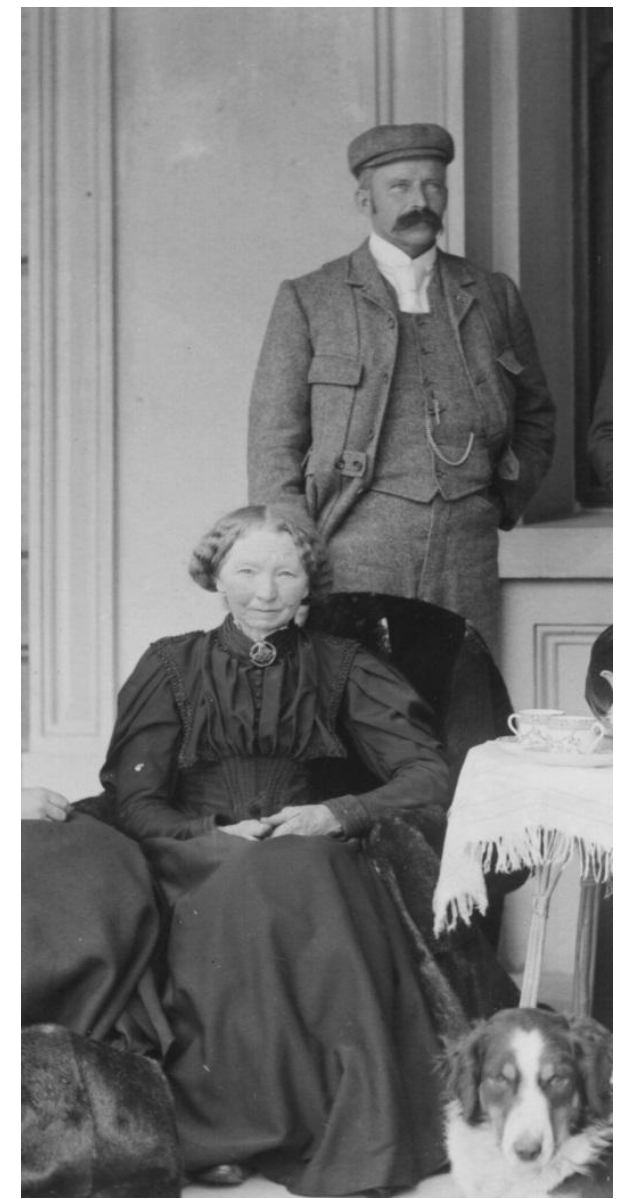

Figure 46: [Mrs Barbara Stoddart and son, James, Diamond Harbour], c. 1897, Mary Stoddart album, $\mathrm{MS}_{2} 29$, Diamond Harbour and Districts Historical Association Inc., Diamond Harbour. 


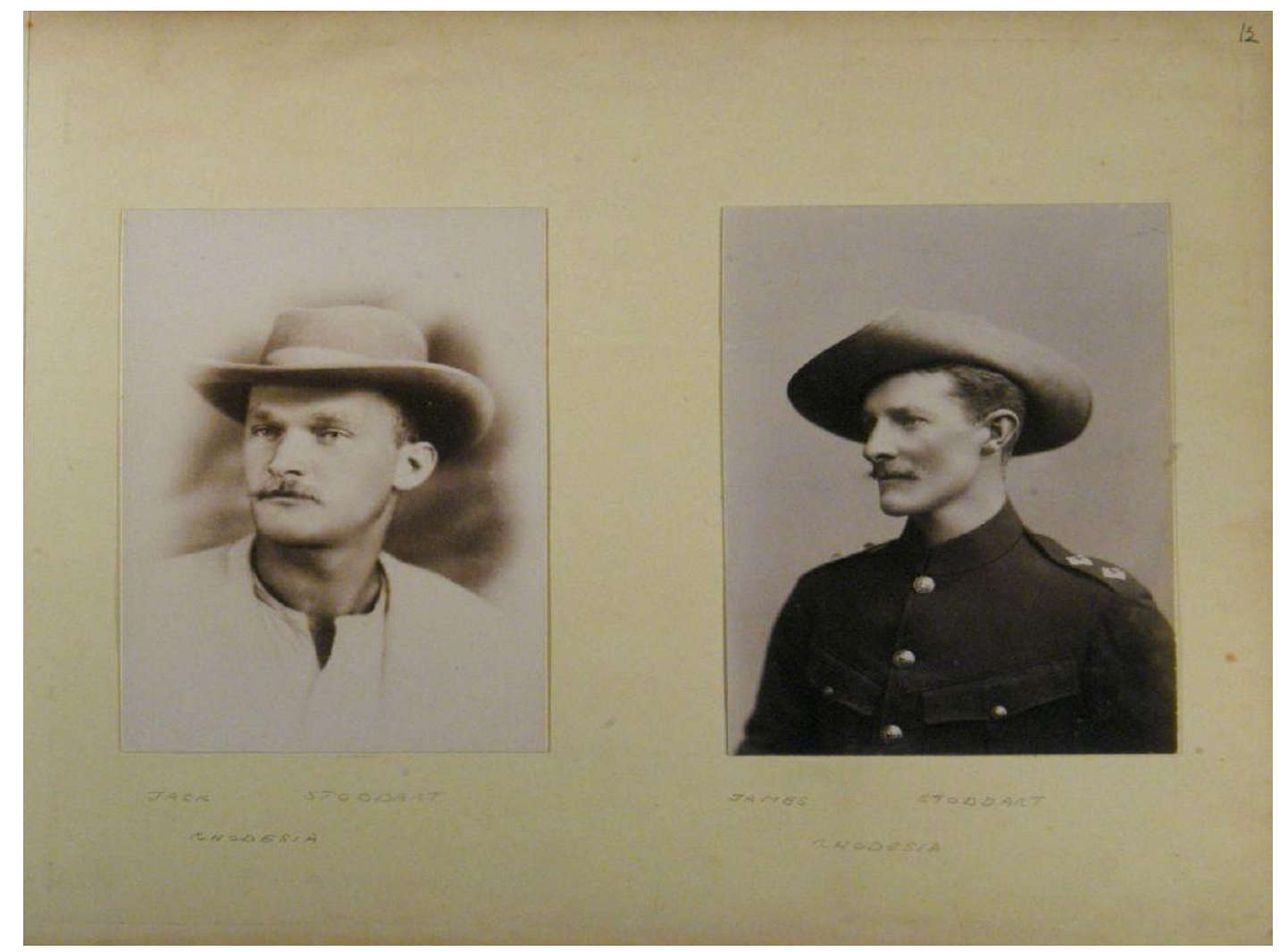

Figure 47: 'John Stoddart; James Stoddart', Mary Stoddart album, $\mathrm{MS}_{1} 12$, Canterbury Museum, Christchurch.

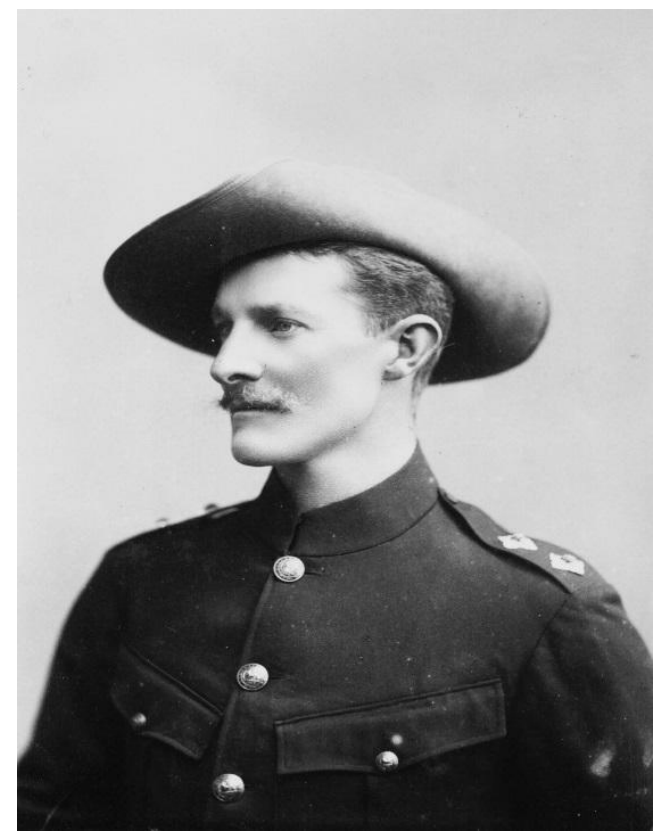

Figure 48: 'James Stoddart', Mary Stoddart Album 2, $\mathrm{MS}_{2} 34$, Diamond Harbour and Districts Historical Association Inc., Diamond Harbour. 


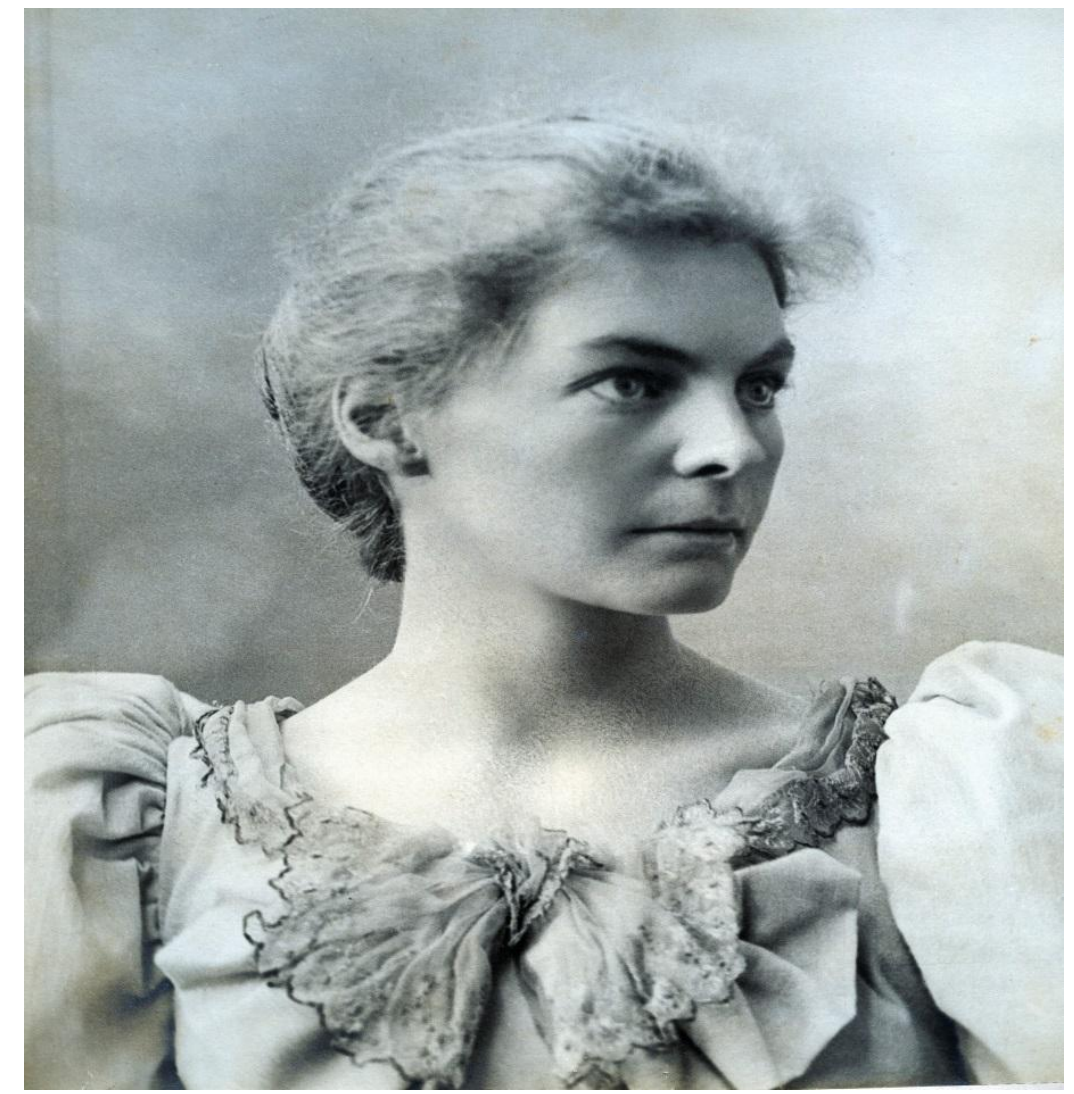

Figure 49: 'Mary Stoddart', Mary Stoddart album, $\mathrm{MS}_{2} 2$, Diamond Harbour, Diamond Harbour and Districts Historical Association Inc., Diamond Harbour.

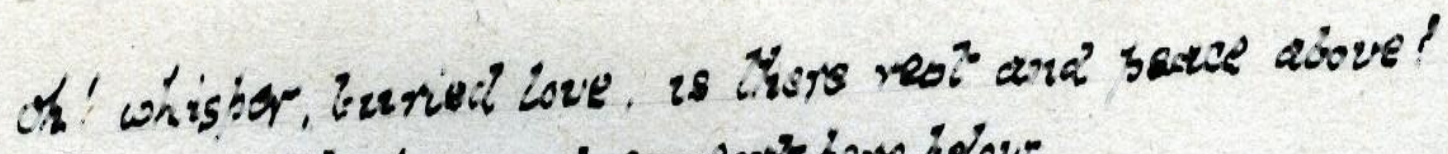
There is izerte tore and comporre hers bolow:

on yout suber incel liss se mortia

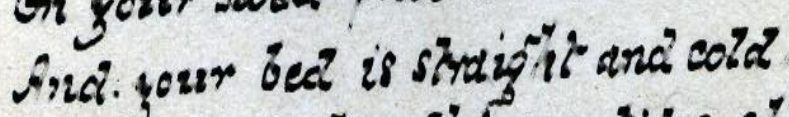

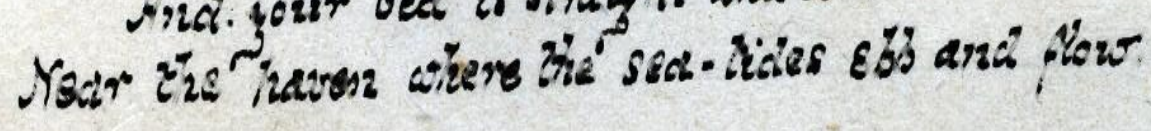

Figure 50: [Verse from 'Whispering' included in Mary Stoddart's album], Mary Stoddart album, $\mathrm{MS}_{2} 2$, Diamond Harbour and Districts Historical Association Inc., Diamond Harbour. 


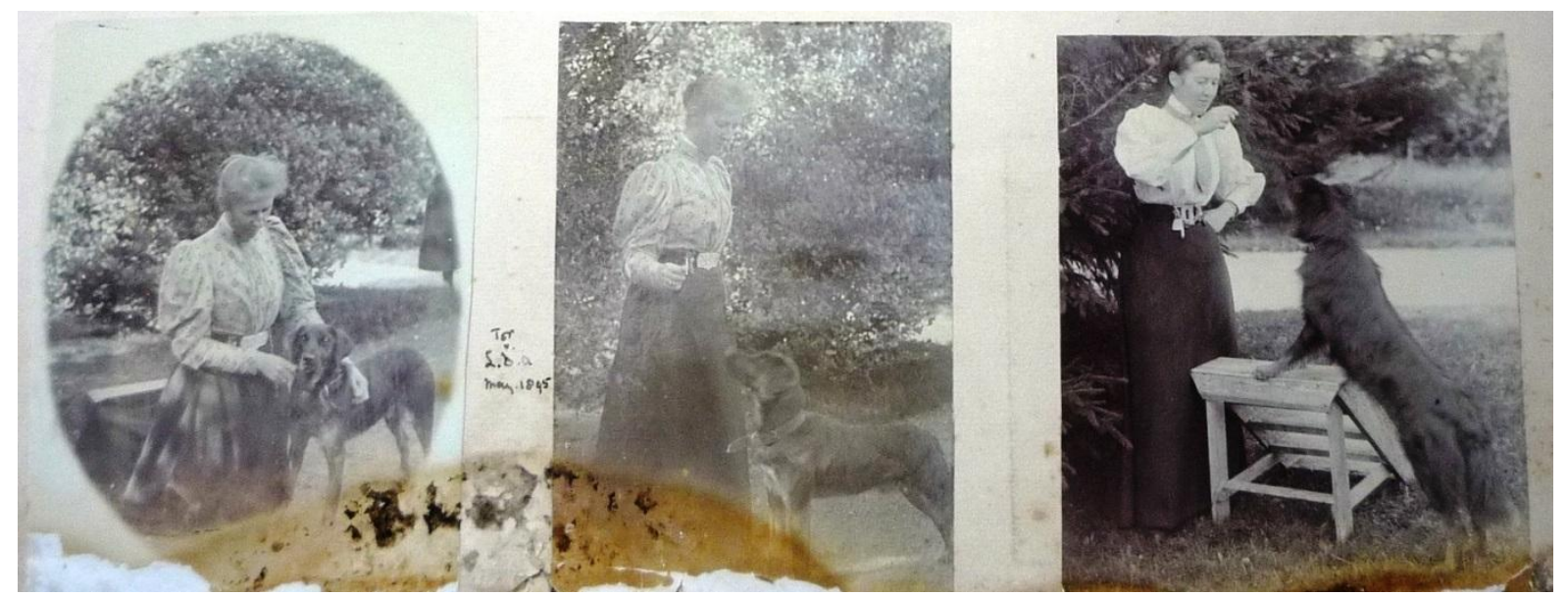

Figure 51: 'Lucy Acland and Tor', Lucy Acland album, LA60, private collection, Christchurch.

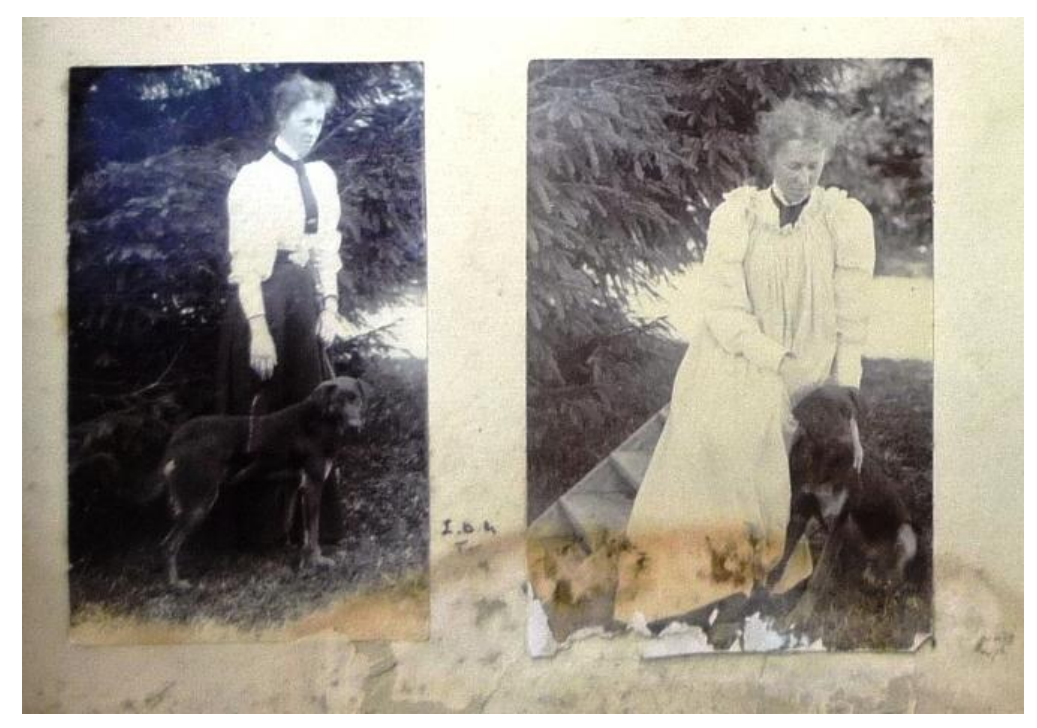

Figure 52: 'Lucy Acland and Tor', Lucy Acland album, LA51, private collection, Christchurch. 


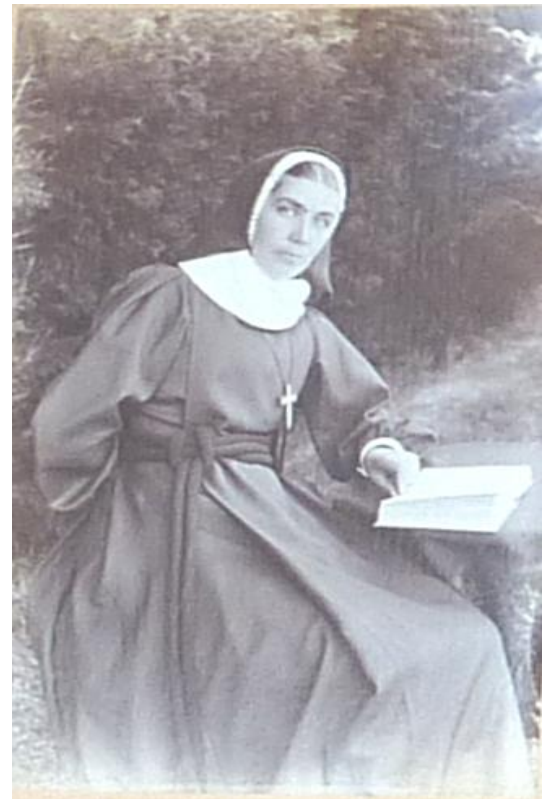

Figure 53: Kate Wood, [Deaconess Kate Spencer Ivens], Kate Wood album 2, $\mathrm{KW}_{2} 10$, private collection, Martinborough

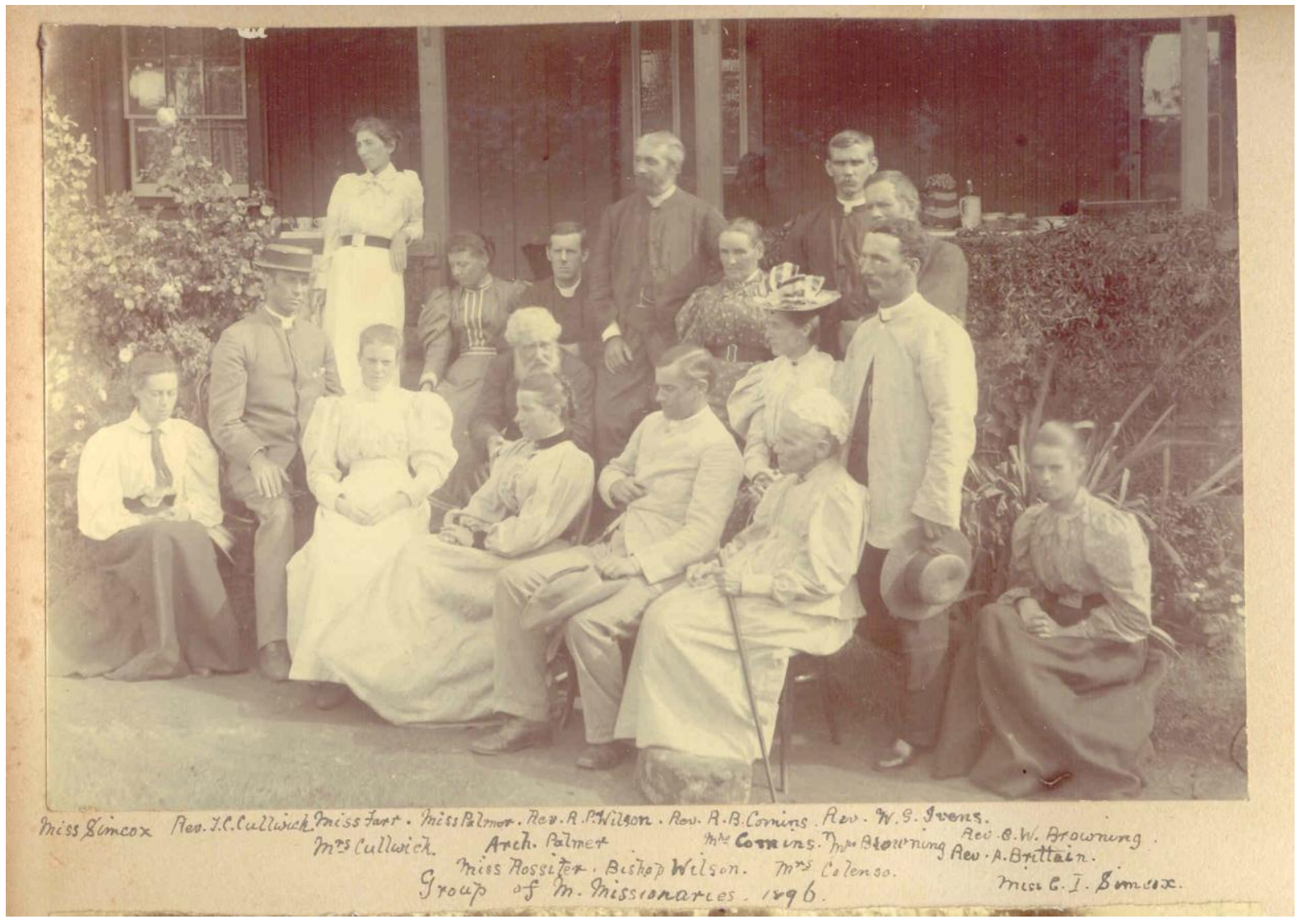

Figure 54: [European Community on Norfolk Island], 1896, Elizabeth Colenso album, EC15, Norfolk Island Museum. 


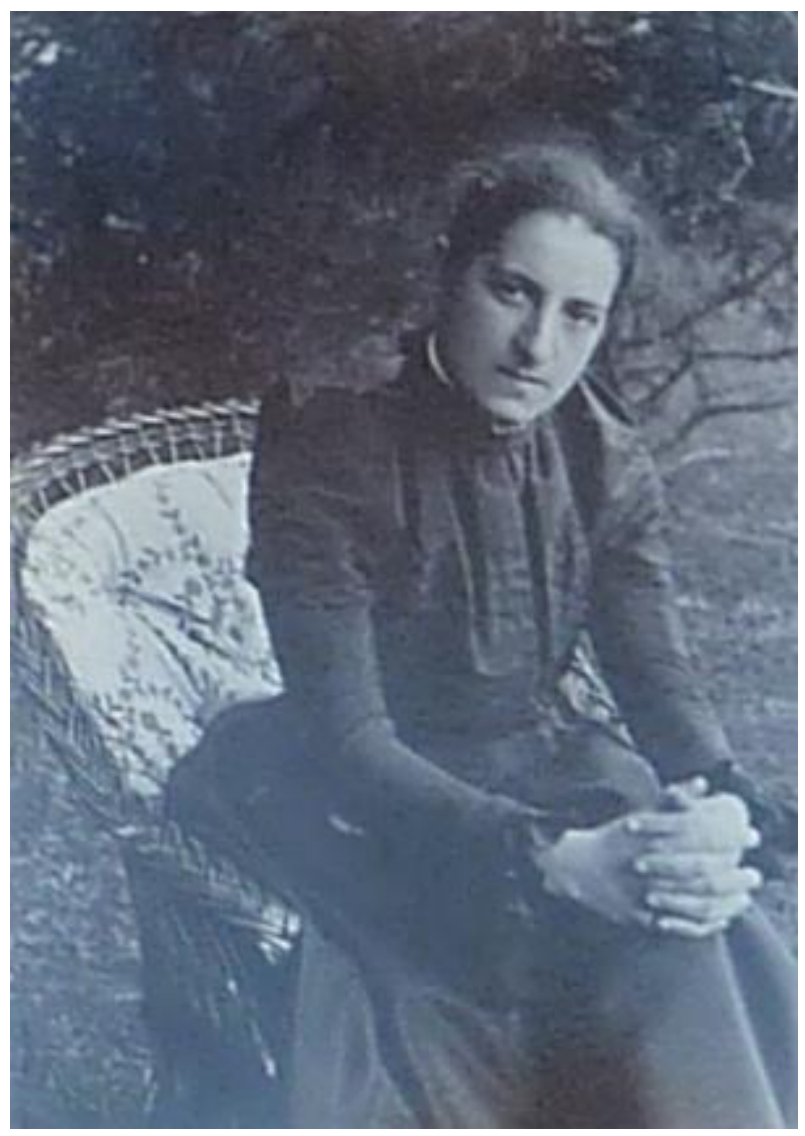

Figure 55: [Kate Wood], Kate Wood Album 2, $\mathrm{KW}_{2}$ 7, private collection, Martinborough. 


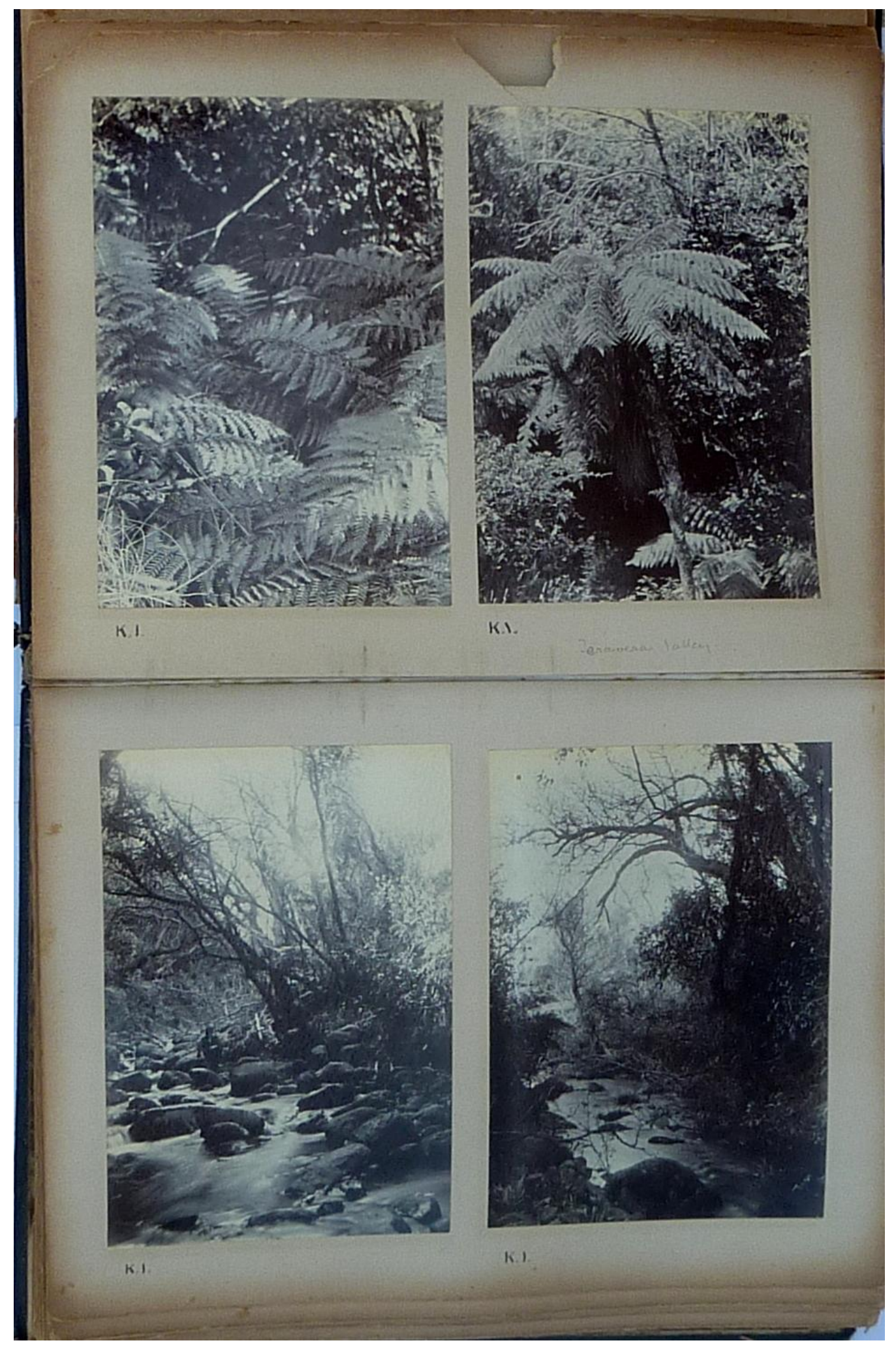

Figure 56: Kate Wood and Kate Ivens, 'Creek Scenes', Kate Wood album 1, $\mathrm{KW}_{1} 13$ \& $\mathrm{KW}_{1} 14$, private collection, Martinborough. 


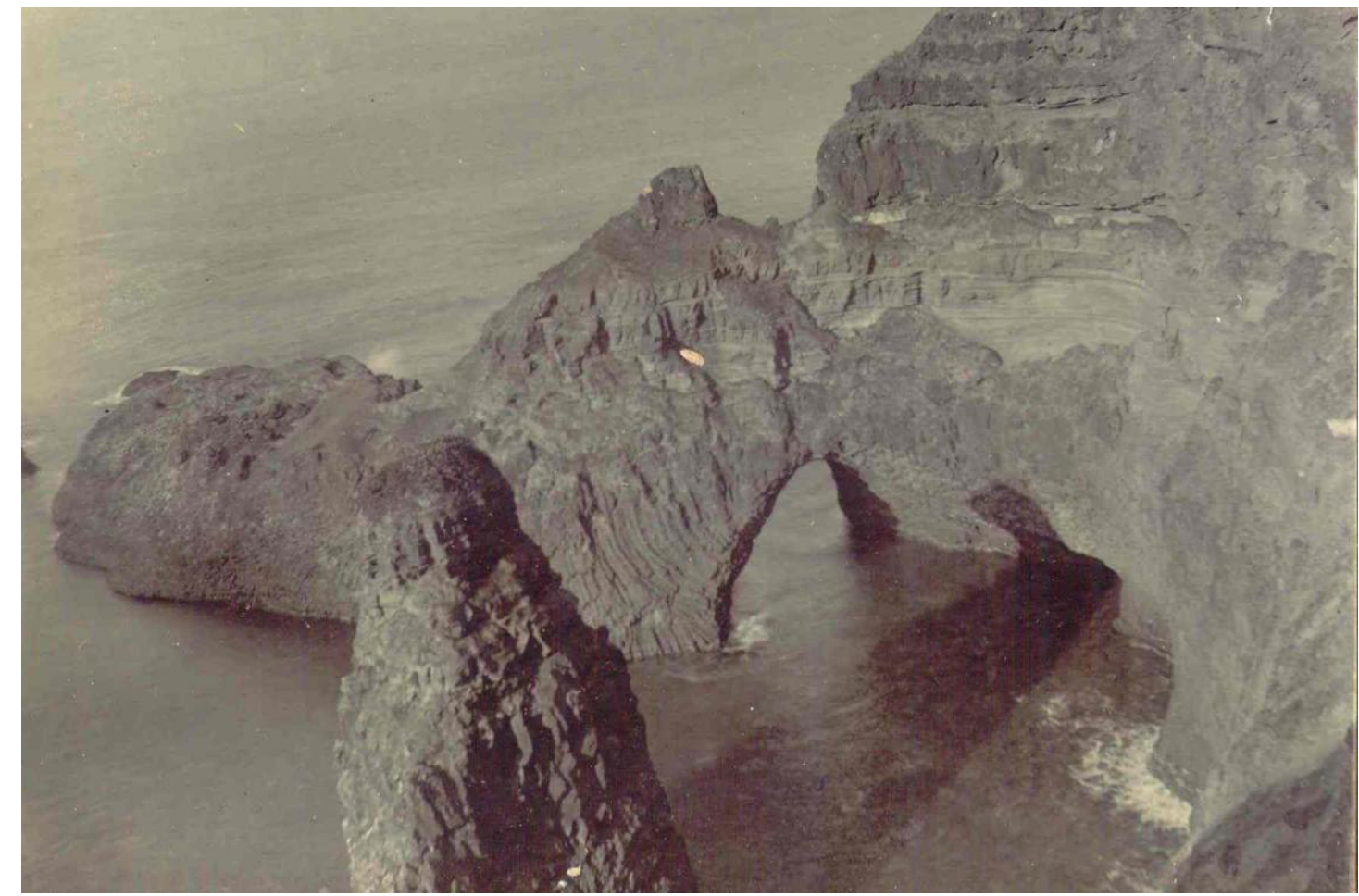

Figure 57: Kate Ivens, 'Red Rocks', Norfolk Island, 1896, Elizabeth Colenso album, EC8, Norfolk Island Museum, Norfolk Island.

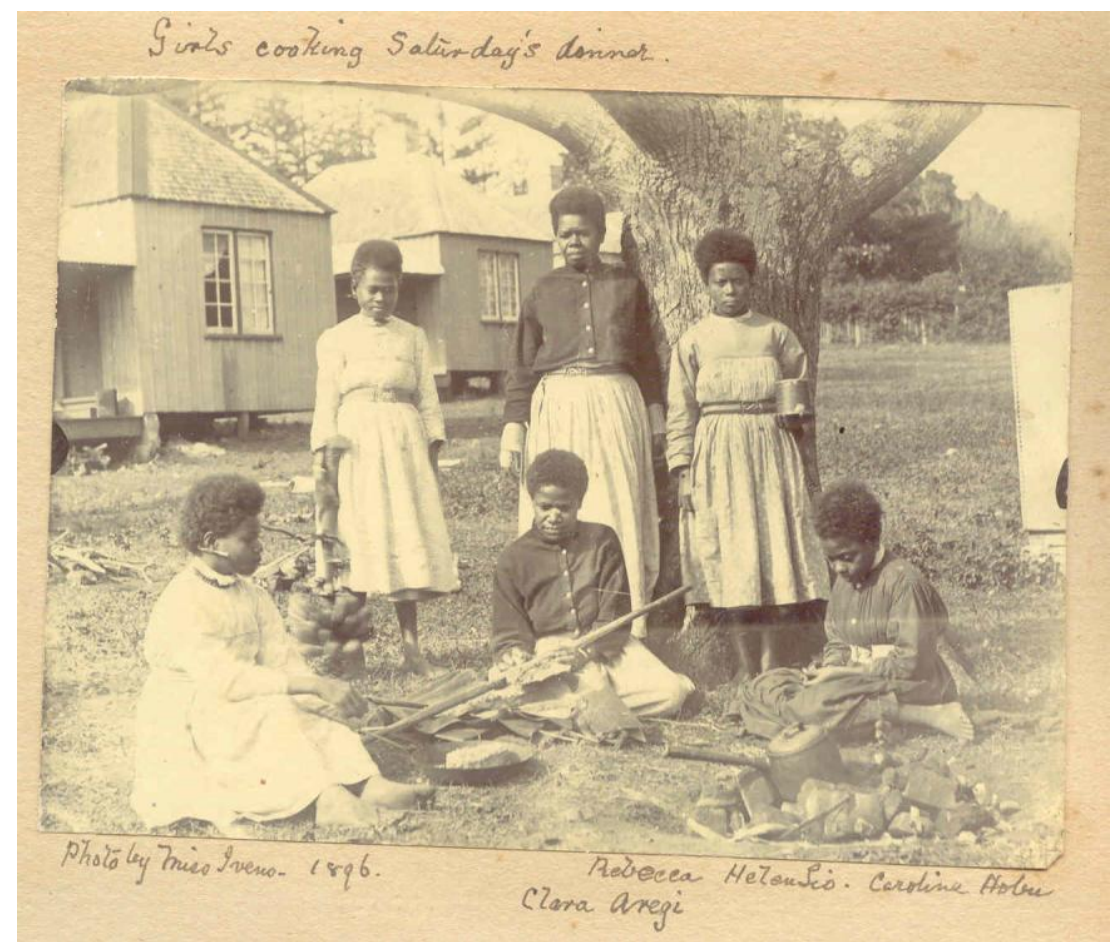

Figure 58: Kate Ivens, 'Girls cooking Saturday's dinner', 1896, Elizabeth Colenso album, EC6, Norfolk Island Museum, Norfolk Island. 


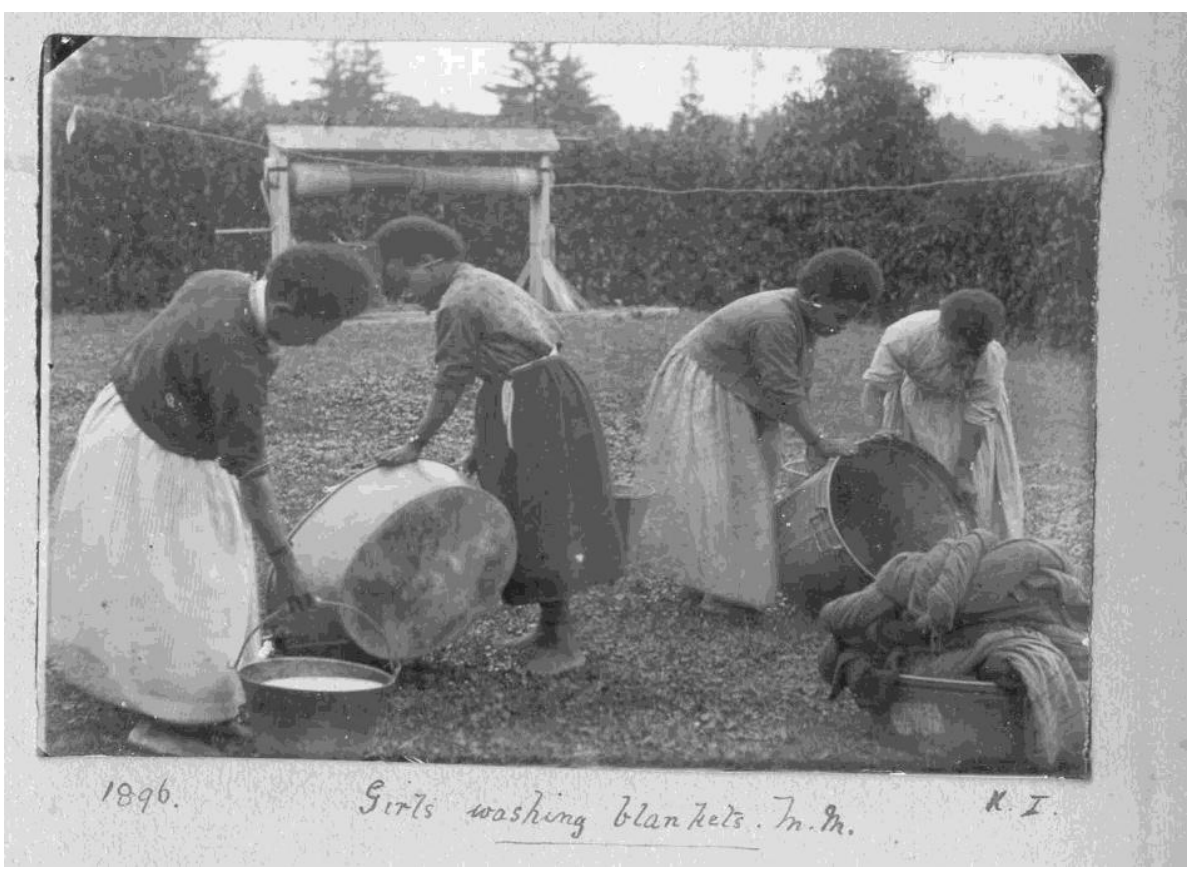

Figure 59: Kate Ivens, 'Girls washing blankets', 1896, Elizabeth Colenso album, EC14, Norfolk Island Museum, Norfolk Island.

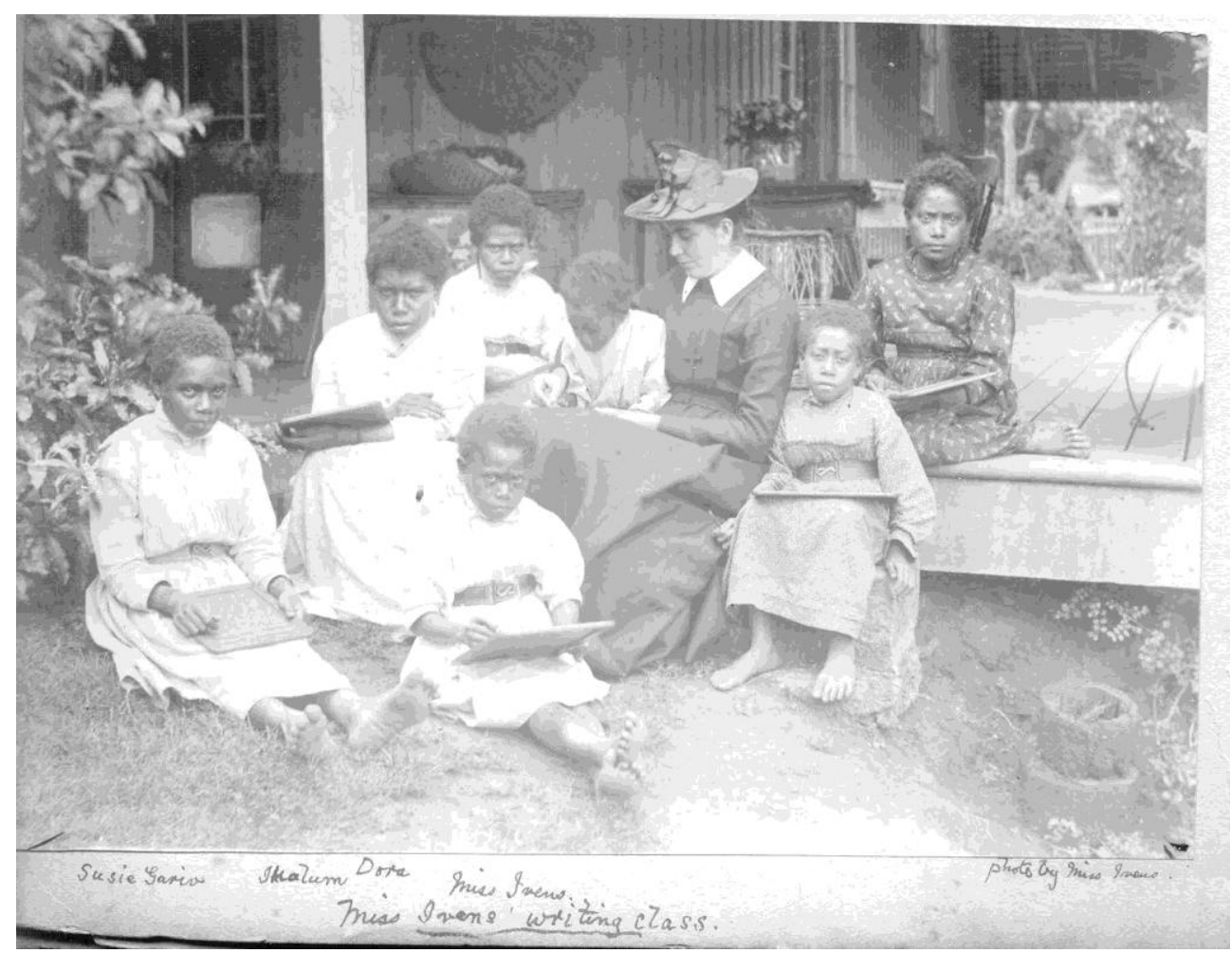

Figure 60: 'Kate Ivens' writing class, Norfolk Island', 1896, Elizabeth Colenso album, EC7, Norfolk Island Museum, Norfolk Island. 


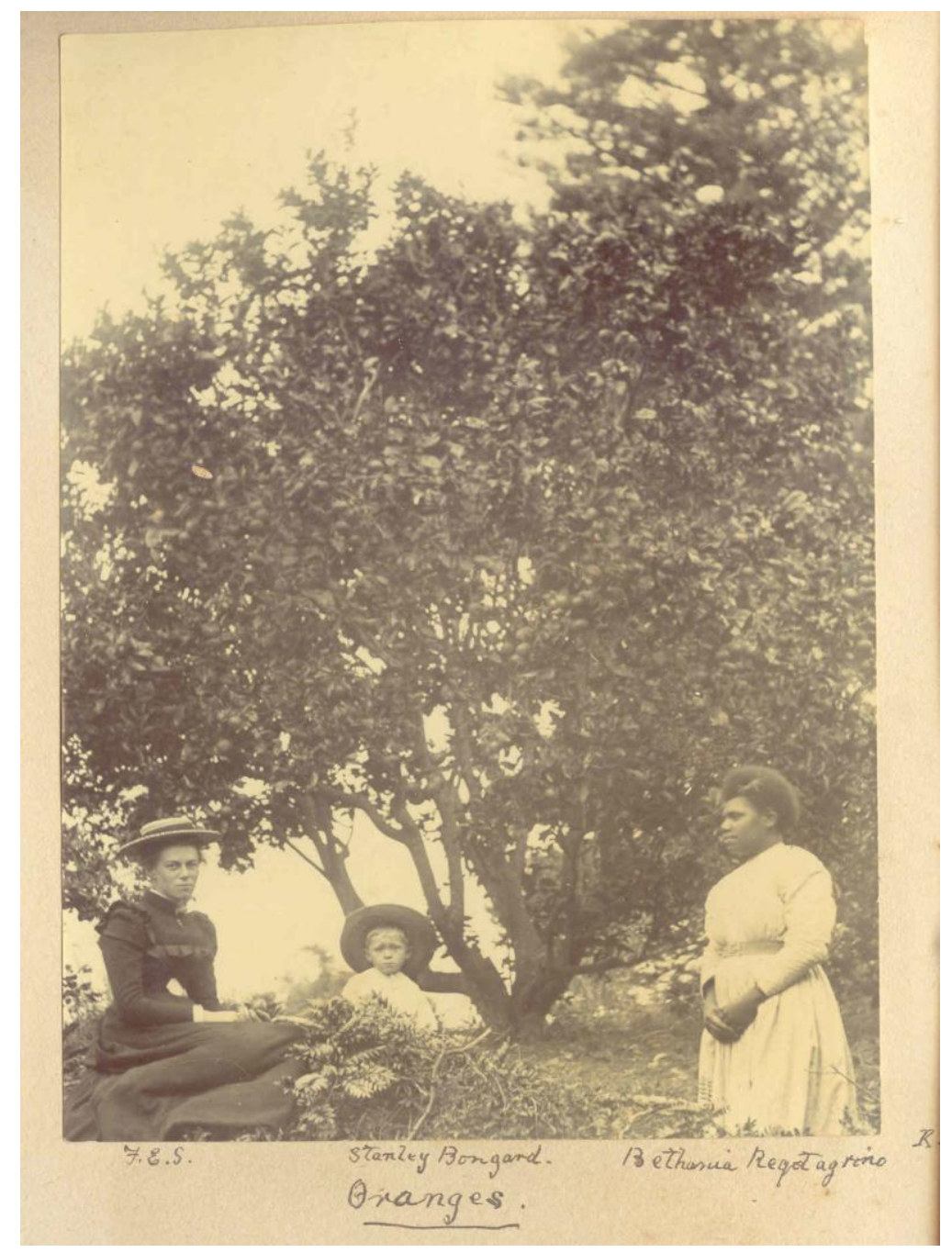

Figure 61: Kate Ivens, 'Oranges', (Frances Simcox, later Swabey, left), Norfolk Island, 1896, Elizabeth Colenso album, EC9, Norfolk Island Museum, Norfolk Island.

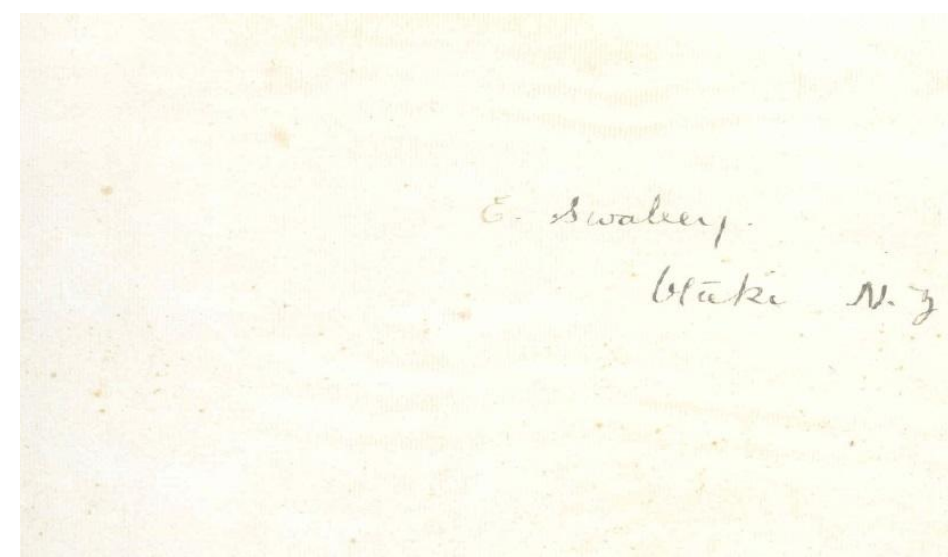

Figure 62: Inscription written by Frances Simcox, later Swabey, inside cover of Elizabeth Colenso's album, EC1, Norfolk Island Museum, Norfolk Island. 


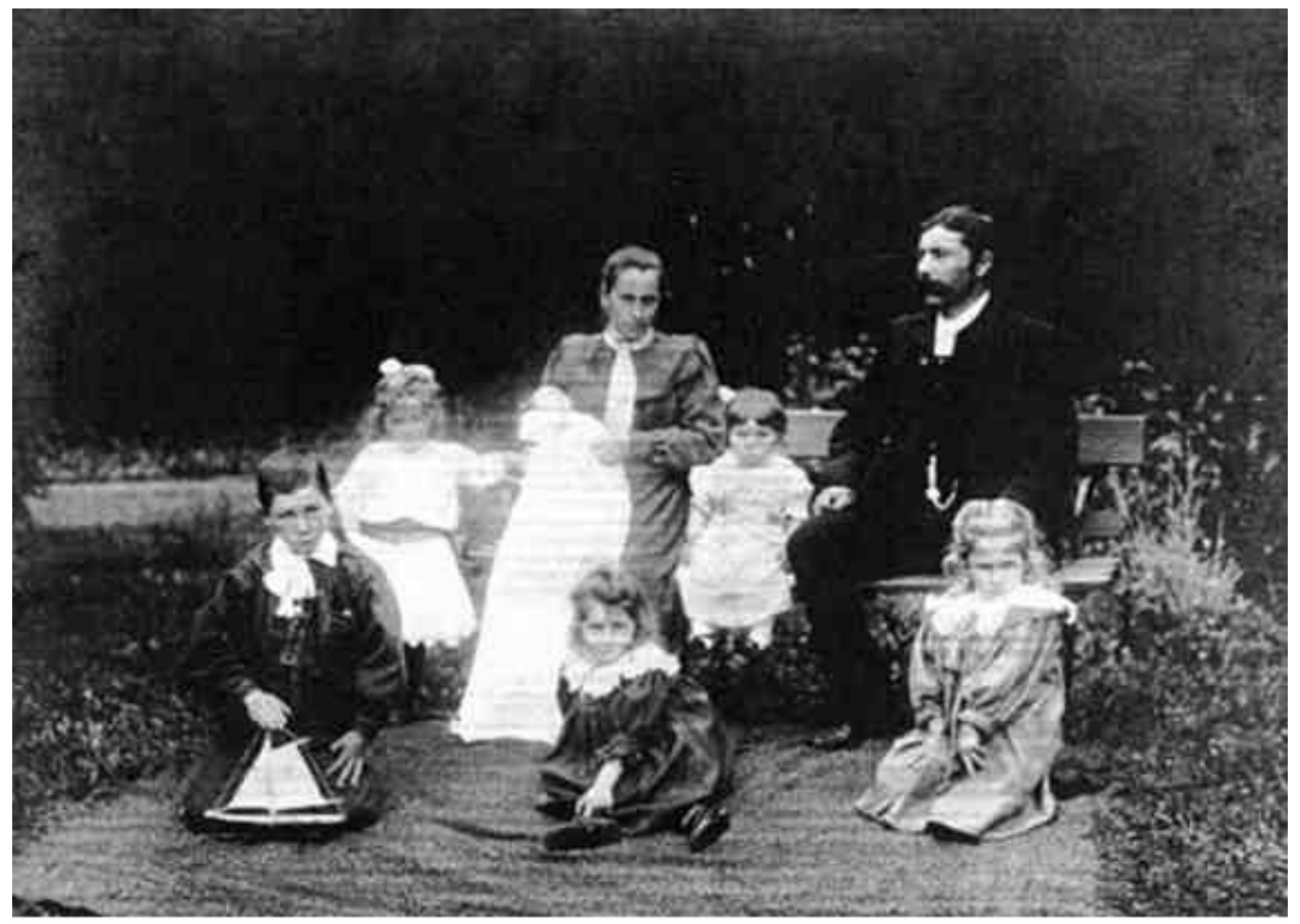

Figure 63: Florence Wright, [The Dell family, Windermere, mid-Canterbury], Dell album, FW1, private collection, Christchurch.

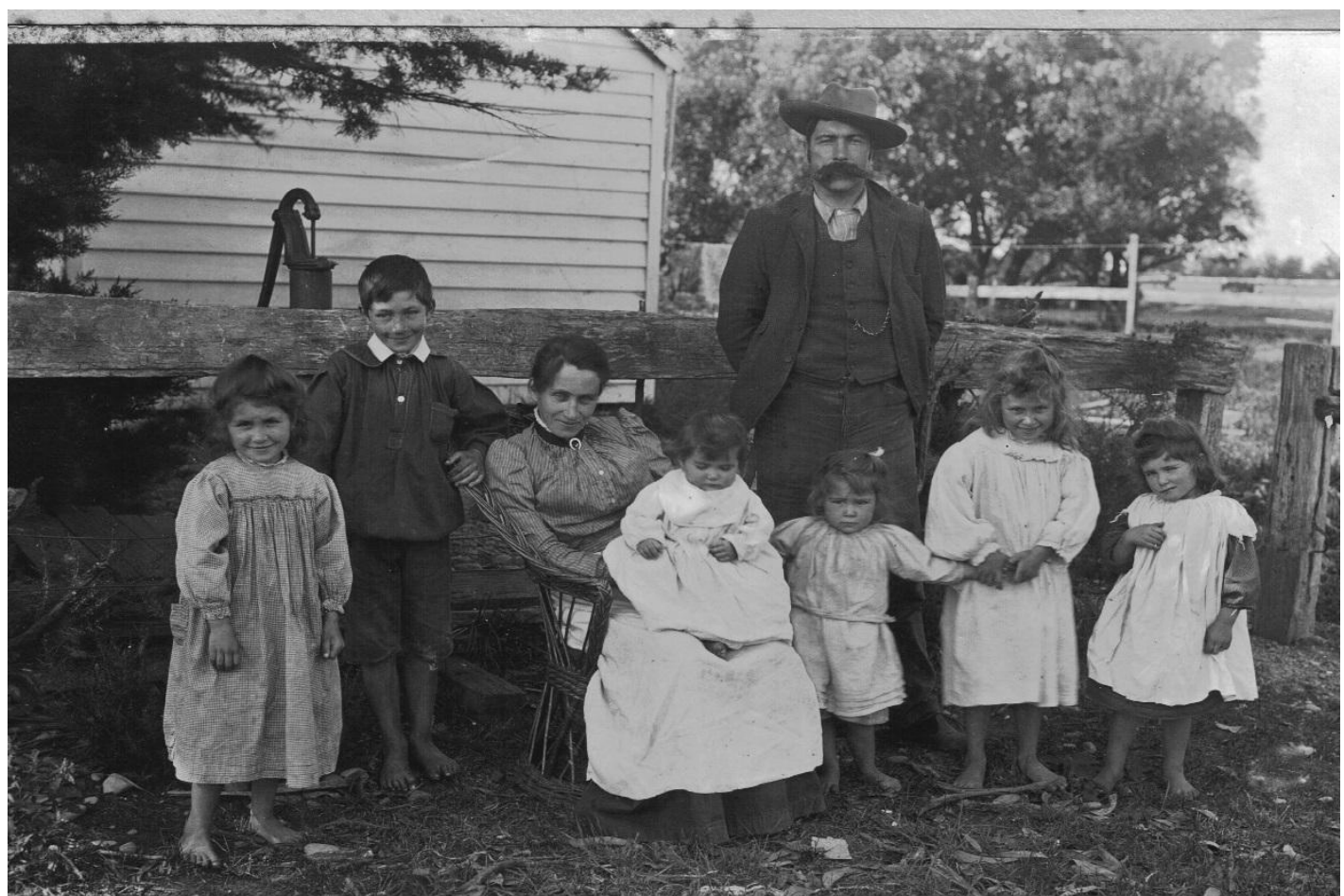

Figure 64: Florence Wright, [The Dell family, Windermere, mid-Canterbury], Dell album, FW2, private collection, Christchurch. 


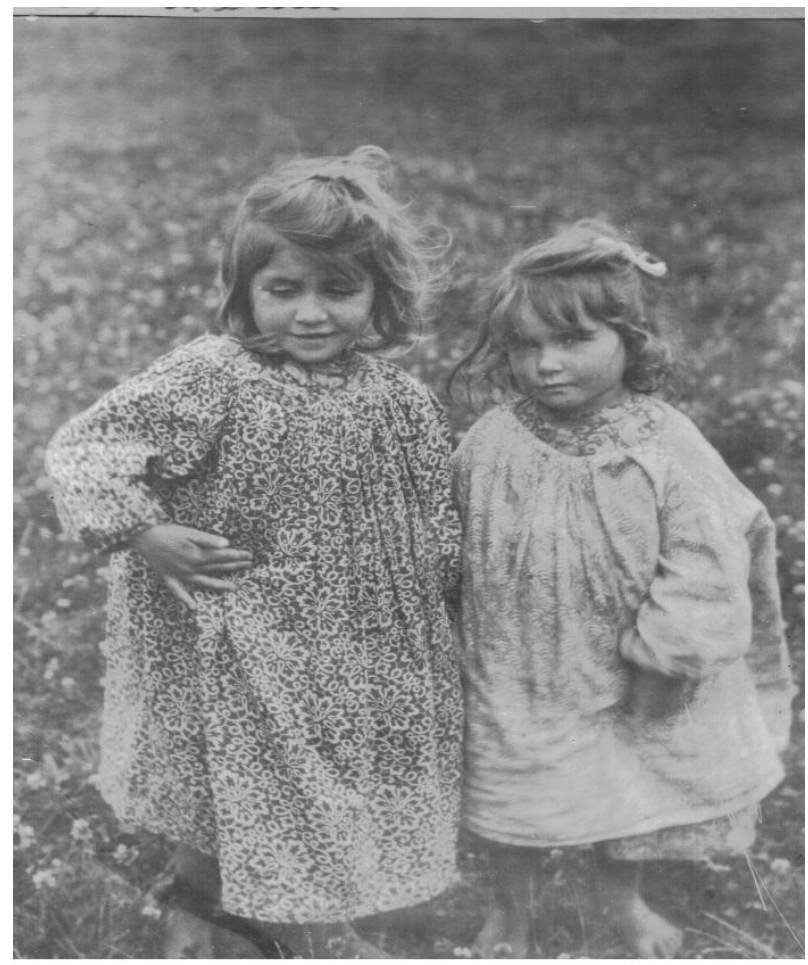

Figure 65: Florence Wright, [The Dell family, Windermere, mid-Canterbury], Dell album, FW29, private collection, Christchurch.

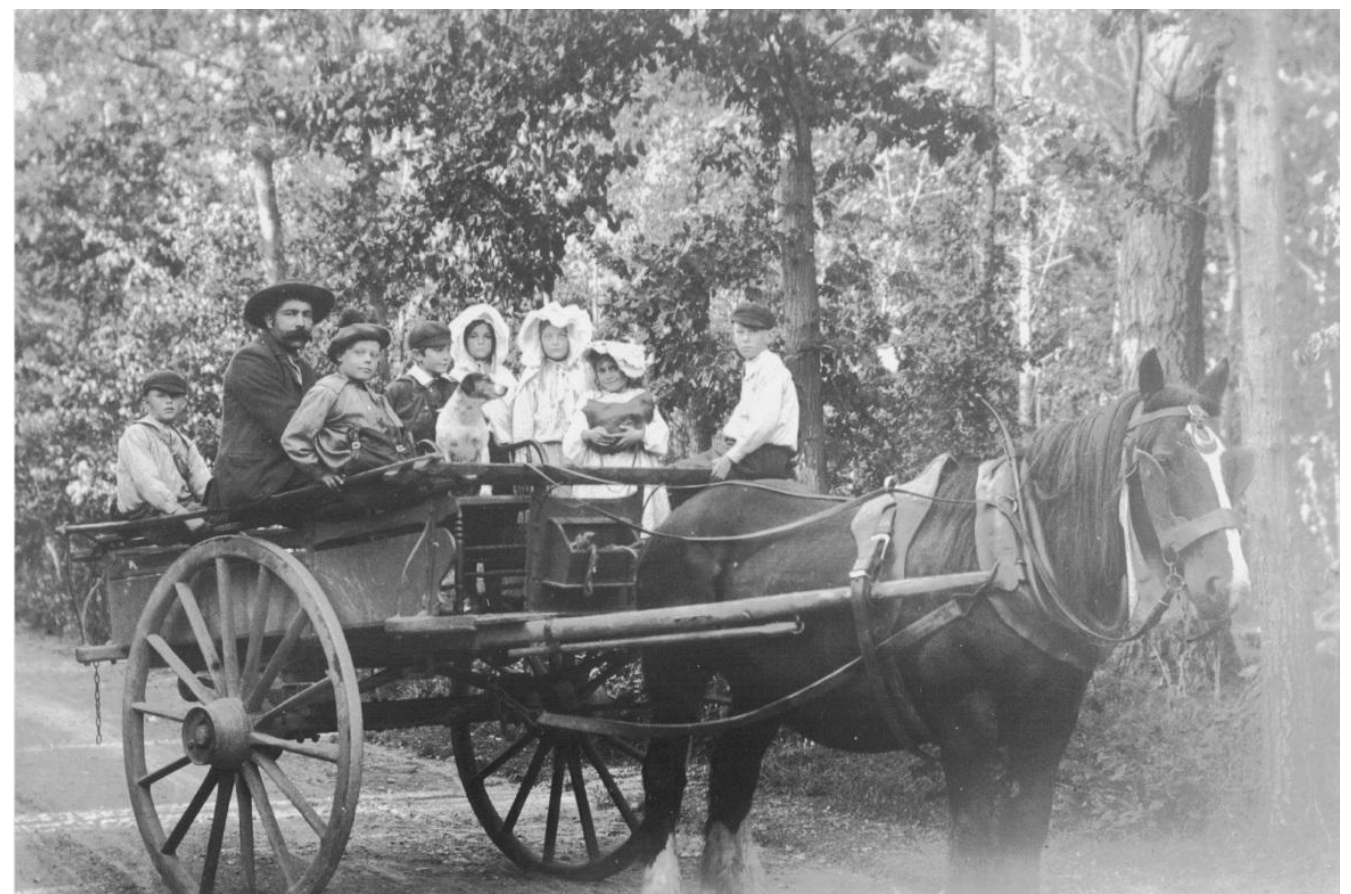

Figure 66: Florence Wright, [The Dell family, Windermere, mid-Canterbury], Dell album, FW27, private collection, Christchurch. 


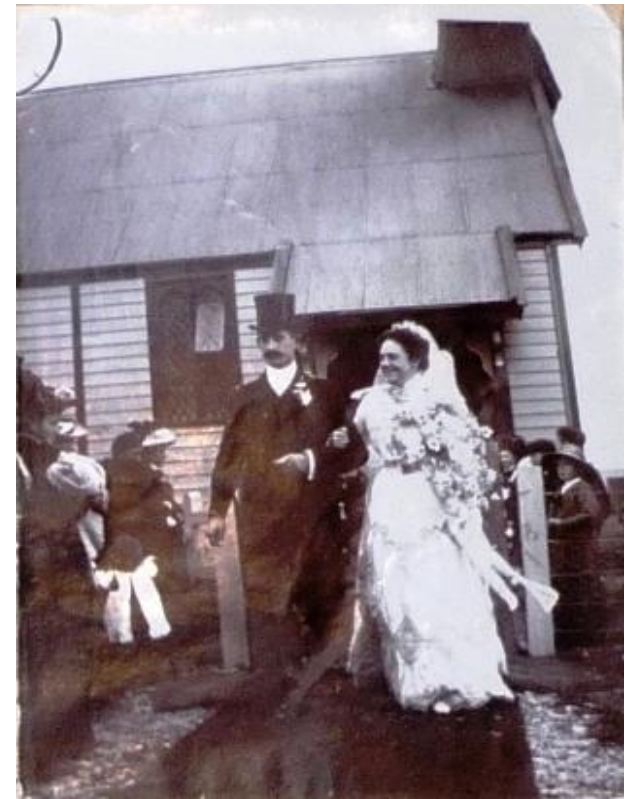

Figure 67: [Wedding of Florence Wright to William Morgan], 1904, FW30, Dell album, private collection, Christchurch.

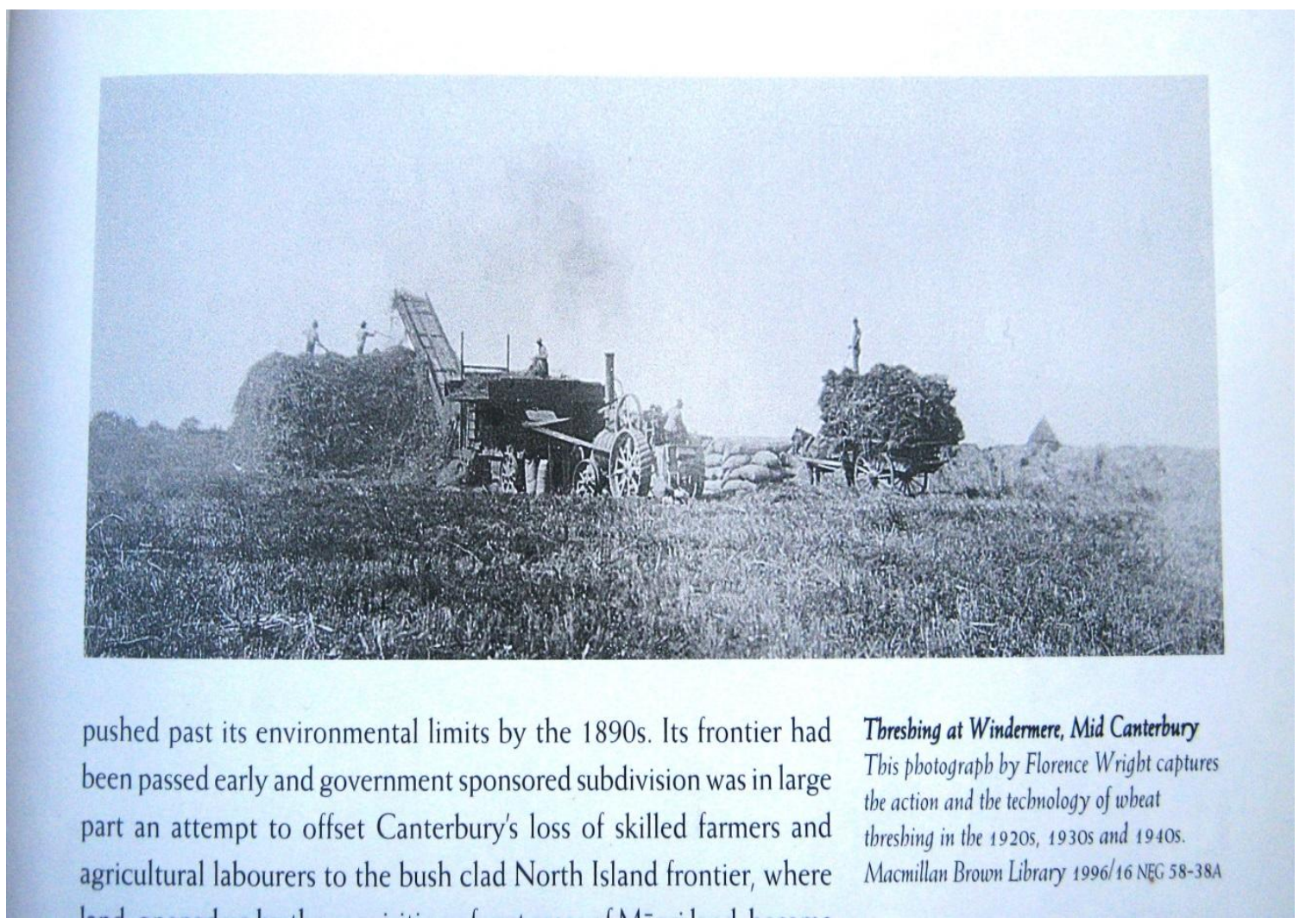

Figure 68: Florence Wright, 'Threshing at Windermere, Mid-Canterbury', from the Dell album, FW23, private collection, Christchurch, in Garth Cant, Rural Canterbury..., p. 99. 


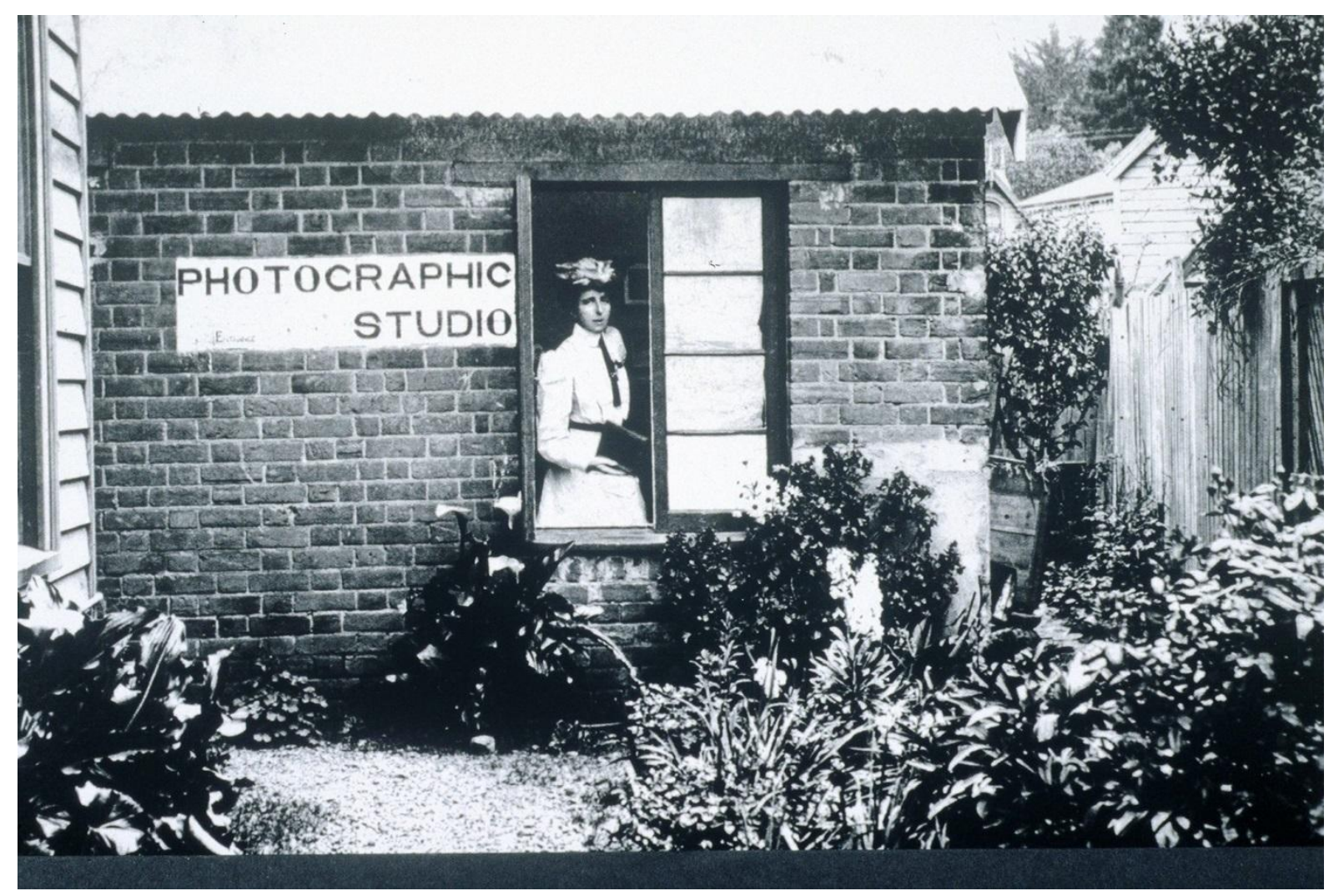

Figure 69: [Jessie Buckland at the window of her photographic studio], c.1907, private collection, Christchurch.

\section{$A^{\text {Rtistic }}$ Photography.}

MISS J. L. BUCKLAND.

WI I88 BUCKLAND has opened her if Mr Munro's, and is now prepared to take itters

\section{HoUn 8: 10 an.m to $4 \mathrm{pm}$.}

Figure 70: Announcement published in the Akaroa Mail between March-May 1907. 


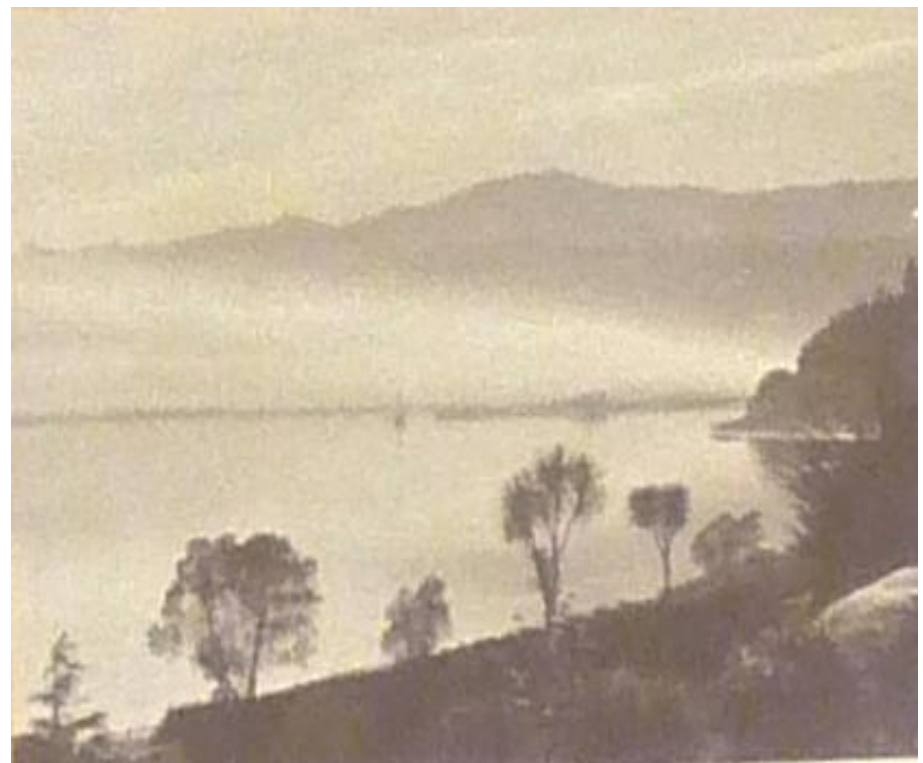

Figure 71: Jessie Buckland, 'Sunrise', [View from the Glen towards Akaroa] Jessie Buckland album, JB27, Hocken Library, University of Otago, Dunedin.

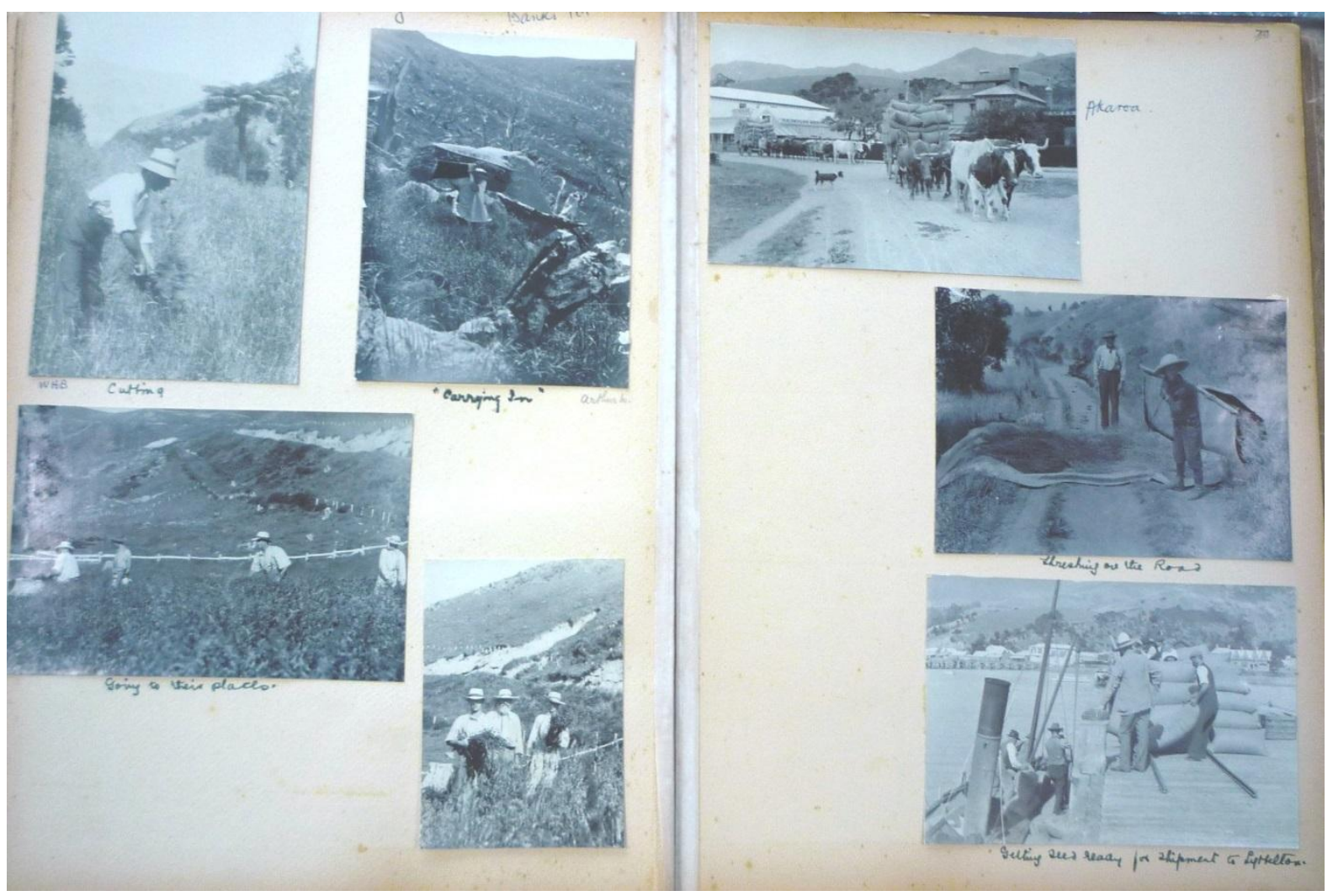

Figure 72: Jessie Buckland, [Series of photographs of harvesting cocksfoot], Jessie Buckland album, JB69 \& JB70, Hocken Library, University of Otago, Dunedin. 


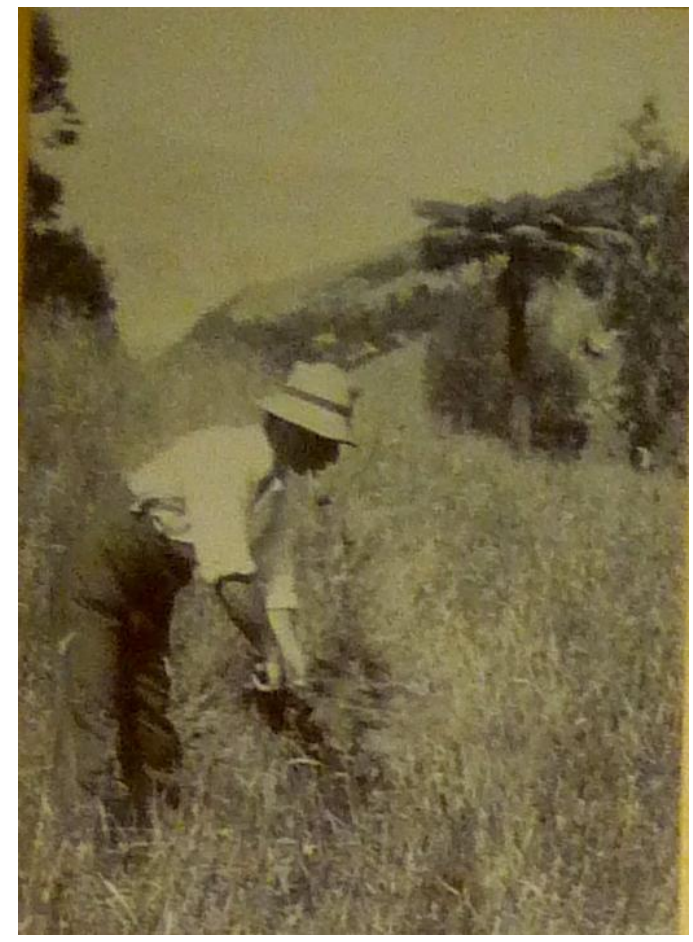

Figure 73: Jessie Buckland, 'Cropping', [Harold Buckland cutting cocksfoot], Jessie Buckland album, JB69, Hocken Library, University of Otago, Dunedin.

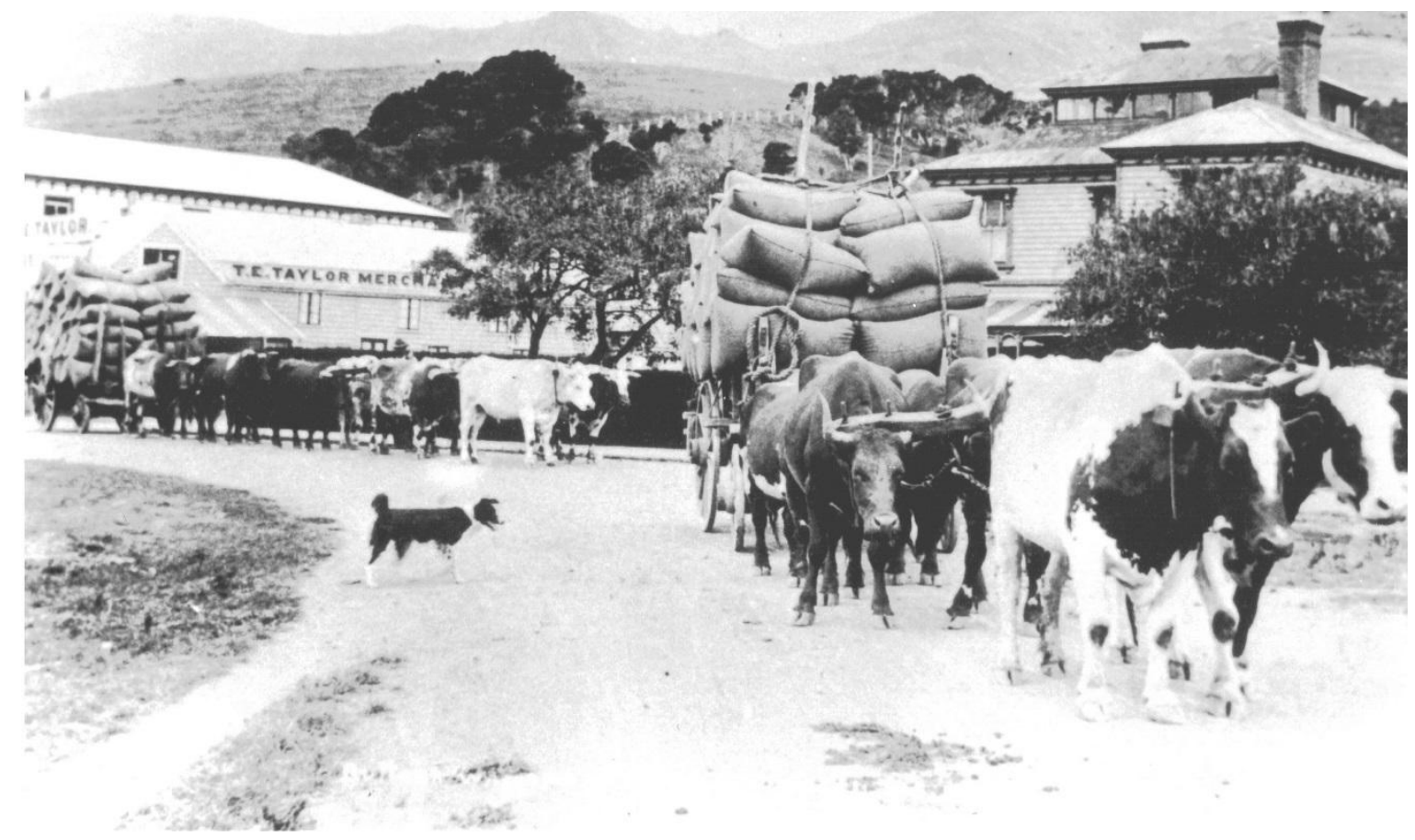

Figure 74: Jessie Buckland, [Bullock wagons wending their way to the wharf at Akaroa], Jessie Buckland album, JB70, Hocken Library, University of Otago, Dunedin. 


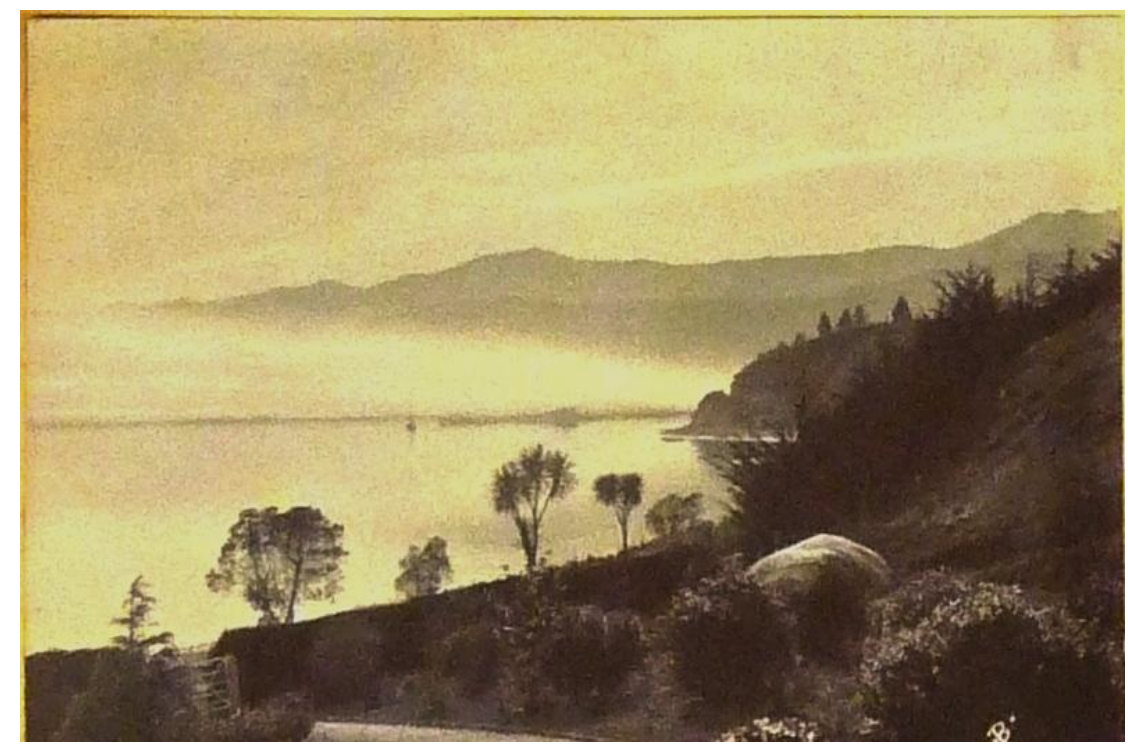

Figure 75: Jessie Buckland, 'Sunrise', [View from The Glen towards Akaroa], Jessie Buckland album, JB55, Hocken Library, University of Otago, Dunedin.

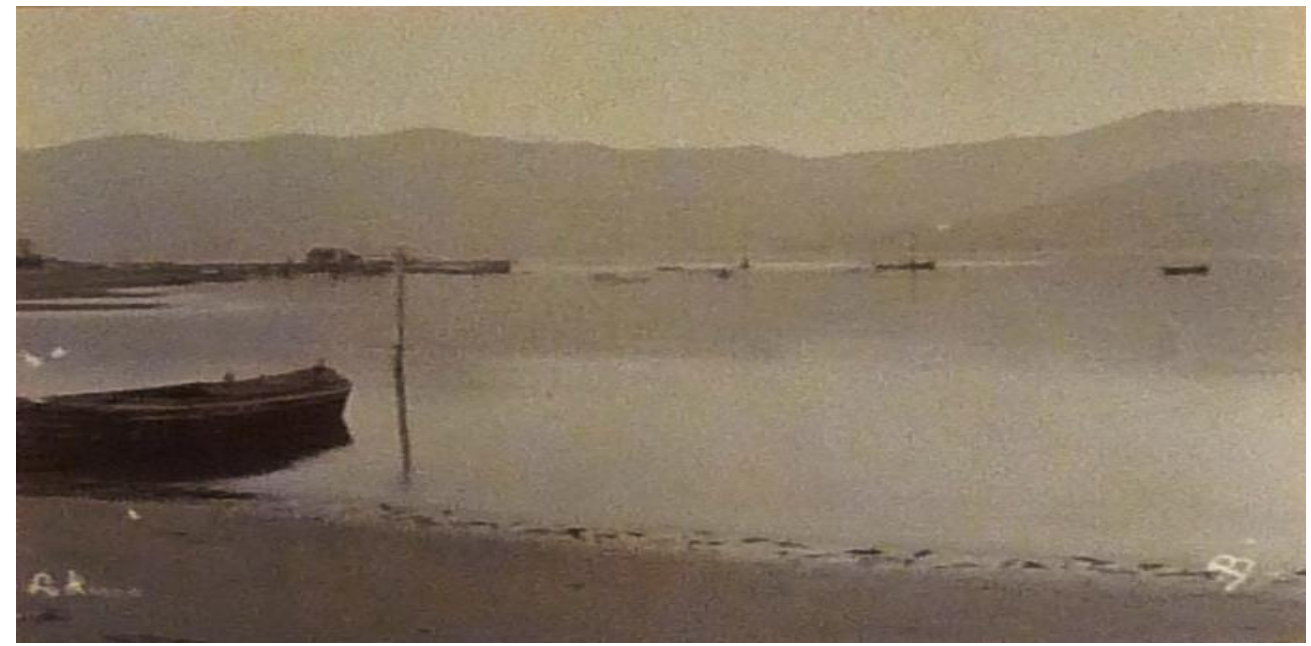

Figure 76: Jessie Buckland, 'Akaroa', Jessie Buckland album, JB55, Hocken Library,University of Otago, Dunedin. 


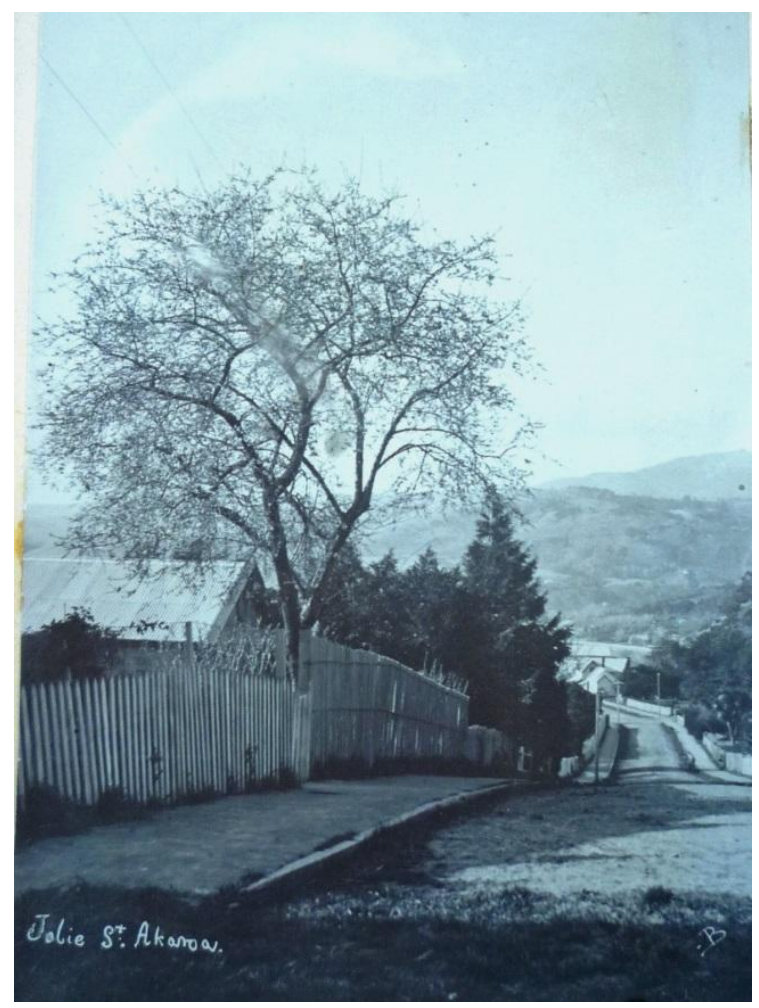

Figure 77: Jessie Buckland, 'Jolie St, Akaroa', Jessie Buckland album, JB64, Hocken Library, University of Otago, Dunedin.

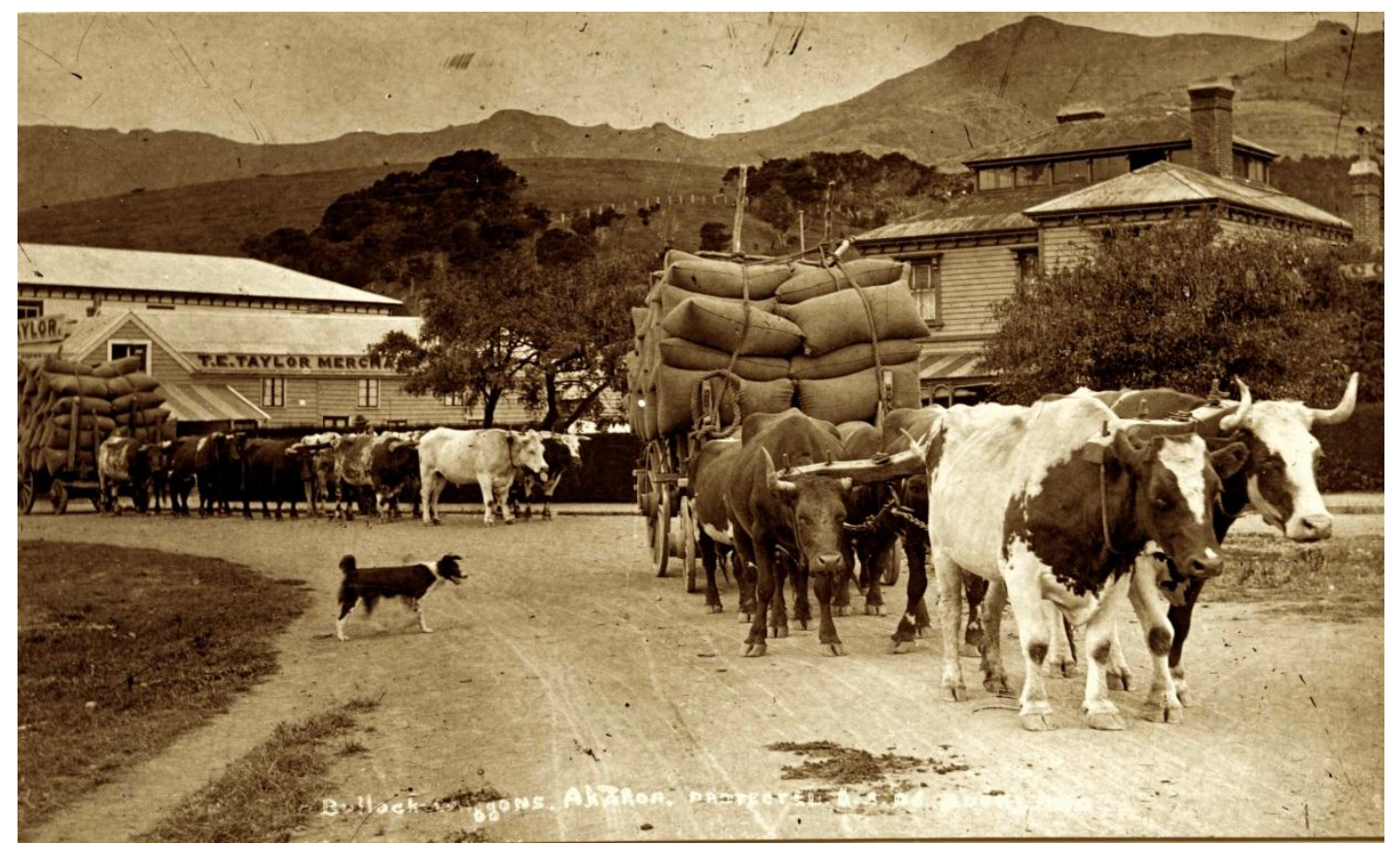

Figure 78: Jessie Buckland, 'Bullock Wagons’ Adolf Mortizson papers, (Arc-0023) Ms1143/01, Hocken Library, University of Otago, Dunedin. 


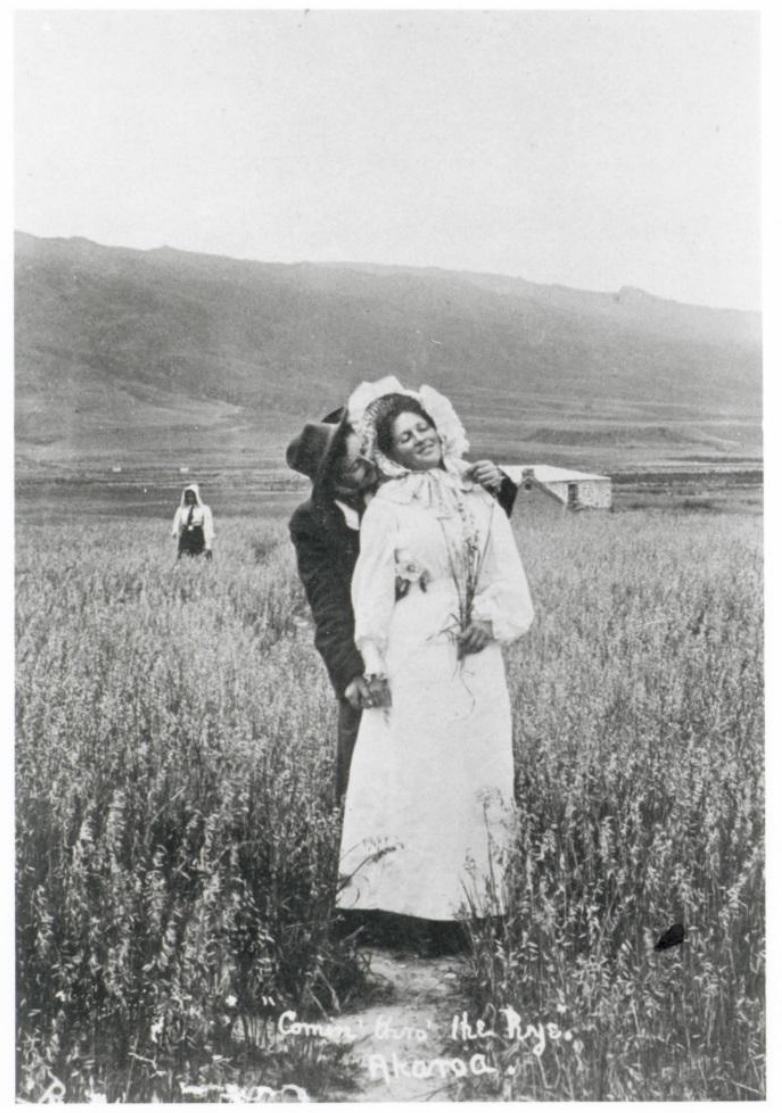

Figure 79: Jessie Buckland, 'Coming Thro' the Rye, Akaroa', Adolf Mortizson papers, (Arc-0023) Ms-1143/01, Hocken Library, University of Otago, Dunedin.

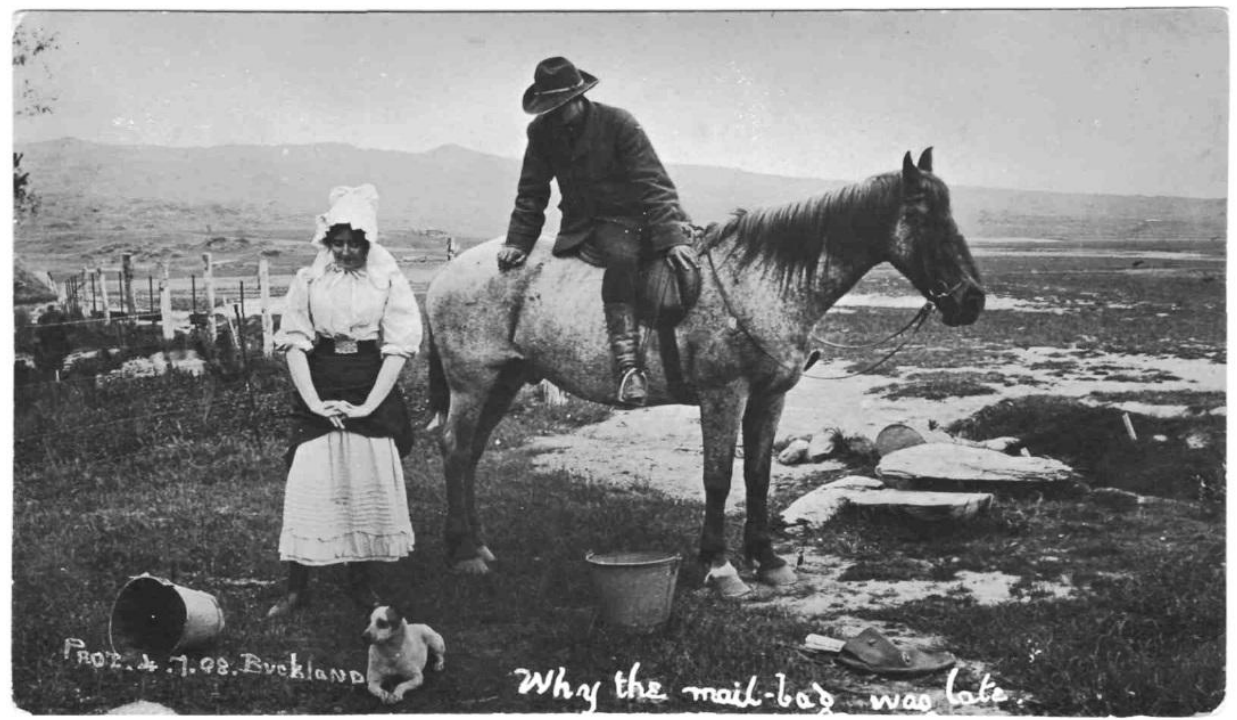

Figure 80: Jessie Buckland, 'Why the Mailbag was late?' Adolf Mortizson papers (Arc0023), Ms-1143/01, Hocken Library, University of Otago, Dunedin. 


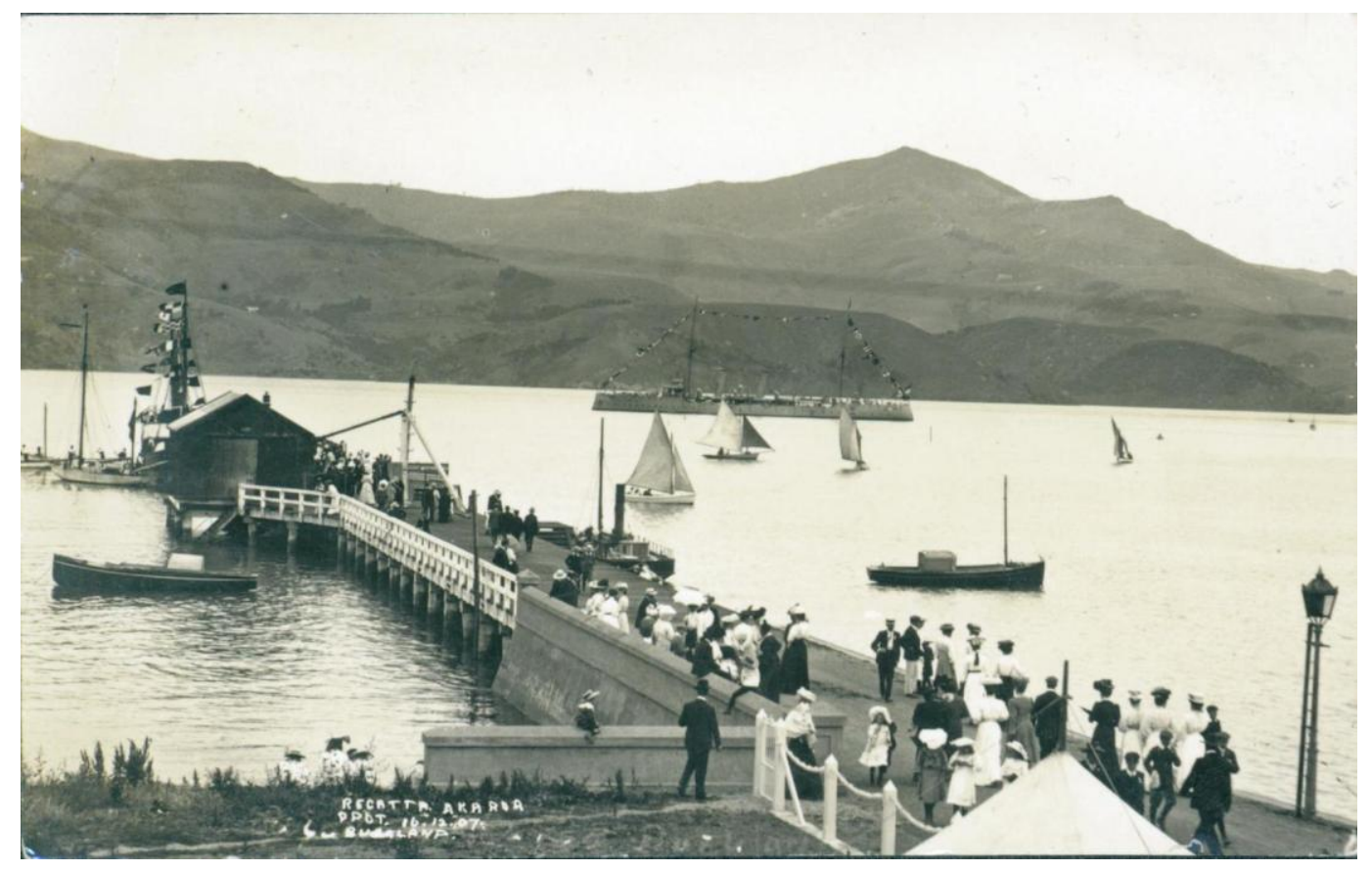

Figure 81: Jessie Buckland, 'Regatta Akaroa', postcard (391A), Akaroa Museum, Akaroa.

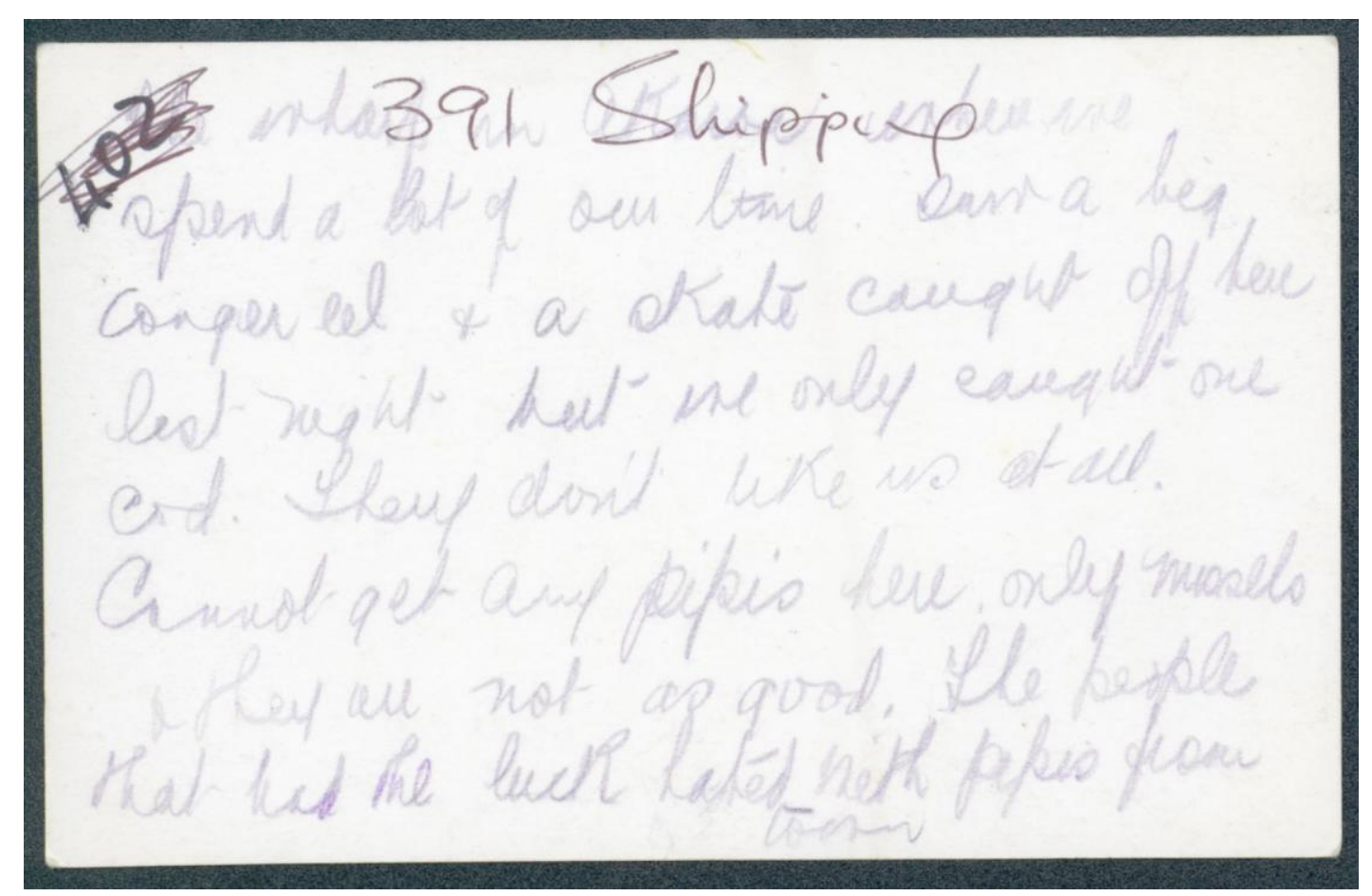

Figure 82: 'Regatta Akaroa', (Reverse of Figure 81), (391B), Akaroa Museum, Akaroa. 


\section{Appendix III}

Graphs I-VI: Timeline of selected photograph albums

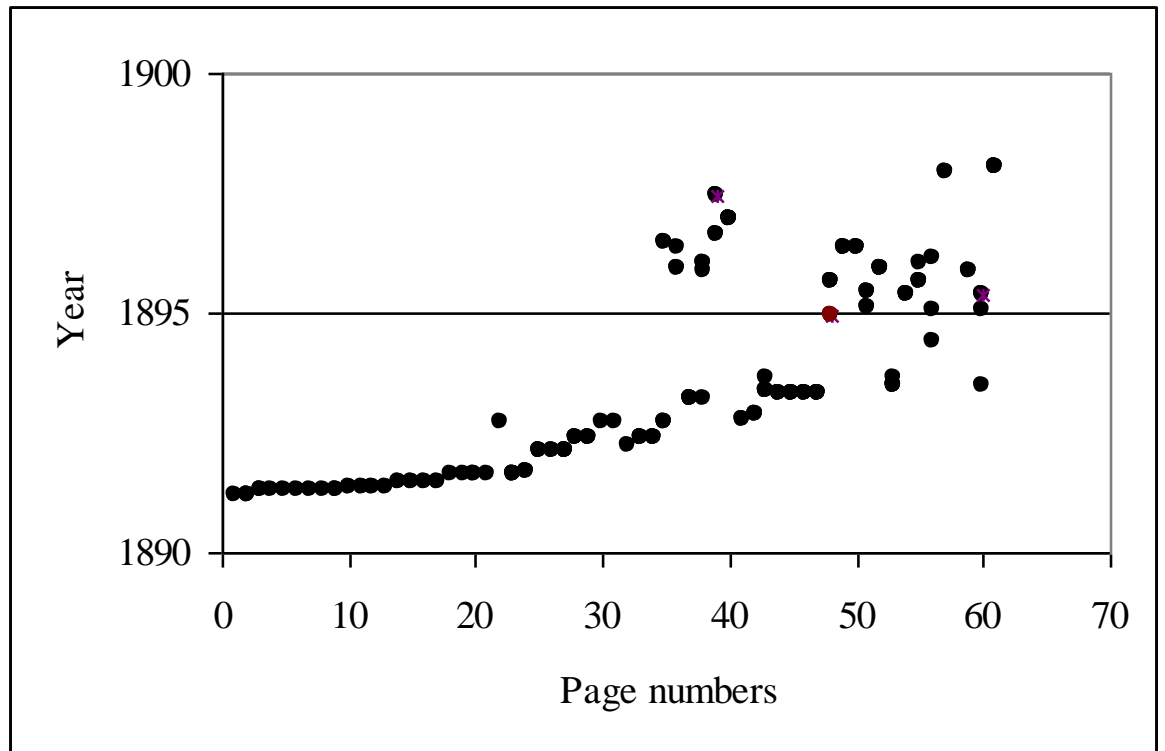

Graph I: Timeline for the photograph album of Lucy Acland.

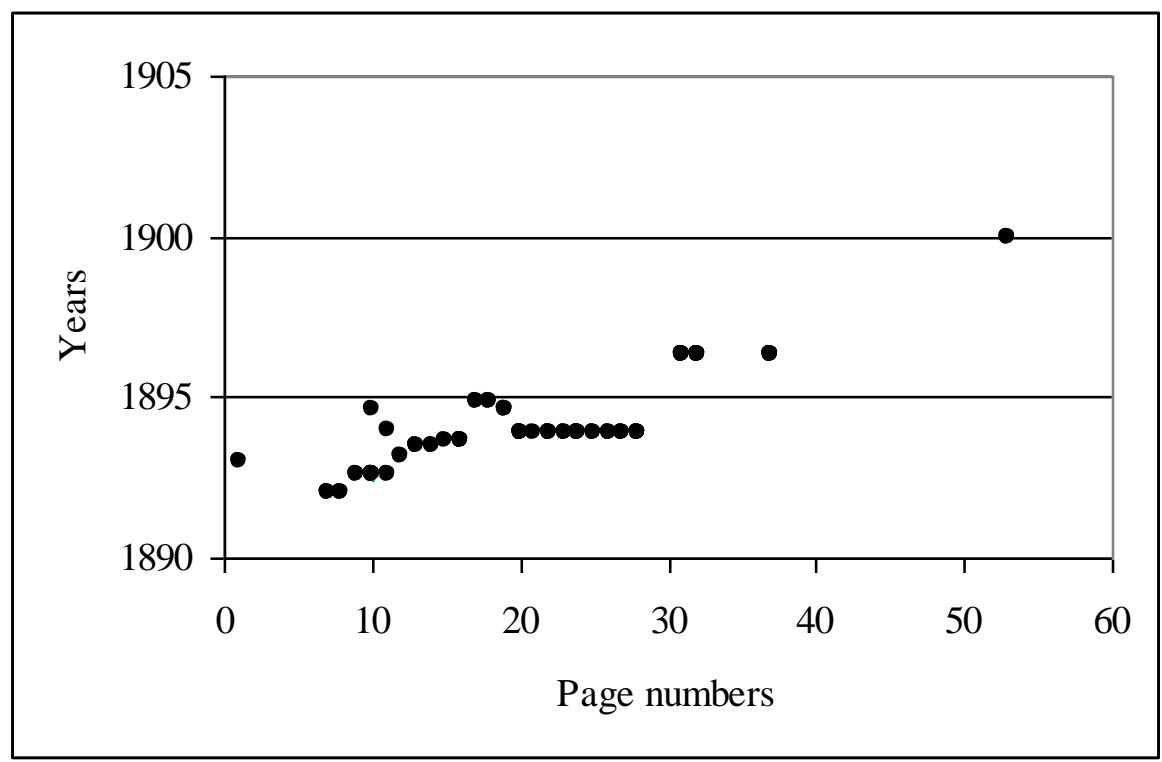

Graph II: Timeline for the photograph album of Margaret Stoddart. 


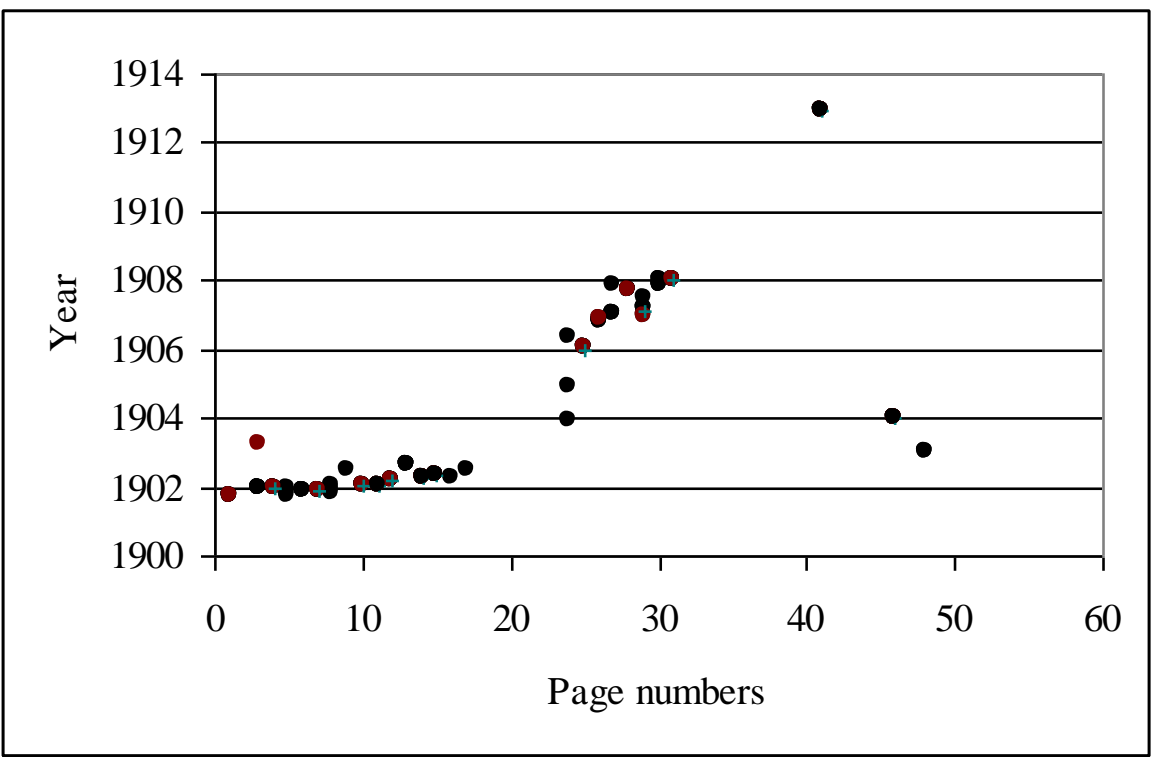

Graph III: Timeline for the photograph album of Margaret and Laura Bowen.

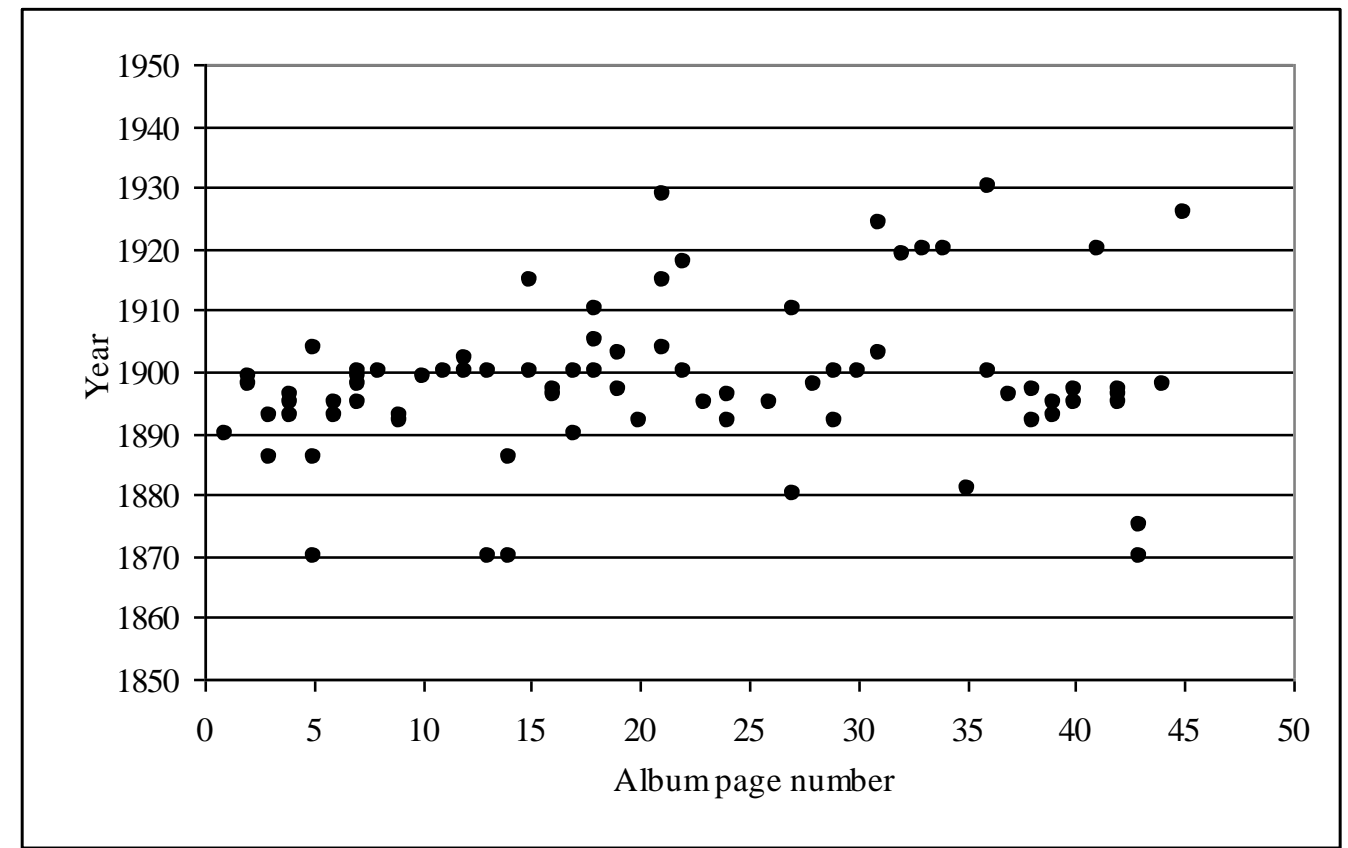

Graph IV: Timeline for the photograph album of Carrie Buckland. 


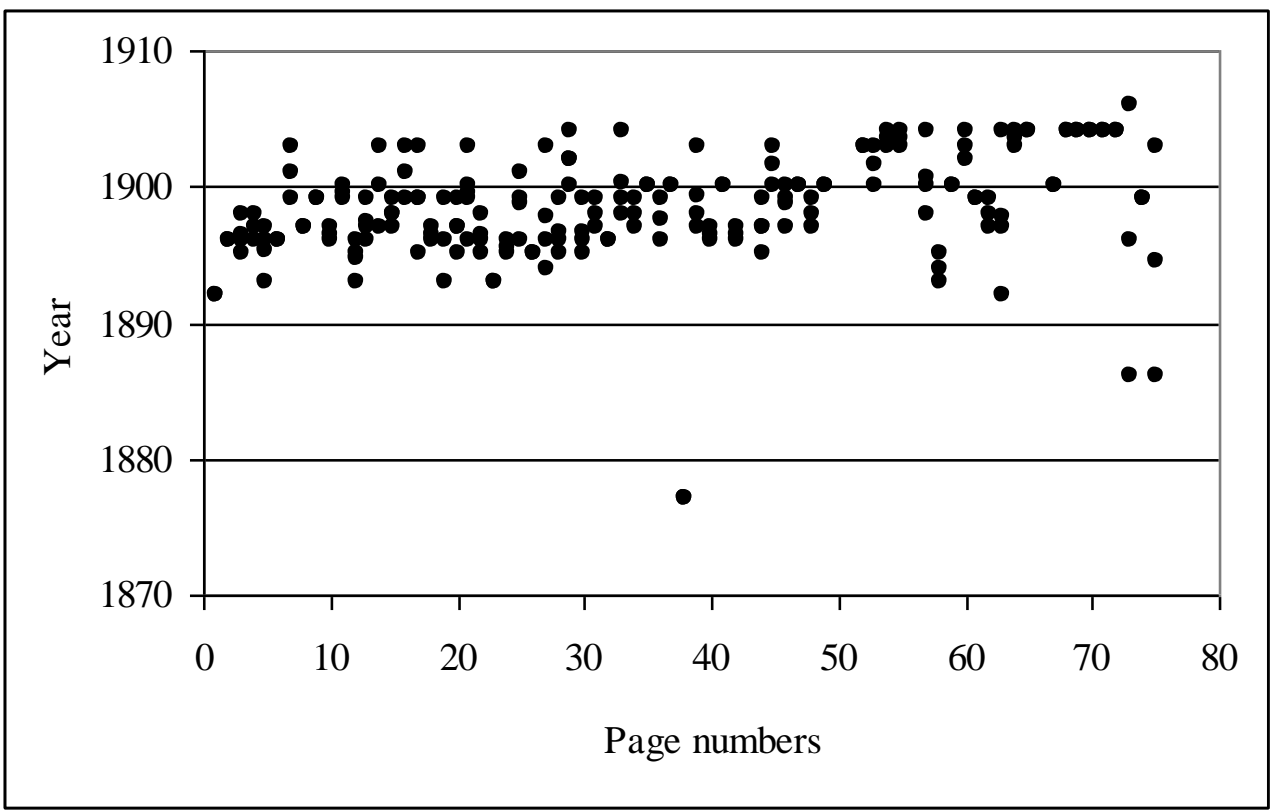

Graph V: Timeline for the photograph album of Jessie Buckland.

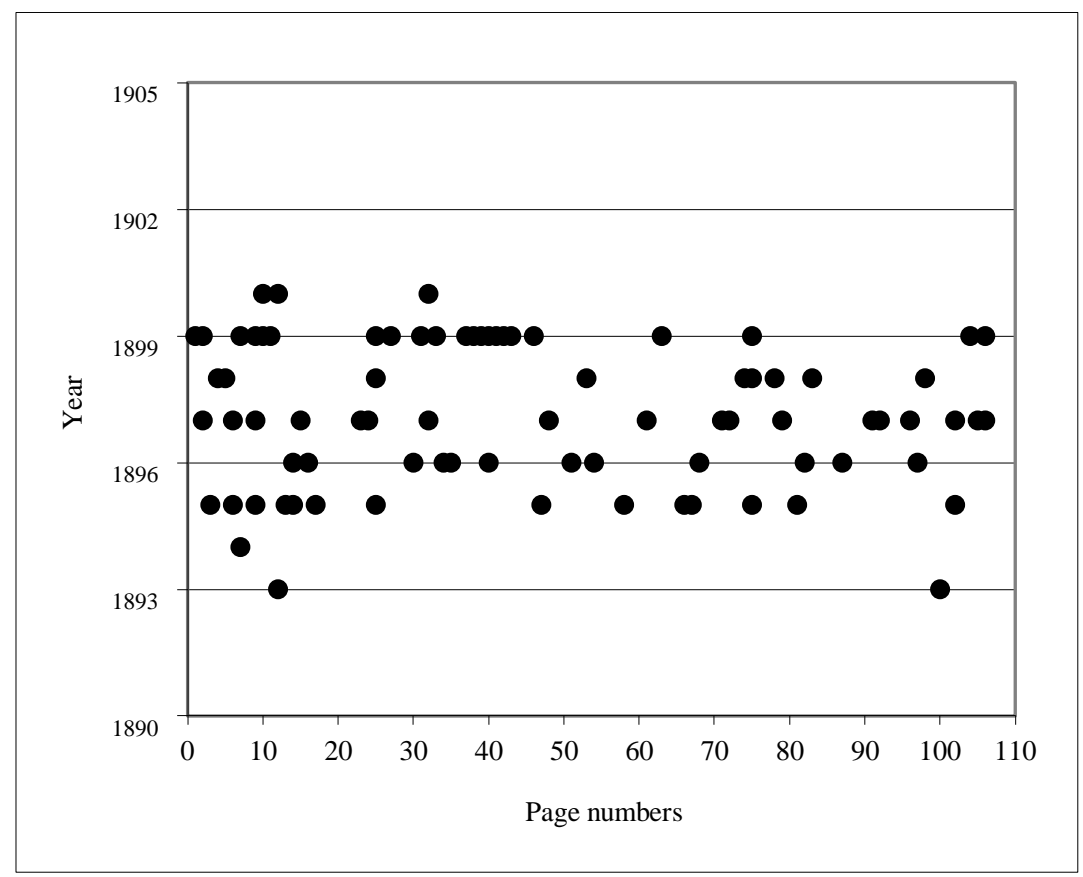

Graph VI: Timeline for the photograph album of Susan Buckland. 


\section{Selected Bibliography}

\section{Published works: Articles and Books}

Alexander, Jeffrey C., Bernhard Giesen and Jason L. Mast, Social performance: Symbolic Action, Cultural Pragmatics and Ritual (Cambridge, Cambridge University Press, 2006).

Appadurai, Arjun, The Social Life of Things: Commodities in Cultural Perspective (Cambridge, Cambridge University Press, 1986).

Armstrong, Carol, Scenes in a Library: Reading the Photography in the Book, 1843-1875 (Cambridge, MA, MIT Press, 1998).

Bal, Mieke, A Mieke Bal Reader (Chicago, University of Chicago Press, 2006).

Bal, Mieke, 'Visual essentialism and the object of visual culture', Journal of Visual Culture, 2, 5 (2003): 5-32.

Barker, Chris, Making Sense of Cultural Studies: Central Problems and Critical Debates (London, Sage Publications, 2002).

Barker, Chris, Cultural Studies: Theory and Practice (Los Angeles, CA, Sage Publications, 2008).

Barker, Mary Ann, Lady, Station Life in New Zealand (London, 1874).

Barthes, Roland, 'Rhetoric of the Image', in Image-Music-Text, Stephen Heath, trans. (London, Fontana Press, 1977): 38-41.

Batchen, Geoffrey, Burning with Desire: The Conception of Photography, (London, MIT Press, 1997).

Batchen, Geoffrey, Forget me not: Photography and Remembrance (Princeton, NJ, Princeton Architectural Press, 2006).

Batchen, Geoffrey, Photography Degree Zero: Reflections on Roland Barthes, Camera Lucida (Cambridge, MA, MIT Press, 2010). 
Belk, Russell W., 'Possessions and the Extended Self', Journal of Consumer Research, 15, 2 (1988): 139-168.

Belk, Russell, Melanie Wallendorf and John F. Sherry, 'The Sacred and The Profane in Consumer Behaviour: Theolicy on the Odyssey', Journal of Consumer Research, 15, 6 (1989): 1-38.

Belk, Russell W., 'Why Not Share Rather Than Own?' Annals of the American Academy of Political and Social Sciences, 611, 5 (2007): 126-140.

Belk, Russell W., 'Sharing', Journal of Consumer Research, 36, 5 (2010): 715 734.

Benjamin, Walter, 'The Work of Art in the Age of Mechanical Reproduction', in Hannah Arendt, ed., Illuminations, trans. Harry Zohn (New York, Schocken Books, 1968).

Benkler, Yochai, 'Sharing Nicely: On Shareable Goods and the Emergence of Sharing as a Modality of Ecomonic Production', Yale Law Journal, 114, 11 (2004): 273-358.

Bennett, L.A., S.J. Wolin and K.J. McAvity, 'Family Identity ritual and myth: A Cultural perspective on life cycle transitions, in Celia Jaes Falicov, ed., Family Transitions:

Continuity and Change over the Life (New York, Guilford Press, 1988): 211-234.

Berger, John, and Jean Mohr, Another Way of Telling (New York, Vintage Books, 1996).

Berger, Lynn, 'Snapshot's, or Visual Culture's Clichés', Photographies, 4, 2 (2011): 175190.

Bevan, Linda, 'Early Women Photographers of NZ', PhotoForum Supplement (1980): 5.

Bieringa, Luit, 'New Zealand Photography from the 1840s to the present: Nga Whakaahua o Aoteroa mai I mai 1840 ki naianei', Journal of New Zealand Photography, 4 (1994): 9-10. 
Brickell, Chris, 'At the borders of colonial masculinity: Robert Gant's photographs of men together', in Angela Wanwalla and Erika Wolf, eds, Early New Zealand Photography: Images and Essays (Dunedin, University of Otago Press, 2011): 66-71.

Bogdan Robert, and Todd Weseloh, Real Photo Postcard Guide: The People's Photography (Syracuse, N.Y., Syracuse University Press, 2006).

Bourdieu, Pierre, The Logic of Practice, Richard Nice, trans. (Stanford, CA, Stanford University Press, 1990).

Bourdieu, Pierre, with L. Boltanski, R. Castel, J-C. Chamboredun, and D. Schapper, Photography: A Middle-Brow Art, trans. by Shaun Whiteside (Stanford, CA, Stanford University Press, 1992).

Buckland, N.M., The Bucklands: a continuation of C.M. Gordon's story and revision of the Buckland and Taylor family tree (Christchurch, New Zealand, 1975).

Bruner, Jerome S., and Susan Weisser, 'The invention of self: autobiography and its forms', in David Olson and Nancy Torrance, eds, Literacy and Orality (Cambridge, Cambridge University Press, 1991): 129-148.

Carr, David, 'Narrative and the Real World: An Argument for Continuity', in Lewis P. Hinchman and Sandra K. Hinchman eds, Memory, Identity, Community: The idea of narrative in the human science (Albany, State University of New York Press, 2001): 725.

Carter, Sarah Anne, 'Picturing Rooms: Interior Photography 1870-1900', History of Photography, 34, 3 (2010): 251-267.

Chafe, Wallace, and Deborah Tannen, 'The Relation between Written and Spoken Language', Annual Review of Anthropology, 16 (1987): 383-407.

Chalfen, Richard, 'Introduction to the Home mode', 13, Folklore Forum (1975): 19-25.

Chalfen, Richard, 'Redundant Imagery: Some observations on the use of Snapshots in American Culture', Journal of American Culture, 4, 1 (1981): 106-113. 
Chalfen, Richard, Snapshot Versions of Life (Ohio, Bowling Green State University Press, 1987).

Chalfen, Richard, Turning Leaves: The Photograph Collections of Two Japanese American Families (Albuquerque, University of New Mexico, 1991).

Chalfen, Richard, 'Interpreting Family Photography as Pictorial Communication' in Jon Prosser, ed, Image-based research: a sourcebook for Qualitative Researchers (London, Routledge Fawler, 1998): 214-234.

Chalfen, Richard, 'Snapshots 'r' us: the evidentiary problematic of home media', Visual Studies, 17 (2002): 141-149.

Chambers, Deborah, 'Family as Place: Family Photograph Albums and the Domestification of Public and Private Space', in Joan M. Schwartz and James R. Ryan, eds, Picturing Place: Photography and Geographical Imagination (London, I.B. Tauris \& Co Ltd, 2003): 96-114.

Chapman, Mary Megan, 'Living Pictures: Women and Tableaux Vivants in the Nineteenth Century American Fiction and Culture', Wide Angle, 18, 3 (1996): 22-52.

Cleveland, L., 'The Tyrees: Notes towards a critical assessment', PhotoForum Supplement (Spring, 1979): 6-9.

Comaroff, Jean and John Comaroff, Modernity and its Malcontents, Ritual and Power in Postcolonial Africa (Chicago, University of Chicago Press, 1993).

Cook, Clarence, House Beautiful (Croton on Hudson, NY, The North River Press, 1878).

Cooper, Annabel, Lachy Paterson and Angela Wanhalla, eds., The Lives of Colonial Objects (Dunedin, University of Otago Press, 2015).

Crombie, Isobel, 'The Work and Life of Viscountess Frances Jocelyn: Private Lives', History of Photography, 22, 1 (1998): 40-51.

Crosbie, Paul V. ed., Interaction in Small Groups (New York, Macmillan, 1975). 
Csikszentmihaly, Mihaly, and Eugene Rochberg-Halton, The Meaning of Things:

Domestic symbols and the self (Cambridge, Cambridge University Press, 1981).

Curasi, Carolyn F., Linda L. Price and Eric J. Arnould, 'How Individuals' Cherished Possessions Become Families' Inalienable Wealth’ Journal of Consumer Research, 12 (2004): 609-622.

Davidoff, Leonore and Catherine Hall, Family Fortunes: Men and Women of the English Class, 1780-1850, (Women in Culture and Society), (London, Routledge, 2002).

Davis, Kingsley, Human Society (New York, Macmillan, 1948).

Derrida, Jacques, Given Time: I. Counterfeit Money, Trans by Peggy Kampf (Chicago, University of Chicago Press, 1992).

di Bello, Patrizia, Women's Albums and Photography in Victorian England, Ladies Mothers and Flirts (London, Ashgate, 2006).

di Bello, Patrizia, 'Seductions and flirtations: photographs, histories, theories', Photographies, 1 (2008): 143-155.

Dibbits, Hester, 'Furnishing the Salon: Symbolic ethnicity and performance practices in Moroccan-Dutch domestic interiors', International Journal of Consumer Studies, 33, (2009): 550-557.

Dimond, Frances and Roger Taylor, Crown \& Camera: The Royal Family and Photography, 1842-1910 (Harmondsworth, England, Viking, Penguin Books Ltd, 1987).

Dimond, Frances, Developing the Picture: Queen Alexandra and the Art of Photography (London, Royal Collections Enterprises Ltd, 2004).

Dodier, Virginia, Clementina, Lady Hawarden, Studies from Life 1857-1864 (London, Victoria and Albert Publications, 1999).

Doman W., and E. Phelps, 'Critical writing among three methods of peer education', International Journal of Educational Research, 13 (1989): 9-19. 
Draper, Robert, 'Rethinking Nero', National Geographic (September, 2014): 82-111. du Gay, Paul, The Production of Culture/Cultures of Production (London, Sage and Oxford University Press, 1997).

Duff, Euan, 'Working World', in H.S. Becker, ed., Exploring Society Photographically (Chicago, Chicago University Press, 1981): 76.

Dunphy, Dexter, The Primary Group: A Handbook for Analysis and Field Research (New York, Appleton-Century-Crofts, 1972).

Edwards, Elizabeth, and Janice Hart, 'Introduction: photography as objects', in Elizabeth Edwards and Janice Hart, eds, Photographs, Objects, Histories: On the materiality of images (London, Routledge, 2004): 1-15.

Edwards, Elizabeth, 'Negotiating Spaces: Some Photographic Incidents in the Western Pacific, 1883-4', in Joan M. Schwartz and James R. Ryan, eds, Picturing Place: Photography and the Geographical Imagination (London, I.B. Tauris \& Co. Ltd, 2006): 261-280.

Eggleton, David, Into the Light: A History of New Zealand Photography, (Nelson, Craig Potton, 2006).

Facer, Annette, 'Mrs Hocken requests...'in Women's contributions to the Hocken Library, Rosemary Entwisle, ed. (Dunedin, Hocken Library, University of Otago,1993): 7-10.

Fetterley, Judith, 'Little Women: Alcott's Civil War', Feminist Studies, 5, 2 (1979): 369383.

Frey, B.S., and S. Meier, pro-social behavior in a natural setting, Journal of Economic Behaviour and Organization, 54 (2004): 65-88.

Frey, B.S., and S. Meier, 'Social comparisons and pro-social behavior: Testing conditional cooperation in a field experiment', American Economic Review, 2, 16 (2004): $1717-1722$ 
Fromm, Erich, ‘To Have or To Be’ (New York, Harper \& Row, 1976).

Frow, John, Time \& Commodity Culture: Essays in Cultural Theory and Postmodernity (Oxford, Clarendon Press, 1997).

Fry, Ruth, Community of the Sacred Name: A Centennial History (Christchurch, The Community of the Sacred Name, 1993).

Gair, Linda, 'Women in Photography: A selected bibliography' PhotoForum 29, (December1975/January 1976).

Gardner, Saundra Lee, 'Exploring the Family Album: Social Class Differences in Images of Family Life', Sociological Inquiry, 61, 2 (1993): 242-251.

Geertz, Clifford, 'Deep Play: Notes on the Balinese Cockfight', in Clifford Geertz, ed., Myth, Symbol, and Culture (New York, Norton, 1972): 165-185.

Genette, Gerard, 'Fictional Narrative, Factual Narrative', Poetics Today; Narrotology Revisited II (Winter, 1990): 755-774.

Gernsheim, Helmut, Lewis Carroll, Photographer, revised ed. (New York, Dover Publications, 1969).

Gibbons, Peter, 'A Note on Writing Identity and Colonisation in Aotearoa', Sites, 13 (Spring, 1986): 32-38.

Giesler, Markus, 'Consumer Gift System: Netnographic Insights from Napster', Journal of Consumer Research, 33, 2 (2006): 283-290.

Gilmore, Leigh, Autobiographies: A Feminist Theory of Women's Self-Representation (Ithaca, New York, Cornell University, 1994).

Goffman, Erving, Presentation of Self in Everyday Life (London, Allen Lane, 1969).

Goffman, Erving, Frame Analysis: An Essay on the Organization of Experience (New York, Harper Colophon Books, 1974). 
Goffman, Erving, Interaction Ritual: Essays in Face to Face Behavior, with introduction by Joel Best (New Brunswick, NJ, Transaction Publishers, 2005).

Golder, C., History of the Deaconess Movement in the Christian Church (Cincinnati, Jennings and Pye, 1903).

Gordon, Beverly, ‘Women's Domestic Body: The Conceptual, Conflation of Women and Interiors in the Industrial Age', Winterthur Portfolio, 31, 4 (1996): 281-302.

Gosden, Chris, and Yvonne Marshall, 'The cultural biography of objects', World Archaeology, 31, 2 (1999): 169-178.

Hackman, J.R., Groups that work (and those that don't): Creating conditions for effective teamwork (San Francisco CA, Jossey-Boss, 1990).

Hall, Stuart, Representation: Representations and Cultural Signifying Practices (London, Sage Publications, 1997).

Haltunnen, Karen, 'Impersonating Little Women: Domestic Drama', Feminist Studies, 10, 2 (1984): 233-54.

Harrison, Barbara, 'Photographic visions and narrative inquiry', in Michael Bamberg and Molly Andrews, eds, Considering counter-narrative: Narrating, resisting, making sense (Amsterdam, John Benjamin, 2004): 113-36.

Harrison, Barbara, 'Snap Happy: Toward a Sociology of 'Everyday’ photography', in J. Pole, ed., 'Seeing is Believing? Approaches to Visual Research', Studies in Qualitative Methodology 7 (Emerald Group Publishing Ltd, 2004): 23-39.

Hearnshaw, Vickie, 'A Study in Black and White: The Life and Work of Photographer Jessie Buckland', Women's Studies Journal, 12, 1 (1997): 41-62.

Herrnstein Smith, Barbara, 'Narrative Versions, Narrative Theories, On Narrative', Critical Inquiry, 7, 1 (1980): 213-236.

Hilliard, David, God's Gentlemen: A History of Melanesian Mission 1849-1942 (Brisbane, University of Queensland Press, 2013). 
Hobsbawm, Eric, Nations and Nationalism since 1780: Programme, Myth, Reality, (Cambridge, Cambridge University Press, 1992).

Holt, Thomas C., 'Marking Race, Race-making, and Writing of History', The American Historical Review, 100, 1 (1995): 1-20.

Homans, Margaret, 'Victoria's Sovereign Obedience: Portraits of the Queen as Wife and Mother', in Carol T. Christ and John O. Jordan, eds, Victorian Visual Imagination, (Berkeley, University of California Press, 1995).

Homans, Margaret and Adrienne Munich, Remaking Queen Victoria (Cambridge, Cambridge University Press, 1997).

Homans, Margaret, Royal Representations: Queen Victoria and British Culture 18371876 (Chicago, University of Chicago Press, 1998).

Hughes, Jabez, 'Photography as an Industrial Occupation for Women', Anthony's Photographic Bulletin, 4 (1873): 162-166. (Reprinted by Peter M. Palmquist, in Camera Fiends and Kodak Girls I: 50 Selections by and about Women in Photography, 18401930, (New York, Midmarsh Arts Press, 1989): 29-36.

Humm, Maggie, Modernist Women and Visual Cultures: Virginia Woolf, Vanessa Bell, Photography and Cinema (New Brunswick, NJ, Rutgers University Press, 2003).

Humm, Maggie, 'Virginia Woolf and Vanessa Bell: the same pair of eyes, only different spectacles', in Woolf and the Real World: Selected papers from the thirteenth International Conference on Virginia Woolf (Clemson University Press, 2005).

Humm, Maggie, Snapshots of Bloomsbury: The private lives of Virginia Woolf and Vanessa Bell (New Brunswick, NJ, Rutgers University Press, 2006).

Hunt, P., 'Gender and the construction of home life', in G. Allan and G. Crow, eds, Home and Family: Creating the Domestic Sphere (London, Macmillan, 1989): 66-81.

Jackson, Alan, NZ Postcards: Rates and regulations to 1939 (Postal History Society of NZ, 1984). 
Jackson Alan, and W. Main, 'Wish you were here:' The story of the New Zealand postcard (New Zealand Postcard Society, 2005).

Jackson, Brad, 'Killing Time: Life in the Arkansas Penitentiary', in H.S. Becker, ed., Exploring Society Photographically (Chicago, Chicago University Press, 1981).

James, Daniel, and M.Z. Lobato, 'Family Photos: Oral Narratives, and Identity Formation: The Ukrainians of Berisso', Hispanic American Historical Review, 84, 1 (2004): 5-36.

James, William, The Principles of Psychology (New York, Henry Holt, 1, (1890): 291292.

Jay, Bill, www.billjayonphotography.com/QnVictoria2ndpassion.pdf.

Johnson, James, The Scots Musical Museum of Six Hundred Songs: Proper basses for the pianoforte (Edinburgh, Wm Blackwood \& Sons, 1787-1803).

Johnston, Frances Benjamin, 'What a Woman Can do with a camera', Ladies Home Journal (September, 1897): 6-7.

Keenan, Catherine, 'On the relationship between personal photographs and individual memory', History of Photography, 22, 1 (1998): 60-64.

King, Andrew, and John Plunkett, Victorian Print Media: a reader (Oxford, Oxford University Press, 2006).

King, Julie, Flowers into Landscape: Margaret Stoddart 1865-1934 (Christchurch, Robert McDougall Art Gallery \& Hazard Press, 1997).

Knapman, Claudia, White Women in Fiji, 1835-1930, The Ruin of Empire? (Sydney, Allen \& Unwin, 1986).

Knight, Hardwicke, Photography in New Zealand: a social and technical history (Dunedin, John McIndoe, 1971). 
Knight, Hardwicke, New Zealand Photographers: a selection (Dunedin, Allied Press, 1981).

Konrad, Monica, Nameless Relations: Anonymity, Melanesia and Reproductive Gift Exchange between British Ova Donors and Recipients (Oxford, Berghahn, 2005).

Kopytoff, Igor, 'The Cultural Biography of Things: Commoditization as process', in A. Appadurai ed., The Social Life of Things: Commodities in cultural perspective (Cambridge, Cambridge University Press, 1986): 64-94.

Langford, Martha, 'Speaking the album: an application of oral-photographic framework', in A. Kuhn and K. McAlister, eds, Locating Memory: Photographic Acts (Oxford, Berghahn, 2006): 223-246.

Langford, Martha, Suspended Conversations: The afterlife of memory in photographic album, (Montreal, McGill-Queens University Press, 2001).

Langland, Elizabeth, Nobody's Angel's: Middle Class women and domestic ideology in Victorian Culture (Ithaca, Cornell University Press, 1995).

Labov, William, Language in the Inner City: Studies in Black English Vernacular (Philadelphia, University of Pennsylvania Press Inc., 1972).

Leggat, Robert, A History of Photography: From its beginning till the 1920s, (1999). (http://www.rleggat.com.photohistory/index.html).

Lenman, Robin, ed., The Oxford Companion to the Photograph (Oxford, Oxford University press): 2005.

Longford, Elizabeth, Queen Victoria: born to succeed (New York, Harper and Row, 1964).

Lury, Celia, Prosthetic Culture: photography memory and identity (London, England, Routledge, 1998).

Lyden, Anne M., A Royal Passion: Victoria and photography (Los Angeles, CA, J. Paul Getty Publications, 2014). 
Madigan R., and M. Munro, 'Negotiating Space in the Family Home', in I. Cieraad, ed., At Home: An Anthropology of Domestic Space (Syracuse, Syracuse University Press, 1999): 107-17.

Maguire, T., The Lantern was Lighted: A History of the Dunedin Photographic Society Inc. 1890-1990 (Dunedin, The Dunedin Photographic Society, 1990).

Main W. and J. B.Turner, New Zealand Photography from 1840s to the present - Nga Whakaahua o Aoteroa mai 1840 ki nainei (Photoforum/Agfa-Gevaert, 1993).

Mannering, G.E., The New Zealand Alpine Journal, (Christchurch, Whitcombe and Tombs Ltd, 1, 4 (1893): 190-96.

Mathers, Jenni, Christine Gillespie and Barbara Hall, Australian Women Photographers, 1890-1950 (Melbourne, George Paton Gallery, Melbourne University Union, 1981).

Mauss, Marcel, The Gift: The form and reason for exchange in archaic societies, foreword by Mary Douglas (London, Routledge Classics, 1990).

McCarthy, Rosalina, 'Women and the Nelson Camera Club 1888-1900', New Zealand Journal of Photography (November, 1994): 16.

McCracken, Grant, 'Culture and Consumption: A Theoretical Account of the Structure and Movement of the Cultural meaning of Consumer Goods', Journal of Consumer Research, 13, 6 (1987): 71-69.

McGill, Robin, Start up: Postal History of New Zealand (Postal History Society of NZ Inc, 3, 1966).

McLay, Geoff, 'New Zealand and the Imperial Copyright Tradition', in Uma Suthersanen and Ysolde Gendrean, eds, A Shifting Empire: 100 Years of Copyright (Cheltenham, England, Edward Edgar Publications Ltd, 2013): 30-51.

McPhail, Clark, The Myth of the Madding Crowd (New York, De Gruyter Series of Texts and Monographs, 1991). 
Merleau-Ponty, Maurice, Phenomenology of Perception, trans. C. Smith (London, Routledge and Kegan Paul, 1962).

Morley, Daniel and Kuan-Hsing Chen, Stuart Hall: Critical dialogues in cultural studies (London, Routledge, 1996).

Motz, Marilyn F., 'Visual Autobiography: Photograph Albums of Turn-of-the-Century Midwestern Women', American Quarterly, 41, 1 (1989): 63-92.

Murray, Janet, Elizabeth Colenso, 1821-1904, Dictionary of New Zealand Biography, 1 (Wellington, Department of Internal Affairs, 1990): 86-87.

Nickel, Douglas R., Dreaming in Pictures: The Photography of Lewis Carroll (San Francisco, San Francisco Museum of Modern Art, 2002): 39-43.

Nixon, II, Howard L. The Small Group (Englewood Cliffs, NJ, Prentice and Hall Inc., 1979).

Nobbs, Raymond, St Barnabas and the Melanesian Mission (Sydney, Macquarie University, Australian History Resources Centre, 1990).

Nobbs, Raymond, Norfolk Island and its First Settlement: The First Hundred Years (Sydney, Library of Australian History, 2006).

Noble, Greg, 'Home, Comfort and banal Nationalism', in Alison Blunt and Robyn Dowling, eds, Home (Oxford, Routledge, 2006): 167-169.

Noble, Greg, 'Comfortable and relaxed: furnishing the home and nation', Continuum, 16, 1, (2002): 53-66.

Olson David, and Nancy Torrance, eds, Literacy and Orality (Cambridge, Cambridge University Press, 1991).

Ong, W.J., The Presence of the Word: Some Prolegomena for Cultural and Religious History (New Haven, CT, Yale University Press, 1967). 
Ong, W.J., Interfaces of the Word: Studies in the Evolution of Consciousness and Culture (Ithaca, NY, Cornell University Press, 1977).

Ong, W.J., Orality and Literacy: The Technologizing of the Word (London, Methuen, 1982).

Ong, W.J., The Presence of the Word, Robert Detweiler and David Jasper, eds, in Religion and Literature: a reader (Westminster, John Knox Press, 2000).

Otnes, Cele, Yina M. Lowrey \& Young Chan Kim. 'Gift selection for Easy and Difficult recipients: a social role interpretations', Journal of Consumer Research, 20, 2 (1993): 229-244.

Parry, Jonathan, 'The Gift, The Indian Gift and The "Indian Gift,"' Man, 21 (1986): 453473.

Pennartz, P. J., 'Home: the experience of atmosphere', in I. Cieraad, ed., At Home: An Anthropology of Domestic Space (Syracuse, Syracuse University Press, 1999): 95-106.

Petersen, A.K.C., New Zealanders at Home: A Cultural History of Domestic Interiors 1814-1914 (Dunedin, University of Otago Press, 2001).

Pink, Sarah, 'Amateur photographic practices, collective representation and the constitution of place', Visual Studies, 26, 2 (2011): 92-101.

Platts, Una, Nineteenth century New Zealand artists: a guide and handbook (Christchurch, Avon Fine Arts, 1980).

Plunkett, John, Queen Victoria: First Media Monarch (Oxford, England, Oxford University Press, 2003).

Porter, Frances and Charlotte Macdonald, eds, My hand will write what my heart dictates: 'The unsettled lives of women in nineteenth century New Zealand as revealed to sisters, family and friends' (Auckland, Auckland University Press, 1996). 
Preston, Rebecca, 'Hope you will be able to recognize us': the representation of women and gardens in early twentieth-century British domestic 'real' photo postcards, Women's History Review, 18, 5 (2009): 781-800.

Price, John A. 'Sharing: The Integration of Intimate Economics', Anthropologica, 17, 1 (1975): 3-37.

Samuels, R.D., NZ Postal Stationery Catalogue, pt 1, Postcards (Dunedin, Dunedin Philatelic Society, Inc., 1976).

Sanjek, David, 'A Department of their Own: A Modest Proposal for the Design of Music and Business Technology Programs', Popular Music and Society, 16, 4 (1992): 41-60.

Scholes, Robert, James Phelan and Robert Kellogg, The Nature of Narrative: Fortieth Anniversary Edition (New York, Oxford University Press, 2006).

Sekula, Allan, 'Reading an archive: photography between labour and capital', in P. Holland, J. Spence and S. Watney (eds), Photography/Politics Two (London, Commedial Photography, 1986): 153-161.

Sontag, Susan, On Photography (New York, Farrar, Strauss and Giroux, 1977).

Spence, J., and P. Holland, Family Snaps: The Meanings of Domestic Photography (London, Virago, 1991).

Staff, Frank, The Picture Postcard and its Origins (London, Lutterworth Press, 1966).

Stewart, Susan, On Longing: Narratives of the Miniature, the Gigantic, the Souvenir, and the Collection (Durham, NC, Duke University Press, 1984).

Stewart, Susan, Nonsense: Aspects of Intertextuality in Folklore and Literature (Baltimore, The Johns Hopkins University Press, 1979).

Reckwitz, Andreas 'Toward a theory of social practices: a development in culturalist theorizing', European Journal of Social Theory, 5 (2002): 243-263. 
Reilly, James M., The Albumen and Salted Paper Book: the history and practice of photographic printing 1840-1895 (New York, Rochester, Light Impressions Corporation, 1980).

Riessman, Catherine Kohler, Qualitative Research Methods (Newbury Park, CA, Sage Publications, 1993).

Rook, Emma Cecilia and Elizabeth Jane Rook, Tableaux, Charades and Pantomines (Philadelphia, Bibliobazaar for The Penn Publishing Co., 1914).

Rose, Gillian, Visual Methodologies: An Introduction to the Interpretation of Visual Materials (London, Sage Publications Ltd, 2001).

Rose, Gillian, Doing Family Photography: The Domestic the Public and the Politics of Sentiment (Farnham, England, Ashgate Publishing Ltd, 2010).

Rose, Gillian, 'Practising photography: an archive, a study, some photographs and a researcher', Journal of Historical Geography, 26, 4 (2000), 555-571.

Rose, Gillian, 'On the relation between "visual research methods" And contemporary visual culture', Sociological Review, 62, 1 (2014): 24-46.

Rose, Gillian, 'Family Photographs and Domestic Spacings: A Case Study', Transactions of Institute of British Geographers; New Series, 28, 1 (2003): 5-18.

Rose, Gillian, 'Everyone's cuddled up and it just looks really:' an emotional geography of some mums and their family photos, Social \& Cultural Geography, 5, 4 (2004): 549-564.

Rosenblum, Naomi, A History of Women Photographers (New York, Abbeville Press, 1994).

Ross, Catherine R., 'Elizabeth Colenso on Norfolk Island', Auckland-Waikato Historical Journal, 29 (1976): 9-12.

Ross, Catherine R., “More than 'Wives' 'Helpmeets' 'Heroines' or 'Partners'," Mission Studies, 20, 1 \& 2 (2003). 
Ross, Catherine R., 'The Legacy of Elizabeth Fairburn Colenso', International Bulletin of Missionary Research, 30, 3 (2006): 148-152.

Sahlins, Marshall, Historical Metaphors and Mythical Realities: Structure in the Early History of the Sandwich Islands Kingdom (Ann Arbour, University of Michigan Press, 1981).

Saukko, Paula, Doing Research in Cultural Studies: An Introduction to Classical and New Methodological Approaches (London, Sage Publications, 2003).

Schatzki, Theodore, Social practices: A Wittgensteinian Approach to Human Activity and the Social (Cambridge, Cambridge University Press, 1996).

Schwartz, Joan M., and James R. Ryan, eds, Picturing Place: Photography and the Geographical Imagination (London, I.B. Tauris \& Co Ltd, 2006).

Seiberling, Grace, and Carolyn Bloore, Amateurs, Photography and the Mid-Victorian Imagination (Chicago, University of Chicago Press, 1986).

Sherry, John F. Jr, 'Gift-giving in Anthropological Perspective', Journal of Consumer Research, 10 (1983): 157-168.

Simmel, Georg, Sociology of Georg Simmel, trans by K. H. Wolff (Glenco, Illinois, Free Press,1950; (Reprinted with permission of Macmillan Publishing Co., Inc. 1978).

Stevens, Joan, Mary Taylor, Friend of Charlotte Brontë, Letters from New Zealand and Elsewhere (1972).

Steinberg, Mein, 'Telling in Time (1): Chronology and Narrative Theory', Narratology Revisited 2, 11, 4 (Winter, 1990): 901-948.

Stewart, Susan, Nonsense, Aspects of Intertextuality in Folklore and Literature (Baltimore, Johns Hopkins University Press, 1979).

Stewart, Susan, On Longing: Narratives of the Miniature, the Gigantic, the Souvenir, the Collection (Baltimore, The Johns Hopkins University Press, 1993). 
Sugiyama Lebra, Takie, Japanese Patterns of Behaviour (Honolulu, University of Hawaii, 1976).

Tagg, John, The Burden of Representation: Essays on Photographies and Histories (London, Macmillan, 1988).

Talbot, William Fox, The Pencil of Nature (New York, Dulapo Press, 1969). (Reprint of the 1844-1846 edition, with introduction by B. Newhall).

Tannen, Deborah, 'Oral and Literate Strategies in Spoken and Written Narratives', Linguistic Society of America, 50, 1 (1982): 1-21.

Tannen, Deborah, 'Relative focus on involvement in oral and written discourse', in Literacy, Language and Learning: The Nature of Consequences, D.R. Olson, Nancy Torrance, Angela Hidyard, eds (Cambridge, University of Cambridge Press, 1985): 124131.

Tannen, Deborah, Talking Voices (Cambridge, Cambridge University Press, 1989).

Tannen, Deborah, 'How is conversation like literary discourse? The role of imagery and details in creating involvement', in Pamela Downing, Susan D. Lima, Michael Noonan, eds, The Linguistics of Literacy (Amsterdam, The Netherlands, John Benjamin Publishing Co., 1992): 31-46.

Tannen, Deborah, 'The sex-class-linked framing of talk at work', in Gender and Discourse (Georgetown, Washington, 1994).

Thompson, Paul, 'Into the Light: A History of New Zealand Photography', Journal of New Zealand Photography (2007): 63.

Tolia Kelly, Divya, 'Materializing post-colonial geographies: examining the textural landscape of migration in the South-Asian home', Geoforum, 35 (2004): 314-319.

Tolia-Kelly, Divya, 'Mobility/stablity: British Asian cultures of "landscape and Englishness", Environment \& Planning, A 38 (2006): 341-358. 
Tuan, Yi-Fu, 'The Significance of the Artefact', Geographical Review, 70, 4 (1980): 462472.

Turner, Jonathan, Face to Face: Toward a Sociological Theory of Interpersonal Behavior (Stanford, Stanford University Press, 2002).

Ussher, Jane and Nigel Watson, Still life: Inside the Antarctic Huts of Scott and Shackleton (Sydney, N.S.W., Murdoch Books, 2010).

Vygotsky, L.S., 'Mind in society: the development of higher psychological processes' (Cambridge, MA, Harvard University, 1978).

Walker, Tim, “A Curious Dislocation’, Art New Zealand, 53 (1989-90): 96-99.

Walker, Tim, 'Margaret Matilda White', PhotoForum, 56 (1987): 8.

Walsh, Katie, 'Expatriate Belongings', in Home, Alison Blunt and Robyn Dowling, eds (Abingdon, Oxford, Routledge, 2006).

Wanhalla Angela, and Erika Wolf, Early New Zealand Photography: Images and Essays (Dunedin, University of Otago Press, 2011).

Warner, Marina, Queen Victoria’s Sketchbook (London, Unwin Hyman, 1987).

Webb, Noreen M. 'Group Collaboration in Assessment: Multiple Objectives, Processes and Outcomes', 'Educational Evaluation and Policy Analysis', 17, 2 (1995): 139-261.

Webb, Noreen M., and Linda Cullinan, 'Group Interaction and Achievement in Small Groups: Stability Overtime', American Educational Research Journal, 20, 3 (1983): 411423.

Wells, Liz, The Photography Reader (London, Routledge, 2003).

White, Hayden, The Content of the Form: Narrative Discourse and Historical Representation (Baltimore, Johns Hopkins University Press, 1987). 
Widlok, Thomas, 'Sharing by default: Outline of an Anthropology of Virtue', Anthropological Theory, 4, 1 (2004): 153-170.

Willis, Anne-Marie, Picturing Australia: A History of Photography (North Ryde, NSW, Australia, Angus \& Robertson, 1988).

Wood, Vaughan, and Tom Brooking, 'Canterbury farming intensifies', in Garth Cant and Russell Kirkpatrick, eds, Rural Canterbury: Celebrating its history (Christchurch, University of Canterbury Press, 2001): 81-100.

Woodburn, James 'Sharing is not a Form of Exchange: An Analysis of Property Sharing in Immediate-Return Hunter-Gatherer Societies', C.M. Hanm, ed., in Property relations: Renewing the Anthropological Traditions (Cambridge, Cambridge University Press, 1998): 48-63.

Woodward, Joan, A Canterbury Album (Christchurch, Te Waihora Press, 1987).

\section{Unpublished works: Theses and research essays}

Ames, Morgan Golata, 'The Social Life of Snapshots: The Past, Present and Future of Personal Photography', Masters in Information and management Systems (University of California at Berkeley, 2006).

Barker, Adam Joseph, 'Being Colonial: Colonial Mentalities in Canadian Settler Society and Political Theory', Master of Arts in Indigenous Studies Governance Program (Victoria, BC, University of Victoria, 2006).

Berlier, Monique, 'Picturing Ourselves: Photographs of Belgian Americans in Northeastern Wisconsin, 1888-1950', PhD in Mass Communications (Iowa City, University of Iowa, 1999).

Bliss, Ann Victoria, 'Fixing the Family: The Function of the Family Photograph in Albums and Literature', $\mathrm{PhD}$ in English (Davis, CA, University of California, 2006). 
Cape, Stephanie, 'The History of the Pictorial Postcard in New Zealand', Research essay for Stage III, History of Design (Christchurch, School of Fine Arts, University of Canterbury, 1978).

Cronin, Orla, 'The Meaning and Psychological Significance of Family Photographic Collections', PhD in Psychology (Southampton, University of Southampton, 1996)

Fletcher, Jane, 'The Way She Looks: Robert Thompson Crawshay's Photographic Portraits of his daughter Rose Hariette', PhD in Photography History and Theory (Derby, University of Derby, England, 2002).

Gush, Nadia Joanne, 'Cultural Fields of the Canterbury Plains: Women and Cultural Citizenship in Canterbury c.1890-1940', PhD in History (Victoria University of Wellington, 2007).

Poister, Geoffrey, 'A Cross-Cultural Study of Family Photographs in India, China, Japan and the United States', PhD in Communications (New York State, NY., Syracuse University, 1998).

Siegel, Elizabeth Ellen, 'Galleries of Fame and Friendship: The history of nineteenthcentury American photograph albums', PhD in Art History (Chicago, University of Chicago, 2003).

Silva, Armando, 'The Family Photo Album: The Image of Ourselves', PhD In Comparative Literature (University of California at Irvine, 1996).

Stolte, Anton, 'George and Elizabeth Pulman, early Auckland photographers', (Research paper for BFA, Auckland, Elam School of Fine Arts, Auckland University, 1989).

Vosmeier, Sarah McNair 'The Family Album: Photography and American Family Life since 1860', PhD in History (Bloomington, University of Indiana, 2003).

Walsh, Katie, 'British Expatriate Belonging in Dubai: Foreignness, Domesticity, Intimacy', $\mathrm{PhD}$ in Geography (Royal Holloway, University of London, 2005). 
Weiss, Marta, 'Dressed Up and Pasted Down: Staged Photography in the Victorian Album', PhD in Art History, (Princeton, N.J., Princeton University, 2008).

Wilson, Philippa, 'We are still English at Heart: Constructions of Englishness by

Englishwomen in nineteenth-century New Zealand' (Master of Arts in History, Auckland, University of Auckland, 1997). 
